\title{
Identifizierung von Chitinasen mit fungizider Wirkung
}

\author{
Dissertation \\ zur Erlangung des Doktorgrades \\ Der Mathematisch-Naturwissenschaftlichen Fakultäten \\ der Georg-August-Universität zu Göttingen
}

vorgelegt von

Frank Hoster

aus Hamburg

Göttingen, 2003 
D7

Referent: PD Dr. R. Daniel

Korreferent: Prof. Dr. G. Gottschalk

Tag der mündlichen Prüfung: 04.11.03 
Die Arbeit wurde durch Mittel der Deutschen Bundesstiftung Umwelt gefördert. 
Meiner Frau Sonja gewidmet 


\section{INHALTSVERZEICHNIS}

INHALTSVERZEICHNIS I I

ABKÜRZUNGSVERZEICHNIS $\quad$ V

$\begin{array}{lll}1 . & \text { EINLEITUNG } & 1\end{array}$

2. MATERIAL und METHODEN 4

2.1 Verwendete Organismen, Plasmide und Oligonukleotide $\quad 4$

$2.2 \quad$ Nährmedien 6

2.2.1 LB- (Luria-Bertani) Medium 6

2.2.2 SOB-Medium 6

2.2.3 Chitin-Mineralmedium 7

2.2.4 Aspergillus-Medium 7

2.2.5 Spurenelementelösung SL-4 8

2.2.6 Vitaminlösung 8

2.2.7 Antibiotika und sonstige Medienzusätze 9

2.2.8 Herstellung von kolloidalem Chitin 9

2.3

2.3.1

2.3.2

2.3.3

2.4

2.4.1

2.4 .2

2.5

2.5.1

2.5.2

2.5.2.1

2.5.2.2

2.5.2.3

2.5.2.4

2.5.2.5

2.5.2.6

2.5.2.7

2.5.2.8
Zellanzucht

Aerobe Anzucht

Anaerobe Anzucht

Stammkulturhaltung

Bestimmung von Wachstumsparametern

Bestimmung der optischen Dichte

Bestimmung des $\mathrm{pH}$-Wertes

Standardtechniken für das Arbeiten mit Nukleinsäuren

Vorbehandlung von Geräten und Lösungen

Reinigung und Konzentration von Nukleinsäuren

Phenol/Chloroform-Extraktion

Mikrodialyse von DNA

Fällung von Nukleinsäuren

DNA-Fällung mit PEG-NaCl nach Saccharose-Dichtegradienten-

zentrifugation

Gelfiltration von DNA-Lösungen

Konzentrationsbestimmung von Nukleinsäuren

Isolierung von DNA-Fragmenten mittels „QIAquick Gel

Extraction"-Kit

Reinigung von DNA-Fragmenten mittels „QIAquick PCR

Purification"-Kit

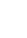

V

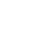

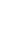
4 6 (6) 列 7 8 9 
2.6

2.6.1

2.6.2

2.7

2.7.1

2.7.2

2.7.2.1

2.7.2.2

2.7.2.3

2.7.2.4

2.8

2.8 .1

2.8.2

2.8 .3

2.8 .4

2.8 .5

2.8 .6

2.8 .7

2.9

2.9 .1

2.9.2

2.9 .3

2.9 .4

2.9 .5

2.9.5.1

2.10

2.10 .1

2.10 .2

2.11

2.12

2.12 .1

2.12 .2

2.12 .3

2.12 .4

2.13

Gelelektrophorese von Nukleinsäuren

Standard-Agarose-Gelelektrophorese

Größenbestimmung von Nukleinsäuren

14

15

Isolierung von Nukleinsäuren $\quad 16$

Isolierung von chromosomaler DNA $\quad 16$

$\begin{array}{ll}\text { Isolierung von Plasmid-DNA } & 17\end{array}$

$\begin{array}{ll}\text { Plasmidschnellpräparation } & 17\end{array}$

$\begin{array}{ll}\text { Minipräparation mittels „,Wizard } & \text { TM } \\ & 18 \text { lus Minipreps DNA }\end{array}$

Purification System“"

Präparative Plasmidisolierung über Anionenaustausch- 19

chromatographie

Minipräparation von Plasmiden mittels „QIAprep Spin Miniprep Kit“ 20

Enzymatische Modifikation von DNA 20

Spaltung von DNA durch Restriktionsendonukleasen $\quad 20$

Herstellung von glatten Enden ('blunt ends') und Phosphorylierung 21

von 5'-Hydroxyl-Enden bei DNA-Fragmenten

Dephosphorylierung von DNA-Fragmenten 22

$\begin{array}{ll}\text { Saccharose-Dichtegradientenzentrifugation } & 23\end{array}$

$\begin{array}{ll}\text { Ligation von DNA-Fragmenten } & 23\end{array}$

Ligation mit dem ,TOPO-TA-Cloning®"-Kit 24

Radioaktive Markierung von DNA-Fragmenten 25

Einführung von DNA in $E$. coli und Selektion 26

rekombinanter Klone

Erstellung hochkompetenter E. coli-Zellen 26

Transformation von E. coli $\quad 27$

Der X-Gal-Test zur Selektion rekombinanter Klone 27

Transformation in E. coli durch Elektroporation $\quad 28$

Anzucht von rekombinanten E. coli-Stämmen zur heterologen 29

Genexpression

Expression mit dem „pET Directional TOPO ${ }^{\circledR}$ Expression“-Kit 29

Screening auf die Verwertung von Chitin

Screening von Anreicherungskulturen bzw. Isolaten auf die

Verwertung von Chitin

Chitinasen

DNA-DNA-Hybridisierung $\quad 32$

Vorbereitung von Nylonmembranen für Koloniehybridisierungen $\quad 32$

"Southern"-Blot $\quad 33$

Dot-Blot $\quad 34$

Hybridisierung mit radioaktiv-markierten Sonden $\quad 34$

Polymerase-Kettenreaktion (PCR) 35 
2.14 Sequenzierung und Analyse von Sequenzdaten

2.15 Herstellung von Rohextrakten 37

2.15.1 Zellaufschluss durch Ultraschallbehandlung 37

2.16 Bestimmung von Chitinaseaktivitäten $\quad 38$

2.16.1 Test zur Aktivitätsbestimmung der Chitinasen mit kolloidalem Chitin 38

2.16.2 Test der fungiziden Wirkung von Enzymen oder Bakteriensuspensionen 38

2.16.3 Proteinbestimmung 39

2.17 Methoden zur Proteinanreicherung 39

2.17.1 Fällung von Chitinasen aus dem Kultur-Überstand 39

2.17.1 Metall-Chelat-Affinitätschromatographie 40

2.17.1.1 Vorbereitung der Säule 40

2.17.1.2 Reinigung löslicher Proteine unter nativen Bedingungen 40

2.17.1.3 Regeneration der Säule 41

$2.18 \quad$ Polyacrylamid-Gelelektrophorese (PAGE) 42

2.18.1 SDS-PAGE nach SCHÄGGER und VON JAGOW 42

2.18.2 Native Polyacrylamid-Gelelektrophorese (PAGE) 44

2.18.3 Nachweis von Chitinase-Aktivität im nativen Gel 45

2.19 Proteinfärbung in Polyacrylamidgelen mittels Coomassie-Blue 45

2.20 Molekularmassenbestimmung 46

2.20.1 Molekularmassenbestimmung durch SDS-PAGE 46

2.20.2 Molekularmassenbestimmung durch Gradienten-PAGE 47

2.21 Chemikalien, Enzyme und Gase 48

3. EXPERIMENTE und ERGEBNISSE 50

$\begin{array}{lll}3.1 & \mathbf{5 1}\end{array}$

3.2 Charakterisierung der Chitinaseproduzenten 53

$\begin{array}{lll}3.3 & \text { Untersuchung der Isolate auf fungizide Eigenschaften } & 54\end{array}$

3.4 Physiologische Analyse der Isolate mit fungiziden Eigenschaften $\quad 57$

3.4.1 Wachstumsparameter der Isolate mit fungizider Wirkung auf Chitin 61

3.5 Identifizierung der Chitinasegene aus isolierten Mikro- 63 organismen mit Hilfe der ,Southern“-Blot- Analyse

3.6 Klonierung der Chitinasegene über Kolonie-Hybridisierung $\quad 67$

$\begin{array}{lll}\text { 3.8 } & \text { Identifizierung und Charakterisierung von Chitinasegenen } & 71\end{array}$

3.8.1 Amplifikation und Charakterisierung des Chitinasegens aus WG3 72 
3.8.2 Amplifikation und Charakterisierung des Chitinasegens aus WG1, 75

3.8.3 Klonierung von Chitinasen aus Anreicherungskulturen mit Boden- $\quad 81$ und Meeres-Proben

3.9 Charakterisierung der Domänen aus den klonierten Chitinase-Genen zu bekannten Chitinasen der Familie 18 und 19

3.9.1 Charakterisierung der Chitinasen aus dem Isolat WG3 und 88

3.9.2 Identifizierung und Charakterisierung von Chitinasen aus den $\quad 91$ Isolaten WG1 und SE1 sowie einer Anreicherungskultur aus MeeresProben

3.10 $\quad$ Expression der identifizierten Chitinasegene $\quad 93$

3.10.1 Expression des chiA-Gens aus pVH 94

3.10.2 Expression der Chitinase-Gene aus den Inserts aus pWG3 und pSG 94

3.11 Charakterisierung der Chitinasen aus $E$. coli BL21/pWG3-1 und 95

3.11.1 Bestimmung der spezifischen Chitinaseaktivität der Chitinasen aus 96 E. coli/pWG3-1 und E. coli/pSG-1

3.11.2 Bestimmung des Temperatur-Optimums der Chitinasen aus 97

3.11.3 Bestimmung des pH-Optimums der Chitinasen aus E. coli/pWG3-1 98

3.11.4 Untersuchung der Chitinasen aus E. coli/pSG-1 und E. coli/pWG3-1 99

3.12 Charakterisierung der Chitinasen aus WG1, SE1, E2 und SL3 101 im Kulturüberstand

3.12.1 Bestimmung des Temperaturoptimums der Chitinasen aus E2, SE1, 102 SL3 und WG1

3.12.2 Bestimmung des pH-Optimums der Chitinasen aus E2, SE1, SL3 102 und WG1

3.13 Bestimmung der molekularen Masse der Chitinasen aus den Isolaten mit fungizider Wirkung

4. Diskussion

4.2 Untersuchung der Isolate auf fungizide Eigenschaften

Klonierung von Chitinase-Genen aus den Isolaten WG1, SE1 und SL3 
4.5 Produktion und Charakterisierung der Chitinasen aus

E. coli/pWG3-1 und $E$. coli/pSG-1

4.6 Charakterisierung der Chitinasen aus den Isolaten WG1, SE1,

129 SL3 und E2

4.7

Ausblick

130

5.

ZUSAMMENFASSUNG

133

6.

LITERATURVERZEICHNIS

136

7.

ANHANG

153 


\section{ABKÜRZUNGSVERZEICHNIS}

A.

Abb.

$A p^{r}$

ATP

Bp.

$B$.

${ }^{\circ} \mathrm{C}$

$\mathrm{cm}$

C-terminal

Da

dest.

DMSO

DNA

DNase

dNTP

DSMZ

E

E.

et al.

F.

$\mathrm{Fa}$.

g

h

Hrsg.

IPTG

$\mathrm{kBp}$

$\mathrm{kDa}$

1

$\lambda$

LB

M
Alteromonas

Abbildung

Ampicillinresistenz

Adenosin-5 -triphosphat

Basenpaar

Bacillus

Grad Celsius

Zentimeter

carboxyterminal

Dalton

destilliert

Dimethylsulfoxid

Desoxyribonukleinsäure

Desoxyribonuklease

Desoxyribonukleotid-5 -triphosphat

Deutsche Sammlung von Mikroorganismen und Zellkulturen GmbH

Extinktion

Escherichia

et alteri

Fusarium

Firma

Erdbeschleunigung, Gramm

Stunde

Herausgeber

Isopropyl- $\beta$-D-thiogalactopyranosid

Kilobasenpaare

Kilodalton

Liter

Bacteriophage Lambda

Luria-Bertani

Molar 


\begin{tabular}{|c|c|}
\hline $\max$. & Maximal \\
\hline $\mathrm{mg}$ & Milligramm \\
\hline$\mu \mathrm{g}$ & Mikrogramm \\
\hline $\min$ & Minute \\
\hline$\mu 1$ & Mikroliter \\
\hline $\mathrm{ml}$ & Milliliter \\
\hline $\mathrm{mM}$ & Millimolar \\
\hline$\mu \mathrm{M}$ & Mikromolar \\
\hline mol & $6.023 \times 10^{23}$ \\
\hline NB & Nutrient Broth \\
\hline N-terminal & aminoterminal \\
\hline $\mathrm{Od}_{\mathrm{x}}$ & Optische Dichte bei einer Wellenlänge von x nm \\
\hline$\%$ & Prozent \\
\hline $\mathrm{p}$ & piko \\
\hline PAGE & Polyacrylamid-Gelelektrophorese \\
\hline PEG & Polyethylenglykol \\
\hline $\mathrm{pH}$ & negativer dekadischer Logarithmus der Protonenkonzentration \\
\hline RNA & Ribonukleinsäuren \\
\hline RNase & Ribonuklease \\
\hline RT & Raumtemperatur \\
\hline $\mathrm{s}$ & Sekunde \\
\hline s. & siehe \\
\hline S & Svedberg-Einheit \\
\hline$S$. & Streptomyces \\
\hline SDS & Natriumdodecylsulfat \\
\hline SL & Spurenelementelösung \\
\hline sp. & Species \\
\hline $\mathrm{t}$ & Zeit \\
\hline $\mathrm{T}$ & Temperatur \\
\hline TAE & Tris-Acetat-EDTA \\
\hline TEMED & $\mathrm{N}, \mathrm{N}, \mathrm{N}^{`}, \mathrm{~N}^{`}$-Tetramethylethylendiamin \\
\hline $\mathrm{TE}$ & Tris-EDTA \\
\hline Tris & Tris-(hydroxymethyl)-aminomethan \\
\hline $\mathrm{U}$ & Unit (Einheit der Enzymaktivität) \\
\hline
\end{tabular}




$\begin{array}{ll}\text { Upm } & \text { Umdrehungen pro Minute } \\ \text { UV } & \text { Ultraviolett } \\ V . & \text { Vibrio } \\ \text { V } & \text { Volt } \\ \text { v/v } & \text { Volumen pro Volumen } \\ \text { w/v } & \text { Masse pro Volumen } \\ \text { X-Gal } & \text { 5-Brom-4-chlor-3-indolyl- } \beta \text {-D-galactosid }\end{array}$




\section{Einleitung}

Bei Chitin handelt es sich um ein lineares unlösliches Polymer aus $\beta-1,4-N$-Acetyl-DGlukosamin-Einheiten (s. Abb. 1). Diese hochpolymere Verbindung ist nach Cellulose das am häufigsten vorkommende Biopolymer der Erde und dient in unterschiedlichen Organismen wie den Mollusken, Coelenteraten und Nematoden sowie Protozoen, Pilzen und den meisten Arthropoden als Gerüstsubstanz (COTTRELL et al., 1999).

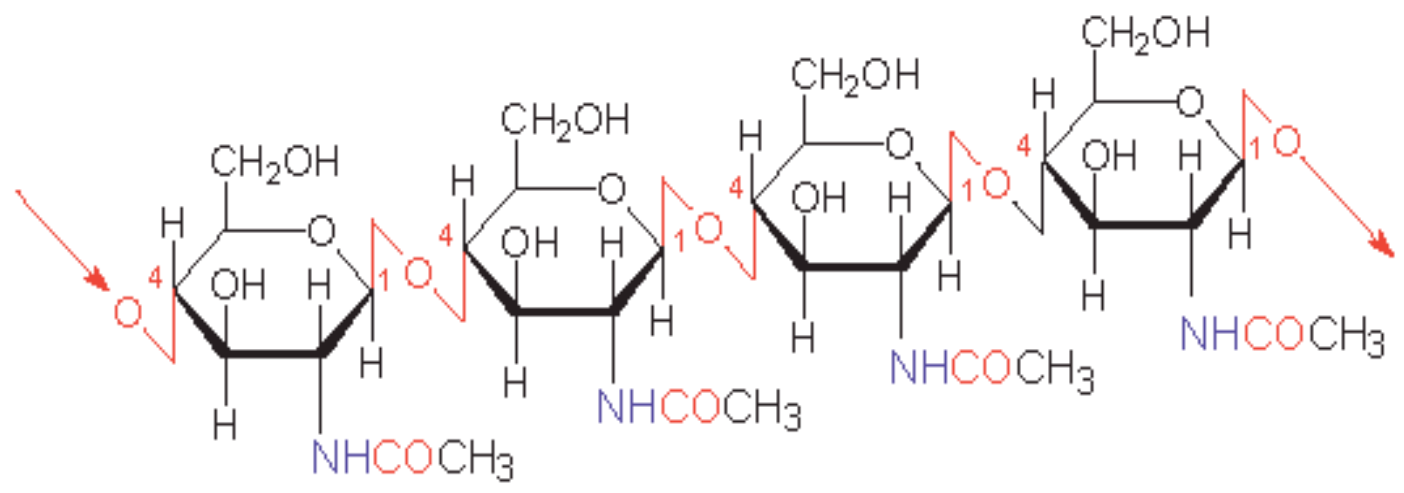

\section{Abb. 1: Struktur des Chitins}

Die auf natürliche Weise entstehenden großen Mengen an Chitin (ca. $10^{9}$ Tonnen) werden durch die in Flora, Fauna und unter den Mikroorganismen verbreiteten chitinspaltenden Enzyme abgebaut. Chitinasen sind in 3 Familien der Glykosyl-Hydrolasen eingeordnet (18, 19 und 20): Familie 18 beinhaltet Chitinasen von Bakterien, Viren und Eukaryoten sowie die Klassen III und V der Pflanzen. In der Familie 19 finden sich die Klassen I, II und IV der Pflanzen. Ausnahme hierbei ist u.a. die bakterielle Chitinase aus Streptomyces griseus HUT6037, welche ebenfalls zur Familie 19 gehört. In der Familie 20 finden sich die $\beta$ Hexosaminidasen und Chitobiasen (OHNO et al., 1996; NIEHAUS et al., 1999). Die Chitinasen können anhand ihrer Wirkungsspektren eingeteilt werden. Endochitinasen reduzieren das Polymer zu Oligomeren, welche durch Exochitinasen weiter zu Chitobiose abgebaut werden können. Chitobiasen setzen Chitobiose zu N-Acetyl-Glukosamin um. Mit Hilfe eines selteneren Abbauweges kann das Chitin durch Deacetylierung in Chitosan (PolyGlucosamin) umgewandelt und anschließend durch Chitosanasen zu Dimeren und Monomeren hydrolysiert werden. Dieser Abbauweg wird von Zygomyceten im Rahmen autolytischer Prozesse zum Abbau der eigenen Zellwand eingeschlagen (DAVIS und 
EVELEIGH, 1984). Zudem sind einige prokaryotische Organismen bekannt, die Chitosan abbauen können (PELLETIER und SYGUSCH, 1990; MASSON et al., 1994; FUKAMIZO et al., 1994). In der Natur produzieren die meisten Bakterien Chitinasen, um Chitin als Cund Energiequelle nutzbar zu machen (YU et al., 1991). Das Enzym wird dabei aus der Zelle in die Umgebung sekretiert. Chitinasen werden jedoch in der Natur auch als Fungizid bzw. Insektizid eingesetzt. So produzieren Pflanzen Chitinasen als Fungizid zur Abwehr schädlicher Pilze (WATANABE et al., 1991). Die Chitinasen binden an chitinhaltige Pilzmycelien und bauen anschließend Chitin ab; ein Lyse der Mycelien ist die Folge (VIONIS et al., 1996). So konnte durch die Einführung des Chitinase-Gens aus Serratia marcescens in das endophyt in Bohnen bzw. Baumwolle lebende Bakterium Pseudomonas fluorescens eine signifikante Reduktion des Befalles mit dem pflanzenpathogenen Pilz Rhizoctonia solani (Wurzelfäule) erzielt werden (KOBY et al., 1994; DOWNING et al., 2000). Des Weiteren wurde ein Chitinase-Gen aus Getreide in Tabakpflanzen exprimiert. Diese transgenen Pflanzen wiesen einen erhöhten Schutz gegen phytopathogene Pilze auf (JACH et al., 1995). Ebenso wurde das Chitinase C-Gen aus Streptomyces griseus HUT6037 in Reis-Pflanzen expremiert. Die transgenen Pflanzen zeichneten sich daraufhin durch einen verstärkten Schutz gegen Pilzbefall aus (ITOH et al., 2002). Durch die direkte Zugabe von bakteriellen Chitinase-Produzenten zum Boden von Nutzpflanzen konnte ebenfalls eine erhebliche Reduktion von Pilzbefall erreicht werden (CHERNIN et al., 1995; PLEBAN et al., 1997). Der Abbau der Pilze wurde mittels biochemischer und immunologischer Methoden analysiert (VIONIS et al., 1996). Daher erscheinen bakterielle Chitinasen für den Einsatz als Fungizid geeignet. Bisher sind in Deutschland keine Verfahren bzw. Chitinasepräparate entwickelt worden, die zum gezielten Abbau von Chitin in Schädlingen führen. Der Einsatz von Chitinasen als Fungizid erscheint entgegen der Verwendung synthetischer Fungizide unbedenklich, da diese biologische Agentien darstellen, die vollständig abbaubar sind und nur Chitin enthaltende Organismen angreifen. Synthetische Fungizide gehören dagegen wie Herbizide und Insektizide zu den Pestiziden. Pestizide sind verantwortlich für eine große Zahl von Vergiftungen und Erkrankungen des Menschen (PETERS et al., 1992; REIGERT et al., 1998).

Einsatzmöglichkeiten von Chitinasen als Fungizid lägen in der Bekämpfung von Verunreinigungen in Innenräumen durch Pilze (Wandfeuchtigkeit). Die schädigende Wirkung eingeatmeter Pilzsporen auf das Immunsystem und die Gefahr ernsthafter Erkrankungen wie z.B. Aspergillosen, Mykosen ist gut dokumentiert (REISS, 1986; BIEBERSTEIN, 1995). Identifizierte Chitinasen mit fungizider Wirkung könnten als Zusatz zu Wandanstrichen bzw. Reinigungslösungen angewendet werden, um den Pilzbefall in 
Innenräumen zu unterbinden. Denkbar wäre auch ein Einsatz zur Reduzierung der Pilzbelastung von Abluft oder im Nutzpflanzenbau zur Bekämpfung phytopathogener Pilze. Um Chitinase-Gene zu identifizieren, sollten zum einen auf dem klassischen Wege Chitinase-produzierende Mikroorganismen angereichert und isoliert werde. Die so erhaltenen Isolate und deren Kulturüberstand waren dann auf fungizide Eigenschaften zu untersuchen. Bei Isolaten, die ein solche Eigenschaft aufweisen, sollten die Chitinase-Gene kloniert werden. Zum anderen wurde Umwelt-DNA die in Vektoren ligiert wurde, auf das Vorhandensein von Chitinase-Genen hin durchmustert. Durch letztere Vorgehensweise wird das genetische Potential eines Standortes (z.B. Sediment, Boden) in seiner Gesamtheit zur Erzeugung von rekombinanten Organismen mit speziellen Eigenschaften ausgenutzt. Diese auf der Klonierung der Gesamt-DNA eines Habitats basierende Verfahren nutzen größere Teile der Biodiversität aus, da eine Isolierung von Organismen nicht erforderlich ist.

Untersuchungen von AMANN et al. (1995) zeigten, dass weniger als $1 \%$ der Mikroorganismen mit den heutigen Methoden kultivierbar sind. Daher ist ein großes genetisches und metabolisches Potential bisher noch unentdeckt und wird mit klassischen Verfahren zur Anreicherung von Mikroorganismen nicht erfasst. Diese Limitierung macht eine alternative Vorgehensweise, die unabhängig von der Kultivierbarkeit der Mikroorganismen ist, zur Erfassung von Enzymaktivitäten von bisher unbekannten bzw. nicht charakterisierten Organismen interessant. Um die Biodiversität eines Habitats in seiner Gesamtheit auszunutzen, wurden in den letzten Jahren mehrere Verfahrensweisen entwickelt, die auf der Isolierung von DNA basieren (OGRAM et al., 1987; JACOBSEN und RASMUSSEN, 1992; ZHOU, et al., 1998, HENNE et al., 1999). Zudem sollten unter Einbeziehung von bekannten DNA-Sequenzen die direkte PCR-Amplifikation der Zielgene aus Anreicherungskulturen durchgeführt werden. Hierbei finden jedoch lediglich Primer für die Amplifikation Verwendung, die von bekannten Bereichen abgeleitet wurden. Daher werden bei diesem Verfahren die mechanistisch oder strukturell abweichenden Vertreter einer Enzymklasse nicht erfasst. Grundlegend neuartige Enzyme können auf diese Weise nicht aufgefunden werden.

Ziel der Arbeit war es, mit Hilfe der dargestellten Methoden bakterielle Chitinasen mit fungizider Wirkung zu identifizieren. Diese sollten in geeignete Expressionsvektoren umkloniert und im Wirt Escherichia coli expremiert werden. Die erhaltenen produzierten Genprodukte sollten daraufhin auf ihre Eignung als Fungizid gegen pflanzenpathogene Pilze untersucht werden. 
2

\section{MATERIAL und METHODEN}

\subsection{Verwendete Organismen, Plasmide und Oligonukleotide}

Die im Rahmen dieser Arbeit verwendeten Organismen sind in Tabelle 1, die Plasmide in

Tabelle 2 aufgeführt. Tabelle 3 gibt eine Übersicht über die verwendeten Oligonukleotide.

Tabelle 1: Verwendete Organismen

\begin{tabular}{|c|c|c|}
\hline Stamm & relevanter Geno- oder Phänotyp & Herkunft/Referenz \\
\hline Vibrio harveyi & Wildtyp & DSMZ 2165 \\
\hline Bacillus licheniformis & Wildtyp & DSMZ 13 \\
\hline $\begin{array}{l}\text { Streptomyces griseus } \\
\text { subsp. griseus }\end{array}$ & Wildtyp & DMSZ 40236 \\
\hline Aspergillus nidulans & Wildtyp & FGSC A4 \\
\hline Botrytis cinerea & Wildtyp & DSMZ 877 \\
\hline Fusarium culmorum & Wildtyp & DSMZ 1094 \\
\hline Guignardia bidwellii & Wildtyp & DSMZ 3513 \\
\hline Sclerotia sclerotiorum & Wildtyp & DSMZ 1946 \\
\hline Escherichia coli $\mathrm{DH} 5 \alpha$ & 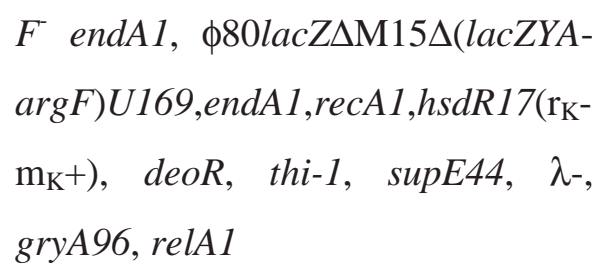 & HANAHAN, 1983 \\
\hline $\begin{array}{l}\text { Escherichia coli } \\
\text { BL21(DE3) }\end{array}$ & 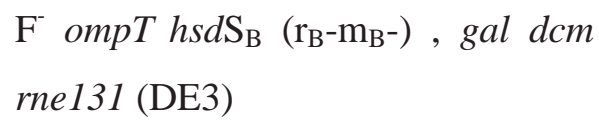 & $\begin{array}{l}\text { Invitrogen,Carlsbad, } \\
\text { USA }\end{array}$ \\
\hline Escherichia coli $\mathrm{TOP} 10$ & $\begin{array}{l}\mathrm{F}^{-} \quad m c r A \quad \Delta(m r r-h s d \mathrm{RMS}-m c r \mathrm{BC}) \\
\Phi 80 \text { lacZ } \Delta \mathrm{M} 15 \quad \Delta l a c \mathrm{X} 74 \quad \text { rec } \mathrm{A} 1 \\
\text { deoR araD139 } \Delta(\text { ara-leu }) 7697 \text { galU } \\
\text { galK rpsL }\left(\mathrm{Str}^{\mathrm{R}}\right) \text { endAl nupG }\end{array}$ & $\begin{array}{l}\text { Invitrogen,Carlsbad, } \\
\text { USA }\end{array}$ \\
\hline
\end{tabular}


Tabelle 2: Vektoren und rekombinante Plasmide

\begin{tabular}{lll}
\hline Plasmid & relevantes Merkmal & Herkunft/Referenz \\
\hline pBluescript ${ }^{\circledR} \mathrm{SK}+$ & $\mathrm{Ap}^{\mathrm{r}}$, lacPOZ, $\mathrm{pMB}$ 1-Replikon & Stratagene, \\
& & Heidelberg, \\
pCR2.1-TOPO & $\mathrm{Ap}^{\mathrm{r}}, \mathrm{Kan}^{\mathrm{r}}{ }^{\mathrm{r}} \mathrm{pMB}$ 1-Replikon & Invitrogen, \\
& & Karlsruhe \\
pET100/D-TOPO & $\mathrm{Ap}^{\mathrm{r}}$, His $_{6}$-tag N-terminal, Xpress-epitop & Invitrogen, \\
& & Karlsruhe \\
pET101/D-TOPO & Ap $^{\mathrm{r}}$ His $_{6}$-tag C-terminal, V5-epitop-tag & Invitrogen, \\
& & Karlsruhe
\end{tabular}

Tabelle 3: Verwendete Oligonukleotide

\begin{tabular}{|c|c|}
\hline Bezeichnung & Sequenz \\
\hline 16S-08 & $\begin{array}{l}\text { 5‘ AGAGTTTGATCATGGC 3’ (REFERENZ : MUYZER et } \\
\text { al. 1995) }\end{array}$ \\
\hline $16 \mathrm{~S}-1504$ & $\begin{array}{l}\text { 5‘ TACCTTGTTACGACTT 3` (REFERENZ : MUYZER et } \\
\text { al. 1995) }\end{array}$ \\
\hline BL1 & $5^{\prime}$ ATGAACATCGTGTTGTTCAAC 3’ \\
\hline BL1020 & 5`GTAGAACGGTGTTCCAAGCAC 3’ \\
\hline BL2530 & 5 CTATCCATTTGACTTTCTGTT 3’ \\
\hline ChiC600 & 5 GTCACCGGCCGCCTTGTAGTT 3’ \\
\hline ChiCcod.for & 5‘ ACGTGTATCGACGTGTCATGAGTC 3’ \\
\hline CHICcod.rev & 5‘ TACGACATCAGCAGCTCAGGTTCG 3’ \\
\hline ChiCrev-Stop & 5‘ GCAGCTCAGGTTCGGACCCGTGGT 3’ \\
\hline SGpET & 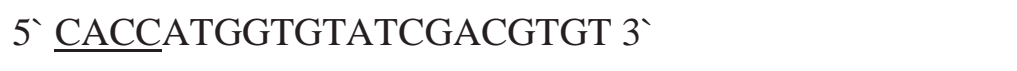 \\
\hline SGpET-Signal. & 5 CACCATGGGCCACCTGCGCCACG 3’ \\
\hline Vh1 & 5‘ATGATTCGATTTAACCTATGT 3’ \\
\hline Vh1170 & 5`TACGACTTCTACGGCGGCTGGAAC 3` \\
\hline Vh2500 & 5` CATTCGCCAGACTTGCTAGGATCT 3` \\
\hline Vh2542 & 5‘ TTAGCAGTGTTTAGTTACAGT 3` \\
\hline $\mathrm{VhF}$ & 5`GCAGCAGATAAGGGTGACCCTGTAA 3’ \\
\hline VhpETfor & 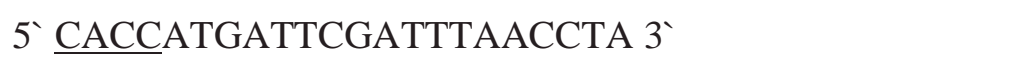 \\
\hline
\end{tabular}


VhpET-Signal. $\quad 5$ CACCATGGCACCAAGTATCGAT 3

VhR 5' CGCAAAGATGTAGTCCATGTACTGA 3’

(Fortsetzung Tab. 3)

Die Erkennungssequenz für die gerichtete Klonierung in die Expressionsvektoren pET100/D-TOPO bzw. pET101/D-TOPO ist unterstrichen.

\section{$2.2 \quad$ Nährmedien}

Alle aufgeführten Medien wurden durch 30 -minütiges Autoklavieren bei $121^{\circ} \mathrm{C}$ sterilisiert. Die C- Quellen für Mineralmedien wurden separat autoklaviert und erst unmittelbar vor dem Animpfen zugegeben. Zur Herstellung von Agarplatten wurde dem Medium vor dem Autoklavieren 1,5\% (w/v) Agar zugefügt.

Anaerobe Medien wurden nach der von COSTILOW (1981) beschriebenen Methode unter Begasung mit sauerstofffreiem Stickstoff hergestellt.

2.2.1 LB- (Luria-Bertani) Medium (SAMBROOK et al., 1989)

$\begin{array}{lrr}\text { Trypton } & 10 & \mathrm{~g} \\ \mathrm{Hefeextrakt} & 5 & \mathrm{~g} \\ \mathrm{NaCl} & 10 & \mathrm{~g} \\ \mathrm{H}_{2} \mathrm{O}_{\text {dest. }} & \text { ad } 1000 & \mathrm{ml}\end{array}$

2.2.2 SOB-Medium (HANAHAN, 1983)

$\begin{array}{lrr}\text { Trypton } & 20 & \mathrm{~g} \\ \text { Hefeextrakt } & 5 & \mathrm{~g} \\ \mathrm{NaCl} & 0,58 & \mathrm{~g} \\ \mathrm{KCl} & 0,18 & \mathrm{~g} \\ \mathrm{MgCl}_{2} & 2,0 & \mathrm{~g} \\ \mathrm{MgSO}_{4} & 2,5 & \mathrm{~g} \\ \mathrm{H}_{2} \mathrm{O}_{\text {dest. }} & \text { ad } 980 & \mathrm{ml}\end{array}$




\subsubsection{Chitin-Mineralmedium}

$\begin{array}{lrr}\mathrm{KH}_{2} \mathrm{PO}_{4} & 3,0 & \mathrm{~g} \\ \mathrm{~K}_{2} \mathrm{HPO}_{4} & 2,0 & \mathrm{~g} \\ \mathrm{NH}_{4} \mathrm{Cl} & 1,0 & \mathrm{~g} \\ \mathrm{MgSO}_{4} \times 7 \mathrm{H}_{2} \mathrm{O} & 0,2 & \mathrm{~g} \\ \mathrm{CaCl}_{2} \times 12 \mathrm{H}_{2} \mathrm{O} & 0,01 & \mathrm{~g} \\ \text { kolloidales Chitin } & 7 & \mathrm{~g} \\ \mathrm{SL}-4 & 1 & \mathrm{ml} \\ \text { Vitaminlösung nach Wolin } & 2 & \mathrm{ml} \\ \mathrm{H}_{2} \mathrm{O} \text { dest. } & \text { ad } 1000 & \mathrm{ml} \\ \text { pH-Wert einstellen auf } & 7,0 & \end{array}$

Wurde das Medium für das Wachstum von Organismen aus Meeresproben verwendet, wurden $40 \mathrm{~g} / \mathrm{l}$ Meeressalz zugefügt.

2.2.4 Aspergillus-Medium (BENNET und LASURE, 1991)

$\begin{array}{cc}\text { Glukose } & 10 \mathrm{~g} \\ \text { Asp A } & 20 \mathrm{ml} \\ \mathrm{MgSO}_{4} & 1 \mathrm{~g} \\ \mathrm{SL} 4 & 1 \mathrm{ml} \\ \mathrm{H}_{2} \mathrm{O}_{\text {dest }} & \mathrm{Ad} 1000 \mathrm{ml} \\ \text { pH-Wert einstellen auf } & 5,5 \\ & \\ \text { Asp A } & 300 \mathrm{~g} \\ \mathrm{NaNO}_{3} & 26 \mathrm{~g} \\ \mathrm{KCL} & 76 \mathrm{~g} \\ \mathrm{KH}_{2} \mathrm{PO}_{4} & \mathrm{ad} 1000 \mathrm{ml} \\ \mathrm{H}_{2} \mathrm{O} & 5,5\end{array}$


2.2.5 Spurenelementelösung SL-4 (PFENNIG und LIPPERT, 1966)

$\begin{array}{lrr}\mathrm{Na}_{2}-\mathrm{EDTA} & 5,0 & \mathrm{~g} \\ \mathrm{FeSO}_{4} \times 7 \mathrm{H}_{2} \mathrm{O} & 2,0 & \mathrm{~g} \\ \mathrm{ZnSO}_{4} \times 7 \mathrm{H}_{2} \mathrm{O} & 0,1 & \mathrm{~g} \\ \mathrm{MnCl}_{2} \times 4 \mathrm{H}_{2} \mathrm{O} & 0,03 & \mathrm{~g} \\ \mathrm{H}_{3} \mathrm{BO}_{4} & 0,3 & \mathrm{~g} \\ \mathrm{CoCl}_{2} \times 6 \mathrm{H}_{2} \mathrm{O} & 0,2 & \mathrm{~g} \\ \mathrm{CuCl}_{2} \times 2 \mathrm{H}_{2} \mathrm{O} & 0,01 & \mathrm{~g} \\ \mathrm{NiCl}_{2} \times 6 \mathrm{H}_{2} \mathrm{O} & 0,02 & \mathrm{~g} \\ \mathrm{NaMoO}_{4} \times 2 \mathrm{H}_{2} \mathrm{O} & 0,03 & \mathrm{~g} \\ \mathrm{H}_{2} \mathrm{O}_{\text {dest. }} & \mathrm{ad} 1000 & \mathrm{ml}\end{array}$

Der pH-Wert wurde auf 6,7 eingestellt und die Lösung lichtgeschützt bei $4{ }^{\circ} \mathrm{C}$ gelagert.

2.2.6 Vitaminlösung (WOLIN et al., 1964, modifiziert)

$\begin{array}{lrr}\text { Biotin } & 2 & \mathrm{mg} \\ \text { Folsäure } & 2 & \mathrm{mg} \\ \text { Pyridoxin x HCl } & 10 & \mathrm{mg} \\ \text { Thiamin x HCl } & 15 & \mathrm{mg} \\ \text { Riboflavin } & 5 & \mathrm{mg} \\ \text { Nikotinsäure } & 5 & \mathrm{mg} \\ \text { Ca-Pantothenat } & 5 & \mathrm{mg} \\ \text { Vitamin } \mathrm{B}_{12} & 10 & \mu \mathrm{g} \\ \text { p-Aminobenzoesäure } & 5 & \mathrm{mg} \\ \alpha \text {-Liponsäure } & 1 & \mathrm{mg} \\ \mathrm{H}_{2} \mathrm{O}_{\text {dest. }} & \mathrm{ad} 1000 & \mathrm{ml}\end{array}$


Antibiotika und sonstige Medienzusätze

Für die Anzucht rekombinanter E. coli-Stämme wurden die in Tabelle 4 aufgeführten Medienzusätze verwendet.

Tabelle 4: Verwendete Medienzusätze und Konzentrationen

\begin{tabular}{lll}
\hline Medienzusatz & Stammlösung & Arbeitskonzentration \\
\hline Ampicillin & $50 \mathrm{mg} / \mathrm{ml} \mathrm{H}_{2} \mathrm{O}_{\text {dest. }}$ & $100 \mu \mathrm{g} / \mathrm{ml}$ \\
X-Gal & $50 \mathrm{mg} / \mathrm{ml} \mathrm{Dimethylformamid}$ & $40 \mu \mathrm{g} / \mathrm{ml}$ \\
IPTG & $50 \mathrm{mg} / \mathrm{ml} \mathrm{H}_{2} \mathrm{O}_{\text {dest. }}$ & $50 \mu \mathrm{g} / \mathrm{ml}$
\end{tabular}

2.2.8 Herstellung von kolloidalem Chitin (WIWAT et al., 1999, modifiziert)

20 g Chitin-Pulver wurden zu $350 \mathrm{ml}$ konzentrierter Salzsäure zugefügt und bei $4{ }^{\circ} \mathrm{C}$ über Nacht unter starkem Rühren inkubiert. Das hydrolisierte Chitin wurde anschließend in 21 $95 \%$ Ethanol gegossen und für $5 \mathrm{~h}$ bei $4{ }^{\circ} \mathrm{C}$ gerührt. Das Präzipitat wurde mit $\mathrm{H}_{2} \mathrm{O}_{\text {dest. }}$ gewaschen, bis der pH-Wert neutral war. Abschließend wurde das Chitin lyophilisiert.

\subsection{Zellanzucht}

\subsubsection{Aerobe Anzucht}

Die aerobe Anzucht von aeroben Kulturen erfolgte in Reagenzgläsern oder Erlenmeyerkolben. Die Kulturen wurden unter Schütteln bei $30^{\circ}$ oder $37^{\circ} \mathrm{C}$ inkubiert. Als Kulturgefäße dienten bei einem Kulturvolumen von $5 \mathrm{ml}$ Reagenzgläser, bei einem Volumen von 250 oder $500 \mathrm{ml}$ 1L-Erlenmeyerkolben. Bei einem Volumen von 1L wurden 2L Erlenmeyerkolben verwendet. 


\subsubsection{Anaerobe Anzucht}

Die Kultivierung der strikt anaeroben Organismen erfolgte nach der Methode von HUNGATE 1969. Als Kulturgefäße dienten entweder 16-ml-Hungate-Röhrchen (Fa. Bellco Glass Inc., Vineland, NJ, USA) oder1-1 Serumflaschen (Fa. Müller und Krempel AG, Bülach, Schweiz). Die Gefäße wurden mit gasdichten Stopfen aus Butylgummi verschlossen. Die Zugabe von Reduktionsmitteln, Substraten oder Vorkulturen erfolgte über sterile Plastikspritzen. Als Inokulum dienten jeweils $10 \%$ einer gut gewachsenen Vorkultur. Die Inkubation erfolgt bei $30^{\circ} \mathrm{C}$.

\subsubsection{Stammkulturhaltung}

\section{Aerobe Kulturen}

Die Stammhaltung erfolgte für E. coli und isolierte Chitinaseproduzenten für kürzere Zeiträume (ca. 6 Wochen) auf LB-Agar-Platten bzw. Chitin-Mineralmedium-Platten bei 4 ${ }^{\circ} \mathrm{C}$. Zur längeren Konservierung wurde $0,8 \mathrm{ml}$ Zellsuspension aus der exponentiellen Wachstumsphase des jeweiligen Organismus mit 0,2 ml sterilem Glycerin (87 \%) versehen und bei $-70^{\circ} \mathrm{C}$ in $1 \mathrm{ml}$ Eppendorf-Reaktionsgefäßen gelagert.

\section{$2.4 \quad$ Bestimmung von Wachstumsparametern}

\subsubsection{Bestimmung der optischen Dichte}

Die Bestimmung der optischen Dichte (OD) erfolgte anhand von Trübungsmessungen bei einer Wellenlänge von $600 \mathrm{~nm}$ gegen sterile Nährlösung in einem Spektralphotometer (UV-VIS Spektrophotometer V-550, Fa. Jasco, Jena) in Plastikküvetten mit einer 
Schichtdicke von $1 \mathrm{~cm}$. Ab Zelldichten $\mathrm{E}_{600}>0,3$ wurden die zu messenden Proben mit entsprechender steriler Nährlösung verdünnt.

\subsubsection{Bestimmung des pH-Wertes}

Der pH-Wert wurde mit einem WTW pH-Meter pH 526 (Fa. WTW GmbH, Weilheim) und einer Glas-Calomel-Elektrode (Fa. Cahn-Ingold, Frankfurt) bestimmt. Vor den Messungen wurde das Gerät für den entsprechenden Meßbereich mit Eichlösungen ( $\mathrm{pH}$ 4,0 pH 7,0 und pH 9,0 der Fa. Riedel de Haen AG, Hannover) geeicht.

\subsection{Standardtechniken für das Arbeiten mit Nukleinsäuren}

\subsubsection{Vorbehandlung von Geräten und Lösungen}

Zur Inaktivierung von Nukleasen wurden alle hitzestabilen Geräte und Lösungen durch Autoklavieren (21 min., $121^{\circ} \mathrm{C}$ ) sterilisiert. Nicht autoklavierbare Materialien wurden mit 96 \%igem Ethanol abgeflammt oder abgespühlt. Hitzelabile Substanzen wurden sterilfiltriert und sterilen Lösungen hinzugegeben.

\subsubsection{Reinigung und Konzentration von Nukleinsäuren}

\subsubsection{Phenol/Chloroform-Extraktion}

Um Proteine aus DNA-Lösungen zu entfernen, stellt die Extraktion mit 1 Vol. Phenol/Chloroform/Isoamylalkohol-Gemisch (24: 24 :1, v/v) eine einfache Methode dar, die bei der Isolierung und Reinigung von Gesamt-DNA und bei Plasmidpräparationen angewendet wurde. Die Phasen wurden durch Schwenken der Reaktionsgefäße gemischt und anschließend durch Zentrifugation (13000 x g, 5 min) getrennt. Die obere wässrige proteinfreie Phase wurde abgenommen und zur Entfernung von Phenolresten mit einem Volumen Chloroform/Isoamylalkohol (24:1, (v/v)) extrahiert. Bei hohen 
Reinheitsansprüchen an die DNA wurden diese Schritte jeweils wiederholt. Im Anschluss an die Phenol-Chloroform-Extraktion wurde eine Fällung mit Isopropanol oder Ethanol mit vorheriger Erhöhung der Ionenstärke durchgeführt. (s. 2.5.2.3).

\subsubsection{Mikrodialyse von DNA}

Um die Effizienz der Elektroporation (siehe 2.9.4) zu erhöhen, wurden die in Ligationsansätzen enthaltenden Salze durch eine Mikrodialyse entfernt. Durchgeführt wurde die Dialyse in einer Petrischale gegen steriles $\mathrm{H}_{2} \mathrm{O}$ als Dialysepuffer. Dazu werden Membranfilter (Porengröße 0,025 $\mu \mathrm{m}$, Fa. Milipore, Eschborn) mit der glänzenden Seite nach oben auf die Wasseroberfläche gelegt und vorsichtig 5 bis $10 \mu 1$ des zu dialysierenden Ansatzes mit einer Pipette auf die Dialysemembran aufgetragen. Nach ca. 30 min konnte die dialysierte Probe abgenommen und für die Elektroporation eingesetzt werden.

\subsubsection{Fällung von Nukleinsäuren}

Die Fällung oder Konzentrierung von Nukleinsäuren erfolgte durch den Einsatz von Ethanol oder Isopropanol. Falls notwendig, wurde die Ionenstärke durch Zugabe von 3 M Na-Acetat (pH 5,5) erhöht (Endkonzentration 0,3 M). Zur Präzipitation der Nukleinsäuren erfolgte die Zugabe von 2 Vol. Ethanol (96 \%) bzw. 1 Vol. Isopropanol (96 $\%)$. Während die Ethanolfällung durch Inkubation bei Raumtemperatur für ca. 20 min erfolgte, wurde bei der Isopropanolfällung für mindestens 5 min bei Raumtemperatur inkubiert. Die Nukleinsäuren wurden anschließend durch Zentrifugation (13000 bis 16000 x g, RT, $30 \mathrm{~min})$ pelletiert. Mit $1 \mathrm{ml}$ Ethanol (70 \%, v/v) wurde das Pellet gewaschen, getrocknet und in dem gewünschten Volumen sterilem $\mathrm{H}_{2} \mathrm{O}$ oder TE-Puffer aufgenommen.

\section{$\underline{\text { TE-Puffer }}$}

Tris $\quad 10 \mathrm{mM}$

EDTA $1 \mathrm{mM}$

$\mathrm{pH} \quad 8,0$ 


\subsubsection{DNA-Fällung mit PEG-NaCl nach Saccharose- Dichtegradientenzentrifugation}

Ziel dieser Fällung war die Entfernung von Saccharose nach der SaccharoseDichtegradienten-Zentrifugation (s. 2.8.4). Dazu wurde jede erhaltene Gradientenfraktion mit 0,5 Vol. PEG-NaCl-Lösung (20\% PEG 6000, 2,5 M NaCl) versetzt und über Nacht bei Raumtemperatur inkubiert. Anschließend erfolgte eine Zentrifugation der Lösungen (30 min, 22650 x g, RT). Der Überstand wurde abgenommen, das Pellet mit 0,5 ml Ethanol $(70 \%(\mathrm{v} / \mathrm{v}), \mathrm{RT})$ versetzt und nochmals unter den gleichen Bedingungen zentrifugiert. Wiederum wurde der Überstand abgenommen, das Pellet gerocknet und in 20 - $30 \mu \mathrm{l}$ sterilem $\mathrm{H}_{2} \mathrm{O}$ oder TE (siehe 2.5.2.3) aufgenommen.

\subsubsection{Gelfiltration von DNA-Lösungen}

Die Trennung niedermolekularer Bestandteile wie z.B. einzelner Nukleotide von DNAFragmenten erfolgte durch eine Gelfiltration mit NAP-5-Säulen (Fa. Pharmacia LKB $\mathrm{GmbH}$, Freiburg). Die Säulen wurden mit $10 \mathrm{ml} \mathrm{H}_{2} \mathrm{O}_{\text {dest. }}$ äquilibriert. Danach wurde 0,5 ml DNA-Lösung aufgetragen und mit $1,0 \mathrm{ml} \mathrm{H}_{2} \mathrm{O}$ eluiert.

\subsubsection{Konzentrationsbestimmung von Nukleinsäuren}

Die Ermittlung der Konzentration von Nukleinsäuren in wässriger Lösung erfolgte photometrisch bei einer Wellenlänge von $260 \mathrm{~nm}$. Eine Extinktion von 1 entspricht dabei etwa $50 \mu \mathrm{g} / \mathrm{ml}$ doppelsträngiger DNA, $40 \mu \mathrm{g} / \mathrm{ml}$ einzelsträngiger DNA oder $30 \mu \mathrm{g} / \mathrm{ml}$ einzelsträngiger Oligonukleotide. Durch das Verhältnis $\mathrm{OD}_{260} \mathrm{zu} \mathrm{OD}_{280}$ konnte dabei die Reinheit von Nukleinsäure-Lösungen bestimmt werden. Bei reinen DNA-Lösungen sollte dieser Wert zwischen 1,8 und 2,0 liegen (SAMBROOK et al., 1989). Niedrigere Werte lassen auf eine Verunreinigung mit Proteinen schließen. 


\subsubsection{Isolierung von DNA-Fragmenten mittels ,QIAquick Gel Extraction“- Kit}

Um DNA-Fragmente zu isolieren, wurde der „QIAquick Gel Extraction“-Kit (Fa. Qiagen $\mathrm{GmbH}$, Hilden) verwendet. Die Methode beruht auf der Bindung von DNA an eine SilicaMembran unter hohen Salzkonzentrationen. Der Kit kann zur Extraktion von DNAFragmenten von einer Größe von 0,1 bis $10 \mathrm{kBp}$ aus Agarosegelen (s. 2.6.1) genutzt werden. Zur Extraktion wurden die im Herstellerprotokoll beschriebenen Arbeitsschritte durchgeführt. Die DNA wurde mit $\mathrm{H}_{2} \mathrm{O}_{\text {dest. }}$ eluiert und bis zur weiteren Verwendung bei $20^{\circ} \mathrm{C}$ aufbewahrt.

\subsubsection{Reinigung von DNA-Fragmenten mittels, ,QIAquick PCR Purification"-Kit}

PCR-Produkten und anderen linearen DNA-Fragmenten wurden mit Hilfe des „QIAquick PCR Purification“-Kit (Fa. Qiagen GmbH, Hilden) gereinigt. Wie auch beim „QIAquick Gelextraction“-Kit (s. 2.5.2.7) wird die DNA bei hohen Salzkonzentrationen an eine SilicaMembran gebunden. Die Reinigung wurde nach den Anweisungen des Herstellers durchgeführt. Die Elution der DNA erfolgte mit $\mathrm{H}_{2} \mathrm{O}_{\text {dest. }}$. Die so gereinigten PCR-Produkte wurden bis zu ihrer weiteren Verwendung bei $-20^{\circ} \mathrm{C}$ gelagert.

\subsection{Gelelektrophorese von Nukleinsäuren}

2.6.1 Standard-Agarose-Gelelektrophorese (SAMBROOK et al., 1989).

Zur analytischen Auftrennung von DNA-Fragmenten diente die AgaroseGelelektrophorese (SAMBROOK et al., 1989). Es wurden Gele mit einem Volumen von ca. 20 bzw. ca. $100 \mathrm{ml}$ gegossen, wobei die Agarosekonzentration $1 \%$ (w/v) in TAEPuffer betrug. Die Proben wurden vor dem Auftragen mit 0,2 Vol. Stop-Mix versetzt, um die DNA zu beschweren und die Lauffront zu markieren. Als Elektrophoresepuffer wurde 
1-fach TAE-Puffer verwendet. Die Elektrophorese wurde bei einer konstanten Spannung von $100 \mathrm{~V}$ durchgeführt, wodurch sich je nach Gelgröße eine Laufzeit von 1 bis 5 h ergab. Nach Abschluß der Elektrophorese wurden die Agarosegele in einem Ethidiumbromidbad $\left(1 \mu \mathrm{g} / \mathrm{ml} \mathrm{H}_{2} \mathrm{O}\right)$ für 10 bis 30 min angefärbt. Nach 10 min Entfärbung im Wasserbad konnten die Gele auf einem UV-Transilluminator (Intas, Fa. Sony Corporation, Japan) bei Licht der Wellenlänge $254 \mathrm{~nm}$ ausgewertet werden. Zur Dokumentation diente ein Videoprinter (Intas Video Graphic Printer UP-890 CE, Fa. Sony Corporation, Japan), der eine Bildübertragung auf Thermopapier ermöglichte.

$\underline{\text { Stop-Mix }}$

TAE-Puffer (50-fach)

Ficoll $400 \quad 15 \%(w / v)$

Tris $\quad 800 \mathrm{mM}$

EDTA $\quad 0,1 \quad \mathrm{M}$

Eisessig $\quad 400 \mathrm{mM}$

Bromphenolblau 0,1\% (w/v)

EDTA

$40 \mathrm{mM}$

Xylencyanol FF $0,1 \%(w / v)$

$\mathrm{pH} 8,0$

\subsubsection{Größenbestimmung von Nukleinsäuren}

Als Größenstandard zur Ermittlung der Länge linearer DNA-Fragmente diente ein „Ladder-Mix“ (Fa. MBI Fermentas, St. Leon-Rot).

Die Größen der Fragmente sind im folgenden aufgeführt.

\begin{tabular}{|c|c|c|}
\hline \multicolumn{3}{|c|}{ Fragmentgrößen des ,Ladder-Mixes“in kB } \\
\hline 10,0 & 3,0 & 0,9 \\
\hline 8,0 & 2,5 & 0,8 \\
\hline 6,0 & 2,0 & 0,7 \\
\hline 5,0 & 1,5 & 0,6 \\
\hline 4,0 & 1,2 & 0,5 \\
\hline 3,5 & 1,03 & 0,4 \\
\hline
\end{tabular}




\subsection{Isolierung von Nukleinsäuren}

\subsubsection{Isolierung von chromosomaler DNA (ANDERSON und McKAY, modifiziert)}

Zur Isolierung der chromosomalen DNA aus isolierten Chitinaseproduzenten wurden 500ml-Kulturen bis zur stationären Phase bei $30{ }^{\circ} \mathrm{C}$ inkubiert und die Zellen durch Zentrifugation bei 5000 Upm für 5 min (Rotor SS34, Sorvall, Fa. Du Pont Instruments, Newton, USA) geerntet. Das Pellet wurde 3 x mit $10 \mathrm{mM}$ Phosphatpuffer $(\mathrm{pH}$ 7,5) gewaschen.

Zum Zellaufschluß wurde das Pellet in $10 \mathrm{ml}$ Saccharose-Lösung und $200 \mu$ l Lysozym (20 $\mathrm{mg} / \mathrm{ml}$ ) suspendiert und $30 \mathrm{~min}$ bei $37^{\circ} \mathrm{C}$ inkubiert. Dann wurde mit $1 \mathrm{ml} \mathrm{0,5} \mathrm{M}$ EDTA (in $50 \mathrm{mM}$ Tris, $\mathrm{pH} 8$,0) und $100 \mu \mathrm{l} 1 \mathrm{M}$ Tris (pH 8,0) gemischt. Nach der Zugabe von $500 \mu \mathrm{l}$ $20 \%$ SDS-Lösung wurde bei $37{ }^{\circ} \mathrm{C}$ für 10 min inkubiert. Schließlich wurde $100 \mu \mathrm{l}$ Proteinase $(10 \mathrm{mg} / \mathrm{ml})$ hinzugefügt und bei $\quad 37^{\circ} \mathrm{C}$ für $3 \mathrm{~h}$ inkubiert. Danach wurden 7 ml 5 M Na-Perchlorat dazu pipettiert.

Zur Trennung der Proteine erfolgte eine zweifache Extraktion mit 1 Volumen Chloroform/Isoamylalkohol (24:1, (v/v)). Der Überstand wurde abgenommen und weiter verwendet. Die Fällung der DNA erfolgte durch Zugabe von $8 \mathrm{ml}$ Isopropanol und anschließende Zentrifugation für $10 \mathrm{~min}$ bei $15000 \mathrm{Upm}$ (Rotor SS34, Sorvall, Fa. Du Pont Instruments, Newton, USA). Das Pellet wurde mit $1 \mathrm{ml}$ Ethanol (70 \%, (v/v)) gewaschen und getrocknet. Es erfolgte die Zugabe von $200 \mu$ TE-Puffer (siehe 2.5.2.3) sowie $100 \mu \mathrm{l}$ RNase-Lösung $(10 \mathrm{mg} / \mathrm{ml})$ und eine Inkubation von $1 \mathrm{~h}$ bei $37^{\circ} \mathrm{C}$. Daran schloß sich eine Inkubation von $3 \mathrm{~h}$ bei gleicher Temperatur nach Zugabe von $50 \mu \mathrm{l}$ Proteinase-Lösung $(10 \mathrm{mg} / \mathrm{ml})$ an. Es folgte eine weitere zweimalige Chloroform/Isoamylalkohol (24:1 (v/v)) Extraktion. Dem Überstand wurde $40 \mu 1 \quad 3 \mathrm{M}$ Na-Acetat ( $\mathrm{pH} 5,5)$ zugefügt und die DNA nach Zugabe von 2 Volumen Ethanol $(70 \%$, (v/v)) bei 15000 Upm (Rotor SS34, Sorvall, Fa. Du Pont Instruments, Newton, USA) gefällt. Das Pellet wurde getrocknet und in $1 \mathrm{ml}$ sterilem $\mathrm{H}_{2} \mathrm{O}$ aufgenommen.

Um einen hohen Reinheitsgrad der DNA zu gewährleisten, wurden letzte Verunreinigungen durch den Einsatz einer Quiagen-tip-100 Säule (Quiagen Midi-Kit, Fa. Qiagen, Düsseldorf) durch Anionenaustauschchromatographie entfernt (s. 2.7.2.3). 


\begin{tabular}{llll} 
SDS-Lösung & & \multicolumn{2}{l}{ Saccharose-Lösung } \\
SDS & $20 \%(\mathrm{w} / \mathrm{v})$ & Tris & $50 \mathrm{mM}$ \\
Tris & $50 \mathrm{mM}$ & Saccharose & $6,7 \%(\mathrm{w} / \mathrm{v})$ \\
EDTA & $20 \mathrm{mM}$ & EDTA & $1 \mathrm{mM}$ \\
pH & 8,0 & $\mathrm{pH}$ & 8,0
\end{tabular}

\subsubsection{Isolierung von Plasmid-DNA}

\subsubsection{Plasmidschnellpräparation (HOLMES \& QUIGLEY, 1981)}

Diese Methode wurde vor allem zum schnellen Nachweis und zur Charakterisierung von Klonierungsergebnissen eingesetzt. 1,5 ml einer über Nacht gewachsenen Kultur wurden geerntet (5000 x g, 5 min, RT) und in $350 \mu 1$ STET-Puffer suspendiert. Nach Zugabe von $25 \mu l$ Lysozym-Lösung (10 mg/ml 10 mM Tris-HCl, pH 8,0) wurde der Ansatz kurz bei RT inkubiert und anschließend für 1 min bei $100{ }^{\circ} \mathrm{C}$ denaturiert. Zellreste und denaturierte Proteine wurden nach Zentrifugation (16000 x g, 10 min) mit einem sterilen Zahnstocher entfernt. Nach der Zugabe von $40 \mu \mathrm{l}$ Na-Acetat (2,5 M, pH 5,2) und $420 \mu$ Isopropanol wurde das Plasmid durch Zentrifugation (16000 x g, 5 min) pelletiert. Das enthaltene Pellet wurde mit Ethanol (70 \%, (v/v)) gewaschen, getrocknet und in $50 \mu$ TE-Puffer (siehe 2.5.2.3) suspendiert.

STET-Puffer

$\mathrm{NaCl}$

Tris

EDTA

Triton X-100

$\mathrm{pH}$ $\underline{\text { TE-Puffer }}$

Tris $\quad 10 \mathrm{mM}$

EDTA $\quad 1 \mathrm{mM}$

$\mathrm{pH} \quad 8.0$

$5 \%(\mathrm{w} / \mathrm{v})$

8,0 


\subsubsection{Minipräparation mittels ,Wizard ${ }^{\mathrm{TM}}$ Plus Minipreps DNA Purification System“6}

Unter Verwendung des „Wizard ${ }^{\mathrm{TM}}$ Plus Minipreps DNA Purification System“ (Fa. Promega Deutschland GmbH, Mannheim) ließ sich eine schnelle Plasmidisolierung zum Erhalt sauberer DNA durchführen.

$\mathrm{Zu}$ diesem Zweck wurden 1,5 ml einer 5-ml-Übernachtkultur für $5 \mathrm{~min}$ bei $6000 \mathrm{x} \mathrm{g}$ zentrifugiert und das Zellpellet in $200 \mu 1$ „Cell Resuspension Solution“ suspendiert. Nach Zugabe von $200 \mu 1$ „Cell Lysis Solution“ wurde der Ansatz bis zum Aufklaren der Lösung geschwenkt und dann mit $200 \mu \mathrm{l}$ „Neutralization Solution“ versetzt. Die Probe wurde anschließend $10 \mathrm{~min}$ bei $13000 \mathrm{x}$ g zentrifugiert und der Überstand mit $1 \mathrm{ml}$ „DNAPurification Resin“ gemischt. Das DNA-Resin-Gemisch wurde dann auf eine vom Hersteller mitgelieferte Minisäule gegeben und mit $2 \mathrm{ml}$ „Column Wash Solution“ gewaschen und durch Zentrifugation (2 min, 10000 x g) getrocknet. Die Elution der DNA von der Matrix erfolgte durch Zugabe von $50 \mu \mathrm{H}_{2} \mathrm{O}$, 1-minütiger Inkubation bei Raumtemperatur und anschließender Zentrifugation (30 s, 12000 x g). Bei der Isolierung von Plasmiden, $>7 \mathrm{kBp}$, wurde das Wasser für die Elution auf $65^{\circ} \mathrm{C}$ vorgewärmt.

\begin{tabular}{lrlrl}
\multicolumn{2}{l}{ „Cell Resupension Solution““ } & \multicolumn{2}{c}{ "Cell Lysis Solution“" } \\
Tris & $50 \mathrm{mM}$ & $\mathrm{NaOH}$ & $0,2 \mathrm{M}$ \\
EDTA & $10 \mathrm{mM}$ & SDS & $1 \%(\mathrm{w} / \mathrm{v})$ \\
Rnase A & $100 \mu \mathrm{g} / \mathrm{ml}$ & \\
pH 7,5 & & &
\end{tabular}

\begin{tabular}{|c|c|c|c|c|}
\hline ,Neutraliz & \multicolumn{4}{|c|}{ „Column Wash Solution” } \\
\hline K-Acetat & $1,32 \mathrm{M}$ & K-Acetat & 80 & $n M$ \\
\hline \multirow[t]{4}{*}{$\mathrm{pH} 4,8$} & & Tris & 8,3 & $\mathrm{nM}$ \\
\hline & & EDTA & 40 & $\mathrm{M}$ \\
\hline & & Ethanol & 55 & $\%(\mathrm{v} / \mathrm{v})$ \\
\hline & & $\mathrm{pH} 7,5$ & & \\
\hline
\end{tabular}




\subsubsection{Präparative Plasmidisolierung über Anionenaustausch- chromatographie}

Die Isolierung größerer Mengen an Plasmid-DNA erfolgte nach alkalischer Lyse mit den Puffern P1, P2 und P3 über Anionenaustauschchromatographie (Quiagen Midi-Kit, Fa. Diagen, Düsseldorf).

$25 \mathrm{ml}$ Zellkultur wurden bei einer $\mathrm{OD}_{600}$ von 1 bis 1,5 geerntet und in $4 \mathrm{ml}$ P1-Puffer suspendiert. Es folgte die Zugabe von $4 \mathrm{ml}$ P2-Puffer und eine Inkubation für $5 \mathrm{~min}$ bei RT. Anschließend wurden $4 \mathrm{ml} \mathrm{P3-Puffer} \mathrm{zugefügt} \mathrm{und} \mathrm{für} 30$ min auf Eis inkubiert. Nach Zentrifugation (30 min, $16000 \mathrm{x} \mathrm{g}, 4^{\circ} \mathrm{C}$ ) wurde der Überstand abgenommen und zur vollständigen Aufklarung erneut für 15 min zentrifugiert. Der hierbei erhaltene Überstand wurde auf eine mit 4 ml QBT-Puffer äquilibrierte Quiagen-tip-100 Säule aufgetragen. Die Säule wurde anschließend mit $20 \mathrm{ml}$ QC-Puffer gewaschen und die Plasmid-DNA durch Zugabe von $5 \mathrm{ml}$ QF-Puffer eluiert. Die DNA wurde mit 0,7 Vol. Isopropanol gefällt und durch Zentrifugation (30 min, $16000 \mathrm{x} \mathrm{g}, 4{ }^{\circ} \mathrm{C}$ ) pelletiert. Das Sediment wurde anschließend mit Ethanol (70 \%, v/v) gewaschen, getrocknet und in 100 bis $200 \mu 1 \mathrm{H}_{2} \mathrm{O}$ oder TE-Puffer aufgenommen. Für die Isolierung von Plasmid- oder Cosmid-DNA aus Kulturvolumina von $250 \mathrm{ml}$ wurde die Menge an P1, P2 und P3 auf $20 \mathrm{ml}$ erhöht. Die Anionenaustauschchromatographie erfolgte dann in mehreren Durchgängen, wobei die Säule nach jeder Elution mit 4 ml QBT-Puffer äquilibriert wurde.

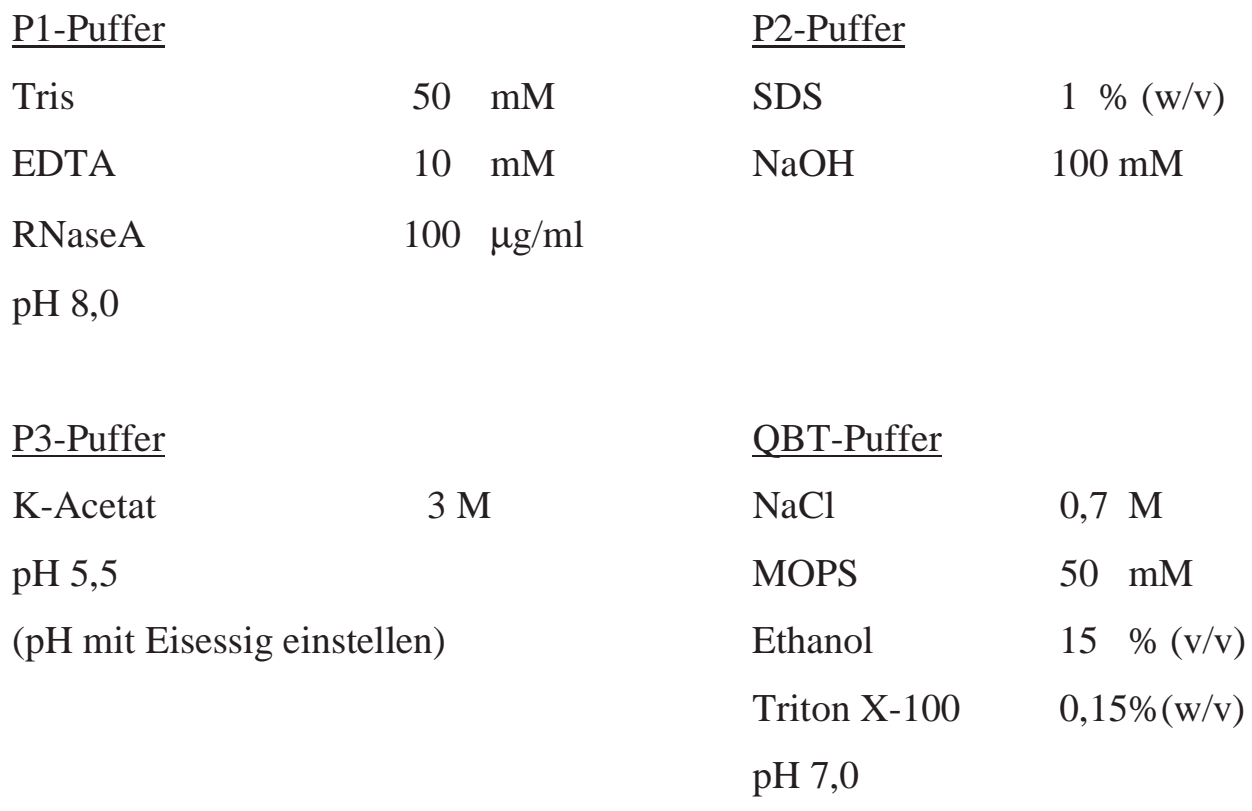




\begin{tabular}{lllrl} 
QF-Puffer & \multicolumn{3}{l}{ QC-Puffer } \\
$\mathrm{NaCl}$ & $1,25 \mathrm{M}$ & NaCl & $1 \mathrm{M}$ \\
$\mathrm{MOPS}$ & $50 \mathrm{mM}$ & MOPS & $50 \mathrm{mM}$ \\
Ethanol & $15 \%(\mathrm{v} / \mathrm{v})$ & Ethanol & $15 \%(\mathrm{v} / \mathrm{v})$ \\
$\mathrm{pH} 8,2$ & & $\mathrm{pH} \mathrm{7,0}$ &
\end{tabular}

\subsubsection{Minipräparation von Plasmiden mittels „QIAprep Spin Miniprep Kit““}

Alternativ zum „Wizard ${ }^{\mathrm{TM}}$ Plus Minipreps DNA Purification System” (s. 2.7.2.2) wurde zum Erhalt von sauberer Plasmid-DNA der „QIAprep Spin Miniprep Kit“ (Fa. Qiagen) verwendet.

1,5 $\mathrm{ml}$ einer 5-ml-Übernachtkultur wurden für $5 \mathrm{~min}$ bei $6000 \mathrm{x} \mathrm{g}$ zentrifugiert und das Zellpellet in $250 \mu \mathrm{l}$ Puffer P1 suspendiert. Es folgte die Zugabe von $250 \mu$ l Puffer P2, Schwenken bis zum Aufklaren der Lösung und Neutralisation durch Zusatz von $350 \mu \mathrm{l}$ Puffer N3. Durch Zentrifugation (10 min, 13000 x g) wurden die ausgefällten Proteine und Zelltrümmer sedimentiert. Der Überstand wurde anschließend auf eine QIAprep Säule aufgetragen, die eine Silica-Gel-Membran für die selektive Adsorption von Plasmid-DNA enthält. Durch Zentrifugation (1 min, 13000 x g) erfolgte die Bindung der DNA an die Membran, der Durchfluß wurde verworfen. Nach einem Waschschritt mit $750 \mu 1$ Puffer PE und dem Trocknen durch Zentrifugation (1 min, 13000 x g) wurde die Plasmid-DNA mit 30 bzw. $50 \mu 1 \mathrm{H}_{2} \mathrm{O}_{\text {dest. }}$ eluiert.

Für die Zusammensetzung der Puffer siehe 2.7.2.3

\subsection{Enzymatische Modifikation von DNA}

\subsubsection{Spaltung von DNA durch Restriktionsendonukleasen}

Die Spaltung von DNA durch sequenzspezifische Restriktionsendonukleasen wurde in einem Volumen von mindestens $10 \mu \mathrm{l}$ pro $\mu \mathrm{g}$ DNA und $37^{\circ} \mathrm{C}$ für 2 bis $16 \mathrm{~h}$ durchgeführt. Die Spaltung erfolgte in 20 bis $400 \mu$ l-Ansätzen in dem Puffersystem, welches vom Hersteller mitgeliefert wurde. Es wurde pro $\mu \mathrm{g}$ DNA 2 bis $10 \mathrm{U}$ Restriktionsenzym 
eingesetzt. Vor der Zugabe des Restriktionsenzyms wurden $\mathrm{H}_{2} \mathrm{O}_{\text {dest. }}$, DNA und Puffer gemischt. Im Endvolumen lag das Enzym mindestens 1:10 verdünnt vor, um eine zu hohe Glycerinkonzentration im Reaktionsansatz zu vermeiden. Die partielle Spaltung von chromosomaler DNA wurde zeitlimitiert durchgeführt. Es wurde routinemäßig mit $1 \mathrm{U}$ Restriktionsenzym gearbeitet. Während des Verdaus wurden in bestimmten Zeitabständen $45 \mu 1$ aus einem Gesamtverdauansatz von $400 \mu$ l entnommmen und durch Zugabe von $5 \mu 1$ EDTA (20 mM) und Inkubation auf Eis gestoppt.

Restriktionsansätze mit mehr als einem Enzym wurden -soweit möglich- im selben Puffersystem eingesetzt. Alle Ansätze wurden durch Agarose-Gelelektrophorese (s. 2.6.1) auf Vollständigkeit des Verdaus überprüft. Sollte die verdaute DNA zur Klonierung eingesetzt werden, wurde zur Entfernung des Restriktionsenzyms eine Phenol/ChloroformExtraktion (siehe 2.5.2.1) mit anschließender Ethanolfällung durchgeführt. Beim partiellen Verdau von chromosomaler DNA schloß sich dem Verdau ein SaccharoseDichtegradientenzentrifugation (siehe 2.8.4) mit anschließender PEG-NaCl-Fällung an (siehe 2.5.2.4).

\subsubsection{Herstellung von glatten Enden ('blunt ends') und Phosphorylierung von 5'-Hydroxyl-Enden bei DNA-Fragmenten}

In einigen Fällen mußten zur Klonierung die Enden von DNA-Fragmenten geglättet werden, bevor sie zur Ligation eingesetzt werden konnten. Zudem mußte sichergestellt sein, daß die DNA-Fragmente an den 5'-Enden phosphoryliert vorlagen. Zu diesem Zweck wurde einerseits DNA-Polymerase I eingesetzt, um die überhängende einzelsträngige DNA auffüllen zu können und andererseits wurde durch Zugabe von T4-Polynukleotid-Kinase in Anwesenheit von ATP die Phosphorylierung der freien 5'-Enden gewährleistet. Beide Enzyme arbeiten in KGB-Puffer, so daß beide Reaktionen in einem Ansatz durchgeführt wurden. Dieser setzte sich folgendermaßen zusammen: 


$\begin{array}{lrr}\text { DNA } & 0,5-1 & \mu \mathrm{g} \\ \text { KGB-Puffer }(10 \mathrm{x}) & 2 & \mu \mathrm{l} \\ \text { ATP }(10 \mathrm{mM}) & 2 & \mu \mathrm{l} \\ \text { dNTP-Gemisch }(20 \mathrm{mM}) & 2 & \mu \mathrm{l} \\ \text { DNA-Polymerase I }(5 \mathrm{U} / \mu \mathrm{l}) & 1 & \mu \mathrm{l} \\ \mathrm{H}_{2} \mathrm{O}_{\text {dest. }} & \text { ad } 20 & \mu \mathrm{l}\end{array}$

Nach 15 minütiger Inkubation bei $37^{\circ} \mathrm{C}$ erfolgte die Zugabe von:

T4-Polynukleotid-Kinase $(2 \mathrm{U} / \mu \mathrm{l}) \quad 1 \quad \mu \mathrm{l}$

Der Ansatz wurde insgesamt $1 \mathrm{~h}$ bei $37^{\circ} \mathrm{C}$ inkubiert. Anschließend wurde die DNA mittels Phenol/Chloroform-Extraktion und anschließender Ethanol-Fällung gereinigt und zur Ligation eingesetzt.

\subsubsection{Dephosphorylierung von DNA-Fragmenten}

Um die Effizienz einer Ligationsreaktion zwischen Insert-DNA und Vektor-DNA zu erhöhen wurde die Vektor-DNA an den 5'-Enden dephosphoryliert. Ziel dabei ist es, eine Rezirkularisierung des Vektors zu verhindern. Die Reaktion wurde dabei direkt im Restriktionsansatz durchgeführt, da die alkalische Phosphatase (Fa. Promega, Deutschland $\mathrm{GmbH}$, Mannheim) in allen Puffersystemen einsetzbar ist (GREENE und GUARANTE, 1987). Nach vollständiger Spaltung des Verktors wurde $1 \mathrm{U}$ alkalische Phosphatase pro $\mu \mathrm{g}$ DNA zugesetzt und für $30 \mathrm{~min}$ bei $37^{\circ} \mathrm{C}$ inkubiert.

Zur Deproteinisierung wurde die DNA mit Hilfe des „QIAquick PCR Purification“-Kit (s. 2.5.2.8) gereinigt und konzentriert. 


\title{
2.8.4 Saccharose-Dichtegradientenzentrifugation (SAMBROOK et
}

\author{
al., 1989; modfiziert)
}

Die Isolierung von Fragmenten partiell verdauter, chromosomaler DNA, die zur Klonierung eingesetzt werden sollten, erfolgte mittels einer SaccharoseDichtegradientenzentrifugation. Bei dieser sehr schonenden Methode werden die verschiedenen Fragmentgrößen entsprechend ihrer Schwebedichte im Saccharosegradienten getrennt. Zunächst wurde ein Saccharose-Stufengradient (10 bis 40 \%) in 10 ml-Zentrifugenröhrchen (Sorvall Polyallomer 3699, Fa. Du Pont de Nemours Deutschland GmbH, Dreieich) hergestellt. Dazu wurden je 1,9 ml $40 \%, \quad 32,5 \%, 25 \%$, $17,5 \%$ und $10 \%$ Saccharose (jeweils w/v in $1 \mathrm{M} \mathrm{NaCl}, 20 \mathrm{mM}$ Tris, $5 \mathrm{mM}$ EDTA, pH $8,0)$ beginnend mit der höchsten Konzentration übereinandergeschichtet und nach jeder Stufe in flüssigem Stickstoff eingefroren. Auf den fertigen Gradienten wurde 100 - $200 \mu \mathrm{g}$ partiell verdauter chromosomaler DNA aufgetragen. Die Zentrifugation erfolgte in einem „swing-out“-Rotor (Sorvall TH641, Fa. Du Pont de Nemours) in einer Ultrazentrifuge (Sorvall OTD 55 B, 27000 Upm, 24 h, $20^{\circ} \mathrm{C}$ ). Zur Ernte des Gradienten wurden vorsichtig je $300 \mu \mathrm{l}$ von oben nach unten abgenommen. Anschließend erfolgte eine DNA-Fällung mit PEG/NaCl aus Saccharose (siehe 2.5.2.4). $10 \mu \mathrm{l}$ jeder dritten Fraktion wurden durch Agarosegelelektrophorese auf Größe und Qualität hin überprüft.

\subsubsection{Ligation von DN-Fragmenten}

Zur Verknüpfung von linearisierter, dephosphorylierter Vektor- und Insert-DNA wurde T4-DNA-Ligase eingesetzt, die in Anwesenheit von ATP eine Phosphodiesterbindung zwischen 3'-OH- und 5'-PO ${ }_{4}$-Enden von Nukleinsäuren katalysiert. Die Ligationen wurden in einem Volumen von $20 \mu \mathrm{l}$ in dem vom Hersteller mitgeliefertem Puffersystem durchgeführt. Die besten Ergebnisse ließen sich mit einem Überschuß des zu ligierenden Fragmentes erzielt. Es wurden jeweils 0,2 bis $1 \mu \mathrm{g}$ Vektor und 0,2-2 $\mu \mathrm{g}$ Insert-DNA 
eingesetzt. Der Ansatz enthielt weiterhin 1 U T4-DNA-Ligase. Die Ligationsansätze mit kohäsiven Enden wurden über Nacht bei $16{ }^{\circ} \mathrm{C}$ oder für $48 \mathrm{~h}$ bei $4{ }^{\circ} \mathrm{C}$ inkubiert. Zur Ligation glatter Enden wurden $2 \mathrm{U}$ Ligase eingesetzt und die Ansätze für $1 \mathrm{~h}$ bei $37^{\circ} \mathrm{C}$ oder über Nacht bei $16{ }^{\circ} \mathrm{C}$ inkubiert.

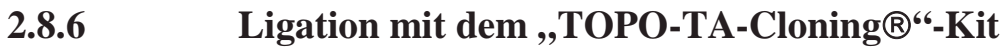

Für eine besonders effektive Klonierung von PCR-Produkten, die mit der Taq-DNAPolymerase in einer Polymerasekettenreaktion (PCR, s. 2.12) amplifiziert wurden, wurde der „TOPO-TA-Cloning®“-Kit (Fa. Invitrogen) verwendet. Für diese Art der Ligation wird keine Ligase benötigt.

Die Taq-DNA-Polymerase besitzt eine von der Matrize unabhängige terminale Transferase-Aktivität und hängt an die 3'-Enden von PCR-Produkten einzelne Desoxyadenosine (A) an. Der im Kit vorhandene, bereits linearisierte Vektor pCR2.1TOPO besitzt analog dazu an den 3'-Enden einzelne Desoyxthymidin-Rest (T). Dies erlaubt eine Ligation nach der sogenannten TA-Methode.

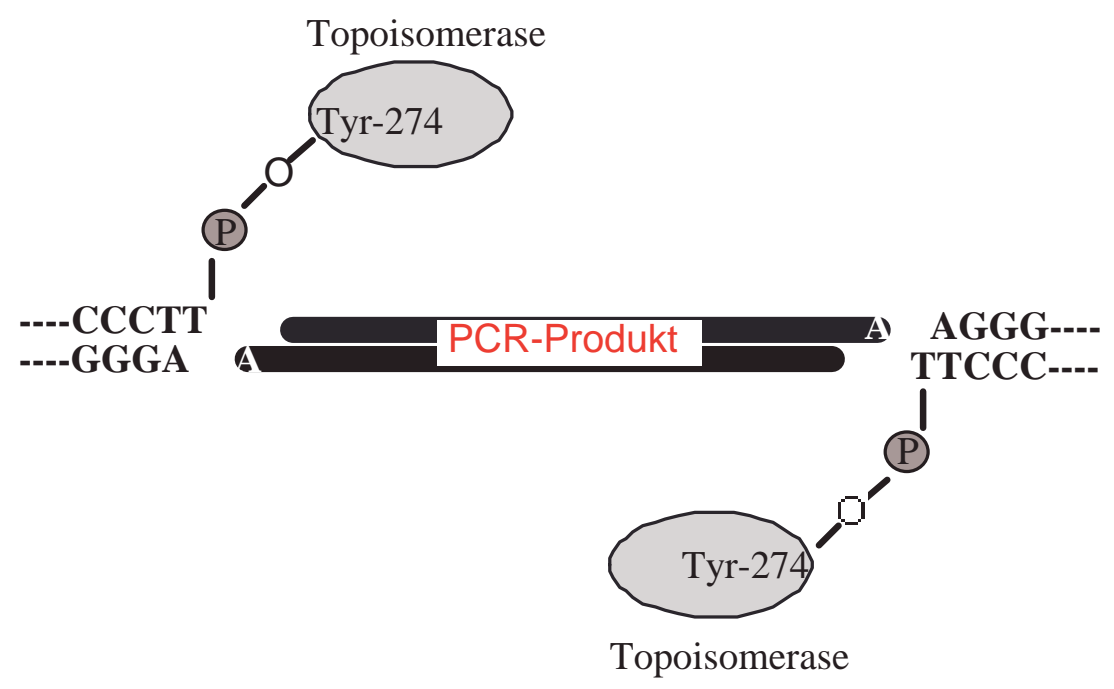

Abbildung 1: Schematische Darstellung der TOPO-TA-Klonierung.

Des Weiteren besitzt der Vektor die kovalent gebundene Topoisomerase I des VacciniaVirus. Die Topoisomerase I bindet an spezifische Sequenzen doppelsträngiger DNA und 
spaltet dort das Phosphodiester-Gerüst stromabwärts der Sequenz 5'-CCCTT in einem Strang (SHUMAN, 1991). Die Energie dieser Spaltungsreaktion wird durch Ausbildung einer kovalenten Bindung zwischen dem 3'-Phosphat des gespaltenen Stranges und dem Tyrosin-274 der Topoisomerase I konserviert. Die Reaktion zwischen DNA und Protein kann durch den Angriff des 5'-Hydroxyl-Restes umgekehrt werden, was dann zur Abspaltung der Topoisomerase I führt (SHUMAN, 1994). Dieses Prinzip wird zur effizienten Klonierung von PCR-Produkten genutzt (s. 2.13).

\subsubsection{Radioaktive Markierung von DN-Fragmenten}

DNA-Fragmente, die als Sonden für Hybridisierungen eingesetzt werden sollten, wurden mit Hilfe des "Random Primed Labeling Kit" (Fa. Gibco BRL, Eggenstein) unter Verwendung von $\left[\alpha-{ }^{32} \mathrm{P}\right]$-dATP radioaktiv markiert. Zur Denaturierung wurden 25 bis 50 ng DNA in $25 \mu \mathrm{H}_{2} \mathrm{O}_{\text {dest. }}$ in einem Eppendorf-Reaktionsgefäß mit Schraubdeckel für 10 min bei $95{ }^{\circ} \mathrm{C}$ denaturiert und danach schnell auf Eis abgekühlt. Die folgenden Bestandteile des Reaktionsansatzes wurden dann auf Eis zusammen pipettiert:

$$
\begin{array}{ll}
\text { denaturierte DNA-Lösung } & 25 \mu \mathrm{l} \\
\text { dCTP, dGTP, dTTP } & \text { je } 2 \mu \mathrm{l} \\
\text { Reaktionspuffer } & 15 \mu \mathrm{l} \\
{\left[\alpha-{ }^{32} \mathrm{P}\right]-\mathrm{dATP}(3000 \mathrm{Ci} / \mathrm{mol}, 10 \mu \mathrm{Ci} / \mathrm{ml})} & 3 \mu \mathrm{l}
\end{array}
$$

Die Reaktion wurde durch Zugabe von $1 \mu$ Klenow-Fragment (2U/ $\mu \mathrm{l})$ gestartet und für $1 \mathrm{~h}$ bei $25^{\circ} \mathrm{C}$ inkubiert. Zur Abtrennung nicht eingebauter Nukleotide wurde die DNA-Lösung über NAP-5-Säulen (s. 2.5.2.5) gelchromatographisch gereinigt. 


\subsection{Einführung von DNA in E. coli und Selektion rekombinanter Klone}

2.9.1 Erstellung hochkompetenter $E$. coli-Zellen (INOUE et al., 1990)

Zur Herstellung hochkompetenter E. coli-Zellen wurde aus einer Stammkultur auf eine LB-Agar-Platte ausgestrichen und über Nacht bei $37{ }^{\circ} \mathrm{C}$ inkubiert. Aus 10 bis 12 Einzelkolonien wurde eine $5 \mathrm{ml}$ Vorkultur in LB-Medium (siehe 2.2.1.1.) angeimpft. Diese diente als Inokulum für $250 \mathrm{ml}$ SOB-Medium (siehe 2.2.1.2). Diese Kultur wurde bei 18 ${ }^{\circ} \mathrm{C}$ unter schütteln bis zu einer $\mathrm{OD}_{600}$ von 0,6 bis 0,8 inkubiert. Nach einer Inkubation für $10 \mathrm{~min}$ auf Eis wurden die Zellen zentrifugiert $\left(10 \mathrm{~min}, 2500 \mathrm{x} \mathrm{g}, 4^{\circ} \mathrm{C}\right)$, in $80 \mathrm{ml}$ eiskalter TB-Lösung suspendiert und für 10 min auf Eis abgekühlt. Es folgte eine Zentrifugation der Zellen (10 min, $2500 \mathrm{x} \mathrm{g}, 4{ }^{\circ} \mathrm{C}$ ) und eine Resuspendierung in $20 \mathrm{ml}$ TB-Lösung mit DMSO (Endkonzentration $7 \%$, v/v). Nach einer Inkubation für 10 min auf Eis wurden Aliquots von $200 \mu \mathrm{l}$ in flüssigem $\mathrm{N}_{2}$ eingefroren und direkt zur Transformation eingesetzt oder bei $70{ }^{\circ} \mathrm{C}$ gelagert.

$\underline{\text { TB-Lösung }}$

$\begin{array}{lcc}\text { Pipes } & 10 & \mathrm{mM} \\ \mathrm{MnCl}_{2} & 55 & \mathrm{mM} \\ \mathrm{CaCl}_{2} & 15 & \mathrm{mM} \\ \mathrm{KCl} & 250 & \mathrm{mM} \\ \mathrm{pH} \mathrm{6,7} & & \end{array}$




\subsection{2} Transformation von $E$. coli

Zur Transformation wurden $200 \mu \mathrm{l}$ der kompetenten E. coli Zellen auf Eis aufgetaut und nach der Zugabe von 1 bis $10 \mu \mathrm{l}$ des zu transformierenden Ligationsansatzes (ca. $100 \mathrm{ng}$ DNA) für 30 min auf Eis inkubiert. Es folgte eine Hitzeschockbehandlung für $45 \mathrm{~s}$ bei 42 ${ }^{\circ} \mathrm{C}$, eine kurze Inkubation auf Eis sowie die Zugabe von 0,8 ml LB-Medium. Nach einer Inkubation von mindestens $45 \mathrm{~min}$ bei $37{ }^{\circ} \mathrm{C}$ wurden je 50 bis $200 \mu \mathrm{l}$ aus dem Transformationsansatz auf LB-Agarplatten mit dem entsprechenden Antibiotikum ausplattiert.

\subsubsection{Der X-Gal-Test zur Selektion rekombinanter Klone}

Bei Klonierungen ist es entscheidend, Klone, die nach Übertragung von DNA nur den Vektor enthalten, von denjenigen, die ein Plasmid mit Insert tragen, zu unterscheiden. Aus diesem Grund wurde ein zusätzliches Screeningsystem neben den plasmidkodierten Antibiotikaresistenzen benutzt. Plasmide der pBluescript-Reihe enthalten neben dem Promotor- und Operator-Bereich des lac-Operons auch das 5'-Ende des lacZ-Genes (VIEIRA und MESSING, 1982). Dieses kodiert für das sogenannte $\alpha$-Peptid, welches die inaktive $\beta$-Galaktosidase von Wirtsstämmen wie E. coli DH5 $\alpha$ komplementieren kann. Da sich die multiple Klonierungsstelle der verwendeten Vektoren innerhalb des aminoterminalen Bereichs des lacZ-Gens befindet, ist eine $\alpha$-Komplementation nur möglich, wenn das Plasmid kein Insert besitzt. Der Nachweis der aktiven $\beta$-Galaktosidase auf Agarplatten erfolgt durch Zugabe des Induktors IPTG (Isopropyl-ßthiogalaktopyranosid) und des Substrats X-Gal (5-Brom-4-chlor-indoyl- $\beta$-D-galaktosid), welches durch das Enzym gespalten wird. Dabei entsteht in Anwesenheit von Sauerstoff der blaue Farbstoff 5-Brom-4-chlor-indigo, welcher der Indikator für rekombinante $E$. coli-Stämme ist, die ein Plasmid ohne Insert tragen. 


\subsubsection{Transformation in $\boldsymbol{E}$. coli durch Elektroporation (DOWER et} al., 1988)

Diese Methode beruht auf der Permeabilisierung der Zellmembran durch Elektroschock. Dieser verursacht einen kurzfristigen reversiblen lokalen Zusammenbruch des Membranpotentials bzw. eine Desorganisation der Membranstruktur (CHASSY et al., 1988) und erleichert damit die Aufnahme von Makromolekülen wie z. B. Plasmid-DNA in die Zelle.

Zur Herstellung elektrokompetenter Zellen wurde eine 5-ml-Übernachtkultur in $250 \mathrm{ml}$ LB-Medium (siehe 2.2.1.1) überimpft und bei $30{ }^{\circ} \mathrm{C}$ unter Schütteln bis zu einer $\mathrm{OD}_{578}$ von 0,5 bis 1,0 inkubiert. Die Kultur wurde für 15 bis 30 min auf Eis gehalten und danach für 10 min bei $5000 \mathrm{x} \mathrm{g}$ und $4{ }^{\circ} \mathrm{C}$ zentrifugiert. Das Pellet wurde dann zweimal mit 1 Volumen $\mathrm{H}_{2} \mathrm{O}_{\text {dest. }}$ gewaschen und anschließend noch einmal mit $10 \mathrm{ml}$ Glycerin (10\%, $(\mathrm{v} / \mathrm{v}))$. Abschließend erfolgte die Suspendierung in 0,5 ml Glycerin $(10 \%,(\mathrm{v} / \mathrm{v}))$. Aliquots der Suspension wurden bei $-70^{\circ} \mathrm{C}$ gelagert.

Pro Ansatz wurden $40 \mu \mathrm{l}$ Zellsuspension auf Eis aufgetaut, in eine sterile vorgekühlte Elektroporationsküvette (Elektrodenabstand $0,2 \mathrm{~cm}$ ) überführt und mit 1 bis $5 \mu \mathrm{l}$ dialysierter DNA-Lösung versetzt. Die Elektroporation erfolgte in einem Gene Pulser TM (Bio-Rad Laboratories GmbH, München) bei $25 \mu \mathrm{F}, 200 \Omega$ und 2,5 kV, wodurch eine Feldstärke von $12,5 \mathrm{kV} / \mathrm{cm}$ und eine Zeitkonstante von 3,5 bis 4,5 ms erreicht wurde. Nach dem Stromimpuls wurden die Zellen sofort in $1 \mathrm{ml} \mathrm{LB}$-Medium aufgenommen, $60 \mathrm{~min}$ bei $37{ }^{\circ} \mathrm{C}$ inkubiert und anschließend auf LB-Agarplatten mit dem entsprechenden Antibiotikum ausplattiert. 


\subsubsection{Anzucht von rekombinanten $E$. coli-Stämmen zur heterologen Genexpression}

\subsubsection{Expression mit dem ,pET Directional TOPO ${ }^{\circledR}$ Expression“-Kit}

Der „pET Directional TOPO ${ }^{\circledR}$ Expression“-Kit (Fa. Invitrogen, Karlsruhe) nutzt die Klonierungsstrategie des „TOPO-Cloning“ (s. Abb. 1 und detaillierte Erklärung des Grundprinzips unter 2.8.3.2), um blunt-end-PCR-Produkte gerichtet in einen ,high-level“Expressionsvektor zu klonieren. Zudem besteht die Möglichkeit, das Zielgen N- oder Cterminal mit einem His $_{6}$-Tag zu versehen, der die Reinigung des gebildeten Proteins ermöglicht. Die physikalische Karten der verwendeten Vektoren pET100/D/lacZ und pET101/D/lacZ sind in Abbildung 1 dargestellt.

Die gerichtete TOPO-Klonierung (s. Abb. 2) wurde durch das Anhängen einer spezifischen Sequenz (5'-CACC) an das durch PCR amplifizierte Zielgen erreicht, die komplementär (3'-GTGG) als Einzelstrang-Überhang auf dem Vektor vorhanden war. Dieser Überhang inserierte in das 5'-Ende des PCR-Produkts und führte so zur korrekten Orientierung des inserierten Gens (s. Abb. 3).

Das pET-Expressionssystem machte sich die hohe Aktivität und Spezifität der T7-RNAPolymerase zu Nutze. Dies ermöglichte ausgehend vom T7-Promotor eine regulierte Expression von heterologen Genen in E. coli (ROSENBERG et al., 1987; STUDIER und MOFFATT, 1986; STUDIER et al. 1990). 

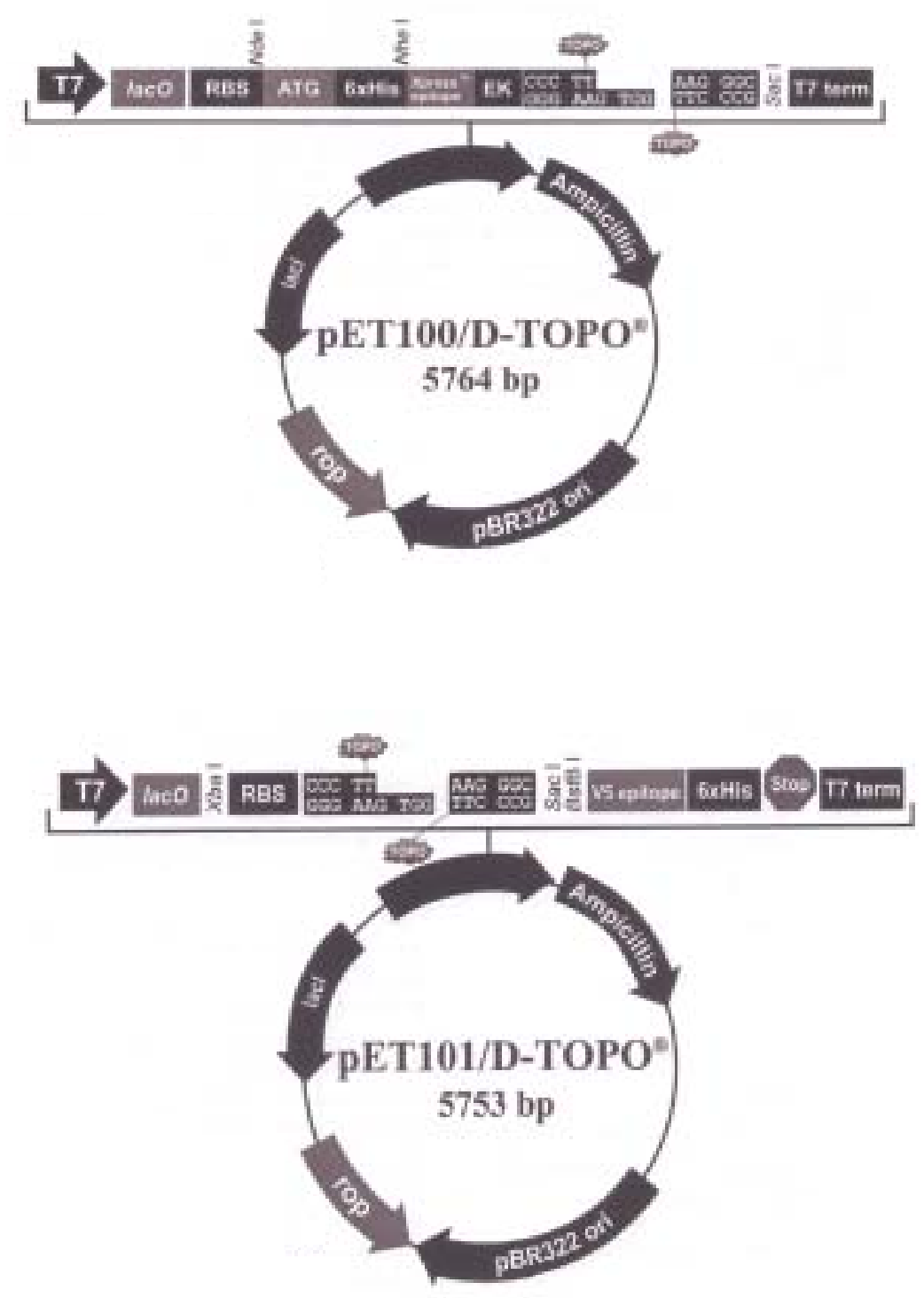
Abbildung 2: Physikalische Karten der Expressionsvektoren pET100/D/lacZ und pET101/D/lacZ.
lacO, lac-Operator; lacI, lac-Repressor; RBS, Ribosomenbindestelle; EK, Enterokinase-Erkennungsstelle; rop, erleichtert „low-copy“- Replikation in E. coli

Für die Expression wird der E. coli-Stamm BL21 Star ${ }^{\mathrm{TM}}$ (DE3) herangezogen. Dieser Stamm trägt den defekten, lysogenen Bakteriophagen DE3 des $\lambda$-Phagen, der folgende Elemente chromosomal kodiert enthält:

1.) den Lac-Repressor lacI

2.) die T7-RNA-Polymerase-Gene unter der Kontrolle des lacUV5-Promotors 
3.) einen Teil des lacZ-Gens

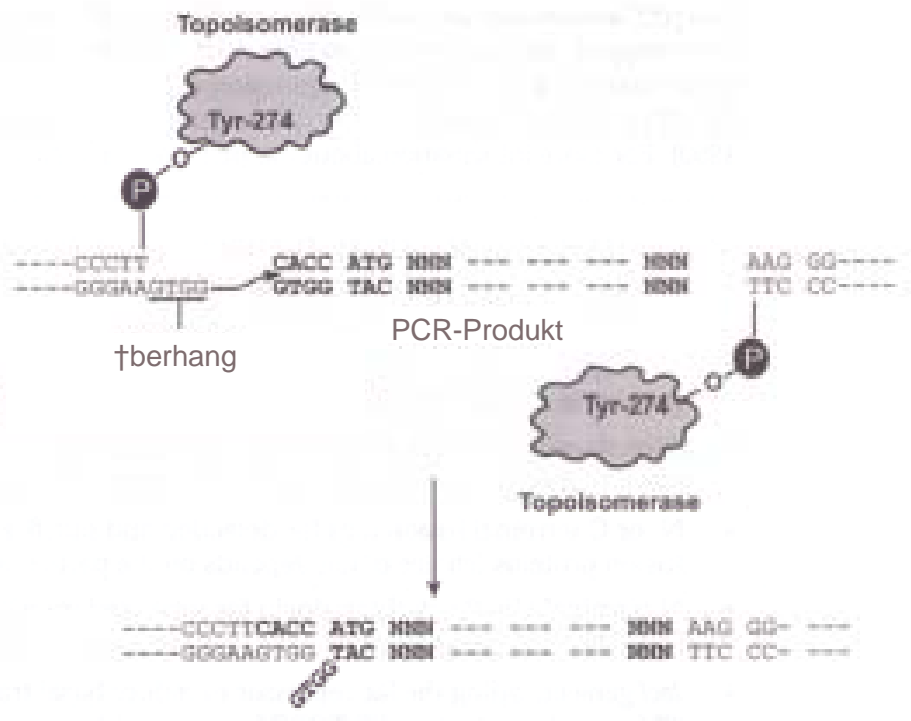

\section{Abbildung 3: Schematische Darstellung der gerichteten TOPO-Klonierung.}

Wenn dieser Vektor in einem DE3-lysogenen Stamm etabliert wurde, wirkte der gebildete lac-Repressor zum einen an dem lacUV5-Promotor im Wirtschromosom und reprimierte dort die Expression der T7-Polymerase und zum anderen am T7-Promotor des Vektors. Letzteres verhinderte die Expression der inserierten Gene. Die Expression der T7-RNAPolymerase und der inserierten Gene ließ sich somit durch die Zugabe von IPTG induzieren.

\subsection{Screening auf die Verwertung von Chitin}

\subsubsection{Screening von Anreicherungskulturen bzw. Isolaten auf die Verwertung von Chitin}

Bodenproben wurden unter aeroben als auch anaeroben Bedingungen in Mineralmedium (siehe 2.2.3.2) mit kolloidalem Chitin als einziger C-Quelle bei einer Temperatur von 30 ${ }^{\circ} \mathrm{C}$ inkubiert. Anreicherungskulturen bzw. die nach mehrerem Überimpfen von Anreicherungskulturen isolierten Organismen wurden auf Chitin- Mineralmedium enthaltenden Agarplatten bei $30{ }^{\circ} \mathrm{C}$ inkubiert. Wird Chitin verwertet, so ist dies anhand 
einer Aufklarungszone um die Kolonie eines Chitinase-Produzenten herum sichtbar (WYNTER et al., 1995). Die isolierten Chitinaseproduzenten wiesen dabei nach 2-3 Tagen eine Aufklarungszone um die Kolonien herum auf.

\subsubsection{Screening rekombinanter $E$. coli-Klone auf die Bildung von Chitinasen}

Um E.coli-Klone, die Insert-DNA aus Chitinaseproduzierenden Organismen enthielten, wurde die Methode der Koloniehybridisierung (s. 2.12.4) eingesetzt.

\subsection{Dialyse von Lösungen}

Zunächst wurden Dialyseschläuche (ca. $30 \mathrm{~cm}$ ) in einem 11 Erlenmeyer-Becherglas mit jeweils 1 Liter der folgenden Lösungen für jeweils 10 min gekocht:

1. in $2 \% \mathrm{Na}_{2} \mathrm{CO}_{3} ; 2$. in destilliertem Wasser; 3. in 1 mM EDTA (pH 5). Nach einem letzten Erhitzungs-Schritt in destilliertem Wasser wurden die Schläuche in $\mathrm{H}_{2} \mathrm{O}_{\text {dest. }}$. autoklaviert und bei $4{ }^{\circ} \mathrm{C}$ gelagert.

$\mathrm{Zu}$ dialysierende Proteinlösungen wurde in einen so vorbereiteten Dialyseschlauch pipettiert und die Schlauchenden mit Klammern verschlossen. Dialysiert wurde über einen Zeitraum von mindestens $12 \mathrm{~h}$ bei $4{ }^{\circ} \mathrm{C}$ unter langsamen Rühren gegen einen geeigneten Puffer. Dieser wurde alle $3 \mathrm{~h}$ gewechselt.

\subsection{DNA-DNA-Hybridisierung}

\subsubsection{Vorbereitung von Nylonmembranen für Koloniehybridisierungen}

Zur Analyse einer großen Anzahl rekombinanter Klone in Hybridisierungsexperimenten dienten runde Nylonmembranen mit 8,2 cm Durchmesser $\left(\right.$ Hybond $^{\mathrm{TM}}-\mathrm{N}$, Fa. Amersham Pharmacia). 
Bis zu 400 Klone wurden auf eine „Masterplatte” mit entsprechendem Antibiotikum plattiert. Nach ca. 20 bis $30 \mathrm{~h}$ Inkubation bei $37{ }^{\circ} \mathrm{C}$ wurde die Membran aufgelegt, leicht angedrückt und wieder abgezogen, um so das Zellmaterial zu übertragen.

Anschließend wurde die Nylonmembran mit dem Impfmaterial nach oben für 2 min auf Filterpapier (Whatman 3MM) gelegt, das mit 2-fachem SSC-Puffer und $5 \%$ SDS (w/v) getränkt war und anschließend für 2,5 min bei $600 \mathrm{~W}$ im Mikrowellenherd erhitzt. Die auf diese Weise für die Hybridisierung vorbereitete Membran wurden anschließend mit 5fachem SSC-Puffer und 0,1 \% SDS (w/v) $1 \mathrm{~h}$ gewaschen und getrocknet und konnten so bis zu 2 Wochen bei RT aufbewahrt werden.

\subsection{2 “Southern”-Blot (SOUTHERN, 1975)}

In Agarosegelen aufgetrennte DNA wurde durch Kapillarblotting auf Nylonmembranen (Hybond-XL, Fa. Amersham Pharmacia) übertragen. Dabei wurde Transferpuffer durch das Gel gesaugt, um die DNA auf der darüberliegenden Membran zu fixieren.

Die zu analysierende DNA wurde im Standard-Agarosegel (Volumen $100 \mathrm{ml}$ ) aufgetrennt, im Ethidiumbromidbad gefärbt, gewässert und zusammen mit einem Lineal fotografiert. Anschließend wurde das Gel für 10 min in $0,25 \mathrm{M} \mathrm{HCl}$ inkubiert, was zu Strangbrüchen in der DNA führt, die den Transfer auf die Membran erleichtern. Dann wurde es für $30 \mathrm{~min}$ in Denaturierungslösung $(0,4 \mathrm{M} \mathrm{NaOH}, \quad 0,6 \mathrm{M} \mathrm{NaCl})$ und nochmals $30 \mathrm{~min}$ in Neutralisierungslösung (1,5 M NaCl, 0,5 M Tris, pH7,5) geschwenkt. Eine Nylonmembran wurde in Gelgröße zugeschnitten, mit $\mathrm{H}_{2} \mathrm{O}_{\text {dest. }}$ angefeuchtet und für mindestens $10 \mathrm{~min}$ in 10x SSC-Puffer (s. 2.5.1) äquilibriert. Die Blottingkammer eigener Bauart wurde mit 10xSSC-Puffer gefüllt. In der Mitte der Kammer wurden wie folgt übereinander gelegt:

-3 Lagen Filterpapier (Whatman 3MM), welches in Kontakt mit dem Transferpuffer stand

- das Agarosegel mit der Unterseite nach oben

- die äquilibrierte Nylonmembran

- bis 6 Lagen Filterpapier (Whatman 3MM)

- ein ca. $10 \mathrm{~cm}$ hoher Stapel Papierhandtücher

- ein Gewicht (ca. 200 bis $500 \mathrm{~g}$ )

Der Transfer der DNA auf die Nylonmembran benötigt etwa 16 bis $24 \mathrm{~h}$. Um eine vollständige Denaturierung der immobilisierten DNA für die Hybridisierung zu gewährleisten, wurde die Membran für $60 \mathrm{~s}$ in $0,4 \mathrm{M} \mathrm{NaOH}$ geschwenkt. Nach der 
Neutralisierung in 2x SSC und 0,2 M Tris (pH 7,5) für 2 min wurde die Nylonmembran bei RT getrocknet. Die auf diese Weise immobilisierte DNA konnte für Hybridisierungen eingesetzt werden.

\subsubsection{Dot-Blot}

Für die Herstellung von Dot-Blots wurden die DNA-Proben direkt auf eine Nylonmembran pipettiert und an der Luft getrocknet. Anschließend wurde die Membran für wenige Minuten auf einem mit 2x SSC, 5\% SDS (w/v) getränkten Filterpapier inkubiert. Das Fixieren der DNA erfolgte in der Mikrowelle bei $600 \mathrm{~W}$ für 2,5 min. Nach Waschen der Membran in 5x SSC, 0,1\% SDS (w/v) für 5 min konnte sie für Hybridisierungen eingesetzt werden.

\subsubsection{Hybridisierung mit radioaktiv-markierten Sonden}

Auf Nylonmembranen fixierte DNA wurde mit radioaktiv-markierten DNA-Fragmenten (s. 2.8.7) hybridisiert. Vor der Hybridisierung war eine Prähybridisierung notwendig, um unspezifische Bindungsstellen für die DNA-Sonde auf den Nylonmembranen abzusättigen. Hierzu wurden die Membranen in speziellen Hybridisierungsröhrchen (Fa. Ochs, Göttingen) mit $10 \mathrm{ml}$ Prähybridisierungsmix versetzt und 1 bis $4 \mathrm{~h}$ in einem Hybridisierungsofen (OV 10, Fa. Biometra, Göttingen) bei $60{ }^{\circ} \mathrm{C}$ prähybridisiert.

Für die Hybridisierung wurde die radioaktiv-markierte Sonde, die zuvor für 10 min bei 95 ${ }^{\circ} \mathrm{C}$ denaturiert und anschließend $5 \mathrm{~min}$ auf Eis gehalten wurde, zugegeben. Die Membranen wurden dann für 12 bis $16 \mathrm{~h}$ bei $60{ }^{\circ} \mathrm{C}$ (homologe Sonde) bzw. bei $45^{\circ} \mathrm{C}$ (heterologe Sonde) inkubiert.

Nach erfolgter Hybridisierung schlossen sich je nach Bedingungen unterschiedlich stringente Waschschritte an. Bei Einsatz von homologen Sonden wurde wegen der zu erwartenden starken Signale grundsätzlich zweimal für je 5 min in 2-fachem SSC-Puffer (s. 2.5.1), anschließend zweimal für je $30 \mathrm{~min}$ in 2-fachem SSC-Puffer mit $1 \%$ (w/v) SDS bei $60{ }^{\circ} \mathrm{C}$ gewaschen. 
Nach Abschluß der Waschprozeduren wurden die Membranen in Haushaltsfolie eingeschweißt. Die Autoradiographie erfolgte mit Hilfe von Autoradiographiekassetten (Storage Phosphor Screen GP, Fa. Kodak, Stuttgart) und eines Phosphoimagers (Storm 860, Fa. Molecular Dynamics GmbH, Krefeld). Zur Quantifizierung wurde das Programm Image Quant für Macintosh Version 1.2 (Fa. Molecular Dynamics GmbH, Krefeld) verwendet.

Prähybridisierungsmix

$\begin{array}{lll}\text { Dextransulfat }(50 \%, \mathrm{w} / \mathrm{v}) & 2 & \mathrm{ml} \\ 0,5 \mathrm{M} \text { Tris } & 1 & \mathrm{ml} \\ 5 \mathrm{M} \mathrm{NaCl} & 2 & \mathrm{ml} \\ \text { SDS-Lösung }(10 \%, \mathrm{w} / \mathrm{v}) & 2 & \mathrm{ml} \\ \mathrm{H}_{2} \mathrm{O}_{\text {dest. }} & \mathrm{ad} 10 & \mathrm{ml}\end{array}$

$\mathrm{pH} 7,5$

\subsection{Polymerase-Kettenreaktion (PCR)}

Die Polymerase-Kettenreaktion (PCR) wurde zur Herstellung spezifischer DNAFragmente für Klonierungen verwendet. Als Enzyme wurden die Taq-DNA-Polymerase (Fa. MBI Fermentas), die Pfu-DNA-Polymerase (Fa. MBI Fermentas) und die Herculase Enhanced DNA Polymerase (Fa. Stratagene) eingesetzt. Die Reaktionen wurden entsprechend den Herstellerempfehlungen in einem Volumen von 50 bzw. $100 \mu \mathrm{l}$ durchgeführt und enthielten folgende Bestandteile:

$\begin{array}{lll}\text { DNA } & 0,5-1 & \mu \mathrm{g} \\ \text { Oligonukleotide } & \text { je } 100 & \mathrm{pmol} \\ \text { dNTP-Gemisch } & 200 & \mu \mathrm{M} \\ \text { DNA Polymerase } & 1 & \mathrm{U} \\ \text { Reaktionspuffer }(10 \mathrm{x}) & 10 & \mu \mathrm{l} \\ \mathrm{MgCl}_{2} \text { oder } \mathrm{MgSO}_{4} & 1,5 & \mathrm{mM} \\ \mathrm{H}_{2} \mathrm{O}_{\text {dest. }} & \text { ad } 100 & \mu \mathrm{l}\end{array}$


Die Temperaturzyklen wurden den jeweiligen Anforderungen in Bezug auf die Hybridisierungstemperatur (x) und die Dauer der Kettenverlängerung (y) angepaßt. Sie wurden nach folgendem Schema durchgeführt:

$\begin{array}{lll}\begin{array}{ll}\text { Denaturierung } \\ \text { 30 Zyklen }\end{array} & 95^{\circ} \mathrm{C} & 2 \mathrm{~min} \\ \text { Denaturierung } & 95^{\circ} \mathrm{C} & 1 \mathrm{~min} \\ \text { Hybridisierung } & \mathrm{x}^{\circ} \mathrm{C} & 1 \mathrm{~min} \\ \text { Kettenverlängerung } & 72 \text { oder } 75^{\circ} \mathrm{C} & \mathrm{y} \text { min } \\ \text { Ende der Zyklen } & & \\ \text { Kettenverlängerung } & 72 \mathrm{o.} 75^{\circ} \mathrm{C} & 10 \mathrm{~min}\end{array}$

Für die Einstellung der Parameter waren die zu erwartende Fragmentlänge und die Schmelztemperatur $\mathrm{T}_{\mathrm{m}}$ der verwendeten Oligonukleotide entscheidend. Für die Hybridisierung wurde entsprechend der zu erwartenden Fragmentlänge eine Zeit von ca. 1 min/1000 Bp gewählt. Die optimale Hybridisierungstemperatur wurde nach der Schmelztemperatur $\mathrm{T}_{\mathrm{m}}$ der Oligonukleotide festgelegt, die über folgende Formel errechnet wurde:

$\mathrm{T}_{\mathrm{m}}=69,3+0,41(\%$ GC-Gehalt $)-650 / \mathrm{L}$

$\mathrm{L}=$ Länge des Oligonukleotids

$\%$ GC-Gehalt $=$ prozentualer GC-Gehalt des Oligonukleotids

Durch Verkürzung der Hybridisierungsdauer, Verringerung der Oligonukleotidkonzentration und Variation der $\mathrm{MgCl}_{2}$-Konzentration konnte die Spezifität der PCR optimiert werden.

Die Temperaturzyklen wurden mit einem Primus-Cycler (Fa. MWG AG-Biotech, München) oder dem „Mastercycler Gradient“ (Fa. Eppendorf, Hamburg) durchgeführt. Die PCR-Produkte wurden durch Agarose-Gelelektrophorese (s.2.7.1) analysiert. 


\subsection{Sequenzierung und Analyse von Sequenzdaten}

Die Isolierung der zu sequenzierenden Plasmide erfolgte unter Verwendung des „,Wizard ${ }^{\mathrm{TM}}$ Plus Miniprep DNA Purification Systems“ (s. 2.7.2.2) bzw. des „QIAprep Spin Miniprep Kits“ (s. 2.7.2.4). Die Sequenzierungen wurde durch das „Göttingen Genomics Laboratory“ (Institut für Mikrobiologie und Genetik, Universität Göttingen) am ABI PRISM 337 DNA-Sequencer durchgeführt.

Die Auswertung der Sequenzdaten erfolgte mit den Programmen ABI Edit View 1.0.1, DNA-Strider 1.2 (MARCK, 1988) und DNAid 1.8.

\subsection{Herstellung von Rohextrakten}

\subsubsection{Zellaufschluss durch Ultraschallbehandlung}

Zum Zellaufschluss durch Ultraschall wurden die Zellen aus 500 bzw 1000 ml Kulturen bei $6000 \mathrm{Upm}, 10 \mathrm{~min}, 4{ }^{\circ} \mathrm{C}$ geerntet (GS3-Rotor, Sorvall RC-5B-Zentrifuge, Fa. Du Pont de Nemours $\mathrm{GmbH}$ ) und in einem geeigneten Puffer aufgenommen. Das Gefäß mit der Zellsuspension wurde in die Halterung des Ultraschallgerätes (Ultraschallprozessor UP200S, Fa. Dr. Hielscher GmbH, Stahndorf) eingespannt. Um eine zu hohe Erwärmung der Zellsuspension zu vermeiden, wurde das Gefäß während des Zellaufschlusses durch ein Eisbad gekühlt. Viermal wurde mit einer Amplitude von 70 Micron beschallt. Zwischen den Beschallungsschritten wurde jeweils für eine halbe Minute pausiert. Nach der Ultraschallbehandlung wurde der Extrakt für $30 \mathrm{~min}$ bei $15000 \mathrm{Upm}$ und bei $4{ }^{\circ} \mathrm{C}$ in einem SS34-Rotor (Sorvall RC-5B-Zentrifuge, Fa. Du Pont de Nemours GmbH) zentrifugiert, um intakte Zellen abzutrennen. Die erhaltenen Extrakte konnten bis zur weiteren Verwendung bei $-20{ }^{\circ} \mathrm{C}$ gelagert werden. 


\subsection{Bestimmung von Chitinaseaktivitäten}

\subsection{1}

\section{Test zur Aktivitätsbestimmung der Chitinasen mit kolloidalem Chitin} (IMOTO et al. 1971)

Zur Messung der Chitinase-Aktivität wurde ein weiterer photometrischer Enzymtest eingesetzt. Dem Test liegt folgendes Prinzip zugrunde: Durch die hydrolytische Spaltung des Chitins durch die Chitinase werden reduzierende N-Acetyl-Glucosamin-Einheiten freigesetzt, die mit Ka-Ferricyanid nachgewiesen werden können. Beim Erwärmen des gelblichen Ka-Ferricyanid mit reduzierenden Zuckern wird die Aldehydgruppe des Monosaccharids zur Carboxylgruppe oxidiert, welche mit Ka-Ferricyanid zu einem farblosen Komplex reagiert.

Zur Aktivitätsbestimmung werden $1 \mathrm{ml}$ Substratlösung (0,3\% kolloidales Chitin in $\quad 0,02$ $\mathrm{M} \mathrm{KaH}{ }_{2} \mathrm{PO}_{4}$-Puffer, $\mathrm{pH} 6.0$ ) mit 0,5 ml Enzymlösung gemischt und bei $45{ }^{\circ} \mathrm{C}$ für $60 \mathrm{~min}$ inkubiert und auf Eis abgekühlt. Anschließend werden $2 \mathrm{ml} \mathrm{Ka-Ferricyanid-Reagenz}$ hinzugegeben, 15 min gekocht, auf Eis abgekühlt und die Extinktion bei $420 \mathrm{~nm}$ gemessen. Zur Kalibrierung diente ein N-Acetyl-Glucosamin-Standard zwischen 10 und $150 \mu \mathrm{g} / \mathrm{ml}$. 1 U Chitinase-Aktivität ist definiert als die Menge an Enzym, welche $1 \mu \mathrm{mol}$ reduzierenden Zuckers pro Minute bei $45^{\circ} \mathrm{C}$ freisetzt.

$\underline{\text { Ka-Ferricyanid-Reagenz }}$

Ka-Ferricyanid $\quad 0,5 \mathrm{~g}$

$\mathrm{NaHCO}_{3} \quad 0,5 \mathrm{M}$

$\mathrm{H}_{2} \mathrm{O}_{\text {dest. }} \quad$ ad $1000 \mathrm{ml}$

Die Lösung wurde lichtgeschützt gelagert.

2.16.2 Test der fungiziden Wirkung von Enzymen oder Bakteriensuspensionen (WATANABE et al. 1999)

Zum Testen der fungiziden Wirkung von Bakteriensuspensionen bzw. von Proteinen wurden Agarplatten mit Aspergillus-Medium (s. 2.2.4) in der Mitte der Platte mit einem Pilz beimpft. An den Rand der Platte wurden sterilisierte Filterplättchen gelegt und mit der 
zu testenden Suspension beträufelt. Wurde das Wachstum des Pilzes im Bereich des Filterplättchens gehemmt, so ließ sich auf diese Weise eine fungizide Eigenschaft der Testlösung nachweisen.

\subsubsection{Proteinbestimmung}

Die Bestimmung der Proteinkonzentration einer Enzymlösung (siehe 2.17.1 und 2.17.1.2) erfolgte in modifizierter Form nach der Methode von BRADFORD (1976).

Hierzu wurden $20 \mu \mathrm{l}$ des dialysierten Enzymes zu $1 \mathrm{ml}$ Bradford-Reagenz gegeben. Nach einer Inkubation für 10 min bei RT wurde die Absorbtion bei einer Wellenlänge von 580 $\mathrm{nm}$ gegen einen Leerwert gemessen. Zur Konzentrationsbestimmung wurde eine Eichgerade mit Rinderserumalbumin in einem Breich von 0 bis $10 \mu \mathrm{g} / \mathrm{ml}$ aufgenommen.

Bradford-Reagenz

$\begin{array}{lr}\text { Serva Blau G-250 } & 70 \mathrm{mg} \\ \text { Ethanol }(96 \%,(\mathrm{v} / \mathrm{v})) & 50 \mathrm{ml} \\ \mathrm{H}_{3} \mathrm{PO}_{4}(85 \%,(\mathrm{v} / \mathrm{v})) & 100 \mathrm{ml} \\ \mathrm{H}_{2} \mathrm{O}_{\text {dest. }} & \text { ad } 1000 \mathrm{ml}\end{array}$

Nach vollständigem Lösen des Farbstoffs in Ethanol und Zugabe der übrigen Bestandteile erfolgte eine Filtration durch einer Faltenfilter. Das Reagenz wurde lichtgeschützt gelagert und war ca. 1 Jahr haltbar.

\subsection{Methoden zur Proteinanreicherung}

\subsubsection{Fällung von Chitinasen aus dem Kultur-Überstand (GAL et al. 1998)}

Um die Chitinase aus dem Kulturüberstand der isolierten Chitinaseproduzenten zu fällen, wurden $500 \mathrm{ml}$ Mineralmedium mit Chitin als C-Quelle (siehe 2.2.3.1) mit dem jeweiligen 
Organismus beimpft und die Kultur bis zum vollständigen Abbau des Chitins bei $30{ }^{\circ} \mathrm{C}$ inkubiert.

Die Zellen wurden bei 16000 x g für 15 min zentrifugiert. Der Überstand wurde durch die Zugabe von Ammoniumsulfat gesättigt (561 g auf 1000 ml Überstand) und das Protein durch Zentrifugation bei 16000 x g für 30 min pelletiert. Das Pellet wurde in einer möglichst kleinen Menge an $\mathrm{KaH}_{2} \mathrm{PO}_{4}(0,02 \mathrm{M}, \mathrm{pH}$ 6,0) suspendiert und für etwa $12 \mathrm{~h}$ gegen den gleichen Puffer dialysiert. Die Enzymlösung wurde bei 13000 x g zentrifugiert und der Überstand für die Bestimmung der Chitinase-Aktivität eingesetzt.

\subsubsection{Metall-Chelat-Affinitätschromatographie}

Das Prinzip der Metall-Chelat-Affinitätschromatographie beruht auf der Fähigkeit bestimmter Aminosäuren z. B. Histidin als Elektronendonator, an Proteinoberflächen zu fungieren und so an Metallionen wie $\mathrm{Ni}^{2+}$ und $\mathrm{Cu}^{2+}$ zu binden (HOCHULI et al., 1988; YIP et al., 1989). Die Metallionen wiederum sind über Chelatgruppen an ein Trägermaterial (Agarose oder Sepharose) gebunden.

Die Metall-Chelat-Chromatographie besitzt im neutralen $\mathrm{pH}-$ Bereich ihre größte Spezifität und Effizienz. Die Elution der Proteine findet unter Verwendung eines Imidazolgradienten statt. Imidazol führt zu einer kompetetiven Verdrängung des Histidins. Alternativ kann eine Elution durch einen $\mathrm{pH}-$ Gradienten erfolgen.

\subsubsection{Vorbereitung der Säule}

Für die Metall-Chelat-Chromatographie wurde $\mathrm{Ni}^{2+}$-Nitrilotriessigsäure-Agarose (NTAAgarose; Fa. Qiagen GmbH) verwendet. Nach dem Einsetzen der unteren Fritte wurden 4 $6 \mathrm{ml} \mathrm{Ni}{ }^{2+}$-NTA-Agarose in eine PD 10-Säule (Fa. Amersham Pharmacia, Freiburg) eingefüllt. Nach der Sedimentation des Trägermaterials wurde die Säule mit dem Zellaufschlußpuffer gespült und bei $4{ }^{\circ} \mathrm{C}$ aufbewahrt.

\subsubsection{Reinigung löslicher Proteine unter nativen Bedingungen}

Zur Reinigung löslicher Proteine unter nativen Bedingungen wurde der Rohextrakt mit der $\mathrm{Ni}^{2+}$-NTA-Agarose, die mit Zellaufschlußpuffer äquilibriert worden war, unter Rühren bei 
$4{ }^{\circ} \mathrm{C}$ für $1 \mathrm{~h}$ inkubiert. Nach dieser Inkubation wurde die Lösung in den Säulenkörper einer PD-10 Säule gefüllt. Nach dem Absetzen der Agarose wurde diese zunächst mit einem geeigneten Volumen Zellaufschlußpuffer gewaschen. Es folgte ein weiterer Waschschritt mit Puffer I. Die Elution der Proteine erfolgte in mehreren Schritten mit Puffer II.

Vor einer erneuten Verwendung der Säule wurde das Chromatographiematerial mit Puffer II gespült und dann mit dem Zellaufschlußpuffer äquilibriert.

Zellaufschlußpuffer

$\mathrm{KH}_{2} \mathrm{PO}_{4}$

$\mathrm{NaCl}$

Imidazol

$\mathrm{pH} 8,0$

$\underline{\text { Puffer II }}$

$\mathrm{KH}_{2} \mathrm{PO}_{4}$

$\mathrm{NaCl}$

Imidazol

$\mathrm{pH} 8,0$

\section{$\underline{\text { Puffer I }}$}

$\begin{array}{rllrl}50 & \mathrm{mM} & \mathrm{KH}_{2} \mathrm{PO}_{4} & 50 & \mathrm{mM} \\ 300 & \mathrm{mM} & \mathrm{NaCl} & 300 & \mathrm{mM} \\ 10 & \mathrm{mM} & \text { Imidazol } & 20 & \mathrm{mM} \\ & & \mathrm{pH} \mathrm{8,0} & & \end{array}$

$50 \mathrm{mM}$

$300 \mathrm{mM}$

$250 \mathrm{mM}$

\subsubsection{Regeneration der Säule}

Die Notwendigkeit einer Regeneration der $\mathrm{Ni}^{2+}$-NTA-Agarose wurde durch eine Farbänderung von grün-blau nach bräunlich-grau angezeigt. Durch das chelatierende Agens EDTA erfolgte die Elution des Nickels von der Säule. Nach einer anschließenden Wiederbeladung mit $\mathrm{Ni}^{2+}$-Ionen stand das Säulenmaterial erneut für mehrere Reinigungszyklen zur Verfügung. Die Regeneration des Säulenmaterials erfolgte anhand des Herstellerprotokolls. 


\subsection{Polyacrylamid-Gelelektrophorese (PAGE)}

Polyacrylamid-Gelelektrophoresen unter denaturierenden und nicht denaturierenden Bedingungen wurden in Minigel-Elektrophorese-Kammern (Fa. Bio-Rad, München) mit $8,5 \times 8,0 \times 0,1 \mathrm{~cm}$ Glasplatten durchgeführt.

\subsubsection{SDS-PAGE nach SCHÄGGER und VON JAGOW (1987)}

Trenn- und Sammelgel hatten folgende Zusammensetzung (Menge für 2 Gele):

\begin{tabular}{|c|c|c|c|}
\hline & & $\underline{12,}$ & \%ig \\
\hline Trenngel: & Gelpuffer & 3 & $\mathrm{ml}$ \\
\hline & Acrylamidlösung & 2,25 & $\mathrm{ml}$ \\
\hline & $\mathrm{H}_{2} \mathrm{O}_{\text {dest. }}$ & 3,75 & $\mathrm{ml}$ \\
\hline & APS-Lösung & 45 & $\mu 1$ \\
\hline & TEMED & 4,5 & $\mu 1$ \\
\hline \multirow[t]{5}{*}{ Sammelgel: } & Gelpuffer & 1,13 & $\mathrm{ml}$ \\
\hline & Acrylamidlösung & 375 & $\mu 1$ \\
\hline & $\mathrm{H}_{2} \mathrm{O}_{\text {dest. }}$ & 3 & $\mathrm{ml}$ \\
\hline & APS-Lösung & 45 & $\mu 1$ \\
\hline & TEMED & 4,5 & $\mu 1$ \\
\hline
\end{tabular}

Zunächst wurden Acrylamidlösung, Gelpuffer und $\mathrm{H}_{2} \mathrm{O}_{\text {dest. }}$ gemischt. Nach der Zugabe von TEMED und APS-Lösung wurde das Gel gegossen und mit $\mathrm{H}_{2} \mathrm{O}_{\text {dest. }}$ überschichtet, um eine ebene Fläche zu erhalten. Nach Polymerisation des Trenngels (ca. 30 min) konnte das $\mathrm{H}_{2} \mathrm{O}_{\text {dest. }}$ abgenommen und das Sammelgel gegossen werden, in das zur Formung von Geltaschen ein Kamm luftblasenfrei eingesetzt wurde. Nach 30 min war das Gel vollständig polymerisiert und konnte verwendet werden.

Die Proben wurden vor dem Auftragen im Verhältnis 1:3 mit Denaturierungspuffer gemischt. Anschließend wurden die Proben auf das mit Elektrophoresepuffer überschichtete Gel mit Hilfe einer Hamiltonspritze aufgetragen. Die Elektrophorese 
erfolgte zunächst bei einer Spannung von 100 V, bis die blaue Markerbande das Trenngel erreicht hatte, und wurde dann auf $130 \mathrm{~V}$ erhöht. Als Netzgerät diente ein Gene-PowerSupply GPS 200/400 (Fa. Amersham Pharmacia). Die Elektrophorese wurde beendet wenn die Markerbande das Gelende erreicht hatte.

Acrylamidlösung

Acrylamid

Bisacrylamid

$\mathrm{H}_{2} \mathrm{O}_{\text {dest. }}$

Kathodenpuffer

Tris

Tricin

SDS

$\mathrm{H}_{2} \mathrm{O}_{\text {dest. }}$

pH 8,5

Denaturierungspuffer

Tris

SDS

Serva-Blau G250

Glycerin

2-Mercaptoethanol

$\mathrm{H}_{2} \mathrm{O}_{\text {dest. }}$.

pH 6,8

\section{Gelpuffer}

Tris

SDS

$\mathrm{H}_{2} \mathrm{O}_{\text {dest. }}$

pH 8,4

$\underline{\text { Anodenpuffer }}$

$12,1 \quad \mathrm{~g}$

$17,9 \quad \mathrm{~g}$

$1 \mathrm{~g}$

ad $1000 \mathrm{ml}$

Tris

24,2 $\mathrm{g}$

$\mathrm{H}_{2} \mathrm{O}_{\text {dest. }}$.

ad $1000 \mathrm{ml}$

pH 8,9

APS-Lösung

$\begin{array}{rrlrr}0,2 & \mathrm{~g} & \text { Ammoniumpersulfat } & 0,1 & \mathrm{~g} \\ 1,2 & \mathrm{~g} & \mathrm{H}_{2} \mathrm{O}_{\text {dest. }} & \text { ad } 1 & \mathrm{ml} \\ 3 & \mathrm{mg} & & \\ 3 & \mathrm{ml} & & \\ 0,5 & \mathrm{ml} & & \\ \text { ad } 10 & \mathrm{ml} & & \end{array}$

$181,7 \quad \mathrm{~g}$

$1,5 \quad \mathrm{~g}$

ad $500 \mathrm{ml}$ 


\subsubsection{Native Polyacrylamid-Gelelektrophorese (PAGE) (ANDERSSON et al., 1972, modifiziert)}

Zur Charakterisierung und Molekularmassenbestimmung von Proteinen wurde eine Polyacrylamidgelelektrophorese unter nicht denaturierenden Bedingungen durchgeführt. Es wurden Gelelektrophoresekammern für Gele der Größe 6,0 x 8,5 x 0,1 cm verwendet (Fa. Biometra, Göttingen). Für ein Gradientengel von 4 bis $20 \%$ wurde eine ,leichte“ und eine „schwere“ Acrylamidlösung verwendet. Für das Trenngel von 4 bis $20 \%$ (w/v) wurden jeweils $3 \mathrm{ml}$,leichte“- bzw. „schwere“- Lösung in die Kammern eines kleinen Gradientenmischers gefüllt und unter Rühren je $3 \mu$ TEMED und $15 \mu 1$ APS-Lösung in die einzelnen Kammern gegeben. Nach dem Öffnen des Gradientenmischers konnte die Acrylamidlösung mit Hilfe einer Peristaltikpumpe (Meredos GS, Fa. Meredos, NörtenHardenberg) zwischen die abgedichteten Glasplatten gegossen werden. Anschließend erfolgte die Überschichtung des Trenngels mit $1 \mathrm{ml}$ wassergesättigtem 1-Butanol. Nach Polymerisierung des Gels über einen Zeitraum von $30 \mathrm{~min}$ wurde das 1-Butanol abgegossen. Nun wurde das Sammelgel gegossen, für welches $3 \mathrm{ml}$ „leichte“-Lösung, $3 \mu \mathrm{l}$ TEMED und $15 \mu \mathrm{l}$ APS-Lösung verwendet wurden. In Anschluß wurde ein Kamm luftblasenfrei eingesetzt. Nach einer Polymerisierung von 45 min, konnte das Gel in die Elektrophoresekammer eingesetzt und die Pufferreservoirs mit Elektrodenpuffer gefüllt werden. Nach Entfernung des Kammes, wurde zunächst eine Vorelektrophorese (100 V, 20 min) durchgeführt. Danach konnten die mit 0,1 Volumen Beschwererlösung versetzten Proben aufgetragen werden. Die Elektrophorese erfolgte bei $4{ }^{\circ} \mathrm{C}$ und $100 \mathrm{~V}$ für 20 bis 24 h. Die molekularen Massen nativer Proteine können nach Durchführung der linearen Gradienten-Page mit Hilfe von Referenzproteinen ermittelt werden.

\section{„Leichte“-Lösung}

Acrylamid

Bisacrylamid

Gelpuffer

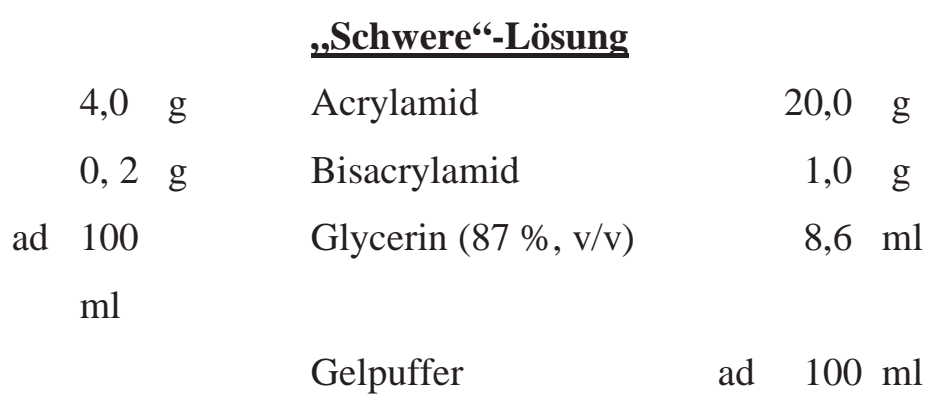

Die Lösungen wurden lichtgeschützt bei $4{ }^{\circ} \mathrm{C}$ gelagert 
Gelpuffer

Tris

$\mathrm{pH}$
$250 \mathrm{mM}$

8,5

\section{Elektrodenpuffer}

Tris

$0,1 \mathrm{M}$

Glycin

$0,1 \mathrm{M}$

$\mathrm{pH}$

\subsubsection{Nachweis von Chitinase-Aktivität im nativen Gel}

Um die Größe von Chitinasen (in kDa) bestimmen zu können, wurden die Proteine des zellfreien Kulturüberstandes der Chitin-verwertenden Isolate gefällt und wie unter 2.21.2 beschrieben elektrophoretisch aufgetrennt. Nach Abschluss der Elektrophorese wurde das

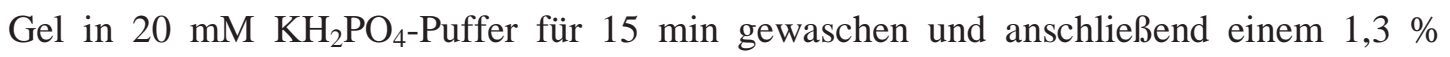
Agarosegel aufgelegt, welches zu 0,3\% mit kolloidalem Chitin versetzt war. Nach Verpackung in Folie als Verdunstungsschutz, wurde 2 Tage bei $45{ }^{\circ} \mathrm{C}$ inkubiert. Anschließend wurde das Chitin-Agarosegel in eine Lösung mit Kongo-Rot (1 g/l) gelegt und für 15 bei leichtem Schütteln inkubiert. Danach wurde das Gel mit einer Lösung aus $1 \mathrm{M} \mathrm{NaCl}$ gewaschen. Bei einem erfolgreichen Aktivitätstest sollten durch Aufklarungszonen auf dem Chitin-Agarose-Gel die Masse der Chitinasen anhand eines Vergleiches zu einem Größen-Standard in kDa ermittelbar sein.

\subsection{Proteinfärbung in Polyacrylamidgelen mittels Coomassie- Blue}

Nach Beendigung der Elektrophorese wurden die Gele kurz mit $\mathrm{H}_{2} \mathrm{O}$ gespült und dann für 30 min bei RT in Coomassie-Färbelösung gelegt. Nach Spülen mit $\mathrm{H}_{2} \mathrm{O}$ wurde das Gel bis 
zur Transparenz des Hintergrundes entfärbt. Die Gele konnten mit 10 \% (v/v) Essigsäure in Plastikfolie eingeschweißt und bei $4{ }^{\circ} \mathrm{C}$ gelagert werden.

Färbelösung

Coomassie-Blau G-250

Coomassie-Blau R-250

Methanol

Eisessig

\section{Entfärbelösung}

$$
\begin{array}{r}
0,08 \%(\mathrm{w} / \mathrm{v}) \\
0,08 \%(\mathrm{w} / \mathrm{v}) \\
45 \%(\mathrm{v} / \mathrm{v}) \\
10 \%(\mathrm{v} / \mathrm{v})
\end{array}
$$

Methanol $33 \%(\mathrm{v} / \mathrm{v})$

Eisessig $\quad 10 \%(\mathrm{v} / \mathrm{v})$

\subsection{Molekularmassenbestimmung}

\subsubsection{Molekularmassenbestimmung durch SDS-PAGE}

SDS lagert sich an Proteine an und zerstört fast alle nicht-kovalenten Wechselwirkungen, so daß die Dissoziation von Proteinen in ihre Untereinheiten erreicht wird. Durch die Bindung des negativ geladenen Detergens wird die Eigenladung der Proteine weitgehend vernachlässigbar und damit eine gelelektrophoretische Auftrennung ermöglicht, die nahezu ausschließlich auf der Masse der Moleküle beruht. Nach der SDS-PAGE und Färbung der Proteine konnte die Molekularmasse eines Proteins ermittelt werden, indem dessen Wanderungsgeschwindigkeit mit der von Markerproteinen verglichen wurde. Die Auftragung des Logarithmus der Molekularmassen der Markerproteine gegen den Rf-Wert (Wanderungsstrecke des Proteins bezogen auf die Wanderungsstrecke des Farbstoffmarkers) ergibt eine Eichgerade, anhand derer die Molekularmasse des jeweiligen Proteins berechnet werden konnte. Als Markerproteine wurden die Proteine des „LMW Calibration“-Kits (Fa. Amersham Pharmacia) eingesetzt. 
Markerproteine „LMW Calibration“-Kit

Phosphorylase $b$ $94 \mathrm{kDa}$

Rinderserumalbumin $67 \mathrm{kDa}$

Ovalbumin $45 \mathrm{kDa}$

Carboanhydrase $30 \mathrm{kDa}$

Trypsininhibitor 20,1 $\mathrm{kDa}$

Laktalbumin $14,4 \quad \mathrm{kDa}$

\subsubsection{Molekularmassenbestimmung durch Gradienten-PAGE (ANDERSON} et al., 1972; NISHIZAWA et al., 1988)

Die Auftrennung von Proteinen im nativen Polyacrylamid-Gradientengel (s.2.18.2) hängt in erster Linie von der Größe der Proteine ab. Mit steigender Acrylamidkonzentration nimmt die Porengröße ab und so wird das Weiterwandern von größeren Proteinen verhindert. Die Eigenladung der Proteine ist hier theoretisch vernachlässigbar (MARGOLIS und KENRICK, 1967).

Nach Auftrennung durch native Gradienten-PAGE (s. 2.18.2) und Anfärben der Proteinbanden (s. 2.19.1) konnte die Molekularmasse von Proteinen ermittelt werden, indem die Wanderungsstrecke mit der von Markerproteinen verglichen wurde. Als Markerproteine wurde der „HMW Calibration“-Kit (Fa. Amersham Pharmacia) oder der LMW Calibration Kit (s. 2.20.1) eingesetzt.

Markerproteine „HMW Calibration“-Kit

\begin{tabular}{lcc}
\hline Protein & Molekularmasse & RF-Wert \\
\hline Thyroglobin & $669 \mathrm{kDa}$ & 0,453 \\
Ferritin & $440 \mathrm{kDa}$ & 0,570 \\
Katalase & $232 \mathrm{kDa}$ & 0,651 \\
Laktat-Dehydrogenase & $140 \mathrm{kDa}$ & 0,714 \\
Rinderserumalbumin & $67 \mathrm{kDa}$ & 0,957 \\
\hline
\end{tabular}




\subsection{Chemikalien, Enzyme und Gase}

Es wurden Chemikalien des handelsüblichen Reinheitsgrades der Firmen Boehringer (Mannheim), Fluka (Buchs, Schweiz), Merck (Darmstadt), Riedel de Haen (Hannover), Serva (Heidelberg) und Sigma (Taufkirchen) verwendet. Des Weiteren wurde mit Biochemikalien, Enzymen etc. folgender Firmen gearbeitet:

Amersham Pharmacia, Freiburg:

Nylonmembranen, NAP-5-Säulen PD10-Säulen

Biozym GmbH, Hess. Oldendorf

Elektroporationsküvetten

Blue Substrates, Göttingen

RBV-Chitin

Eurogentec, Seraing, Belgien:

Agarose

Gerbu Biotechnik GmbH, Gaiberg:

IPTG, X-Gal, Ampicillin, Proteinase K

Gibco BRL, Eggenstein:

Random Primed Labeling Kit

Hartmann Analytic, Braunschweig:

[ $\alpha-32 \mathrm{P}]-\mathrm{dATP}$

Invitrogen, Karlsruhe

pET Directional TOPO Expression Kit, TOPO TA Cloning Kit, Platinum Pfx-DNA-

Polymerase, Oligonukleotide

MBI Fermentas GmbH, St. Leon-Rot:

Taq-DNA-Polymerase, T4-DNA-Ligase, Ladder-Mix, Nukleotide,

Restriktionsendonukleasen

Messer Griesheim GmbH, Kassel:

Gase $\left(\mathrm{N}_{2}, \mathrm{H}_{2}, \mathrm{~N}_{2} / \mathrm{CO}_{2}\right)$

Metabion, Martiensried

Oligonukleotide

Millipore, Eschborn:

Mikrodialyse-Filter 
Promega, Deutschland GmbH, Mannheim:

Wizard $^{\mathrm{TM}}$ Plus Minipreps DNA Purificaton System, Pfu-DNA-Polymerase Qiagen GmbH, Hilden:

Plasmid Midi-Kit, QIAprep Spin Miniprep Kit, Qiaquick PCR-Purification-Kit;

Qiaquick Gel Extraction Kit,

Sartorius AG, Göttingen:

Sterilfilter

Sigma Chemie GmbH, Deisenhofen:

Chitin, Ka-Ferricyanid, N-Acetyl-Glucosamin, Kongo-Rot

Stratagene, USA:

Gigapack ${ }^{\circledR}$ III Gold Packaging Extract, Herculase enhanced DNA Polymerase Whatman, Maidstone, England:

Whatman-Filterpapier 3MM 


\section{EXPERIMENTE und ERGEBNISSE}

Chitin ist ein lineares unlösliches Polymer, welches aus $\beta-1,4-\mathrm{N}-$ Acetyl-GlukosaminEinheiten aufgebaut ist. Diese hochpolymere Verbindung dient unterschiedlichen Organismen wie z.B. Pilzen als Gerüstsubstanz. Die auf natürliche Weise entstehenden großen Mengen an Chitin werden durch die in Flora, Fauna und unter den Mikroorganismen verbreiteten chitinspaltenden Enzyme abgebaut. In der Natur produzieren die meisten Bakterien Chitinasen, um Chitin als C- und Energiequelle zu nutzen. Chitinasen werden jedoch in der Natur auch als Fungizid bzw. Insektizid eingesetzt (WATANABE et al., 1991; SAMPSON et al., 1998). Versuche zeigten, dass bakterielle Chitinasen an chitinhaltigen Pilzmycelien binden und anschließend Chitin abbauen; eine Lyse der Pilzmycelien ist die Folge. Die fungiziden Eigenschaften von Chitinasen können zur Entwicklung eines Chitinasepräparates zum Einsatz als umweltfreundliches biologisches Fungizid ausgenutzt werden. Eine Verwendungsmöglichkeit eines solchen Präparates könnte läge zum Beispiel im Bereich des Pflanzenschutzes. Generell bieten sich zwei Möglichkeiten zur Nutzung von Chitinasen an: Zum einen könnten gereinigte Enzyme eingesetzt werden, alternativ der Produzent selbst.

Zur Identifizierung von Chitinasen mit fungizider Wirkung sollen zwei Wege beschritten werden. Zum einen werden Chitinase-produzierende Mikroorganismen angereichert, isoliert und nach Bestimmung der fungiziden Eigenschaften der Enzyme die entsprechenden Gene aus den dabei identifizierten Organismen kloniert. Außerdem sollen Chitinasen direkt aus Anreicherungskulturen amplifiziert werden. Dazu werden Oligonukleotide verwendet, die aus bekannten Chitinasegenen abgeleitet wurden. Zum anderen sollen Standortgenbanken auf die Anwesenheit von Genen für Chitinasen durchmustert werden. Die Grundlage dieses Verfahrens ist, das gesamte genetische Potential eines Habitats auszunutzen. Dies umfasst die Herstellung und das Screening von Umweltgenbanken auf rekombinante Organismen, welche Chitinasen mit den gewünschten Eigenschaften produzieren. Dies ist unabhängig von der Kultivierbarkeit der Mikroorganismen und nutzt daher größere Teile der Biodiversität eines Habitats zur Erfassung von grundlegend neuartigen Enzymaktivitäten aus. Zur Anlegung einer Genbank eines Standortes wird die Gesamt-DNA isoliert, mit Restriktionsenzymen partiell verdaut und in geeignete Vektorsysteme kloniert. Für das Durchmustern von Genbanken und für die Produktion der Enzyme wird Escherichia coli als Wirtsorganismus verwendet. In der vorliegenden Arbeit wurde auf bereits bestehende Genbanken für die Durchmusterung auf Chitinasegene zurückgegriffen. Die auf der Grundlage der dargestellten 
Methoden erhaltenen Chitinase-Genprodukte waren im folgenden auf ihre fungiziden Eigenschaften hin zu überprüfen. Zur Bestimmung der fungiziden Wirkung von Chitinasen bzw. Chitinase-produzierenden Mikroorganismen wurde die Hemmung des Wachstums von Pilzen in einem Agartestverfahren untersucht (s. 2.16.2).

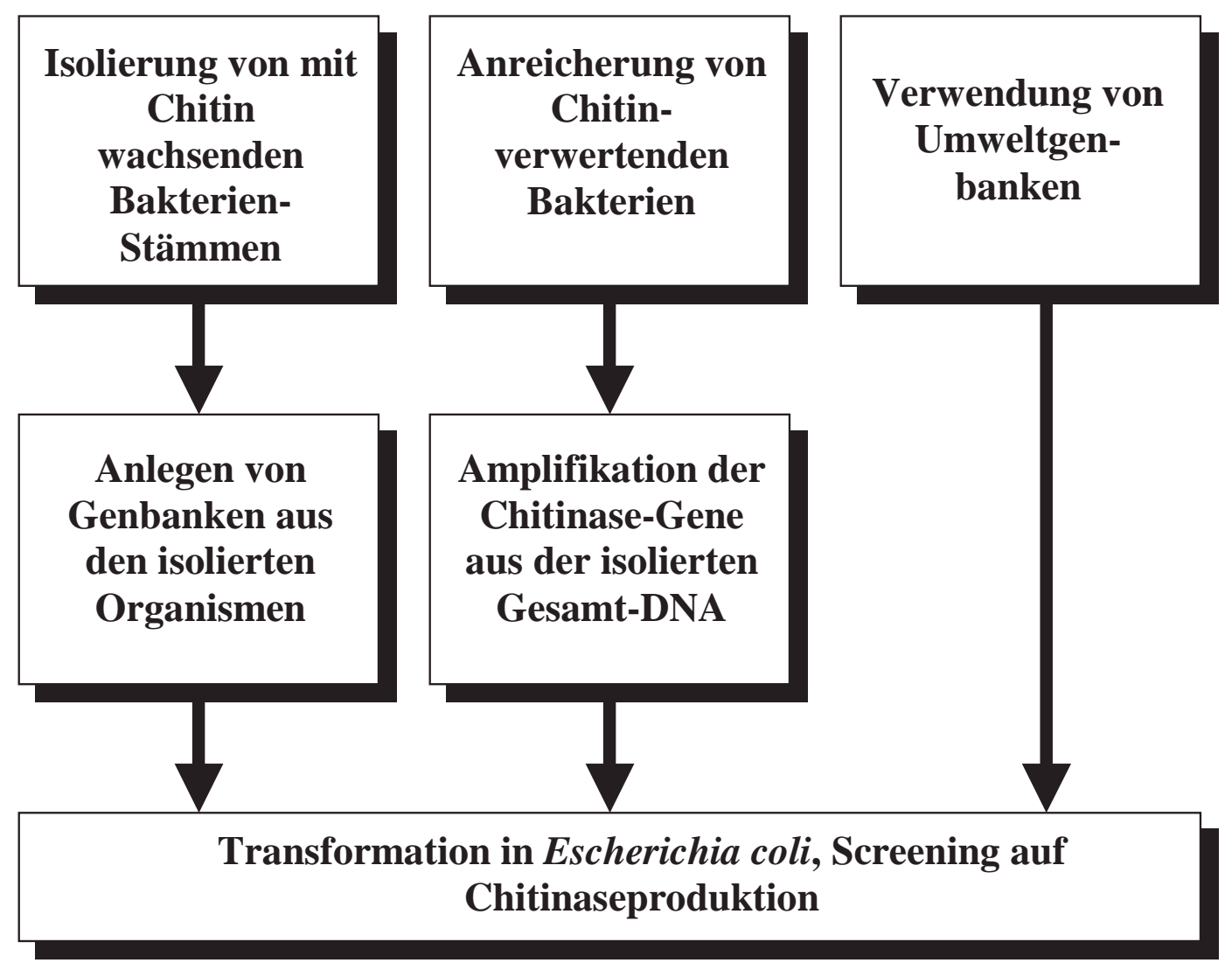

Abb. 4: Strategien zur Klonierung von Chitinasen

\subsection{Isolierung von Chitinaseproduzenten}

Zur Isolierung von Chitinaseproduzenten wurde Mineralmedium (s. 2.2.3) mit Chitin als einziger Kohlenstoff- und Energiequelle mit Boden- bzw. Meeresproben aus Deutschland, Israel und Ägypten beimpft und bei $30{ }^{\circ} \mathrm{C}$ unter aeroben als auch anaeroben Bedingungen 
inkubiert. Die für die Isolierung benötigten Proben stammen z.T. aus Israel und Ägypten, die im Rahmen einer marinmikrobiologischen Exkursion (April 2000) gesammelt wurden. Ein Teil der Proben wurden marinen Habitaten entnommen, weil in diesen Standorten Chitin als die Hauptenergie- und Kohlenstoffquelle vorliegt. Daher ist eine große Anzahl an mikrobiellen Chitinaseproduzenten in den Ozeanen vertreten, so dass der Versuch der Isolierung verschiedener Stämme mit hoher Wahrscheinlichkeit zum Erfolg führen sollte. Zudem wurden auch Bodenproben aus Israel und Göttingen eingesetzt. Zur Isolierung von Chitin-verwertenden Organismen wurden Anreicherungskulturen, bei denen Wachstum zu verzeichnen war, mehrmals (jeweils $0,5 \%(\mathrm{v} / \mathrm{v})$ ) in neues Mineralmedium überimpft und unter gleichen Bedingungen inkubiert. Nach 6 Transfers wurden die Anreicherungen auf Chitinhaltige Mineralagarplatten ausgestrichen. Chitinaseproduzenten sind anhand einer Hofbildung auf diesen Platten zu erkennen (Abb. 5).

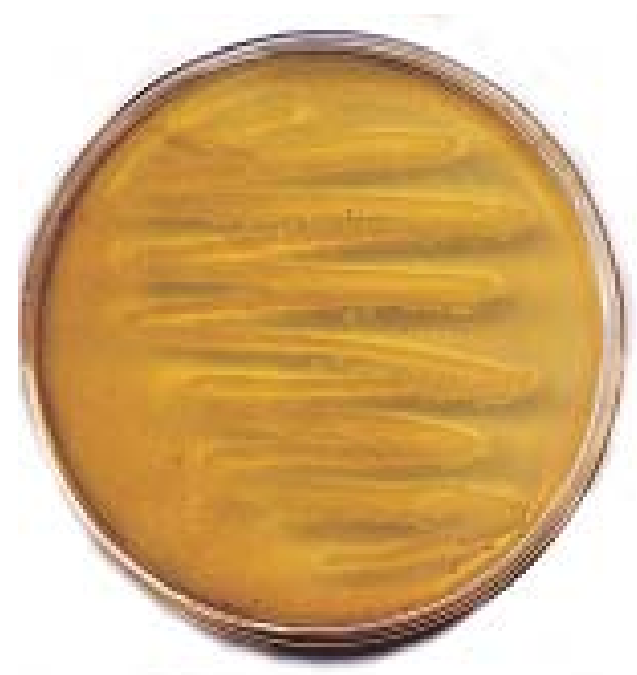

\section{Abb. 5: Hofbildung eines isolierten Chitinaseproduzenten auf einer chitinhaltigen Mineralagarplatte}

Zur Isolierung von Reinkulturen wurden Vereinzelungsausstriche durchgeführt und bei $30{ }^{\circ} \mathrm{C}$ inkubiert. Die Reinheit der Stämme wurde mikroskopisch und anhand der Koloniemorphologie überprüft. Auf diese Weise konnten dreizehn verschiedene prokaryotische Chitinaseproduzenten isoliert werden (siehe Tab. 5). Diese so isolierten Mikroorganismen entstammen ausschließlich aeroben Anreicherungen. 
Tabelle 5: Isolierte Chitinaseproduzenten

\begin{tabular}{|c|c|c|}
\hline $\begin{array}{c}\text { Anzahl der } \\
\text { erhaltenen Isolate }\end{array}$ & $\begin{array}{c}\text { Bezeichnung der } \\
\text { Isolate }\end{array}$ & Standort \\
\hline 3 & E1-E3 & Seewasser, Eilat (Israel) \\
\hline 1 & LK & Luftkeim, Göttingen (Deutschland) \\
\hline 1 & SE1 & Sediment, Eilat (Israel) \\
\hline 4 & SL1-SL4 & Sediment Solar Lake (Ägypten) \\
\hline 4 & WG1-WG4 & Wiese, Göttingen (Deutschland) \\
\hline
\end{tabular}

Vier der Isolate entstammten Bodenproben, die im Raum Göttingen entnommen worden waren. Diese erhielten die Bezeichnung WG1 bis WG 4. Ein Stamm stellte einen Luftkeim dar, der in Göttingen isoliert wurde. Dieser erhielt die Bezeichnung LK. Aus Bodenproben, die dem Sediment des Solar Lake in Ägypten entstammten, ließen sich 4 Stämme (SL1-SL4) isolieren. Ein Stamm konnte aus einer Sediment-Probe aus Eilat (Israel) isoliert werden und erhielt die Bezeichnung SE1. Aus den zur Verfügung stehenden Seewasserproben, die vor der Küste des Golfes von Eilat (Israel) genommen wurden, entstammten weitere 3 Isolate. Diese wurden mit E1 bis E3 bezeichnet.

\subsection{Charakterisierung der Chitinaseproduzenten}

Zur phylogenetischen Klassifizierung der isolierten Chitinaseproduzenten (siehe Tab. 5), wurde jeweils das 1,5 kB umfassende 16S rRNA-Gen amplifizert und sequenziert.

Die 16S rDNA aller 13 isolierten Prokaryoten außer der des Isolates WG1 wurde mit Hilfe der PCR (s. 2.13) unter Verwendung der Oligonukleotide „16S-08“ und „16S-1504“ (s. 2.1), amplifiziert. Abgeleitet wurden diese aus dem gesamten 1508 Bp umfassenden 16S rRNAGen von E. coli (MUYZER et al. 1995) im Abschnitt 5 $\rightarrow 3 ` 08$ bis 1504, so dass bei der PCR der größte Teil des 16S rRNA-Gens amplifiziert werden sollte. Die jeweiligen Sequenzen finden sich im Anhang. Die erhaltenen PCR-Produkte wurden mit Hilfe des TOPO-TACloning-Kits (s. 2.8.6) in den Vektor pCR2.1-TOPO kloniert und sequenziert. Die 16S rDNA des Isolates WG1 wurde von der DSMZ (Braunschweig) analysiert.

Die Analyse der Sequenzen ergab, das es sich bis auf das Isolat WG4 bei allen Isolaten um bislang unbekannte Stämme verschiedener Gattungen handelte (s. Tab. 6). 
Tabelle 6: Analyse der 16S rRNA der Isolate

\begin{tabular}{|c|c|}
\hline Isolat & $\begin{array}{l}\text { Übereinstimmung der 16S rRNA- } \\
\text { Genanalyse zu bekannten Prokaryoten }\end{array}$ \\
\hline E1 & Alcaligenes xylosoxidans $98,9 \%$ \\
\hline E2 & Bacillus chitinolyticus $98,9 \%$ \\
\hline E3 & Sphingobakterium multivorum $99 \%$ \\
\hline LK & Flexibacter cf. sankti. $99 \%$ \\
\hline SE1 & Bacillus chitinolyticus $98,3 \%$ \\
\hline SL1 & Paenibacillus macerans $98,5 \%$ \\
\hline SL2 & Paenibacillus macerans $99,2 \%$ \\
\hline SL3 & Bacillus chitinolyticus $98,8 \%$ \\
\hline SL4 & Paenibacillus macerans $98,4 \%$ \\
\hline WG1 & Bacillus ehimensis $98,3 \%$ \\
\hline WG2 & Sphingobakterium multivorum $99 \%$ \\
\hline WG3 & Streptomyces griseus $98,4 \%$ \\
\hline WG 4 & Stenotrophomonas maltophilia $100 \%$ \\
\hline
\end{tabular}

So ergab die Sequenzanalyse der Isolate, das es sich bei E2, SE1, SL3 und WG1 um bislang unbekannte Vertreter der Gattung Bacillus handelte. Das Isolat E1 ließ sich als bislang unbekannter Vertreter in die Gattung Alcaligenes, WG2 und E3 in Sphingobakterium und LK in die Gattung Flexibacter einordnen. 3 Isolate, SL1, SL2 und SL4, zeigten Ähnlichkeiten zur Gattung Paenibacillus. Das Isolat mit der Bezeichnung WG3 erwies sich als unbekannter Vertreter der Spezies Streptomyces. Beim Isolat WG4 handelte es sich um das bereits bekannte Bakterium Stenotrophomonas maltophilia.

\subsection{Untersuchung der Isolate auf fungizide Eigenschaften}

Die 13 isolierten Chitinaseproduzenten und deren Kulturüberstand wurden auf ihre fungizide Wirkung hin untersucht. Für den Fungizid-Test wurden wie unter 2.16 .2 beschrieben Filterscheiben auf mit verschiedenen Pilzen beimpfte Agarplatten gelegt und entweder mit konzentriertem Enzymüberstand oder der entsprechenden Bakteriensuspension getränkt. 
Verfügte die zu testende Enzym- oder Bakteriensuspension über fungizide Eigenschaften, zeigte sich eine Hemmhofbildung gegenüber dem Pilzwachstum um die Filterscheibe herum (s. Abb. 6). Für den Test wurden 4 pflanzenpathogene Pilze eingesetzt: Guignardia bidwellii (Schwarzfäule), Sclerotia sclerotiorum (Weißstengeligkeit), Fusarium culmarum (Ährenfusariose) und Botrytis cinerea (Grauschimmelfäule). Des weiteren wurde ein Vertreter der Schimmelpilze, Aspergillus nidulans verwendet.

Bei diesem Test wurde nur überprüft, welche der chitinolytischen Isolate über fungizide Eigenschaften verfügten. Die Ursache für diese Eigenschaft ist nicht zwangsläufig auf die Aktivität von Chitinasen zurückführbar, da die fungizide Wirkung auch durch andere Enzyme oder Verbindungen verursacht werden kann. Der Test lieferte jedoch die Möglichkeit zu selektieren, welche Isolate für die Erfüllung des Zieles dieser Arbeit in Frage kamen. Durch Klonierung des für die jeweilige Chitinase kodierenden Genes und dessen rekombinante Expression in E. coli sollte überprüft werden, ob die fungiziden Eigenschaften der fünf Isolate auf die Aktivität der produzierten Chitinasen zurückzuführen ist.

Bei Fünf der dreizehn Isolaten (WG1, WG3, SE1, E2 und SL3) und deren Kulturüberständen konnten dabei fungizide Eigenschaften nachgewiesen werden (s. Tab. 7).

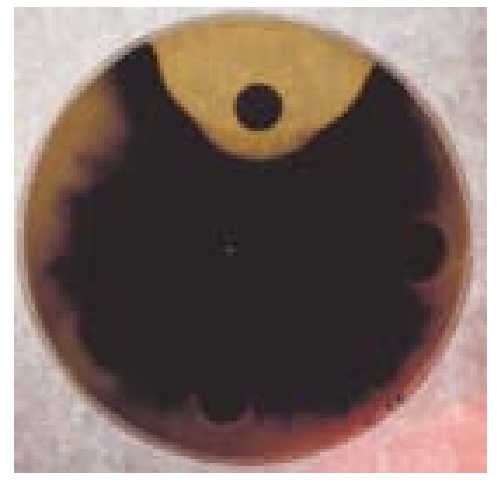

Abb. 6A: Hemmung des fungalen Wachstums von Sclerotia sclerotiorum durch den Kulturüberstand des Isolates WG3

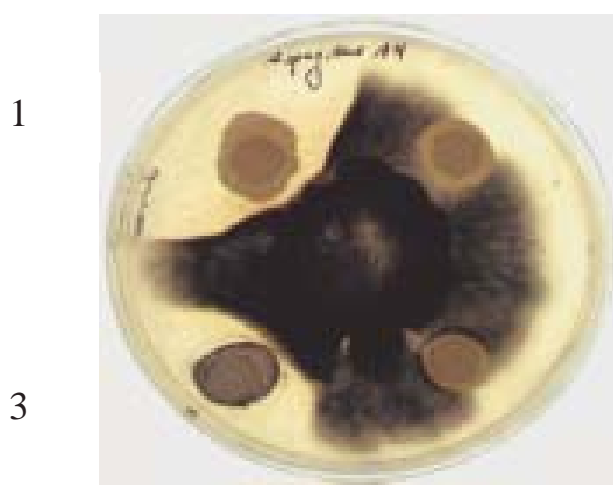

2

Abb. 6B: Hemmung des fungalen Wachstums von Aspergillus nidulans durch Chitinase-produzierende Mikro-organismen

1: WG3; 2 SE1; 3 WG1; 4 E2

Dabei zeigte sich, das die Isolate WG1 und WG3 gegenüber allen eingesetzten Pilzstämmen eine Wachstumsinhibition bewirkten. Die Isolate SE1 und SL3 zeigten eine schwache fungizide Wirkung gegenüber allen Pilzen außer F. culmarum. E2 wies eine schwache 
fungizide Wirkung gegenüber A. nidulans und S. sclerotiorum auf (s. Tab. 7).

Tabelle 7: Test der Isolate und ihres jeweiligen Kulturüberstandes auf fungizide Eigenschaften

\begin{tabular}{|l|c|c|c|c|c|}
\hline Isolat & $\begin{array}{l}\text { Aspergillus } \\
\text { nidulans }\end{array}$ & $\begin{array}{l}\text { Botrytis } \\
\text { cinerea }\end{array}$ & $\begin{array}{l}\text { Fusarium } \\
\text { culmarum }\end{array}$ & $\begin{array}{l}\text { Guignardia } \\
\text { bidwellii }\end{array}$ & $\begin{array}{l}\text { Sclerotia } \\
\text { sclerotiorum }\end{array}$ \\
\hline WG1 & + & + & + & + & + \\
\hline WG3 & + & + & + & + & + \\
\hline SE1 & $(+)$ & $(+)$ & - & $(+)$ & $(+)$ \\
\hline E2 & $(+)$ & $(+)$ & - & - & $(+)$ \\
\hline SL3 & $(+)$ & - & - & $(+)$ \\
\hline
\end{tabular}

+ starke Hemmhofbildung: Um die beimpfte Filterscheibe herum bildete sich ein deutlicher Hemmhof $(>0,5 \mathrm{~cm}) ;(+)$ schwache Hemmhofbildung: Die beimpfte Filterscheibe wurde nicht vom Pilz überwuchert; - keine Hemmhofbildung: Die beimpfte Filterscheibe wurde vom Pilz überwuchert

Bildete sich bei diesem Plattentest ein Hemmhof, so war er über den gesamten Testzeitraum von sechs Wochen stabil. Aufgrund dieses Ergebnisses sollten die Chitinasen der Isolate WG1, WG3, SE1, E2 und SL3 kloniert werden, wobei der Fokus bei den Chitinasen von WG1 und WG3 lag, da bei diesen Organismen gegenüber allen getesteten Pilzen die fungizide Wirkung am stärksten ausgeprägt war (s. Tab. 7).

Um Hinweise darauf $\mathrm{zu}$ erhalten, ob die fungizide Wirkung des Kulturüberstandes auf Enzymaktivitäten oder vom Stamm gebildeten Verbindungen herrührten, wurden diese zum einen mit Proteasen (20 $\mu 1$ einer $10 \mathrm{mg} / \mathrm{ml}$ Proteinaselösung auf $1 \mathrm{ml}$ Kulturüberstand) und zum anderen durch 1 minütige Erhitzung auf $100{ }^{\circ} \mathrm{C}$ behandelt (s. Tab. 8). Die so behandelten Kulturüberstände wurden daraufhin analog zum beschriebenem Test auf fungizide Eigenschaften untersucht. Dabei wurde der Pilz A. nidulans verwendet. 
Tabelle 8: Test der fungiziden Wirkung der Isolate WG1, WG3, E2, SL3 und E2 nach Behandlung des Kulturüberstandes mit Proteasen bzw. nach Erhitzung auf $100{ }^{\circ} \mathrm{C}$

\begin{tabular}{|c|c|c|}
\hline Isolat & $\begin{array}{c}\text { Fungizide Wirkung nach } \\
\text { Proteasebehandlung }\end{array}$ & $\begin{array}{c}\text { Fungizide Wirkung nach } \\
\text { Erhitzung auf 100 }{ }^{\circ} \text { C für 1 } \\
\text { Minute }\end{array}$ \\
\hline E2 & - & - \\
\hline SE1 & - & - \\
\hline SL3 & - & + \\
\hline WG1 & + & - \\
\hline WG3 & + & - \\
\hline
\end{tabular}

+ Hemmhofbildung: Um die beimpfte Filterscheibe herum bildete sich ein deutlicher Hemmhof $(>0,5 \mathrm{~cm})$; - keine Hemmhofbildung: Die beimpfte Filterscheibe wurde vom Pilz überwuchert

Bei diesem Test zeigte sich, das sowohl nach Proteasebehandlung als auch nach Erhitzung des Kulturüberstandes beim Isolat WG1 weiterhin eine Hemmhof-Bildung nachzuweisen war. Beim Isolat WG3 zeigte der Kulturüberstand nach Proteasebehandlung weiterhin eine Wachstumsinhibition gegenüber A. nidulans. Diese Wirkung war nach Erhitzung auf $100{ }^{\circ} \mathrm{C}$ für 1 Minute nicht mehr feststellbar. Die Kulturüberstände aus SE1, E2 und SL3 verloren nach beiden Inaktivierungs-Tests ihre fungizide Wirkung. Daraus ist zu schließen, das die inhibitorische Wirkung bei den Isolaten aus WG1 und WG3 nicht nur von Enzymen sondern auch von Verbindungen wie z.B. Antibiotika verursacht sein könnte. Bei den übrigen Isolaten geht die fungizide Eigenschaft nur auf Enzyme zurück.

\subsection{Physiologische Analyse der Isolate mit fungiziden Eigenschaften}

Die fünf Isolate mit fungiziden Eigenschaften wurden einer Reihe von Wachstumstests unterzogen, um durch den Erhalt weiterer Charakteristika die 16S rRNA-Analyse zu ergänzen. Hierfür wurden die Isolate in Mineralmedium mit jeweils einer zu testenden Kohlenstoff- und Energiequelle überimpft. Die Ergebnisse der physiologischen Analyse sind in den Tabellen 9, 10 und 11 zusammengefaßt. 
Tabelle 9: Untersuchung der Verwertung verschiedener Kohlenstoffquellen von SE1, SL3 und E2 im Vergleich mit $B$. chitinolyticus

\begin{tabular}{|c|c|c|c|c|}
\hline Kohlenstoffquelle & E2 & SE1 & SL3 & $\begin{array}{c}\text { B. } \\
\text { chitinolyticus }\end{array}$ \\
\hline Zellform & $\begin{array}{l}\text { Stäbchen- } \\
\text { förmig }\end{array}$ & $\begin{array}{l}\text { Stäbchen- } \\
\text { förmig }\end{array}$ & $\begin{array}{l}\text { Stäbchen- } \\
\text { förmig }\end{array}$ & $\begin{array}{l}\text { Stäbchen- } \\
\text { förmig }\end{array}$ \\
\hline L-Arabinose & + & - & - & - \\
\hline D-Xylose & + & - & - & - \\
\hline D-Glukose & + & + & + & + \\
\hline Fruktose & + & + & + & n.b. \\
\hline Saccharose & + & + & + & n.b. \\
\hline Laktose & - & $(+)$ & - & n.b. \\
\hline Maltose & + & + & + & n.b. \\
\hline Cellobiose & - & + & + & n.b. \\
\hline Raffinose & - & + & + & n.b. \\
\hline Cellulose & - & - & - & n.b. \\
\hline Stärke & + & - & + & - \\
\hline Dextran & - & - & - & n.b. \\
\hline Chitin & + & + & + & + \\
\hline Mannit & + & + & + & - \\
\hline Tributyrin & - & $(+)$ & + & n.b. \\
\hline Triolein & - & - & + & n.b. \\
\hline Pepton & + & + & + & n.b. \\
\hline Hefeextrakt & + & + & + & n.b. \\
\hline Trypton & + & + & + & n.b. \\
\hline
\end{tabular}

+, Wachstum durch Messung der optischen Dichte der Bakteriensuspension bei $600 \mathrm{~nm}$ verzeichnet; (+), schwaches Wachstum, optische Dichte der Bakteriensuspension bei $600 \mathrm{~nm}$ stieg leicht an; -, kein Wachstum verzeichnet; n.b., Eigenschaft die von KUROSHIMA (1996) nicht bestimmt wurde

Das Substratspektrum von WG3 wurde mit dem Streptomyceten-Cluster 1B verglichen, dem S. griseus zugeordnet wurde (Williams et al., 1983; Bergey`s Manual of Determinative Bacteriology, 1996). Die Referenz-Werte sind daher in Prozent der Stämme angegeben, die innerhalb des Clusters in der Lage sind, das betreffende Substrat zu verwerten (s. Tab. 10). 
Tabelle 10: Vergleich des Substratspektrums von WG3 zu dem am nächsten verwandten Streptomyceten-Cluster 1B.

\begin{tabular}{|c|c|c|}
\hline Kohlenstoffquelle & WG3 & $\begin{array}{c}\text { Cluster 1B } \\
\text { Stämme, die Substrat } \\
\text { verwerten können (in \%) }\end{array}$ \\
\hline Zellform & Stäbchen & Stäbchen \\
\hline L-Arabinose & - & n.b. \\
\hline D-Xylose & - & n.b. \\
\hline D-Glukose & + & 100 \\
\hline Fruktose & + & 90 \\
\hline Saccharose & $(+)$ & 45 \\
\hline Lactose & - & 50 \\
\hline Maltose & $(+)$ & n.b. \\
\hline Cellobiose & - & n.b. \\
\hline Raffinose & - & 5 \\
\hline Cellulose & - & 90 \\
\hline Stärke & + & n.b. \\
\hline Dextran & - & 20 \\
\hline Chitin & + & 100 \\
\hline Mannit & - & n.b. \\
\hline Tributyrin & - & n.b. \\
\hline Triolein & - & n.b. \\
\hline Pepton & + & n.b. \\
\hline Hefeextrakt & + & n.b. \\
\hline Trypton & + & n.b. \\
\hline
\end{tabular}

+, Wachstum durch Messung der optischen Dichte der Bakteriensuspension bei $600 \mathrm{~nm}$ verzeichnet; (+), schwaches Wachstum, optische Dichte der Bakteriensuspension bei $600 \mathrm{~nm}$ stieg leicht an; -, kein Wachstum verzeichnet; Die Werte in Prozent geben die Zahl der Stämme innerhalb des Streptomyceten-Clusters an, die ein bestimmtes Substrat verwerten können. n.b., Eigenschaft die von BERGEY'S Manual of Determinative Bacteriology (1996) nicht bestimmt wurde

Das Isolat mit der Bezeichnung WG1 wurde von der DSMZ (Braunschweig) näher charakterisiert. Die dabei ermittelten Daten sind in Tabelle 11 aufgeführt. 
Tabelle 11: Eigenschaften des Isolates WG1 im Vergleich mit B. ehimensis

\begin{tabular}{|c|c|c|}
\hline Charakteristik & WG1 & B. ehimensis \\
\hline Zellform & Stäbchen & Stäbchen \\
\hline Breite $\mu \mathrm{m}$ & $0,6-0,8$ & $0,4-0,6$ \\
\hline Länge $\mu \mathrm{m}$ & $2,5-3,5$ & $1,7-5$ \\
\hline Anaerobes Wachstum & - & - \\
\hline VP-Reaktion & - & + \\
\hline $\mathrm{pH}$ in $\mathrm{VP}$ & 5,3 & 6,0 \\
\hline Gasbildung aus Glukose & - & - \\
\hline Säurebildung aus D-Glukose & + & + \\
\hline Säurebildung aus L-Arabinose & + & + \\
\hline Säurebildung aus D-Xylose & + & + \\
\hline Säurebildung aus D-Mannit & + & + \\
\hline Säurebildung aus D-Fruktose & + & + \\
\hline Hydrolyse von Casein & + & + \\
\hline Hydrolyse von Gelatine & + & + \\
\hline Hydrolyse von Stärke & + & + \\
\hline Hydrolyse von Chitin & + & + \\
\hline Hydrolyse von Tween 80 & + & n.b. \\
\hline NaCl-Toleranz 2\% & + & n.b. \\
\hline NaCl-Toleranz 5\% & - & n.b. \\
\hline Argininhydrolase & - & n.b. \\
\hline Wachstum bei $50^{\circ} \mathrm{C}$ & + & + \\
\hline Wachstum bei $55^{\circ} \mathrm{C}$ & + & - \\
\hline Esculinhydrolyse & + & n.b. \\
\hline Tyrosin & - & n.b. \\
\hline Phenylalanindesaminase & - & n.b. \\
\hline Nitratreduktion & + & + \\
\hline Indol & - & n.b. \\
\hline Wachstum bei pH 5,7 & + & + \\
\hline Lecithinase & + & n.b. \\
\hline
\end{tabular}




\begin{tabular}{|c|c|c|}
\hline Citrat & + & - \\
\hline Propionat & + & n.b. \\
\hline
\end{tabular}

(Fortsetzung der Tab. 11)

+, Wachstum durch Messung der optischen Dichte der Bakteriensuspension bei $600 \mathrm{~nm}$ verzeichnet; (+), schwaches Wachstum, optische Dichte der Bakteriensuspension bei 600 nm stieg leicht an; -, kein Wachstum verzeichnet; n.b., Eigenschaft die von KUROSHIMA (1996) nicht bestimmt wurde

Die aus dem Vergleich des Substratspektrums mit B. chitinolyticus und B. ehimensis und der aus der 16S rRNA-Gen-Analyse erhaltenen Daten zeigten, dass es sich bei WG1, SE1, E2 und SL3 um bisher unbekannte Spezies innerhalb der Gattung Bacillus handelte. Keines der Isolate wies ein in allen Punkten identisches Substratspektrum zum Referenzorganismus auf. Die Analyse der Verwertbarkeit verschiedener Kohlenstoffquellen und die 16S rRNAAnalyse beim Isolat WG3 führte zu dem Ergebnis, das dieser Organismus einen bislang unbekannten Vertreter der Gattung der Streptomyceten darstellte.

\subsubsection{Wachstumsparameter der Isolate mit fungizider Wirkung auf Chitin}

Die Wachstumskurve der Organismen mit fungiziden Eigenschaften, WG1, WG3, SE1, E2 und SL3 wurde bei der Verwertung von Chitin als einziger Kohlenstoff- und Energiequelle ermittelt und die Verdopplungszeit sowie die Wachstumsrate der Organismen berechnet. Dazu wurden die Isolate in Chitin-Mineralmedium (s. 2.2.3) als Vorkulturen angezogen und mit diesen die Hauptkultur (gleiches Medium) beimpft. Das Wachstum der Organismen wurde photometrisch bei einer OD von $600 \mathrm{~nm}$ verfolgt. Das Wachstum wurde solange beobachtet, bis die Isolate nach Erreichen der stationäre Phase in die Absterbephase übergingen. Die Wachstumskurven sind in Abb. 7 und 8 wiedergegeben.

Es zeigte sich, das die stationäre Phase bei dem Isolat SL3 mit etwa $35 \mathrm{~h}$ am schnellsten erreicht wurde. Bei WG1, E2 und WG3 wurde diese Phase zwischen 45 und $50 \mathrm{~h}$ und bei SE1 bei ca. 65 h erreicht. Des weiteren wurde für jeden Organismus die Wachstumsrate $(\mu)$ und die Verdopplungszeit (td) aus der exponentiellen Wachstumsphase berechnet (s. Tab. 12). Dabei wies das Isolat SL3 mit 2,39 h die kürzeste Verdopplungszeit auf. E2 zeigte eine Verdopplungszeit von 3,65, WG3 von 3,85 und WG1 von 6,3 h. Die längste Verdopplungszeit zeigte SE1 mit 11,55 h. 


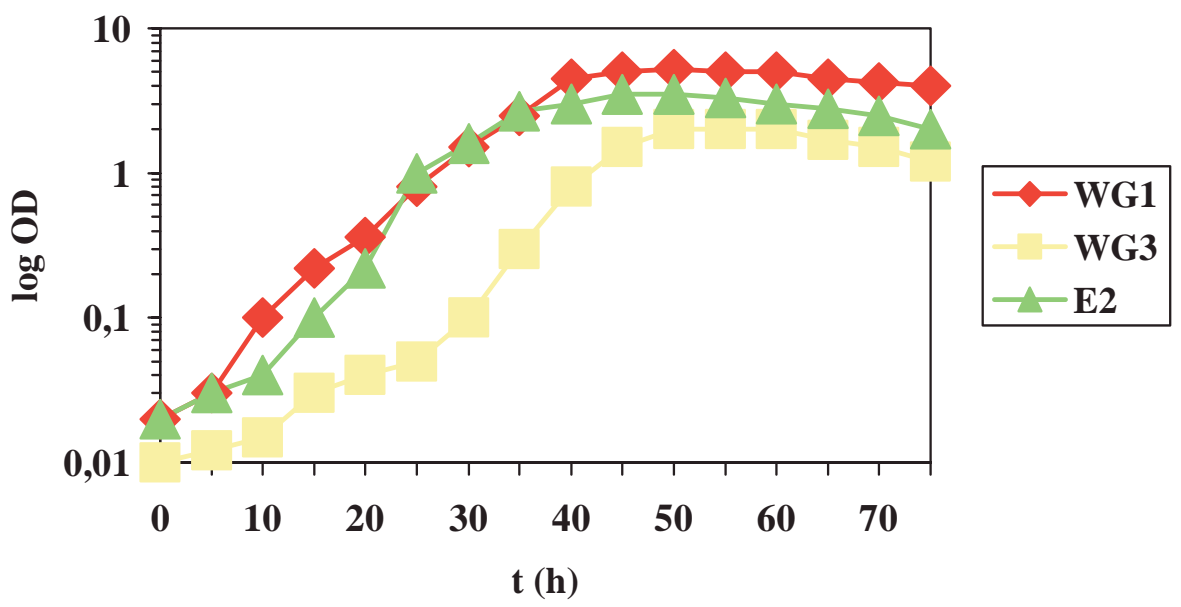

\section{Abb. 7: Wachstumskurve der Isolate E2, WG1 und WG3 mit kolloidalem Chitin}

Es wurde die optische Dichte der Isolate beim Wachstum in Mineralmedium mit Chitin als einziger C-Quelle bestimmt. Diese Daten sind zeitabhängig gegen die logarithmisch dargestellte optische Dichte aufgetragen.

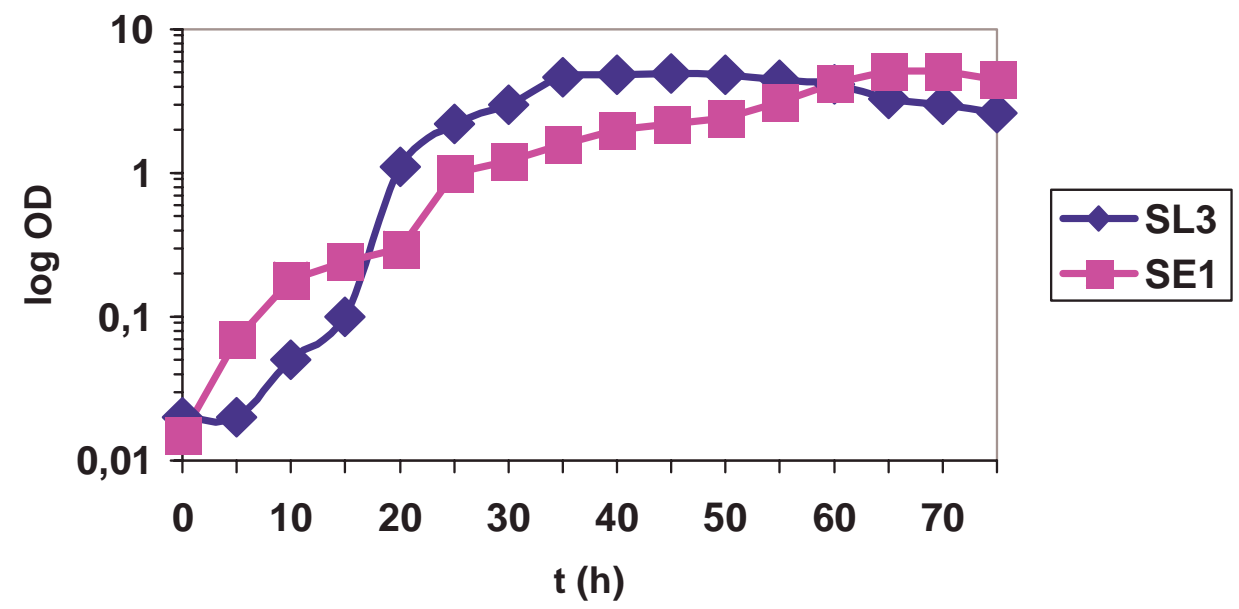

Abb. 8: Wachstumskurve der Isolate SE1 und SL3 mit kolloidalem Chitin

Es wurde die optische Dichte der Isolate beim Wachstum in Mineralmedium mit Chitin als einziger C-Quelle bestimmt. Diese Daten sind zeitabhängig gegen die logarithmisch dargestellte optische Dichte aufgetragen. 
Tabelle 12: Ermittlung der Wachstumsrate und der Verdopplungszeit der Isolate mit fungiziden Eigenschaften

\begin{tabular}{|c|c|c|}
\hline Isolat & Verdopplungszeit td (h) & Wachstumsrate $\boldsymbol{\mu} \mathbf{h}^{\mathbf{- 1}}$ \\
\hline SL3 & 2,39 & 0,29 \\
\hline E2 & 3,65 & 0,19 \\
\hline WG3 & 3,85 & 0,18 \\
\hline WG1 & 6,3 & 0,11 \\
\hline SE1 & 11,55 & 0,06 \\
\hline
\end{tabular}

\subsection{Identifizierung der Chitinasegene aus isolierten Mikro- organismen mit Hilfe der ,Southern“-Blot- Analyse}

Zur Identifizierung der Chitinasegene der fünf Isolate WG1, WG3, SE1, E2 und SL3 wurde die chromosomale DNA der Organismen extrahiert (s. 2.7.1) und mit verschiedenen Restriktionsenzymen behandelt. Die auf diese Weise verdaute DNA wurde wie im Punkt 2.12.2 beschrieben mit radioaktiv markierten Sonden einer „Southern“ Blot-Analyse unterzogen. Die dafür benötigten heterologen Sonden wurden durch partielle Amplifikation der Chitinasegene bekannter Chitinaseproduzenten erstellt. Dafür wurden partiell das chiCGen aus S. griseus (OHNO et al. 1996), das chiA-Gen aus V. harveyi (SUGINTA et al., 2000) und das chiB-Gen aus B. licheniformis (TANTIMAVANICH et al. 1996) amplifiziert (s. Abb. 9). Das chiC-Gen aus S. griseus gehört der Familie 19 der Glykosyl-Hydrolasen an, während das chiA-Gen und das chiB-Gen der Familie 18 entstammten. Die für die Erstellung von Sonden gewählten Chitinase-Gene weisen untereinander keine signifikanten Ähnlichkeiten auf und sind wie erwähnt Vertreter beider Chitinase-Familien. Dadurch sollte die Wahrscheinlichkeit erhöht werden, verschiedene Chitinasen zu finden. Die Sonden wurden dabei aus Abschnitten des betreffenden Gens amplifiziert, die Sequenzen im Bereich der Chitin-Bindedomäne bzw. der katalytischen Domäne erhalten. In diesen Domänen finden sich konservierte Bereiche (SVITIL und KIRCHMAN, 1998), die mit den Chitinasegenen der Isolate hybridisieren sollten. 
A

chiC-Gen (885 Bp)

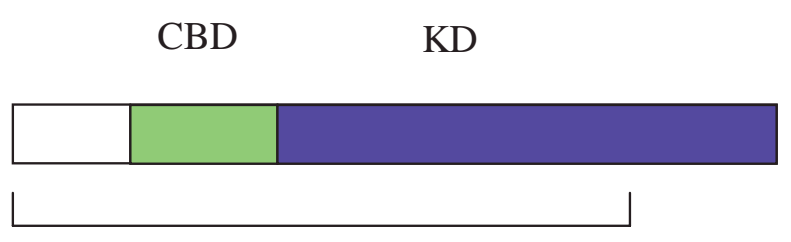

Sonde ChiC600

B

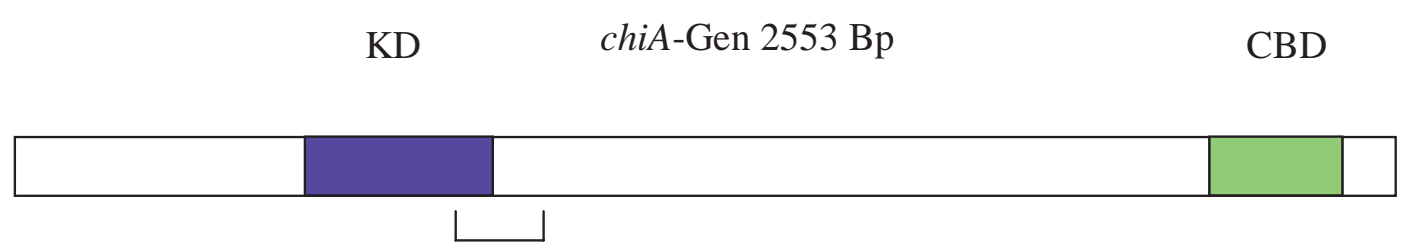

Sonde ChiA220

Sonde ChiA1300

Sonde ChiA2500

C

$\mathrm{KD}$

chiB-Gen $1800 \mathrm{Bp}$

CBD

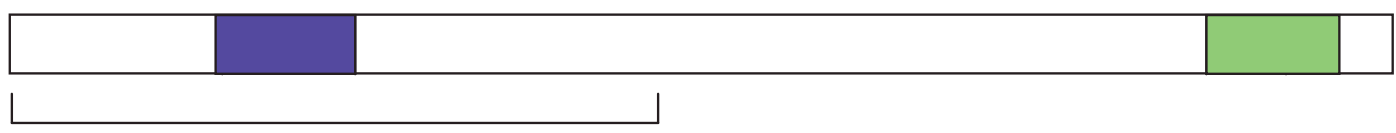

Sonde $C h i B 1000$

\section{Abb. 9: Schematische Darstellung der abgeleiteten Sonden}

$\mathrm{CBD}=$ Chitin-Bindedomäne (grün) des betreffenden Gens; $\mathrm{KD}=$ katalytische Domäne des betreffenden Gens (blau). Die für die Erstellung der Sonden verwendeten Oligonukleotide sind in 2.1 ersichtlich.

A: Abschnitt der aus dem chiC-Gen von S. griseus amplifizierten Sonde ChiC600 (5` $\rightarrow 3 ` 1-$ 600), Oligonukleotide ChiCcodfor/ChiC600

B: Drei Abschnitte der aus dem chiA-Gen von V. harveyi amplifizierte Sonden: ChiA220 $\left(5^{`} \rightarrow 3^{`}\right.$ 968-1164), Oligonukleotide VHF/VHR; ChiA1300 (5’ $\rightarrow 3^{\prime}$ 1170-2500), Oligonukleotide VH1170-VH2500; ChiA2500 ( $\left.5^{\prime} \rightarrow 3^{\prime} 1-2542\right)$, Oligonukleotide VH1/VH2542

C: Abschnitt der aus dem chiB-Gen von B. licheniformis amplifizierten Sonde ChiB1020 $\left(5^{\prime} \rightarrow 3^{\prime} 1-1020\right)$ 
Diese auf dem beschriebenem Wege erstellten Sonden kamen zudem bei der Koloniehybridisierung zum Einsatz (s. 3.6). Die verwendeten Sonden und die Oligonukleotide, mit denen sie erstellt wurden, sind in Tabelle 13 aufgelistet. Zudem ist der Tabelle zu entnehmen, mit welcher mit Restriktionsenzymen geschnittener chromosomaler DNA aus den Isolaten die jeweilige Sonde hybridisierte. Eine Hybridisierung zwischen Sonde und chromosomaler DNA ist nur möglich, wenn sich Ähnlichkeiten innerhalb der DNASequenzen zwischen Sonde und Ziel-Gen finden. Die aus dem chiA-Gen von $V$. harveyi abgeleitete Sonde ChiA220 (s. Tab. 13 und Abb. 9) wurde bereits von anderen Arbeitsgruppen mit Erfolg als Sonde zur Detektion von chiA-Genen eingesetzt (RAMAIAH et al., 2000).

Durch die dabei erreichte Identifizierung von spezifischen DNA-Fragmenten, die die Chitinasegene umfaßten, wird die angestrebte Klonierung dieser Gene erleichtert, da durch die „Southern“ Blot-Analyse die Ähnlichkeit der Chitinasegene der Isolate zu bereits bekannten Genen ermittelt werden kann. So ist die Sequenz und die Größe des zu klonierenden Gens abschätzbar. Im Rahmen dieser Untersuchungen konnten Chitinasegeneenthaltende DNA-Fragmente bei vier Organismen lokalisiert werden (siehe Abb. 10).

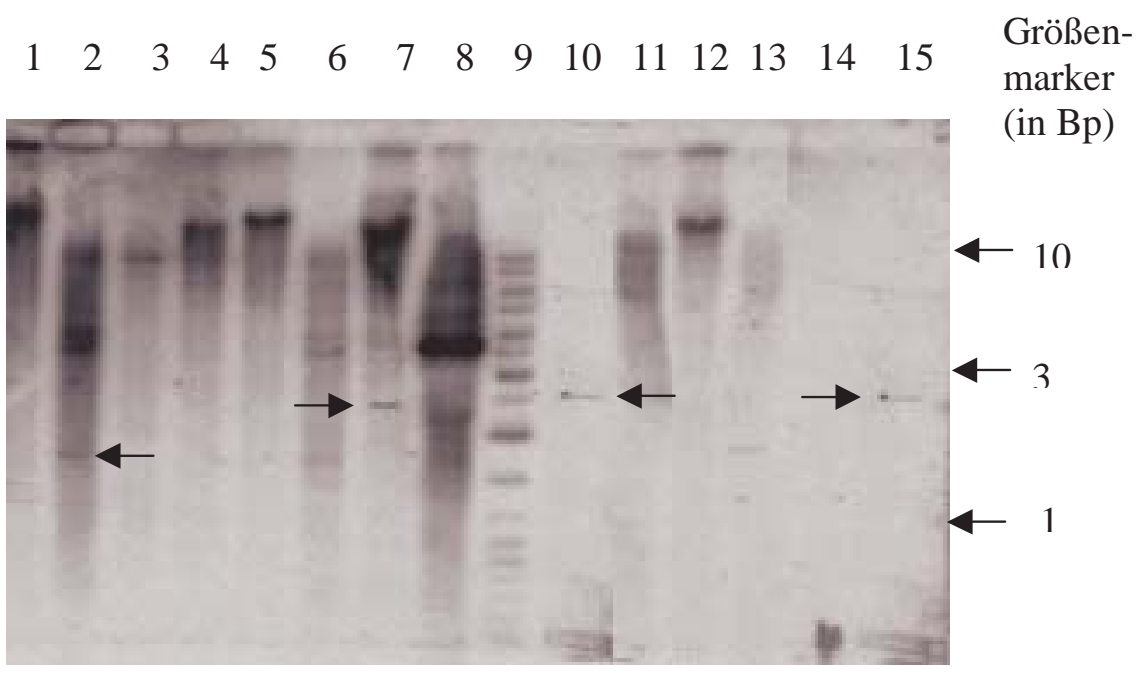

\begin{abstract}
Abb. 10: „Southern"-Blot Analyse von mit Restriktionsenzymen geschnittener chromosomaler DNA der Isolate WG1, SE1, E2 und SL3 mit Sonde (ChiA220) aus $V$. harveyi sowie des Isolates WG3 mit Sonde aus $S$. griseus
\end{abstract}

Spuren 1-3: Isolat SL3 nach Restriktionsverdau mit PstI, HindIII und EcoRI Spur 4-7: SE1 nach Restriktionsverdau mit BamHI PstI HindIII und BgIII Spur 8: Positivkontrolle mit Restriktionsverdau HindIII von V. harveyi Spur 9: Größenmarker Spur 10: WG1 nach Restriktionsverdau mit HindIII Spur 11-12: SL3 nach Restriktionsverdau mit SacI und BamHI Spur 13-15: WG3 nach Restriktionsverdau mit PstI BglII und SacI 
(Fortsetzung Abb. 10)

Lokalisierte Chitinasegene sind anhand von Banden innerhalb der aufgetrennten DNA-Spuren ersichtlich. Drei Banden sind als Beispiele mit Pfeilen markiert

So ließ sich zeigen, dass das Chitinase-Gen aus dem Isolat WG3 Ähnlichkeiten zum chiC-

Gen aus S. griseus und das Gen aus WG1, SE1 und SL3 zum chiA-Gen aus V. harveyi aufwiesen (s. Tab. 13). Keine der eingesetzten Sonden hybridisierte mit dem Chitinasegen aus E2. Dieses konnte somit keiner der als Sonde eingesetzten bekannten Chitinasen zugeordnet werden.

Tabelle 13: Für die „Southern“-Blot-Analyse eingesetzte Sonden und detektiertes Signal bei chromosomaler DNA aus den Isolaten

\begin{tabular}{|c|c|c|c|}
\hline $\begin{array}{l}\text { Sonde aus partiell } \\
\text { kloniertem Chitinasegen }\end{array}$ & $\begin{array}{l}\text { Für Sonde ver- } \\
\text { wendete Oligo- } \\
\text { nukleotide }\end{array}$ & $\begin{array}{l}\text { Größe der } \\
\text { Sonde in Bp }\end{array}$ & $\begin{array}{l}\text { Erfolgte Hybridisierung } \\
\text { mit verdauter DNA aus } \\
\text { Isolat und Größe des } \\
\text { erhaltenen Fragments in } \\
\text { kBp }\end{array}$ \\
\hline $\begin{array}{l}\text { ChiC600 Streptomyces } \\
\text { griseus }\end{array}$ & $\begin{array}{l}\text { ChiCcod.for/ } \\
\text { ChiC600rev }\end{array}$ & 600 & $\begin{array}{c}\text { WG3 1,8 (BglII) } \\
\text { 2,5 (SacI) }\end{array}$ \\
\hline ChiA220 Vibrio harveyi & VhF/VhR & 220 & $\begin{array}{l}\text { SE1 2,5 (BglII) und 3,5 } \\
\text { (PstI), SL3 2,0 (HindIII), } \\
\text { WG1 2,5 (HindIII) }\end{array}$ \\
\hline ChiA1300 Vibrio harveyi & VH1170-VH2500 & 1300 & $\begin{array}{c}\text { SE1 2,5 (BglII) und 3,5 } \\
\text { (Pst I), SL3 2,0 (HindIII), } \\
\text { WG1 2,5 (HindIII) }\end{array}$ \\
\hline ChiA2500 & Vh1/Vh2542 & 2500 & $\begin{array}{l}\text { SE1 3,0 (Bgl II) und 4,0 } \\
\text { (Pst I), SL3 2,5 (HindIII), } \\
\text { WG1 3,0 (HindIII) }\end{array}$ \\
\hline $\begin{array}{l}\text { ChiB1000 Bacillus } \\
\text { licheniformis }\end{array}$ & BL1/BL1000rev & 1020 & - \\
\hline
\end{tabular}




\subsection{Klonierung der Chitinasegene über Kolonie-Hybridisierung}

Zur Identifizierung der Chitinasegene der vier Isolate SE1, SL3 und WG1, die durch „Southern“ Blot-Analyse identifiziert werden konnten (s. 3.5), wurde die DNA der Organismen extrahiert, mit den Restriktionsenzymen behandelt mit denen beim „Southern“ Blot ein Signal detektiert worden war und mit Hilfe eines Saccharose-Gradienten (s. 2.8.4) größenfraktioniert.

Nach Größenfraktionierung der verdauten chromosomalen DNA der jeweiligen Isolate wurden die Fraktionen einer Dot-Blot-Analyse (s. 2.12.3) unterzogen. Dabei werden die Fraktionen mit den erwähnten Sonden hybridisiert. Auf diese Weise ließ sich feststellen, welche Fraktionen das Chitinase-Gen enthielten. So wird das Klonieren des Zielgens erleichtert. Zudem wurden für die Dot-Blot-Analyse homologe Sonden aus der chromosomalen DNA von WG1, SL3 und SE1 verwendet. Um diese zu erstellen wurde mit Hilfe der PCR von jedem dieser Isolate ein 220 Bp umfassendes Teilstück des jeweiligen Chitinasegens kloniert. Als Oligonukleotide wurden dazu diejenigen verwendet, mit denen auch die 220 Bp umfassende Sonde ChiA220 aus V. harveyi (s. Tab. 13) für den „Southern“Blot erstellt worden war. In allen drei Fällen waren diese homologen Sonden zu ca. $90 \%$ identisch mit der amplifizierten Sonde ChiA220. Die dabei ein Signal gebenden Fraktionen wurden für die Ligation in den analog geschnittenen Vektor pBluescript $\mathrm{SK}^{+}$eingesetzt und anschließend in E. coli transformiert. Die so erhaltenen Klone wurden mittels Koloniehybridisierung (siehe 2.12.4) mit den für die Isolate spezifischen homologen Sonden auf das Vorhandensein von Chitinase-Genen hin durchmustert und analysiert (s. Abb. 11 und 12).

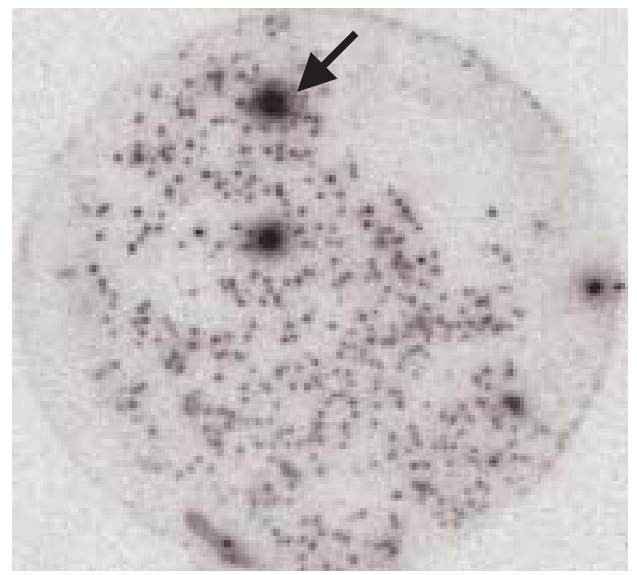

\section{Abb. 11: E. coli-Klone mit SE1-Inserts nach Kolonie-Hybridisierung}

E. coli-Klone, die das Chitinasegen von SE1 aufweisen, sind anhand ihrer vertärkten Strahlung (siehe Pfeil) zu erkennen. 
Die rekombinanten Plasmide aus den Klonen, die auch im zweiten Test ein Signal aufwiesen wurden isoliert und sequenziert.

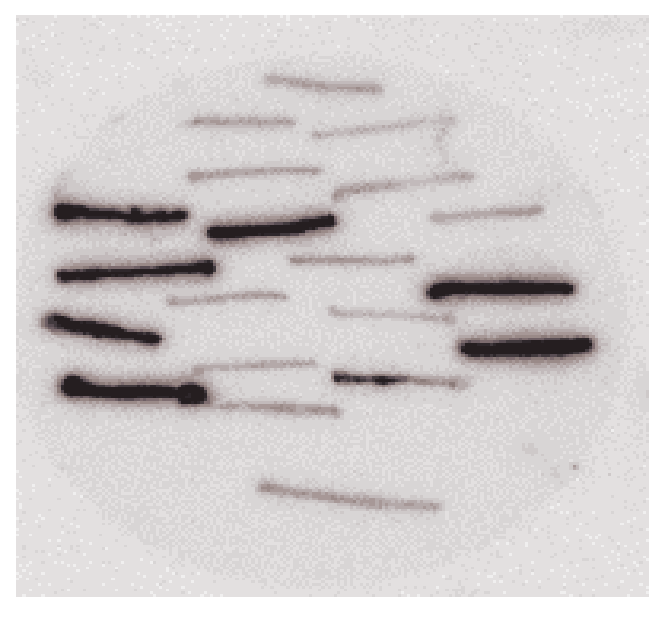

\section{Abb. 12: Identifizierung positiver Klone von SE1 nach Vereinzelung auf einer neuen Agarplatte und nochmaliger Hybridisierung}

Bei der chromosomalen DNA aus WG1, SE1 und SL3 wurde zunächst wie erwähnt eine homologe Sonde eingesetzt, die aus dem Chitinasegen von $V$. harveyi abgeleitet wurde und 220 Bp umfasste (s. Tab. 13). Die daraufhin ein Signal gebenden Klone zeigten nach Sequenzierung keinerlei Homologie zu Chitinasen sondern nur zu Klonierungsvektoren. Weitere Untersuchungen belegten, dass die Sonde mit dem Vektor pSK hybridisierte. Daraufhin wurde die Sonde durch eine 1300 Bp und eine 2500 Bp umfassende Sonde aus dem Chitinasegen von V. harveyi (s. Tab. 13) ersetzt (ChiA1300 und ChiA2500), die diesen unerwünschten Effekt nicht aufwiesen. Trotz der Durchmusterung der in Tab. 14 angegeben Zahl an Klonen, konnten nur bei SE1 ein positiver Klon detektiert werden.

Tabelle 14: Resultat der Koloniehybridisierung mit Klonen aus den Isolaten

\begin{tabular}{|c|c|c|c|c|}
\hline Isolat & $\begin{array}{c}\text { Zahl der } \\
\text { erhaltenen Klone }\end{array}$ & $\begin{array}{c}\text { Durchschnittliche } \\
\text { Insertgröße }\end{array}$ & $\begin{array}{c}\text { Anteil der } \\
\text { Plasmide mit } \\
\text { Insert }\end{array}$ & $\begin{array}{c}\text { Bezeichnung des } \\
\text { Klons und Größe } \\
\text { des Inserts }\end{array}$ \\
\hline E2 & 5000 & 2,0 & $75 \%$ & - \\
\hline SE1 & 7000 & 2,6 & $70 \%$ & $\mathrm{pSE} / 1120 \mathrm{Bp}$ \\
\hline WG1 & 10000 & 2,5 & $65 \%$ & - \\
\hline
\end{tabular}

Die Insertgröße variierte bei allen Klonen zwischen 1 und 5 kBp, der Hauptanteil lag jedoch 
unterhalb von $3 \mathrm{kBp}$. Dadurch ergab sich eine durchschnittliche Insertgröße von 2,0 kBp bei E2, 2,5 bei WG1 und 2,6 kBp bei SE1. Als Berechnungsgrundlage für das Anlegen einer vollständigen genomischen Genbank aus einem Organismus, diente die in Abb. 12 dargestellten Formel (BLATTNER et al., 1997).

$$
\mathrm{N}=\frac{\ln (1-\mathrm{P})}{\ln (1-\mathrm{f})}
$$

\section{Abb. 13: Formel zur Berechnung einer statistisch vollständigen Genbank}

Als Berechnungsgrundlage diente in Anlehnung an das E. coli-Genom eine Größe von 4700 kBp.

$\mathrm{P}=$ Wahrscheinlichkeit des Vorkommens eines Gens in der Genbank

$\mathrm{F}=$ Verhältnis der durchschnittlichen Größe der eingebauten DNA zur Größe des Gesamtgenoms

$\mathrm{N}=$ Zahl der Plasmid-Klone

Bei der folgenden Berechnung wurde eine Genomgröße für die Isolate angenommen, die der Größe des E. coli-Genoms von 4700 kBp entsprach (BLATTNER et al., 1997). Die Formel geht von einer Gengröße von $1 \mathrm{kBp}$ aus. Das bedeutet, das von der angelegten Genbank aus E2 14000 Klone durchmustert werden mußten, um mit einer 99,99 \% Wahrscheinlichkeit davon auszugehen, dass das gesuchte Gen innerhalb der Genbank vorlag. Bei SE1 und WG1 wären dies ca. 11000 Klone. Dabei ist jedoch zu berücksichtigen, das die Berechnung von einem Gen von 1 kBp ausgeht. Die gesuchten Chitinase-Gene wurden jedoch auf ca. 2500 Bp eingeschätzt, da die Chitinase-Gene beider Isolate Ähnlichkeiten zum 2,5 kBp umfassenden chiA-Gen aus V. harveyi aufwiesen (s. 3.5). Aufgrund dessen hätten bei den Genbanken wesentlich mehr als die berechnete Anzahl von Klonen erstellt und durchmustert werden müssen. Von einer weiteren Klonierung wurde jedoch nach der in Tabelle 14 angegebenen Zahl von Klonen Abstand genommen, da sich im Screening außergewöhnlich viele falschpositive Klone fanden. Es wurden allein beim Screening der Genbank aus WG1 ca. 40 falschpositive Klone detektiert. Trotz stringenterer Bedingungen beim Hybridisieren gelang es nicht, die Selektivität zu verbessern. Aufgrund dessen wurde die Koloniehybridisierung mit den genannten Sonden nicht fortgesetzt. Nur ein durch Hybridisierung identifizierter rekombinanter Vektor aus SE1, pSE, umfasste ein Insert von 1120 Bp., dessen Sequenzanalyse zeigte, dass dieses Ähnlichkeiten zum chiA-Gen aus $V$. harveyi aufwies (s. 3.5). Das chiA-Gen umfasste $2500 \mathrm{Bp}$, so dass anzunehmen war, dass das Chitinasegen nur zu 
etwa $45 \%$ kloniert vorlag. Die erhaltene 1120 Bp umfassende Sequenz des rekombinaten Plasmids pSE ist in Abb. 19 markiert. Die Signalsequenz ist partiell und die katalytische Domäne des Chitinasegens ist komplett auf dem Insert enthalten. Da das so partiell erhaltene Gen innerhalb des in 3.8.2 beschriebenen erhaltenen PCR-Produktes lag, wird hier auf eine weitere Charakterisierung des Inserts aus pSE verzichtet. Der fehlende Abschnitt des Gens sollte im folgenden aus SE1 mit Hilfe der PCR-Technik komplett kloniert werden (s. 3.8.2).

Da es nicht gelang, positive Klone bei der Durchmusterung von rekombinanten Vektoren mit Insert-DNA aus den Isolaten WG1 und SL3 mit Hilfe der Koloniehybridisierung zu erhalten, sollte ebenfalls versucht werden, die jeweiligen Chitinasegene mit Hilfe der PCR zu klonieren. Die Klonierung von DNA aus dem Isolat E2 in den Vektor pSK wurde unterlassen, da keine der getesteten Sonden eine Homologie zur Chitinase aus diesem Organismus aufwies. Aufgrund dessen bestand unter diesen Bedingungen keine Möglichkeit, über Koloniehybridisierung das Gen zu identifizieren. Bei der Identifizierung des Chitinasegens aus dem Isolat WG3 wurde ebenfalls auf die Methode der Koloniehybridisierung verzichtet, da es gelang, das Gen mit Hilfe der PCR zu amplifizieren und zu klonieren (s. 3.8.1).

Eine andere Möglichkeit Chitinase-Gene zu identifizieren, lag in der Durchmusterung von Standortgenbanken, die in unserer Arbeitsgruppe angelegt worden waren. Bei diesen wurden bei der Erstellung keine Organismen isoliert, sondern die Gesamt-DNA eines Habitates in geeignete Vektoren kloniert. Zur Durchmusterung dieser Standortgenbanken auf das Vorhandensein von Chitinasen wurde ebenfalls die Methode der Koloniehybridisierung angewandt. Hierbei wurden alle in Tab. 13 angegebenen Sonden (bis auf das 220 Bp Fragment ChiA220 aus $V$. harveyi) zusammen eingesetzt, um möglichst viele verschiedene Chitinasegene, die in den Standortgenbanken vorliegen könnten, zu identifizieren.

Für das Screening der im Vektor pBluescript $\mathrm{SK}^{+}$angelegten Plasmidgenbanken auf das Vorhandensein von Chitinase-Gene, wurden $2 \mu \mathrm{l}$ der jeweiligen Genbank in den E. coliStamm DH5 $\alpha$ transformiert und die Klone wie im Punkt 2.12.4 beschrieben hybridisiert. Dabei wurde darauf geachtet, das nicht mehr als ca. 600 Klone pro Platte anwuchsen, um zu gewährleisten, dass positive Klone sicher identifiziert werden können.

Etwa 800000 Klone aus diesen Standortgenbanken wurden so auf Chitinasen hin untersucht. 46 dabei identifizierte positive Klone zeigten eine verstärkte Strahlung. Jedoch wiesen diese nach Sequenzierung des rekombinaten Plasmides keinerlei Homologien zu Chitinasen auf.

Das keiner der getesteten Klone ein Chitinase-Gen trug, konnte zum einen daran liegen, dass die Anzahl der getesteten Klone nicht ausreichte. Zum anderen zeigte sich wie bei der Hybridisierung von Genbanken aus den Isolaten eine hohe Zahl von falsch-positiven Klonen. Dies weist ebenfalls daraufhin, das die Sonden unspezifisch banden. Das Screening wurde 
daher nach Durchmusterung der dargestellten Klone nicht fortgesetzt.

\subsection{Identifizierung und Charakterisierung von Chitinasegenen aus Isolaten und Anreicherungen durch PCR-Amplifikation}

Chitinasen lassen sich in die Familie 18 und 19 der Glykosyl-Hydrolasen einordnen. Bis zur Entdeckung der Chitinase C aus S. griseus HUT 6037 (OHNO et al. 1996) wurde davon ausgegangen, dass die Chitinasen der Familie 19 auschließlich Pflanzen vorbehalten sei. Untersuchungen verschiedener Arbeitsgruppen haben seitdem weitere bakterielle Chitinase der Familie 19 entdeckt (SAKUDA und NAGASAWA, 2003). Beim Sequenzvergleich der Chitinasen dieser beiden Familien sind keine signifikanten Ähnlichkeiten zueinander festzustellen. So liegt die Molekularmasse von Chitinasen der Familie 19 bei ca. 30 kDa, während diejenige von Chitinasen der Familie 18 ein breites Spektrum von bis zu 120 kDa erreichen kann (KOGA et al., 1999). Ein weiterer Unterschied der beiden Familien zueinander besteht darin, das die Chitin-Bindedomäne bei der Familie $19 \mathrm{~N}$-terminal und bei Chitinasen der Familie 18 C-terminal innerhalb des Proteins lokalisiert ist. Im folgenden sollen die klonierten Chitinasen den entsprechenden Familien zugeordnet und näher charakterisiert werden.

Eine andere Strategie zur Klonierung der Chitinasen aus den Isolaten lag außer in der Koloniehybridisierung in der direkten Amplifikation der Chitinasegene. Aufgrund der in 3.5 beschriebenen „Southern“-Blot-Methode konnten den Isolaten SE1, SL3, WG1 und WG3 Ähnlichkeiten zu bereits bekannten Chitinase-Genen zugeordnet werden. Das Isolat WG3 wies dabei Ähnlichkeiten zum chiC-Gen aus S. griseus auf. Beim chiC-Gen handelte es sich um eine Chitinase der Familie 19 der Glykosyl-Hydrolasen. Aus der bekannten Sequenz des chiC-Gens aus S. griseus HUT6037 wurden daraufhin Oligonukleotide abgeleitet, die den gesamten Bereich des erwarteten Zielgenes aus dem Isolat abdecken und somit eine Amplifikation ermöglichen sollten.

Die Chitinase-Gene aus SE1, SL3 und WG1 zeigten nach „Southern“-Blot Analyse Ähnlichkeiten zum chiA-Gen aus V. harveyi (s. 3.5). Diese Chitinase ist ein Verterter der Familie 18 der Glykosyl-Hydrolasen. Aus dem chiA-Gen wurden daraufhin Oligonukleotide abgeleitet, um die Chitinasen aus diesen drei Isolaten zu amplifizieren.

Bei der Suche nach Chitinasen aus Anreicherungskulturen wurde die DNA direkt aus den Kulturen extrahiert und mit PCR auf Chitinase-Gene durchsucht. Dazu wurden die erwähnten 
Oligonukleotide aus dem chiC-Gen und dem chiA-Gen verwendet. Zudem wurden aus dem chiB-Gen aus B. licheniformis Oligonukleotide abgeleitet, die die Amplifikation eines in der Anreicherungskultur vorliegenden $c h i B-G e n s$ ermöglichen sollten.

\subsubsection{Amplifikation und Charakterisierung des Chitinasegens aus WG3}

Für die Klonierung des Chitinase-Gens aus dem Isolat WG3 wurden die Oligonukleotide ChiCcodfor/ChiCcodrev (s. 2.1) aus dem chiC-Gen von S. griseus HUT6037 abgeleitet. Bei den folgenden Reaktionen konnte ein PCR-Produkt von ca. 900 Bp amplifiziert und sequenziert werden (s. Abb. 14). Das chiC-Gen aus S. griseus HUT6037 wies eine Größe von 890 Bp auf, so dass die Größe des PCR-Produktes der erwarteten entsprach.

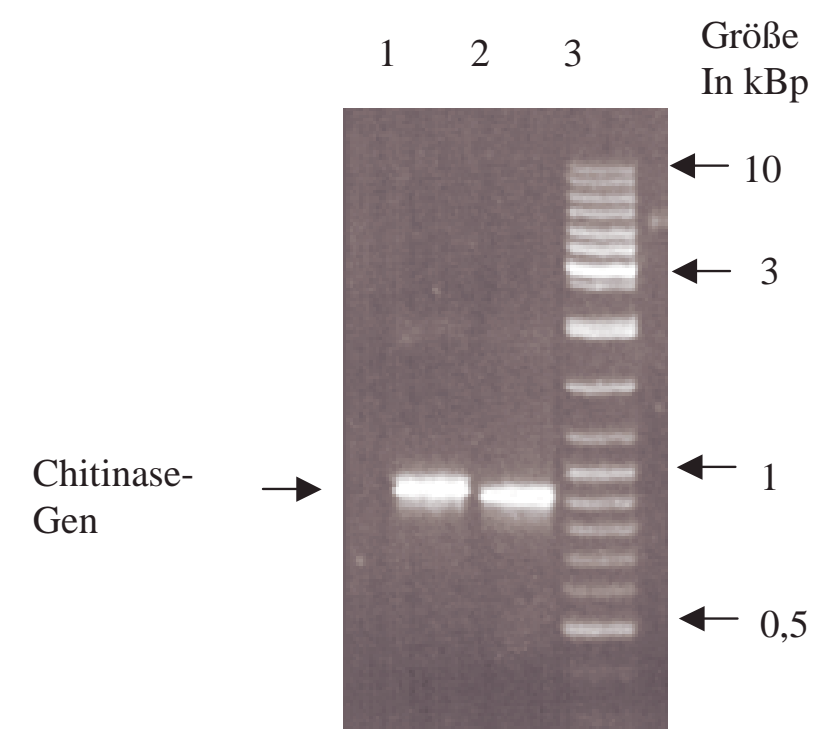

\section{Abb. 14: Amplifikation des Chitinasegens aus dem Isolat WG3}

Spur 1 und 2: Amplifiziertes Chitinase-Gen aus WG3

Spur: Größenmarker

Nach Klonierung des Produktes in den Vektor pCR2.1 TOPO wurde der rekombinate Vektor als pWG3 bezeichnet. Das Insert umfasste $900 \mathrm{Bp}$ und die aus der DNA-Sequenz abgeleitete Aminosäuresequenz wies eine Molekularmasse von 31 kDa auf. Die Signalsequenz umfasste 36 Aminosäuren, gefolgt von der N-terminalen Chitin-Bindedomäne in der Position 37-88. Die katalytische Domäne befand sich im Abschnitt 89-301 der Aminosäuresequenz (s. Abb. $15)$. 


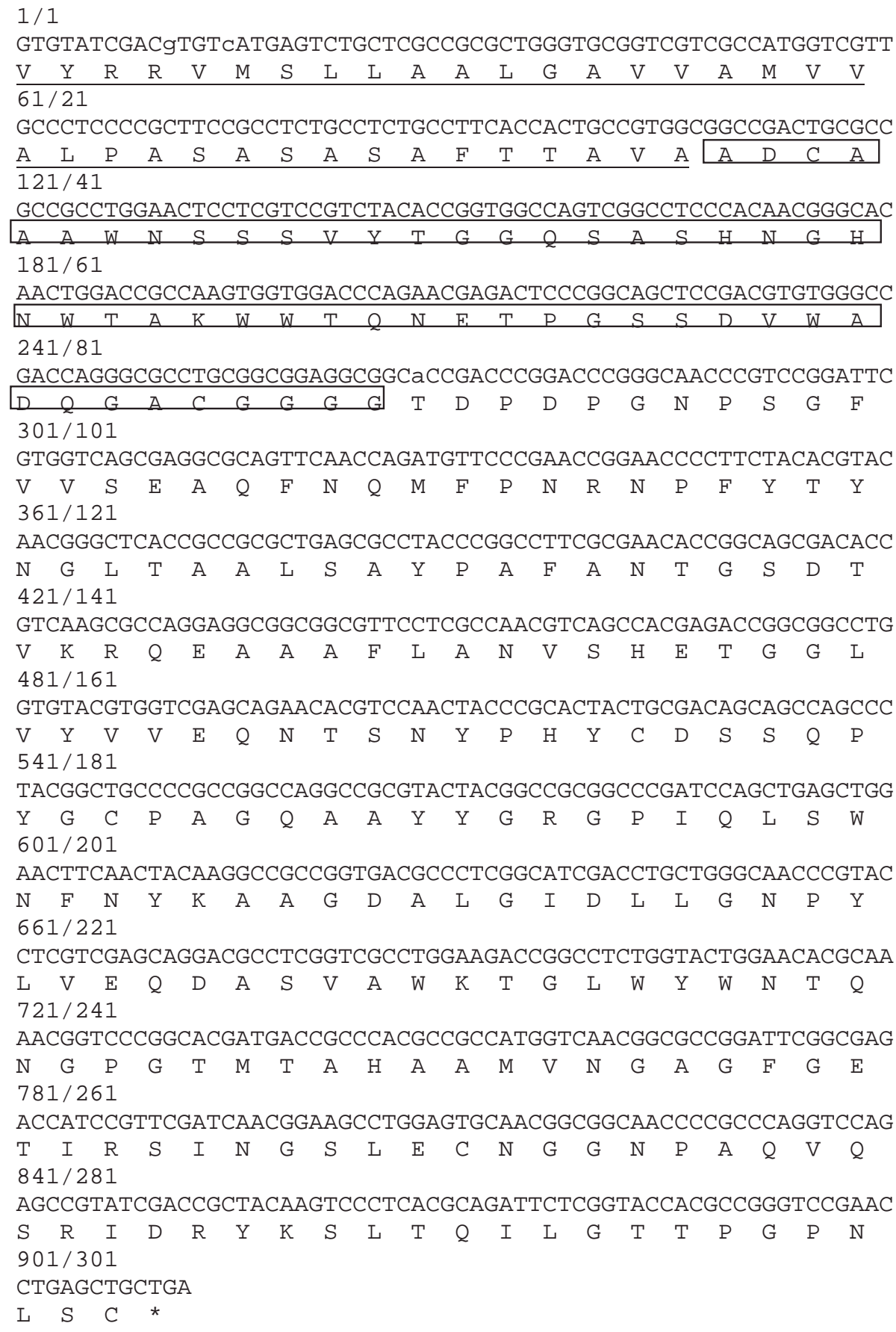

\section{Abb. 15: DNA-Sequenz des Inserts von pWG3}

Gezeigt ist der DNA-Strang vom 5'-zum 3`-Ende. Die aus dem Gen abgeleitete Aminosäuresequenz ist im Ein-Buchstaben-Code angegeben. Die N-terminale Signalsequenz ist unterstrichen und die folgende Chitin-Bindedomäne mit einem Rahmen versehen. Unmittelbar daran befindet sich die katalytische Domäne der Chitinase, deren Anfang mit einem Pfeil markiert ist. Der Stern symbolisiert das Stopkodon.

Diese Zuordnung konnte Sequenzvergleichen mit dem chiC-Gen aus S. griseus HUT6037 entnommen werden (OHNO et al. 1996), zu dem die aus dem Chitinase-Gen von WG3 
abgeleitete Aminosäuresequenz eine Ähnlichkeit von $76 \%$ aufwies. Beim Vergleich der DNA-Sequenz des Chitinase-Gens aus WG3 mit bekannten Chitinase-Genen konnte die größte Ähnlichkeiten zum chiIS-Gen aus S. sp. AJ9463 (SAKUDA und NAGASAWA, 2003) mit $88 \%$ festgestellt werden. Die abgeleitete Aminosäuresequenz des korrespondierenden Gens lag im Vergleich zur Chitinase IS bei $90 \%$ (s. Abb. 16). Daher wurde das ChitinaseGen aus WG3 als chiIS-Gen bezeichnet.

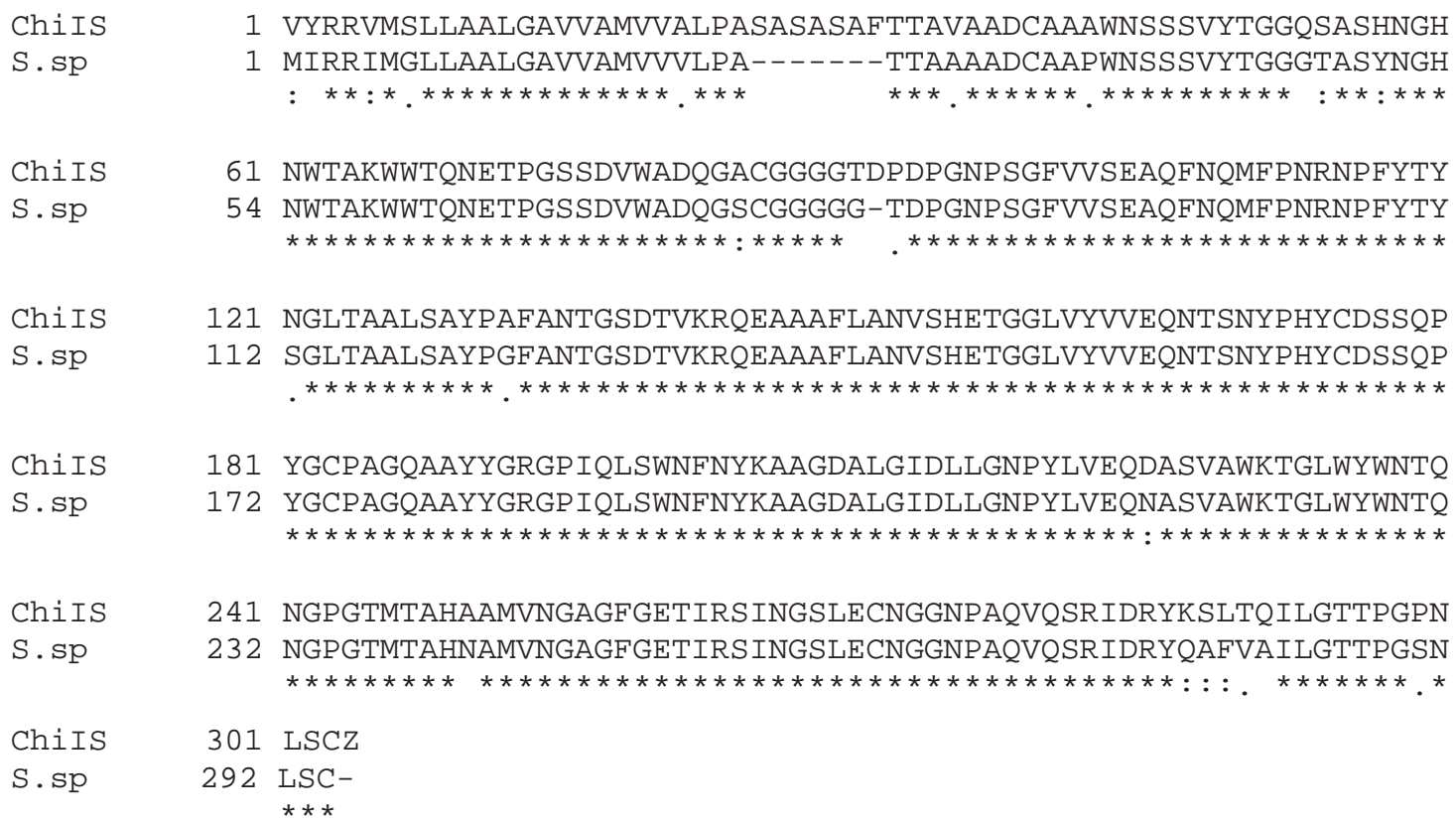

\section{Abb. 16: Vergleich der Aminosäuresequenzen der Chitinase IS aus WG3 und der Chitinase IS aus $S$. sp. AJ9463}

Die Übereinstimmung der Sequenzen betrug $90 \%$. Die in der Abb. dargestellte Sterne deuten identische Aminosäuren an, die Doppelpunkte und Punkte ähnliche Aminosäuren. S.sp = chiIS aus S.sp AJ9463 (AB104621); ChiIS= Chitinase aus dem Isolat WG3

Die Übereinstimmungen zur Chitinase C aus $S$. griseus HUT6037 und zur Chitinase IS aus $S$. s.p AJ9463, die beide in die Familie 19 der Glykosyl-Hydrolasen eingeordnet wurden, zeigte, das es sich bei der Chitinase IS aus WG3 ebenfalls um eine Chitinase der Familie 19 handelte. 
3.8.2

Amplifikation und Charakterisierung des Chitinasegens aus WG1, SL3 und SE1

Zur Amplifikation und anschließender Klonierung der Chitinasegene aus den Isolaten WG1, SE1 und SL3 wurde die jeweilige chromosomale DNA der Organismen extrahiert und für PCR eingesetzt (siehe 2.13). Oligonukleotide wurden aus dem chiA-Gen von $V$. harveyi abgeleitet (s. 3.5). Diese sollten zu einem PCR-Produkt führen, da bei allen drei Isolaten Ähnlichkeiten zum chiA-Gen über die „Southern“-Blot-Analyse gefunden wurden (s. 3.5). Aufgrund der Ermittelten Ähnlichkeiten der Chitinase-Gene aus SE1, SL3 und WG1 zum chiA-Gen aus $V$. harveyi, wurde erwartet, dass das Chitinasegen der drei Isolate ebenso wie das chiA-Gen ca. 2500 Bp umfassen müsste.

Zunächst wurden die Primer Vh1 und Vh 2542 (s. 2.1) eingesetzt, die aus der Anfangs- und der Endsequenz des gesamten chiA-Gens aus $V$. harveyi abgeleitet worden waren (s. Abb. 17B). Es ließ sich ein PCR-Produkt in der erwarteten Größe von 2500 Bp. bei der chromosomalen DNA von SE1 und WG1 amplifizieren. Nach Klonierung dieses Produktes in pCR2.1-TOPO und anschließender Sequenzierung ergab sich jedoch keinerlei Ähnlichkeit zu einer Chitinase. Daraufhin wurde die Oligonukleotide VH1/VH2500 aus dem chiA-Gen abgeleitet, um den Anfang des Gens bis über die C-terminale Chitin-Bindedomäne hinaus zu amplifizieren (s. Abb 17-C). Ebenso wurden die Oligonukleotide VH1/VH2300 verwendet (s. Abb. 17-D). Bei dieser PCR wurde der reverse $\left(3^{\prime} \rightarrow 5^{`}\right)$ Primer so gewählt, dass dieser im Endbereich der Chitin-Bindedomäne lag. PCR-Produkte konnten erhalten werden, die die erwartete Größe aufwiesen. Jedoch zeigte keines der DNA-Fragmente nach Sequenzierung eine Ähnlichkeit zu einem Chitinase-Gen.

Erst bei der Verwendung der Oligonukleotide VH1 und VHR (s. Abb. 17-E) konnte ein PCRProdukt von 1164 Bp bei WG1 und SE1 amplifiziert werden (Abb. 18). Diese erzielten PCRProdukte wurden in den Vektor pCR2.1 TOPO kloniert und die daraus resultierenden Konstrukte als pWG bzw. pSE1 bezeichnet (s. Tab. 15). Nach Sequenzierung der Inserts dieser beiden rekombinanten Vektoren konnte festgestellt werden, dass das Zielgen partiell kloniert worden war. Daraufhin wurde versucht, den fehlenden Rest des Gens mit der ChitinBindedomäne unter Verwendung des Oligonukleotid-Paar VH1140/VH2542 (s. Abb. 17-F) zu amplifizieren. Dabei konnte kein PCR-Produkt erhalten werden. Beim Versuch der Klonierung des chiA-Gens aus dem Isolat SL3 mittels PCR konnte bei allen in Abb. 17 erwähnten Oligonukleotiden kein PCR-Produkt erhalten werden. 
A

$\mathrm{KD}$

CBD

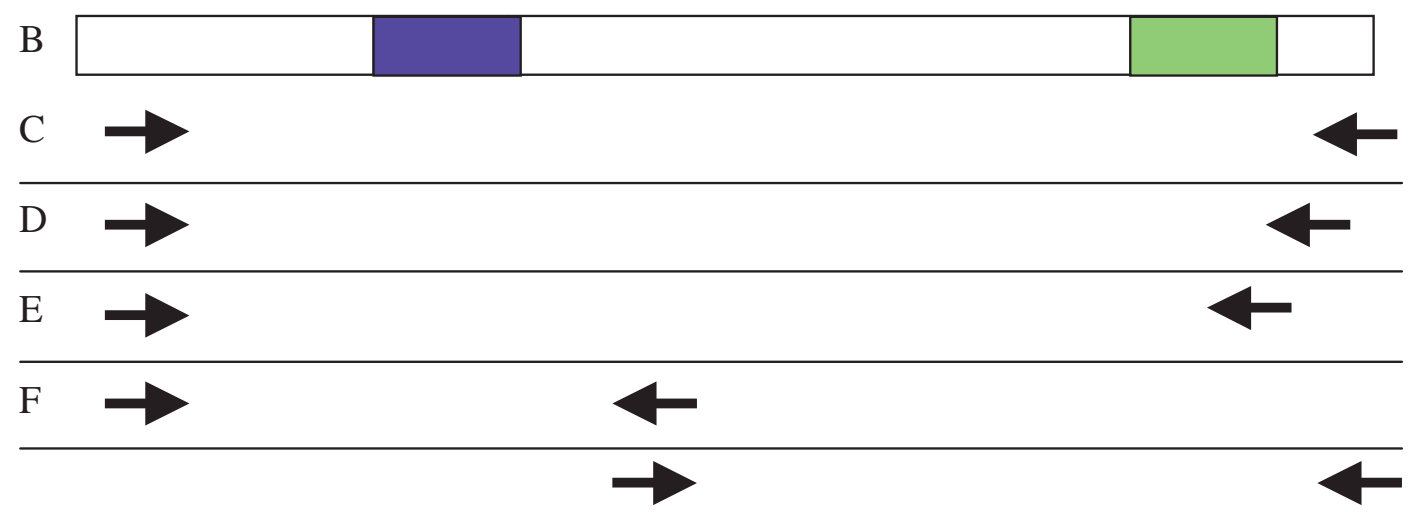

Abb. 17: Strategie zur Klonierung des chiA-Gens aus den Isolaten SL3, SE1 und WG3

A: chiA-Gen aus $V$. harveyi

$\mathrm{KD}=$ katalytische Domäne (blau); $\mathrm{CBD}=$ Chitin-Bindedomäne (grün)

Pfeile symbolisieren die als Primer eingesetzten Oligonukleotide

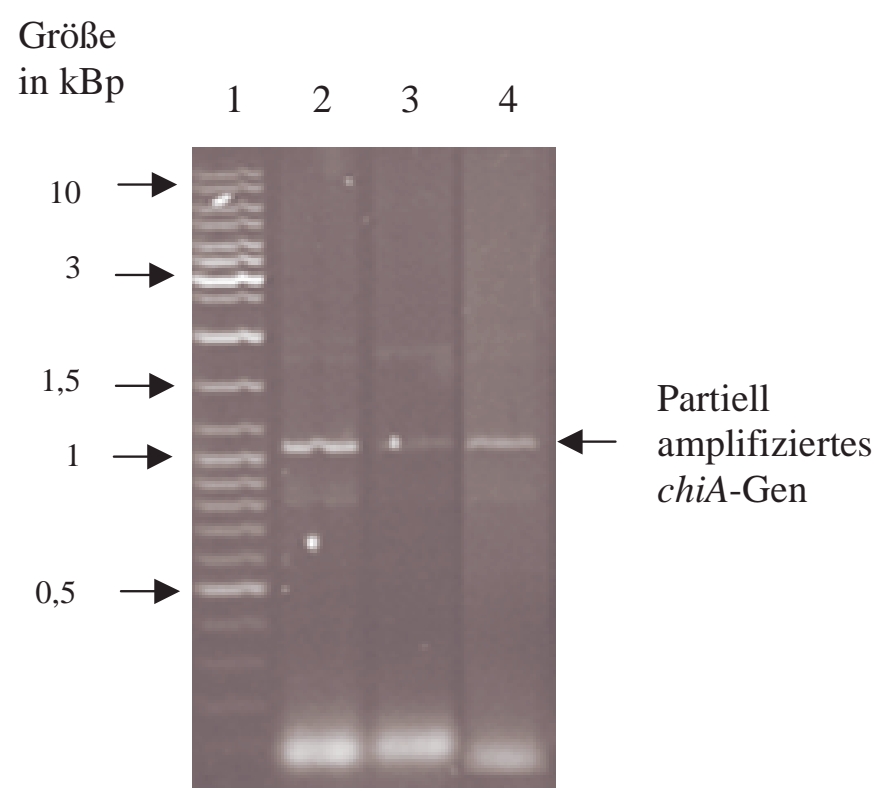

Abb. 18: Amplifikation von 1100 Bp des Chitinasegens aus WG1 und SE1 mittels PCR

Spur 1: Standardmarker

Spur 2 und 3: partiell amplifiziertes Chitinasegen aus WG1 von ca. $1100 \mathrm{Bp}$

Spur 4: partiell amplifiziertes Chitinasegen aus SE1 von ca. 1100 Bp

Aufgrund dieses Befundes gelang durch Einsatz der PCR nur die partielle Amplifikation des chiA-Gens aus SE1 und WG1. Die Sequenz des chiA-Gens aus SE1 ist in Abb. 19 und diejenige des chiA-Gens aus WG1 in Abb. 20 wiedergegeben. Der Sequenzabschnitt des partiell durch Koloniehybridisierung erhaltenen chiA-Gens aus dem Insert von pSE (s. 3.6), 
der innerhalb des Inserts aus pSE1 lag, ist dabei in Abb. 17 markiert. Das amplifizierte Gen umfasste $1164 \mathrm{Bp}$, welches für 388 Aminosäuren kodierte.

$1 / 1$

ATG ATT CGA TTT AAC CTA TGT GCA GCT GGG GTT GGC CTA GCA TTA TCT GGC GCG GCA AAC $61 / 21$

GCG GCT CCT ACC GCA CCA AGT ATC GAT ATG TAC GGT TCC AAC AAC CTG CAA TTT TCT AAA $\begin{array}{llllllllllllllllllllll}\mathrm{A} & \mathrm{A} & \mathrm{P} & \mathrm{T} & \mathrm{A} & \mathrm{P} & \mathrm{S} & \mathrm{I} & \mathrm{D} & \mathrm{M} & \mathrm{Y} & \mathrm{G} & \mathrm{S} & \mathrm{N} & \mathrm{N} & \mathrm{L} & \mathrm{Q} & \mathrm{F} & \mathrm{S} & \mathrm{K}\end{array}$ $121 / 41$

ATT GAG TTG GCA ATG GAA ACC ACA TCT GGC TAC AAC GTC ATG GTt AAg TAC CAT GAA CTA $\begin{array}{llllllllllllllllllllll}I & \mathrm{E} & \mathrm{L} & \mathrm{A} & \mathrm{M} & \mathrm{E} & \mathrm{T} & \mathrm{T} & \mathrm{S} & \mathrm{G} & \mathrm{Y} & \mathrm{N} & \mathrm{V} & \mathrm{M} & \mathrm{V} & \mathrm{K} & \mathrm{Y} & \mathrm{H} & \mathrm{E} & \mathrm{L}\end{array}$ $181 / 61$

GCC AAg AtC AAC GTG AAA tTC AAC CAg TGg AGC GGC ACA TCT GGC GAC ACt tAC AAC AtC $\begin{array}{lllllllllllllllllllll}A & K & I & N & V & K & F & N & Q & \text { W } & \text { S } & G & \text { T } & \text { S } & \text { G } & \text { D } & \text { T } & \text { Y } & \text { N } & \text { I }\end{array}$ $241 / 81$

TAT tTt GAT GGT GTT CAG GTT GCA ACT GGC CCT ATC ACT GGT AgC CAA ACC ACA GCG TCG $\begin{array}{lllllllllllllllllllllll}Y & F & D & G & V & Q & V & A & T & G & P & I & T & G & S & Q & T & T & A & S\end{array}$ $301 / 101$

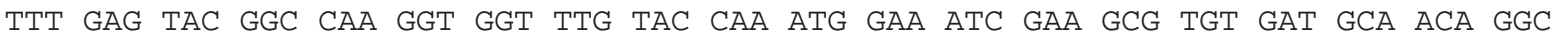
$\begin{array}{llllllllllllllllllllllll}\mathrm{F} & \mathrm{E} & \mathrm{Y} & \mathrm{G} & \mathrm{Q} & \mathrm{G} & \mathrm{G} & \mathrm{L} & \mathrm{Y} & \mathrm{Q} & \mathrm{M} & \mathrm{E} & \mathrm{I} & \mathrm{E} & \mathrm{A} & \mathrm{C} & \mathrm{D} & \mathrm{A} & \mathrm{T} & \mathrm{G}\end{array}$ $361 / 121$

TGT GCC AAg AGT GCA CCT GTA GAg ATt ACT ATC GCA GAT ACC GAT GGg tCT CAC TTG CCA $\begin{array}{lllllllllllllllllllll}\mathrm{C} & \mathrm{A} & \mathrm{K} & \mathrm{S} & \mathrm{A} & \mathrm{P} & \mathrm{V} & \mathrm{E} & \mathrm{I} & \mathrm{T} & \mathrm{I} & \mathrm{A} & \mathrm{D} & \mathrm{T} & \mathrm{D} & \mathrm{G} & \mathrm{S} & \mathrm{H} & \mathrm{L} & \mathrm{P}\end{array}$ $421 / 141$

CCT CTA ACC ATG AAT GTT GAC CCG AAC AAC AAA GCC TAC AAC ACA GAC CCA Agt GTC GTG $\begin{array}{lllllllllllllllllllll}\mathrm{P} & \mathrm{L} & \mathrm{T} & \mathrm{M} & \mathrm{N} & \mathrm{V} & \mathrm{D} & \mathrm{P} & \mathrm{N} & \mathrm{N} & \mathrm{K} & \mathrm{A} & \mathrm{Y} & \mathrm{N} & \mathrm{T} & \mathrm{D} & \mathrm{P} & \mathrm{S} & \mathrm{V} & \mathrm{V}\end{array}$ $481 / 161$

Atg GGT ACA TAC TTT GTt GAA TGg GGC ATC TAC GGC CGT GAT TAC ACt GTC GAC AAC ATG $\begin{array}{llllllllllllllllllllll}M & G & \text { T } & \text { Y } & \text { F } & \text { V } & \text { E } & \text { W } & \text { G } & \text { I } & \text { Y } & \text { G } & \text { R } & \text { D } & \text { Y } & \text { T } & \text { V } & \text { D } & \text { N } & \text { M }\end{array}$ $541 / 181$

CCA GTC GAC AAC CTA ACG CAC ATC CTT TAC GGC TTC ATt CCA ATt TGT Ggt CCA AAC GAA $\begin{array}{lllllllllllllllllllllll}\mathrm{P} & \mathrm{V} & \mathrm{D} & \mathrm{N} & \mathrm{L} & \mathrm{T} & \mathrm{H} & \mathrm{I} & \mathrm{L} & \mathrm{Y} & \mathrm{G} & \mathrm{F} & \mathrm{I} & \mathrm{P} & \mathrm{I} & \mathrm{C} & \mathrm{G} & \mathrm{P} & \mathrm{N} & \mathrm{E}\end{array}$ $601 / 201$

TCG GTG AAA TCG GTt GGC GGT AAC AGC TTC AAC GCA CTG CAA ACA GCA TGT CGC GGC GTG $\begin{array}{lllllllllllllllllllllll}\mathrm{S} & \mathrm{V} & \mathrm{K} & \mathrm{S} & \mathrm{V} & \mathrm{G} & \mathrm{G} & \mathrm{N} & \mathrm{S} & \mathrm{F} & \mathrm{N} & \mathrm{A} & \mathrm{L} & \mathrm{Q} & \mathrm{T} & \mathrm{A} & \mathrm{C} & \mathrm{R} & \mathrm{G} & \mathrm{V}\end{array}$ $661 / 221$

AAC GAC TAC GAA GTG GTT ATC CAT GAC CCA TGG GCA GCG TAC CAA AAg AgC TTC GCG CAA $\begin{array}{lllllllllllllllllllll}\mathrm{N} & \mathrm{D} & \mathrm{Y} & \mathrm{E} & \mathrm{V} & \mathrm{V} & \mathrm{I} & \mathrm{H} & \mathrm{D} & \mathrm{P} & \mathrm{W} & \mathrm{A} & \mathrm{A} & \mathrm{Y} & \mathrm{Q} & \mathrm{K} & \mathrm{S} & \mathrm{F} & \mathrm{A} & \mathrm{Q}\end{array}$ $721 / 241$

GCA GGC CAT GAg tAC AgC ACG CCG ATC AAg Ggt AAC tAt gCA Atg cta Atg gCg titg aAA $\begin{array}{lllllllllllllllllllllll}A & G & H & E & Y & S & \text { T } & \text { P } & \text { I } & \text { K } & \text { G } & \text { N } & \text { Y } & \text { A } & \text { M } & \text { L } & \text { M } & \text { A } & \text { L } & \text { K }\end{array}$ $781 / 261$

CAA CGT AAC CCT GAT CTA AAA ATC ATT CCA TCT ATC GGT GGT TGG ACA CTG TCT GAC CCA \begin{tabular}{lllllllllllllllllllllll}
\hline & $R$ & $N$ & $P$ & $D$ & $L$ & $K$ & $I$ & $I$ & $P$ & $S$ & $I$ & $G$ & $G$ & W & T & L & S & D & P \\
\hline
\end{tabular} $841 / 281$

TTC TTC GAT TTC GTT GAT AAA GCC AAC CGT GAC ACG TTT GTC GCG TCA GTT AAG AAA TTC \begin{tabular}{|lllllllllllllllllllll}
$\mathrm{F}$ & $\mathrm{F}$ & $\mathrm{D}$ & $\mathrm{F}$ & $\mathrm{V}$ & $\mathrm{D}$ & $\mathrm{K}$ & $\mathrm{A}$ & $\mathrm{N}$ & $\mathrm{R}$ & $\mathrm{D}$ & $\mathrm{T}$ & $\mathrm{F}$ & $\mathrm{V}$ & $\mathrm{A}$ & $\mathrm{S}$ & $\mathrm{V}$ & $\mathrm{K}$ & $\mathrm{K}$ & $\mathrm{F}$ \\
\hline
\end{tabular} $901 / 301$

CTG AAA ACG TGG AAG TTC TAC GAC GGT GTGGAC ATC GAT TGG GAA TTC CCT GGT GGC GGC \begin{tabular}{|llllllllllllllllllll}
\hline $\mathrm{L}$ & $\mathrm{K}$ & $\mathrm{T}$ & $\mathrm{W}$ & $\mathrm{K}$ & $\mathrm{F}$ & $\mathrm{Y}$ & $\mathrm{D}$ & $\mathrm{G}$ & $\mathrm{V}$ & $\mathrm{D}$ & $\mathrm{I}$ & $\mathrm{D}$ & $\mathrm{W}$ & $\mathrm{E}$ & $\mathrm{F}$ & $\mathrm{P}$ & $\mathrm{G}$ & $\mathrm{G}$ & $\mathrm{G}$ \\
\hline
\end{tabular} $961 / 321$

GGC GCT GCA GCT GAT AAg GGT GAC CCA GTA AAC GAT GgT CCA GCA TAC ATC GCG TTG ATG $\begin{array}{llllllllllllllllllllll}G & A & A & A & D & \text { K } & \text { G } & \text { D } & \text { P } & \text { V } & \text { N } & \text { D } & \text { G } & \text { P } & \text { A } & \text { Y } & \text { I } & \text { A } & \text { L } & M\end{array}$ $1021 / 341$ CGT GAA CTG CGC GCA ATG CTT GAT GAg CTA GAA GCA GAA ACT GGC CGT ACT TAC GAG CTA $\begin{array}{lllllllllllllllllllll}\mathrm{R} & \mathrm{E} & \mathrm{L} & \mathrm{R} & \mathrm{A} & \mathrm{M} & \mathrm{L} & \mathrm{D} & \mathrm{E} & \mathrm{L} & \mathrm{E} & \mathrm{A} & \mathrm{E} & \mathrm{T} & \mathrm{G} & \mathrm{R} & \mathrm{T} & \mathrm{Y} & \mathrm{E} & \mathrm{L}\end{array}$

$1081 / 361$ ACT TCA GCA ATC GGT GTG GGT TAC GAC AAA ATt GAA CAC GTT GAT TAC GCA AAC GCA GTT $\begin{array}{lllllllllllllllllllll}\mathrm{T} & \mathrm{S} & \mathrm{A} & \mathrm{I} & \mathrm{G} & \mathrm{V} & \mathrm{G} & \mathrm{Y} & \mathrm{D} & \mathrm{K} & \mathrm{I} & \mathrm{E} & \mathrm{H} & \mathrm{V} & \mathrm{D} & \mathrm{Y} & \mathrm{A} & \mathrm{N} & \mathrm{A} & \mathrm{V}\end{array}$ 
$\begin{array}{lllllllll}1141 / 381 & & & & & & \\ \text { CAG } & \text { TAC } & \text { ATG } & \text { GAC } & \text { TAC } & \text { ATC } & \text { TTT } & \text { GCG A } \\ \text { Q } & \text { Y } & \text { M } & \text { D } & \text { Y } & \text { I } & \text { F } & \text { A }\end{array}$

\section{Abb. 19: Sequenz des partiell klonierten $C h i A-G e n s$ aus SE1}

Gezeigt ist der DNA-Strang vom 5`zum 3`-Ende. Die aus dem Gen abgeleitete Aminosäuresequenz ist im Ein-Buchstaben-Code angegeben. Die Signalsequenz ist unterstrichen und die katalytische Domäne ist mit einem Rahmen versehen. Der Stern symbolisiert das Startkodon. Der Pfeil markieren den Start- und Endpunkt des Inserts aus pSE. Die aus dem Gen abgeleitete Aminosäuresequenz kodierte für ein Protein von 41 kDa.

Der so erhaltene Teilbereich des Chitinasegens aus dem Isolat verfügt komplett über die Signalsequenz und die katalytische Domäne. Die Signalsequenz umfasste 24 und die katalytische Domäne 57 Aminosäuren. Beim Vergleich der DNA-Sequenz des partiell klonierten Chitinasegens aus SE1 zeigte sich ebenso wie beim Vergleich der abgeleiteten Aminosäuresequenz des $41 \mathrm{kDa}$ umfassenden partiellen Proteins eine hohe Übereinstimmung mit dem der Chitinase A aus V. harveyi, einer Chitinase der Familie 18 der GlykosylHydrolasen.

Das 1164 Bp umfassende Insert aus pWG1 (s. Abb. 20) wies ebenfalls komplett Signalsequenz und die katalytische Domäne auf. Auch hier umfasste die Signalsequenz 24 und die katalytische Domäne 57 Aminosäuren.

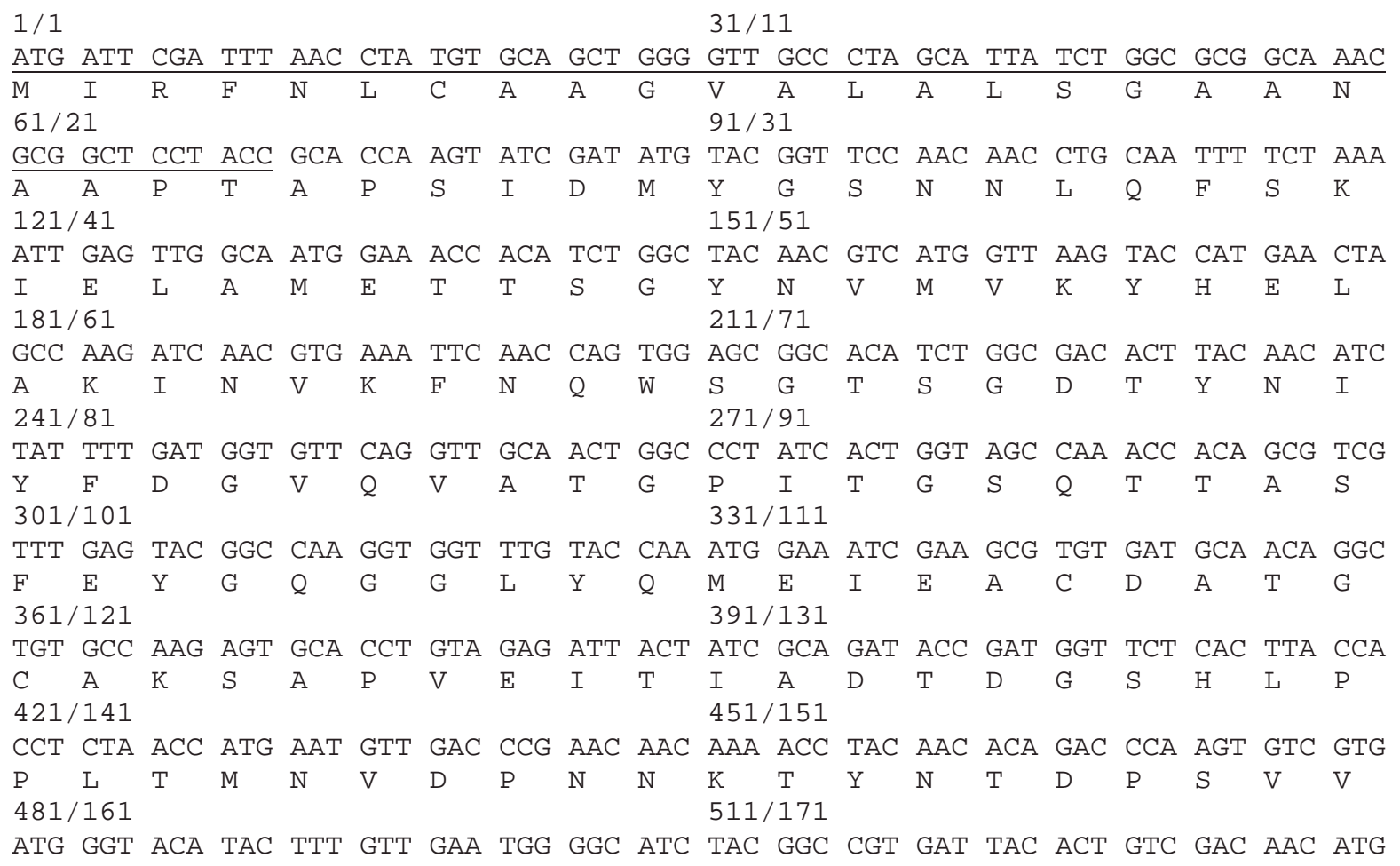




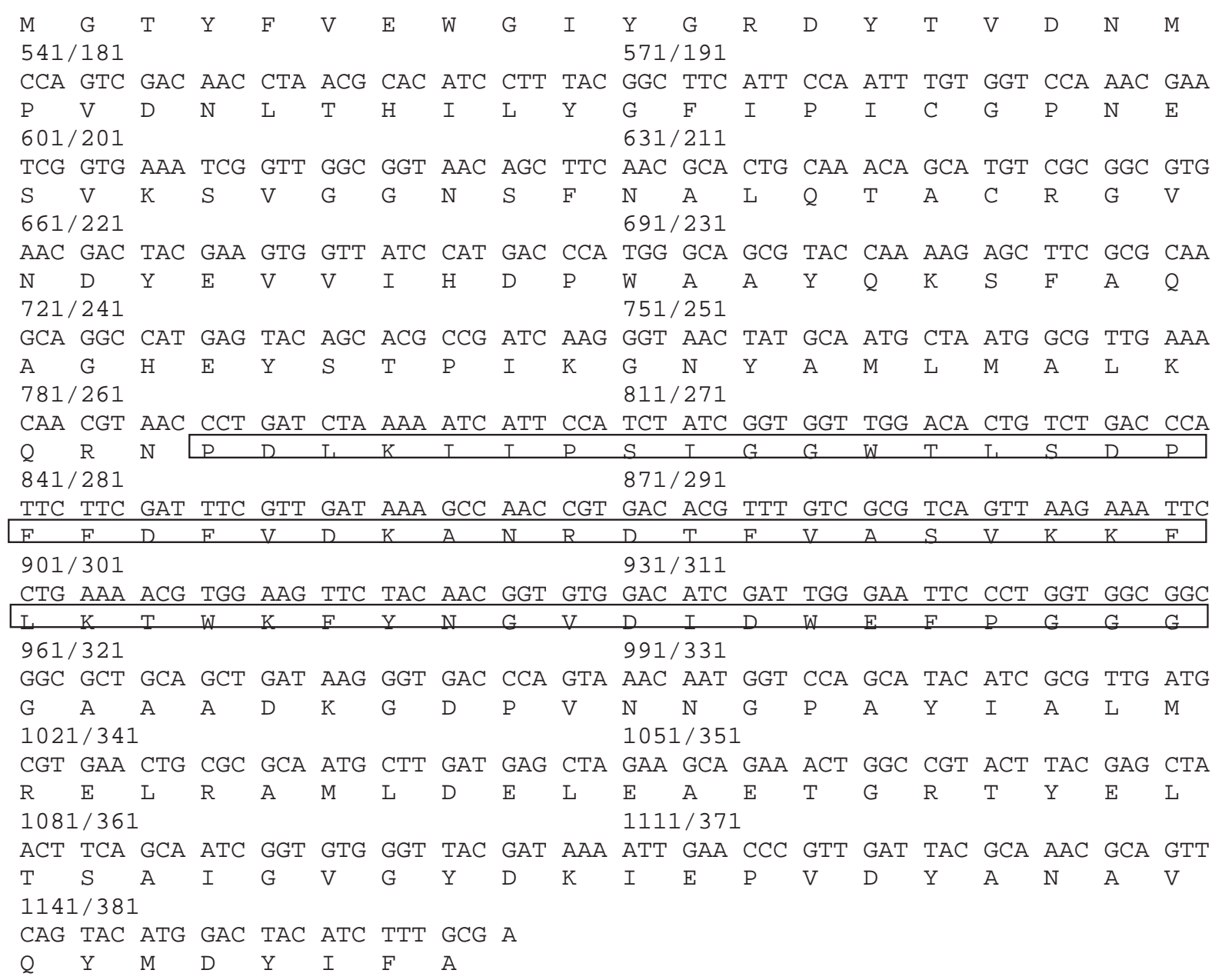

\section{Abb. 20: Sequenz des partiell klonierten chiA-Gens aus WG1}

Gezeigt ist der DNA-Strang vom 5`zum 3`-Ende. Die aus dem Gen abgeleitete Aminosäuresequenz ist im Ein-Buchstaben-Kode angegeben. Die Signalsequenz ist unterstrichen und die katalytische Domäne ist mit einem Rahmen versehen. Der Stern symbolisiert das Startkodon.

Das Insert aus pWG1 wurde ebenfalls auf seine Ähnlichkeit zu bekannten Chitinasen hin untersucht. Dabei zeigte sich eine große Übereinstimmung zum chiA-Gen aus $V$. harveyi. In Abb. 21 wurde ein Vergleich der partiell klonierten Chitinasen aus SE1 und WG3 zur Chitinase A aus $V$. harveyi, durchgeführt.

WG1

SE1

$\mathrm{VH}$

WG1

SE1

$\mathrm{VH}$
1 MIRFNLCAAGVALALSGAANAAPTAP SIDMYGSNNLQFSKIELAMETTSGYNVMVKYHEL

1 MIRFNLCAAGVGLALSGAANAAP TAP S IDMYGSNNLQF SKIELAMETTSGYNVMVKYHEL

1 MIRFNLCAAGVALALSGAANAAPTAP S IDMYGSNNLQF SKIELAMETTSGYNDMVKYHEL

61 AKINVKFNQWSGTSGDTYNIYFDGVQVATGP ITGSQTTASFEYGQGGLYQMEIEACDATG 61 AKINVKFNQWSGTSGDTYNIYFDGVQVATGPITGSQTTASFEYGQGGLYQMEIEACDATG

61 AKIKVKFNQWSGTSGDTYNVYFDGVKVATGAITGSQTTASFEYGQGGLYQMEIEACDATG

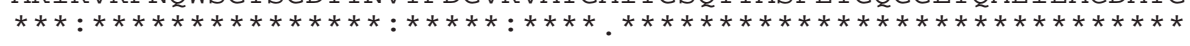




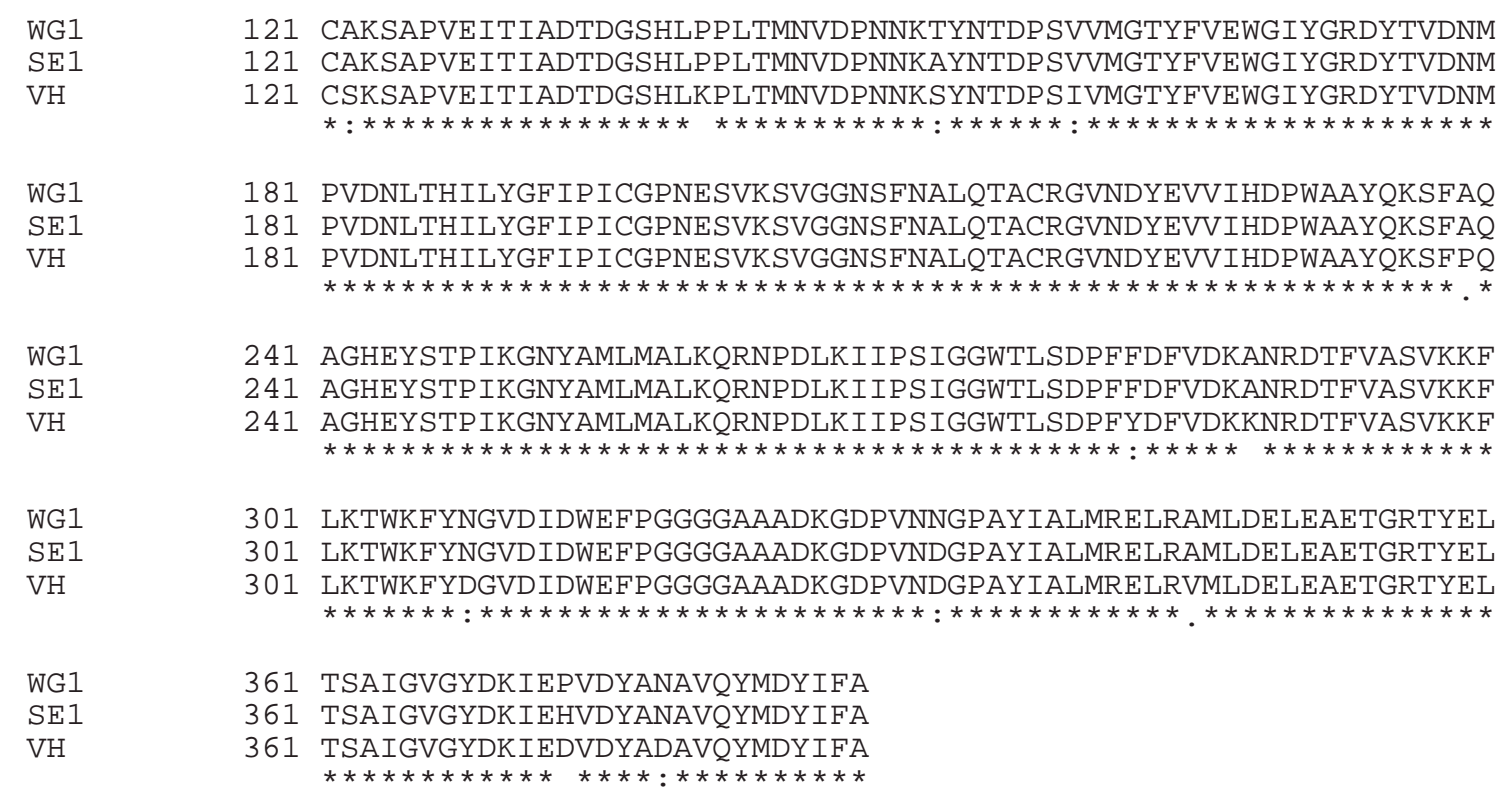

\section{Abb. 21: Vergleich der Aminosäure-Sequenzen kodiert vom Insert aus pWG1 und pSE1} mit dem korrespondierendem Abschnitt der Chitinase A aus $V$. harveyi.

Die Ähnlichkeit der Chitinase aus WG1 und SE1 zueinander beträgt $99 \%$ und zur Chitinase A aus V. harveyi (VH; AF323180) jeweils $95 \%$. Dargestellten Sterne deuten identische Aminosäuren an, die Doppelpunkte und Punkte ähnliche Aminosäuren.

Die Ähnlichkeit der Aminosäuresequenzen der Chitinasen aus SE1 und WG1 zueinander lagen bei $99 \%$. Beim chiA-Gen aus SE1 lag die Ähnlichkeit auf DNA-Ebene bei $88 \%$ und beim chiA-Gen aus WG1 bei $89 \%$ im Vergleich zum chiA-Gen aus $V$. harveyi. Bei der abgeleiteten Aminosäuresequenz der beiden klonierten Chitinase-Gene lagen diese im Vergleich zur Chitinase A aus $V$. harveyi bei jeweils $95 \%$. Aufgrund der hohen Ähnlichkeit zur bekannten Chitinase A sind beide Genprodukte der klonierten Chitinasen aus SE1 und WG1 in die Familie 18 der Glykosyl-Hydrolasen einzuorden. Ebenso ist aufgrund der hohen Übereinstimmung davon auszugehen, dass das komplette Gen aus WG3 und SE1 ca. 2500 Bp und das abgeleitete Protein $91 \mathrm{kDa}$ wie bei der Chitinase A aus $V$. harveyi, umfassen müsste. Damit wären beide Chitinasen zu $45 \%$ kloniert worden.

Bei der Familie 18 liegt die Chitin-Bindedomäne am C-terminalen Bereich des Proteins, so dass die Chitin-Bindedomäne nicht auf dem partiellen Gen von WG1 und SE1 enthalten sein konnte. Bei der Amplifikation des Chitinasegens aus SL3 gelang es lediglich, für die Ertsellung einer homologen Sonde ein 220 Bp umfassendes DNA-Fragment zu erhalten (s. 3.4) und zu klonieren. Dieses wies eine Homologie von $95 \%$ zur Chitinase A aus V. harveyi auf. Da wie erwähnt kein positiver Klon bei der Koloniehybridisierung erhalten wurde (s. 3.5) sollte auch hier das Chitinasegen mit Hilfe der PCR amplifiziert und kloniert werden. Trotz 
des Einsatzes der gleichen Oligonukleotide, die auch bei SE1 und WG1 Verwendung fanden, gelang es nicht, das Gen aus SL3 zu klonieren.

\subsection{3}

\section{Klonierung von Chitinasen aus Anreicherungskulturen mit Boden- und Meeres-Proben}

Eine weitere Möglichkeit Chitinasen zu klonieren, bestand in der Amplifikation von DNA, die direkt aus Anreicherungskulturen extrahiert wurde. Bei diesen wurde Mineralmedium mit Chitin als einziger C-Quelle mit Boden- oder Wasserproben verschiedener Standorte beimpft und solange inkubiert, bis sich mikrobielles Wachstum durch eine Trübung des Mediums nachweisen ließ. Auf eine Isolierung der Organismen wurde in dieser Vorgehensweise verzichtet. Stattdessen wurde die Gesamt-DNA der jeweiligen Anreicherung extrahiert und für PCR eingesetzt.

Chitin-Mineralmedium (s. 2.2.3) wurde mit Boden-Proben beimpft, die aus einer Wiese in Göttingen und Sediment-Proben aus Israel stammten und PCR-Reaktionen unterzogen. Dabei wurden aus den in Tab. 13 erwähnten bekannten Chitinase-Genen Oligonukleotide abgeleitet, die das jeweilige gesamte Gen umfassten. Beim Einsatz der Oligonukleotide ChiCcod.for/ChiCcod.rev konnte ein PCR-Produkt erhalten werden. Das Produkt wies ca. 900 Bp. auf. Dieses wurde in den Vektor pCR-2.1 TOPO kloniert und der rekombinante Vektor als pSG bezeichnet. Nach Sequenzierung zeigte sich bei dem aus dem Insert abgeleiteten Protein, das es sich um eine Chitinase handelte, die eine sehr hohe Ähnlichkeit zur Chitinase C aus S. griseus HUT6037 aufwies. In Abb. 22 ist die Sequenz des Inserts aus pSG aufgeführt, die für ein $30 \mathrm{kDa}$ großes Protein kodierte.

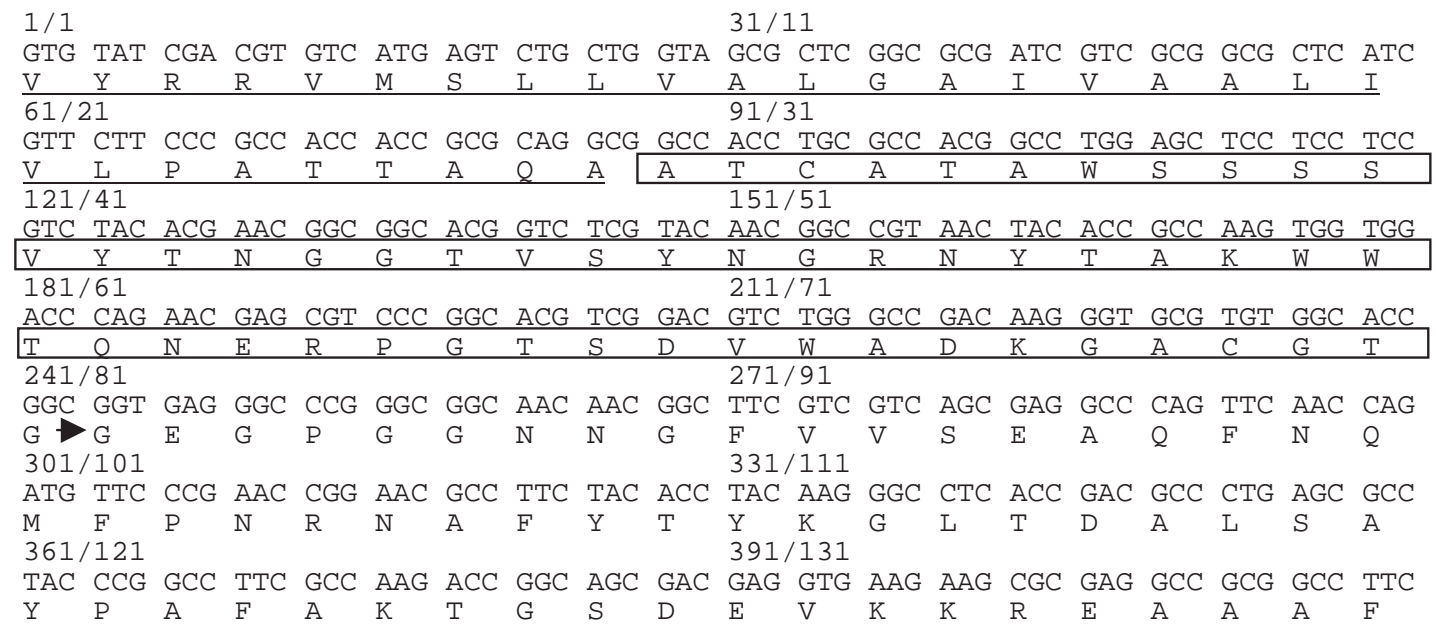




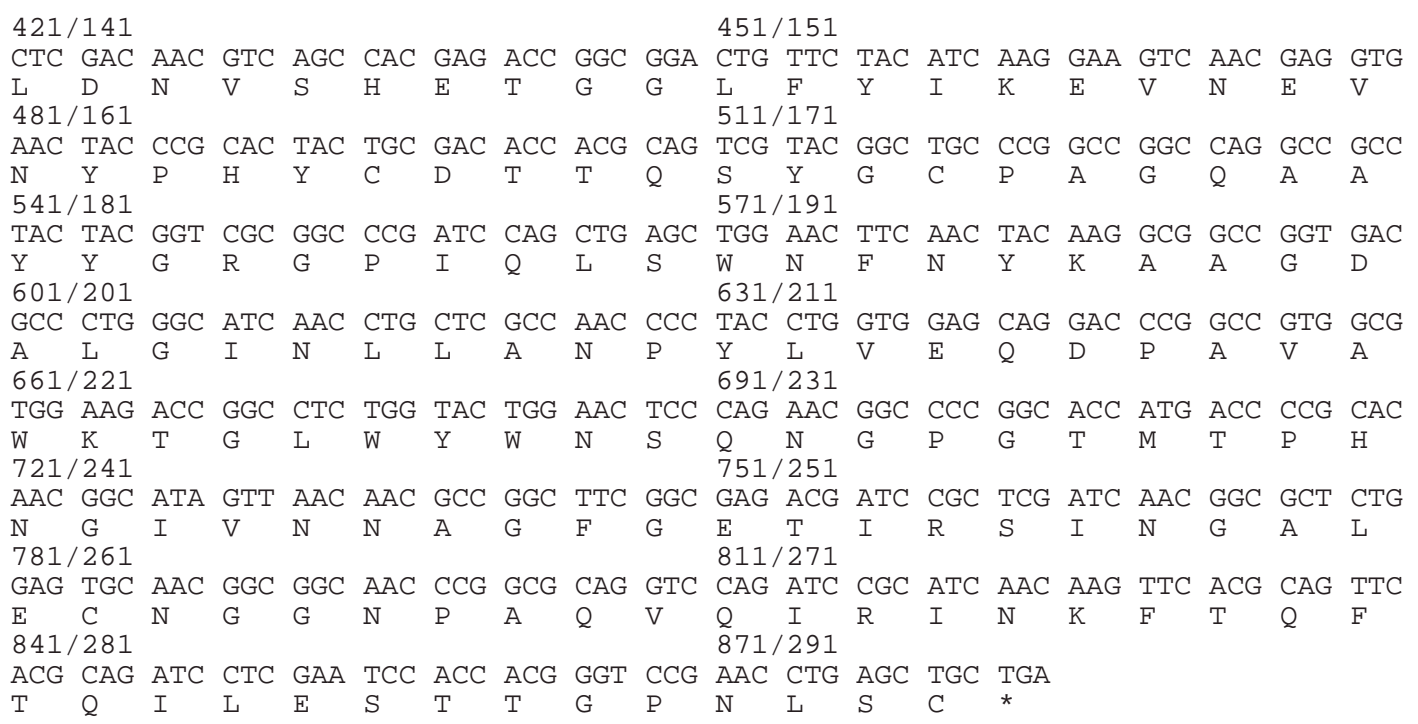

\section{Abb. 22: Sequenz des Inserts aus pSG}

Gezeigt ist der DNA-Strang vom 5'-zum 3`-Ende. Die aus dem Gen abgeleitete Aminosäuresequenz ist im Ein-Buchstaben-Code angegeben. Die N-terminale Signalsequenz ist unterstrichen und die folgende Chitin-Bindedomäne mit einem Rahmen versehen. Unmittelbar daran befindet sich die katalytische Domäne der Chitinase, deren Anfang mit einem Pfeil markiert ist. Der Stern symbolisiert das Stopkodon.

Das Gen enthielt 885 Bp, die für 294 Aminosäuren kodierten. Die Signalsequenz des abgeleiteten Protein wies 30 Aminosäuren und die N-terminale Chitin-Bindedomäne 51 Aminosäuren auf. Die katalytische Domäne nahm den Bereich von 81-294 ein (s. Abb. 22). Diese Sequenzanalyse beruhte auf der Charakterisierung der Chitinase C aus $S$. griseusHUT 6037 (OHNO et al., 1996). Die Ähnlichkeit des klonierten chiC-Gens aus pSG zum chiCGen aus S. griseusHUT 6037 betrug auf DNA-Ebene $98 \%$. Auf Proteinebene zeigte sich eine Übereinstimmung von $99 \%$. Das Alignment der beiden Chitinasen zueinander ist in Abb. 23 aufgeführt.

\footnotetext{
ChIC 1 VYRRVMSLLVALGAIVAALIVLPATTAQAATCATAWSSSSVYTNGGTVSYNGRNYTAKWW Sg 1 MYRRVMSLLVALGAIVAALIVLPATTAQAATCATAWSSSSVYTNGGTVSYNGRNYTAKWW

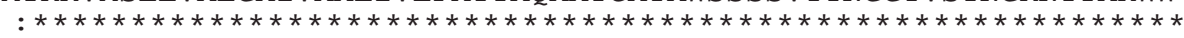


ChIC 161 NGIVNNAGFGETIRSINGALECNGGNPAQVQIRINKFTQFTQILESTTGPNLSCZ

Sg 161 NAIVNNAGFGETIRSINGALECNGGNPAQVQSRINKFTQFTQILGTTTGPNLSCZ

Abb. 23: Sequenzvergleich zwischen der Chitinase C aus pSG (ChiC) und der Chitinase C aus $S$. griseus HUT 6037

Die Ähnlichkeit der Aminosäuresequenzen zueinander betrug $99 \%$. Dargestellte Sterne deuten identische Aminosäuren an, die Doppelpunkte und Punkte ähnliche Aminosäuren.

Sg, Chitinase C aus S. griseus HUT6037 (AB009289)

Aufgrund der fast identischen Sequenz der Chitinase C aus der Anreicherungskultur zur bekannten Chitinase C aus $S$. griseus lässt sich diese ebenso wie die Chitinase IS aus WG3 in die Familie 19 der Glykosyl-Hydrolasen einordnen.

Beim Vergleich der Aminosäuresequenzen zwischen der Chitinase C, kodiert vom Insert aus pSG und der Chitinase IS aus WG3 zeigte sich eine Ähnlichkeit von 76 \% (Abb. 24).

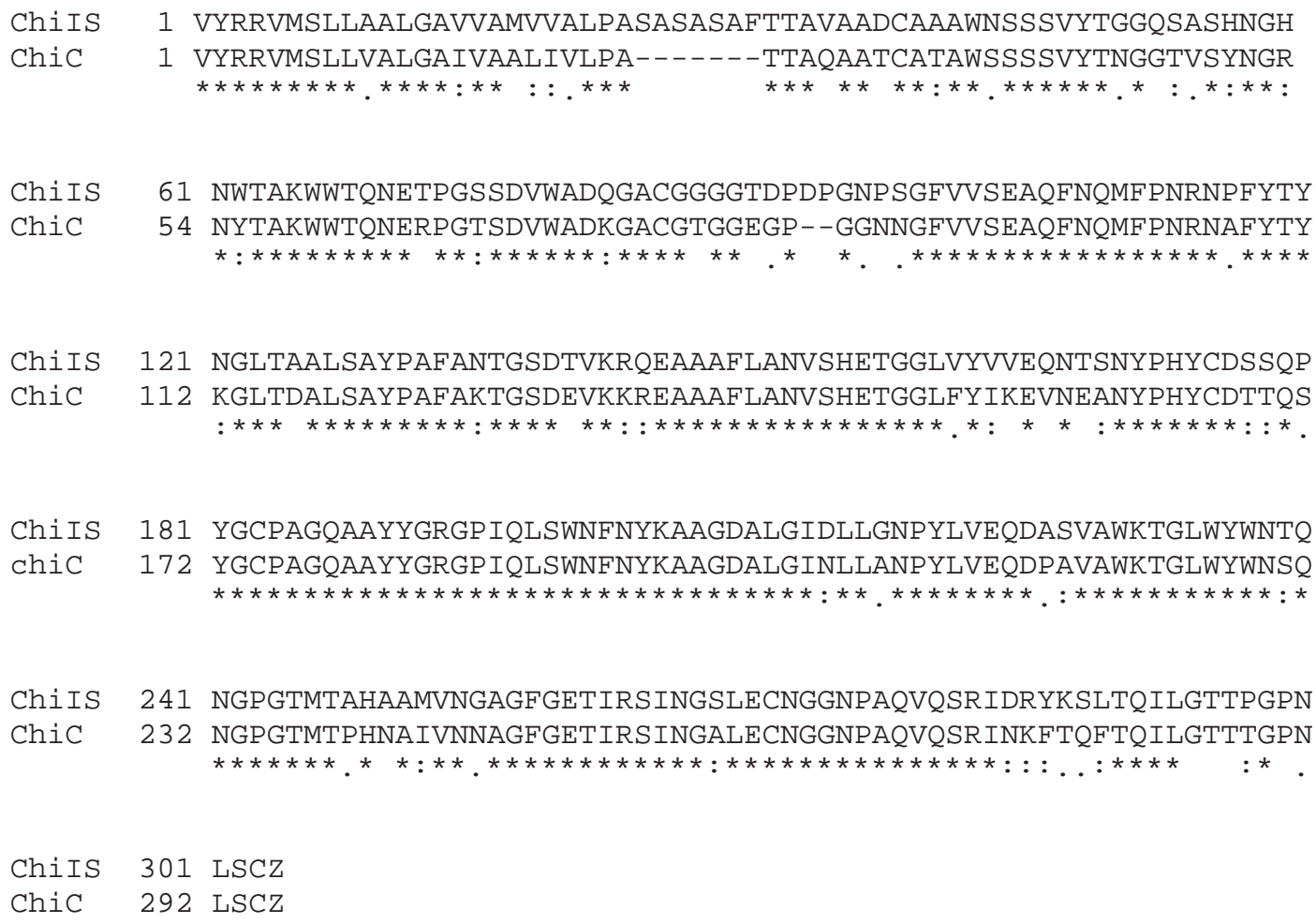

Abb. 24: Vergleich der Aminosäuresequenzen der Chitinase IS aus WG3 und der Chitinase $\mathbf{C}$ abgeleitet aus dem Insert von pSG.

Die Übereinstimmung betrug 76 \%. Dargestellte Sterne deuten identische Aminosäuren an, die Doppelpunkte und Punkte ähnliche Aminosäuren.

Die Charakterisierung der Chitin-Bindedomäme und der katalytischen Domäne ist im Punkt 3.9.1 durchgeführt worden. Die Expression des Gens ist in 3.10 beschrieben.

Des weiteren wurde Chitin-Mineralmedium (s. 2.2.3) mit Wasserproben aus dem Golf von Eilat beimpft und inkubiert. Nach Isolierung der Gesamt-DNA (s. 2.7.1) wurde diese PCR- 
Reaktionen unterzogen, bei denen die Oligonukleotide Vh1/Vh2542, ChiCcod.for und ChiCcod.rev und BL1/BL2530 verwendet wurden. Diese Oligonukleotide sollten zur kompletten Amplifikation des Zielgenes führen. Beim Einsatz der Oligonukleotide Vh1 und Vh 2542 (s. 2.1) konnte ein PCR-Produkt von ca. 2500 Bp erhalten (s. Abb. 25) und in den Vektor pCR2.1 TOPO kloniert werden.

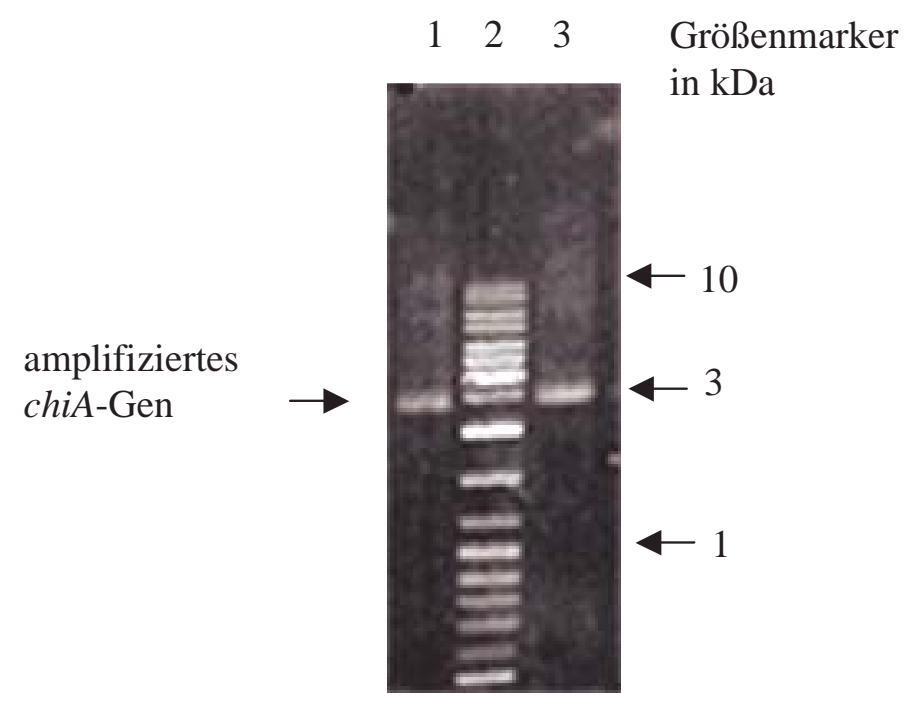

Abb. 25 : Amplifikation eines 2,5 kB umfassenden Chitinasegens aus der Gesamt-DNA einer Anreicherungskultur von Meeresproben

Spur 1 und 3: Amplifiziertes Gen

Spur 2: Größenmarker

Nach Sequenzierung des Inserts zeigte sich eine hohe Ähnlichkeit zur Chitinase A aus $V$. harveyi. Der rekombinante Vektor wurde als pVH bezeichnet. Die Sequenz ist in Abb. 26 abgebildet.

$1 / 1$

$31 / 11$

ATG ATt CGA TTT AAC CTA TGT GCA GCT GGg GTT GCC CTA GCA CTA TCT GGC GCG GCA $\begin{array}{lllllllllllllllllllll}M & I & R & F & N & \text { L } & \text { C } & \text { A } & \text { A } & \text { G } & \text { V } & \text { A } & \text { L } & \text { A } & \text { L } & \text { S } & \text { G } & \text { A } & \text { A } & \text { N }\end{array}$ $61 / 21 \quad 91 / 31$ GCA GCT CCA ACC GCA CCA Agt ATC GAT ATG TAC GGT TCC AAC AAC CTG CAA tTt tCT AAA $\begin{array}{llllllllllllllllllll}A & A & P & \text { T } & \text { A } & \text { P } & \text { S } & \text { I } & \text { D } & \text { M } & \text { Y } & \text { G } & \text { S } & \text { N } & \text { N } & \text { L } & Q & F & S & K\end{array}$ $121 / 41 \quad 151 / 51$ ATt GA TTG GCA ATg GAA ACC ACA TCT GGC TAC AAC GAC ATg GTt AAg TAC CAt GAA CTG $\begin{array}{llllllllllllllllllll}I & \mathrm{E} & \mathrm{L} & \mathrm{A} & \mathrm{M} & \mathrm{E} & \mathrm{T} & \mathrm{T} & \mathrm{S} & \mathrm{G} & \mathrm{Y} & \mathrm{N} & \mathrm{D} & \mathrm{M} & \mathrm{V} & \mathrm{K} & \mathrm{Y} & \mathrm{H} & \mathrm{E} & \mathrm{L}\end{array}$ $181 / 61 \quad 211 / 71$

GCC AAG ATC AAA GTG AAA TTC AAC CAG TGG AGC GGC ACA TCT GGC GAC ACT TAC AAC GTC $\begin{array}{llllllllllllllllllll}A & K & \text { I } & \text { K } & \text { V } & \text { K } & \text { F } & \text { N } & \text { Q } & \text { W } & \text { S } & \text { G } & \text { T } & \text { S } & \text { G } & \text { D } & \text { T } & \text { Y } & \text { N } & \text { V } \\ 241 / 81 & & & & & & & & & 271 / 91 & & & & & & & \end{array}$ TAC TTt GAT GGT GTA AAg GTT GCA ACA GGC CCT ATC ACT GGT AGC CAA ACC ACA GCT TCG

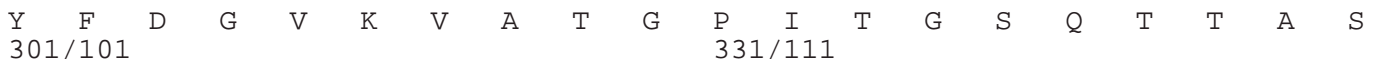
TTt GAA TAC GGC CAA GGT GGT TTG TAC CAA ATG GAA ATC GAA GCG TGT GAC GCA ACA GGC $\begin{array}{llllllllllllllllllll}\mathrm{F} & \mathrm{E} & \mathrm{Y} & \mathrm{G} & \mathrm{Q} & \mathrm{G} & \mathrm{G} & \mathrm{L} & \mathrm{Y} & \mathrm{Q} & \mathrm{M} & \mathrm{E} & \mathrm{I} & \mathrm{E} & \mathrm{A} & \mathrm{C} & \mathrm{D} & \mathrm{A} & \mathrm{T} & \mathrm{G}\end{array}$ $361 / 121 \quad 391 / 131$

TGT TCT AAG AGC GCT CCT GTA AAG ATT ACC ATT GCA GAT ACA GAT GGC TCT CAC TTG AAG

$\begin{array}{llllllllllllllllllll}C & \mathrm{~S} & \mathrm{~K} & \mathrm{~S} & \mathrm{~A} & \mathrm{P} & \mathrm{V} & \mathrm{K} & \mathrm{I} & \mathrm{T} & \mathrm{I} & \mathrm{A} & \mathrm{D} & \mathrm{T} & \mathrm{D} & \mathrm{G} & \mathrm{S} & \mathrm{H} & \mathrm{L} & \mathrm{K}\end{array}$ 
$421 / 141$

$451 / 151$

CCT CTG ACC ATG AAT GTT GAC CCG AAC AAC AAA ACC TAC AAC ACA GAC CCA Agt GTC GTG $\begin{array}{llllllllllllllllllll}\mathrm{P} & \mathrm{L} & \mathrm{T} & \mathrm{M} & \mathrm{N} & \mathrm{V} & \mathrm{D} & \mathrm{P} & \mathrm{N} & \mathrm{N} & \mathrm{K} & \mathrm{T} & \mathrm{Y} & \mathrm{N} & \mathrm{T} & \mathrm{D} & \mathrm{P} & \mathrm{S} & \mathrm{V} & \mathrm{V}\end{array}$ 481/161 511/171

ATG GGT ACA TAC TTt GTt GAA TGg GGC ATC TAC GGC CGT GAt TAC ACT GTC GAC AAC ATG $\begin{array}{llllllllllllllllllll}M & G & \text { T } & \text { Y } & \text { F } & \text { V } & \text { E } & \text { W } & \text { G } & \text { I } & \text { Y } & \text { G } & \text { R } & \text { D } & \text { Y } & \text { T } & \text { V } & \text { D } & \text { N } & M\end{array}$ $541 / 181 \quad 571 / 191$

CCA GTC GAC AAC CTA ACG CAC ATC CTT TAC GGC TTC ATT CCA ATT TGT GGT CCA AAC GAA $\begin{array}{llllllllllllllllllll}\mathrm{P} & \mathrm{V} & \mathrm{D} & \mathrm{N} & \mathrm{L} & \mathrm{T} & \mathrm{H} & \mathrm{I} & \mathrm{L} & \mathrm{Y} & \mathrm{G} & \mathrm{F} & \mathrm{I} & \mathrm{P} & \mathrm{I} & \mathrm{C} & \mathrm{G} & \mathrm{P} & \mathrm{N} & \mathrm{E}\end{array}$ $601 / 201 \quad 631 / 211$

TCG GTG AAA TCG GAT GGC GGT AAC AGC TTC AAC GCA CTG CAA ACA GCA TGt CGC GGC GTG $\begin{array}{llllllllllllllllllll}\mathrm{S} & \mathrm{V} & \mathrm{K} & \mathrm{S} & \mathrm{D} & \mathrm{G} & \mathrm{G} & \mathrm{N} & \mathrm{S} & \mathrm{F} & \mathrm{N} & \mathrm{A} & \mathrm{L} & \mathrm{Q} & \mathrm{T} & \mathrm{A} & \mathrm{C} & \mathrm{R} & \mathrm{G} & \mathrm{V}\end{array}$ 661/221 691/231

AAC GAC TAC GAA GTG GTT ATC CAT GAC CCA TGG GCA GCG TAC CAA AAg AGC TTC CCG CAA $\begin{array}{llllllllllllllllllll}\mathrm{N} & \mathrm{D} & \mathrm{Y} & \mathrm{E} & \mathrm{V} & \mathrm{V} & \mathrm{I} & \mathrm{H} & \mathrm{D} & \mathrm{P} & \mathrm{W} & \mathrm{A} & \mathrm{A} & \mathrm{Y} & \mathrm{Q} & \mathrm{K} & \mathrm{S} & \mathrm{F} & \mathrm{P} & \mathrm{Q}\end{array}$ 721/241 751/251

GCA GGC CAT GAg tAC AGC ACG CCA ATC AAg GGT AAC TAC GCA Atg CtA Atg gCg tTg AAA $\begin{array}{llllllllllllllllllll}\text { A } & G & \text { H } & \text { E } & \text { Y } & \text { S } & \text { T } & \text { P } & \text { I } & \text { K } & \text { G } & \text { N } & \text { Y } & \text { A } & \text { M } & \text { L } & \text { M } & \text { A } & \text { L } & \text { K }\end{array}$ $781 / 261$

CAA CGT AAC CCG GAT CTA AAA ATT ATC CCA TCT ATC GGT GGT TGG ACA CTT TCT GAC CCA \begin{tabular}{lllllllllllllllllllll}
$\mathrm{Q}$ & $\mathrm{R}$ & $\mathrm{N}$ & $\mathrm{P}$ & $\mathrm{D}$ & $\mathrm{L}$ & $\mathrm{K}$ & $\mathrm{I}$ & $\mathrm{I}$ & $\mathrm{P}$ & $\mathrm{S}$ & $\mathrm{I}$ & $\mathrm{G}$ & $\mathrm{G}$ & $\mathrm{W}$ & $\mathrm{T}$ & $\mathrm{L}$ & $\mathrm{S}$ & $\mathrm{D}$ & $\mathrm{P}$ \\
\hline
\end{tabular} $841 / 281 \quad 871 / 291$

TTC TAC GAC TTC GTT GAT AAG AAG AAT CGT GAC ACG TTT GTC GCG TCA GTT AAG AAA TTC \begin{tabular}{|llllllllllllllllllll|}
\hline $\mathrm{F}$ & $\mathrm{Y}$ & $\mathrm{D}$ & $\mathrm{F}$ & $\mathrm{V}$ & $\mathrm{D}$ & $\mathrm{K}$ & $\mathrm{K}$ & $\mathrm{N}$ & $\mathrm{R}$ & $\mathrm{D}$ & $\mathrm{T}$ & $\mathrm{F}$ & $\mathrm{V}$ & $\mathrm{A}$ & $\mathrm{S}$ & $\mathrm{V}$ & $\mathrm{K}$ & $\mathrm{K}$ & $\mathrm{F}$ \\
\hline $901 / 301$ & & & & & & & & $931 / 311$ & & & & & & & &
\end{tabular} CTG AAA ACT TGG AAA TTT TAC GAC GGC GTA GAT ATT GAC TGG GAA TTC CCT GGT GGC GGC \begin{tabular}{|llllllllllllllllllll}
\hline L & K & T & W & K & F & Y & D & G & V & D & I & D & W & E & F & P & G & G & G \\
\hline $961 / 321$ & & & & & & & & $991 / 331$ & & & & & & & &
\end{tabular} GGC GCT GCA GCA GAT AAg GGT GAC GCT GTA AAC GAT GGT CCT GCA TAC ATt GCA TTG ATg

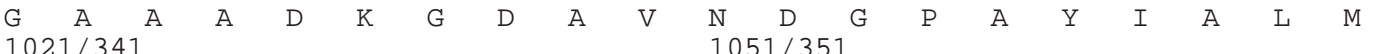
CGT GAA CTA CGT GTA ATG CTA GAT GAA CTT GAA GCA GAA ACA GGT CGT ACT TAC GAg CTA $\begin{array}{llllllllllllllllllll}R & E & L & R & V & M & L & D & E & L & E & A & E & T & G & R & T & Y & E & L\end{array}$ $1081 / 361 \quad 1111 / 371$

ACT TCA GCA ATC GGT GTT GGT TAC GAC AAg ATT GAA GAC GTA GAT TAC GCA GAC GCG GTt $\begin{array}{llllllllllllllllllll}T & S & A & I & G & V & G & Y & D & K & I & E & D & V & D & Y & A & D & A & \text { V }\end{array}$ $1141 / 381 \quad 1171 / 391$

CAg tAC ATG GAC TAC ATC TTt GCG ATG ACT TAC GAC TTC TAC GGC GGC TGg AAC AAC GTt $\begin{array}{llllllllllllllllllll}\mathrm{Q} & \mathrm{Y} & \mathrm{M} & \mathrm{D} & \mathrm{Y} & \mathrm{I} & \mathrm{F} & \mathrm{A} & \mathrm{M} & \mathrm{T} & \mathrm{Y} & \mathrm{D} & \mathrm{F} & \mathrm{Y} & \mathrm{G} & \mathrm{G} & \mathrm{W} & \mathrm{N} & \mathrm{N} & \mathrm{V}\end{array}$ $1201 / 401 \quad 1231 / 411$

CCT GGT CAC CAA ACT GCT CTT TAC TGT GGC TCA TTC ATg CGT CCT GGT CAg tGt GAt GGC $\begin{array}{llllllllllllllllllllll}P & G & H & Q & \text { T } & A & \text { L } & \text { Y } & \text { C } & G & \text { S } & \text { F } & M & R & P & G & Q & C & D & G\end{array}$ $1261 / 421 \quad 1291 / 431$

GGC GGC GTG GAT GAA AAC GGC GAA CCG TAC AAA GGT CCA GCA TAC ACT GCA GAT AAC GGT

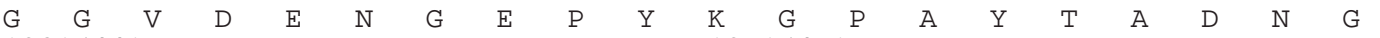
$1321 / 441$

AtC CAg CTt CTT CTA GCG CAA Ggt GTt CCT GCA ATt AAA CTG GTt CTT Ggt ACA GCG GTG

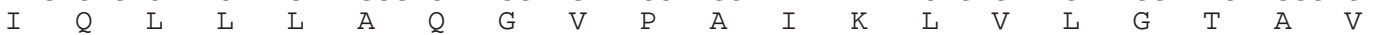
1381/461 1411/471

TAT GGT CGT GGT TGG GAA GGT GTA ACA CCT GAT ACG CTA ACA GAT CCA AAt GAC CCA ATg $\begin{array}{llllllllllllllllllll}Y & G & R & G & W & E & G & V & T & P & D & T & L & T & D & P & N & D & P & M\end{array}$ $1441 / 481 \quad 1471 / 491$

ACC GGT ACT GCA ACA GGC AAA CTG AAA GGC AGC ACA GCT CAA GGT GTT TCG GAA GAt GGC $\begin{array}{llllllllllllllllllll}T & G & \text { T } & \text { A } & \text { T } & \text { G } & \text { K } & \text { L } & \text { K } & \text { G } & \text { S } & \text { T } & \text { A } & \text { Q } & \text { G } & \text { V } & \text { S } & \text { E } & \text { D } & G\end{array}$ $1501 / 501 \quad 1531 / 511$

GTA AAC GAC TAC AAA Ggt ATt AAg TCA TTt ATG CTA Ggt GCG AAC AAC ACt GGC ATC AAC $\begin{array}{llllllllllllllllllll}\mathrm{V} & \mathrm{N} & \mathrm{D} & \mathrm{Y} & \mathrm{K} & \mathrm{G} & \mathrm{I} & \mathrm{K} & \mathrm{S} & \mathrm{F} & \mathrm{M} & \mathrm{L} & \mathrm{G} & \mathrm{A} & \mathrm{N} & \mathrm{N} & \mathrm{T} & \mathrm{G} & \mathrm{I} & \mathrm{N}\end{array}$ 1561/521 1591/531

GGC TTT GAA TAC GGC TAT GAT GCG CAA GCA GAA GCA CCT TGG GTG TGG AAC CGT TCG ACt

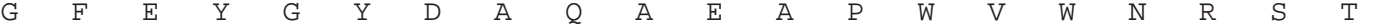
$1621 / 541 \quad 1651 / 551$

GGT GA CTA ATC ACA TTT GAC GAT CAT CGT TCT GTG TTA GCG AAA GGC AAC TAC GCA AAA

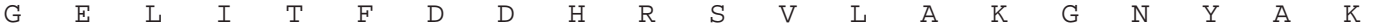
$1681 / 561 \quad 1711 / 571$

TCT CTA GGT CTA GCA GGT CTA TTC TCT AAg GAg ATT GAT GCA GAT AAC GGC GAC ATC CTT

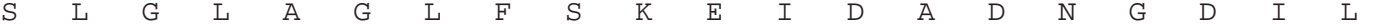
$1741 / 581 \quad 1771 / 591$

AAT GCA ATG CAC GAA GGT ATG GCT GGC GGC GTC GTT CCT CCA CCA AAC CGT AAA CCA ACG $\begin{array}{llllllllllllllllllllllll}\mathrm{N} & \mathrm{A} & \mathrm{M} & \mathrm{H} & \mathrm{E} & \mathrm{G} & \mathrm{M} & \mathrm{A} & \mathrm{G} & \mathrm{G} & \mathrm{V} & \mathrm{V} & \mathrm{P} & \mathrm{P} & \mathrm{P} & \mathrm{N} & \mathrm{R} & \mathrm{K} & \mathrm{P} & \mathrm{T}\end{array}$ $1801 / 601 \quad 1831 / 611$

GCA GCA GCA GGT GCA GAC CAA GCA GTA ACA GGT CCT GCA AGT GTt GTA CTT GAT GGC AGC $\begin{array}{llllllllllllllllllll}A & A & A & G & A & D & Q & A & V & T & G & P & A & S & V & V & \text { L } & \text { D } & G & S\end{array}$ $1861 / 621 \quad 1891 / 631$

AAC TCA ACA GAC TCT GAT GGC ACA ATC GCA AGC TAC GCT TGG GAA CAA GTA TCT GGT ACt

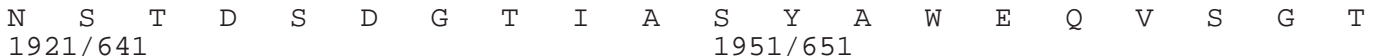
GCA GTC GTG CTA TCT GGC GCG AAC GCA GCG ACA GCA AGC TTC GAT GTA GCA GAA GTC GCA $\begin{array}{llllllllllllllllll}\mathrm{A} & \mathrm{V} \\ 1981 / 661 & \mathrm{~V} & \mathrm{~L} & \mathrm{~S} & \mathrm{G} & \mathrm{A} & \mathrm{N} & \mathrm{A} & \mathrm{A} & \mathrm{T} \underset{2011 / 671}{\mathrm{~A}} & \mathrm{~S} & \mathrm{~F} & \mathrm{D} & \mathrm{V} & \mathrm{A} & \mathrm{E} & \mathrm{V} & \mathrm{A}\end{array}$ GTT GAg GAA CAg CTG ACG TTC AAg CTA ACT GTC ACT GAT AAC GAA GGT GCA ACG GCT TCT 


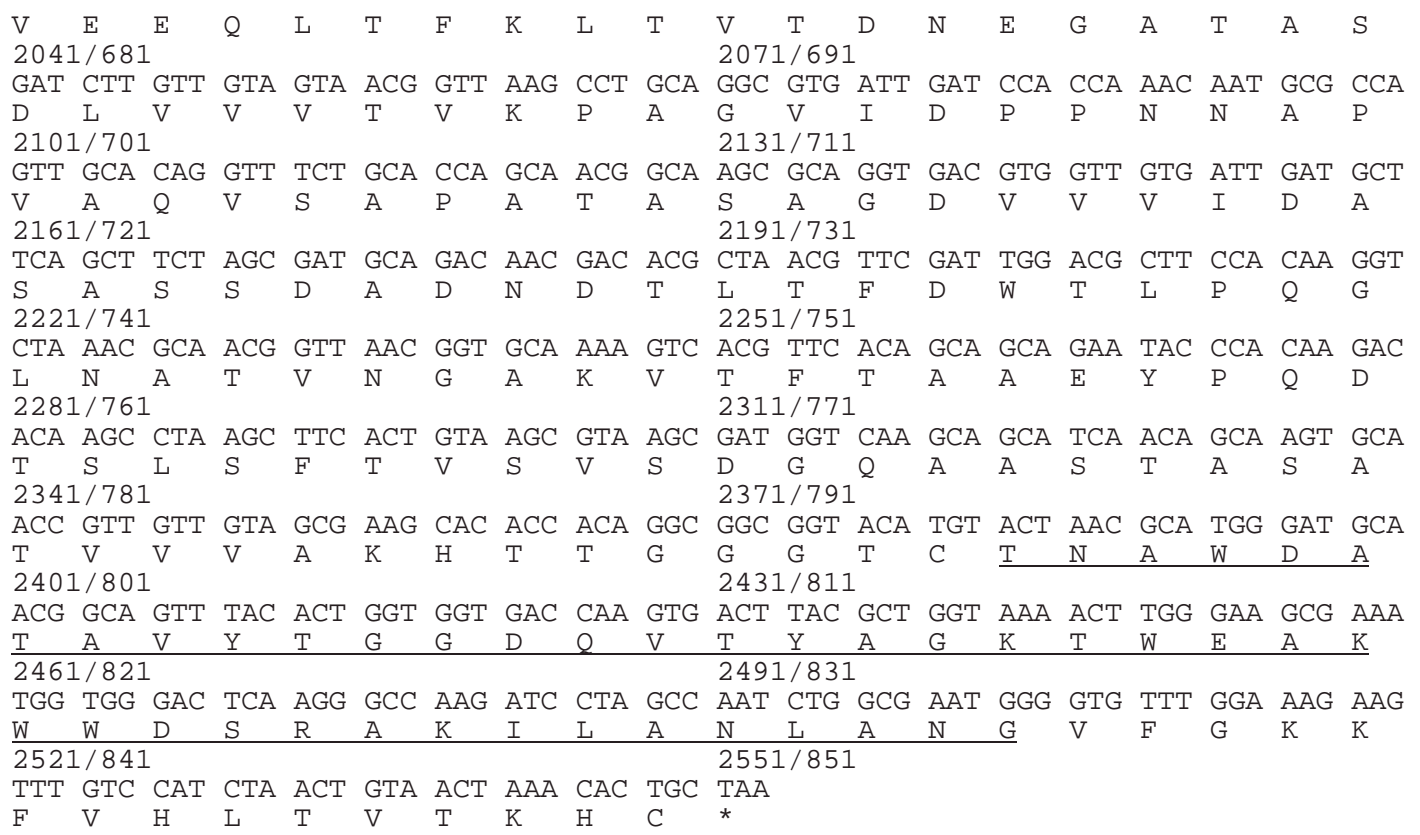

\section{Abb. 26: Sequenz des Inserts aus pVH}

Gezeigt ist der DNA-Strang vom 5'-zum 3`-Ende. Die aus dem Gen abgeleitete Aminosäuresequenz ist im Ein-Buchstaben-Code angegeben. Die katalytische Domäne ist mit einem Rahmen versehen. Die Chitin-Bindedomäne ist unterstrichen dargestellt. Der Pfeil symbolisiert das Startkodon und der Stern das Stopkodon.

Das Gen umfasste 2553 Bp, die für 850 Aminosäuren kodierten. Die abgeleitete molekulare Masse des Proteins wies $91 \mathrm{kDa}$ auf. Das Insert aus pVH wies komplett die Signalsequenz mit 24 Aminosäuren sowie die katalytische Domäne mit 57 Aminosäuren auf. Ebenso gelang es, die C-terminale Chitin-Bindedomäne mit 41 Aminosäuren zu klonieren. Auf DNA-Ebene ergab sich eine Ähnlichkeit von $97 \%$ zum chiA Gen aus V. harveyi. Der Abgleich der Aminosäuresequenz ergab eine Übereinstimmung von $98 \%$ zur Chitinase A aus $V$. harveyi (s. Abb. 27)

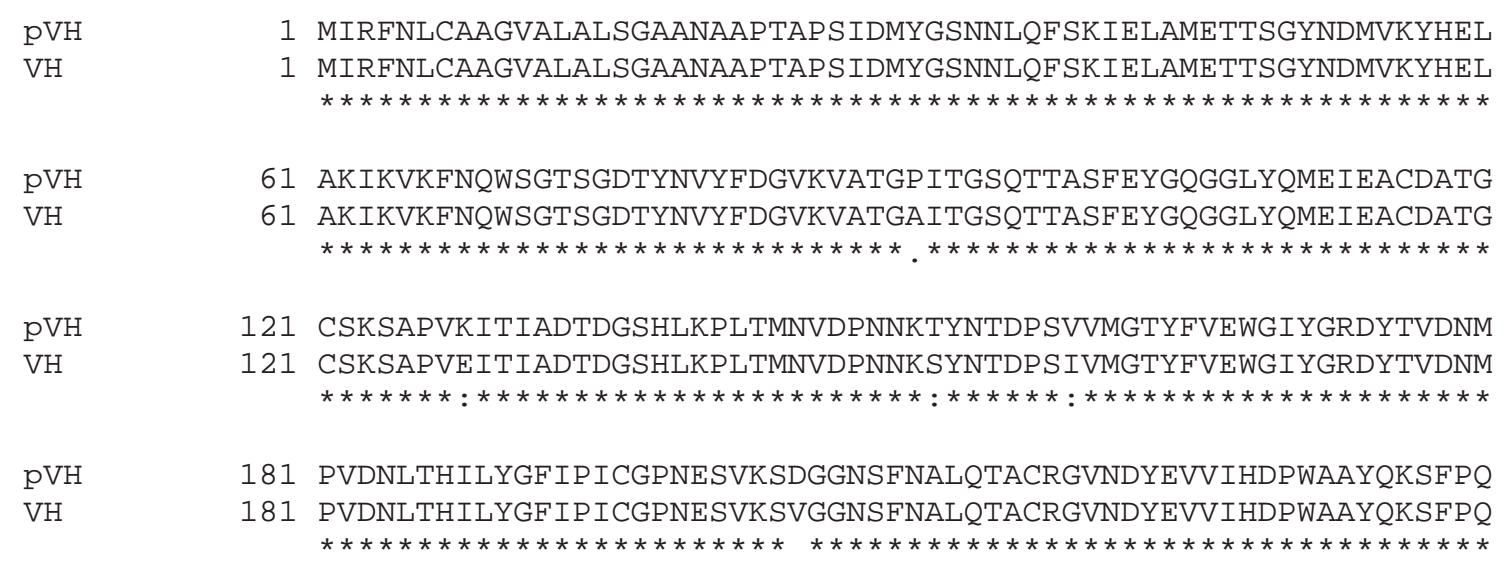




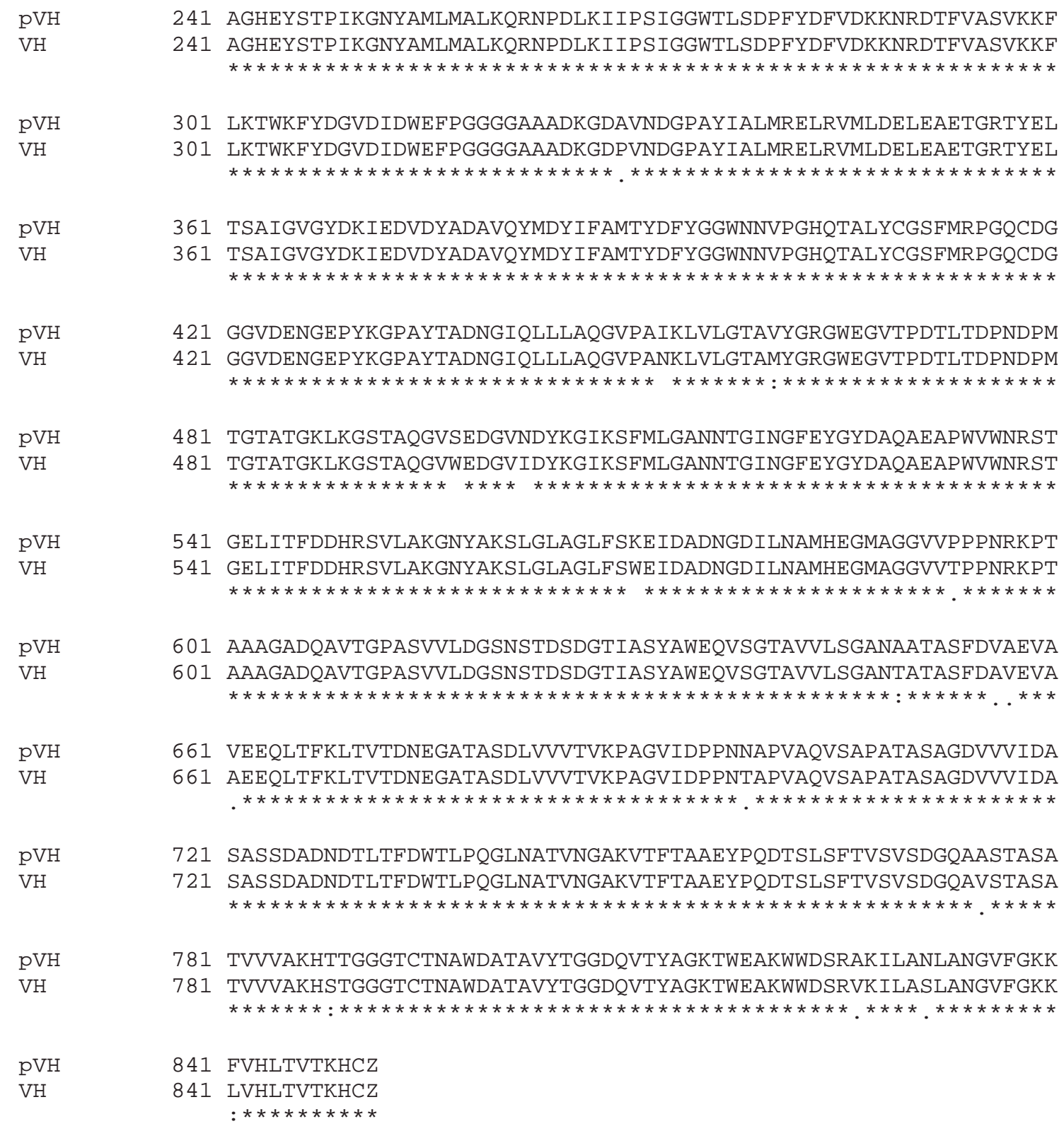

Abb. 27: Vergleich der Aminosäuresequenz, abgeleitet vom Insert aus pVH, mit der Chitinase A aus $V$. harveyi

Die Übereinstimmung der Chitinase aus pVH mit der Chitinase A aus V. harveyi $(\mathrm{VH}$, AF323180) auf Aminosäurebasis betrug $98 \%$. Dargestellte Sterne deuten identische Aminosäuren an, die Doppelpunkte und Punkte ähnliche Aminosäuren.

Die Ähnlichkeit der Chitinase A aus WG1 und SE1 zur Chitinase A kodiert vom Insert aus pVH betrug bei beiden Chitinasen $98 \%$.

Es gelang, 5 Chitinase-Gene zu klonieren. Drei davon entstammten Isolaten (WG1, WG3 und SE1), zwei weitere wurden aus Anreicherungskulturen amplifiziert. Im Punkt 3.9 wurden die so identifizierten Chitinase-Gene und deren abgeleitete Proteine im Vergleich mit bekannten Chitinasen verglichen und analysiert. 
In Tabelle 15 sind die Eigenschaften aller durch PCR amplifizierten Chitinasen aus den Isolaten WG1, WG3 und SE1 sowie aus Anreicherungskulturen aufgeführt.

Tab. 15: Identifizierte Chitinasen aus den Isolaten WG1, WG3, SE1 und Anreicherungskulturen

\begin{tabular}{|c|c|c|c|}
\hline $\begin{array}{l}\text { Kloniertes } \\
\text { Chitinase-Gen }\end{array}$ & $\begin{array}{l}\text { Größe des erhaltenen } \\
\text { Gens (in Basenpaaren) } \\
\text { und des Genproduktes } \\
\text { (in kDa) }\end{array}$ & $\begin{array}{l}\text { Abgleich der DNA- } \\
\text { Sequenz zu bekannten } \\
\text { Chitinasen }\end{array}$ & $\begin{array}{lr}\text { Abgleich } & \text { der } \\
\text { Proteinsequenz } & \mathrm{zu} \\
\text { bekannten } & \\
\text { Chitinasen } & \end{array}$ \\
\hline chilS aus WG3 & $906 / 31$ & $\begin{array}{c}88 \% \text { chilS aus } S . s p . \\
\text { AJ9463 }\end{array}$ & $\begin{array}{l}90 \% \text { Chitinase IS } \\
\text { aus } S . s p . \text { AJ9463 }\end{array}$ \\
\hline chiA aus SE1 & $1164 / 41$ & $\begin{array}{l}89 \% \text { ChiA } \\
\text { V. harveyi }\end{array}$ & $\begin{array}{c}95 \% \text { Chitinase } \mathrm{A} \\
V . \text { harveyi }\end{array}$ \\
\hline chiA aus WG1 & $1164 / 41$ & $\begin{array}{l}88 \% \text { ChiA } \\
\text { V. harveyi }\end{array}$ & $\begin{array}{c}95 \% \text { Chitinase A } \\
\text { V. harveyi }\end{array}$ \\
\hline $\begin{array}{l}\text { chiC aus } \\
\text { Anreicherungs- } \\
\text { kultur }\end{array}$ & $880 / 30$ & $98 \%$ ChiC S. griseus & $\begin{array}{c}99 \% \text { Chitinase C } \\
\text { S. griseus }\end{array}$ \\
\hline $\begin{array}{l}\text { chiA aus } \\
\text { Anreicherungs- } \\
\text { kultur }\end{array}$ & $2553 / 91$ & $97 \%$ ChiA V. harveyi & $\begin{array}{c}98 \% \text { Chitinase } \mathrm{A} \\
\text { V. harveyi }\end{array}$ \\
\hline
\end{tabular}

\subsection{Charakterisierung der Domänen aus den klonierten Chitinase- Genen zu bekannten Chitinasen der Familie 18 und 19}

Die durch die PCR-Technik amplifizierten und klonierten Chitinase-Gene wurden im folgenden näher analysiert. Dabei lag der Fokus auf der Charakterisierung der katalytischenDomäne und der Chitin-Bindedomäne der jeweiligen aus den Inserts der identifizierten Chitinase-Gene abgeleiteten Aminosäuresequenzen.

3.9.1 Charakterisierung der Chitinasen aus dem Isolat WG3 und einer Anreicherungskultur aus Boden-Proben

Im folgenden wurde die Chitin-Bindedomäne und die katalytische Domäne der Chitinase IS 
aus dem Isolat WG3 und die Chitinase C aus einer Anreicherungskultur auf ihre Ähnlichkeit zu Pflanzenchitinasen der Familie 19 und bakteriellen Chitinasen der Familie 18 untersucht und näher charakterisiert.

Um die Chitin-Bindedomäne und die katalytische Domäne der Chitinasen C und der Chitinase IS mit Chitinasen der Familie 19 zu vergleichen, wurden die Aminosäuresequenzen der Chitinasen aus Oryza sativa (Reis, KIM et al., 1994) und Nicotiana tabacum (Tabak, VAN BUUREN et al., 1992) als Beispiel ausgewählt und den beiden klonierten bakteriellen Chitinasen einander gegenübergestellt (s. Abb. 28).

\begin{tabular}{|c|c|}
\hline Chic & VYRRVMSLLVALGAIVAALIVLPA-------TTAQA ATCATAWSSSSVYTNGGTVSYNGA \\
\hline Chis & VYRRVMSLLAALGAVVAMVVALPASASASAFTTAVAADCAAAWNSSSVYTGGQSASHNG \\
\hline Reis & --------- MRALALAVVAMAVVAVREQCGSQAGGALCPNCLCCSQYGWCGST SDYCGA \\
\hline \multirow[t]{2}{*}{ Tabak } & ----MRLLEFTALSSLLVLF LLLAVSAEQCGKQAGGARCP SGMCCSNF GWCGNTQDYCGP \\
\hline & 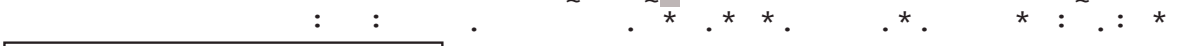 \\
\hline & NYTAKWWTQNERPGTSDVWADKGACGTGGEGP--GGNNGFVVSEAQFNQMFP NRNA--- \\
\hline IIS & LNWTAKWWTQNETP GSSDVWADdGACGGGGTDPDP GNP S GFVVSEAQFNQMFPNRNP --- \\
\hline eis & G-SESQCSGGCAGRP------P SSGG---------GSVAS I I SP S LFDQMLLHRND-QVR \\
\hline \multirow[t]{2}{*}{ Tabak } & GKCQSQCP S GP GPTPRPP TP TP GP ST---------GD I SNI I SS SMFDQMLKHRNDNTCQ \\
\hline & 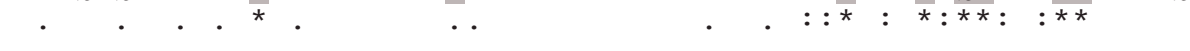 \\
\hline & ---FYTYKGLTDALSAYPAFAKTGSDEVKKREAAAF LDNVSHETGG------------LF \\
\hline LIS & ---FYTYNGLTAALSAYPAFANTGSDTVKRQEAAAF LANVSHETGG------------LV \\
\hline & AKGFYTYDAFVAAANAYPDFATSDADTCKR--EIAFLAQTSHETTGGWPTAPDGPYSWGY \\
\hline \multirow{2}{*}{ Tabak } & GKSFYTYNAF ITAARSFRGFGTTGDTTRRKREVAAFFAQTSHETTGGWDTAPDGRYAWGY \\
\hline & 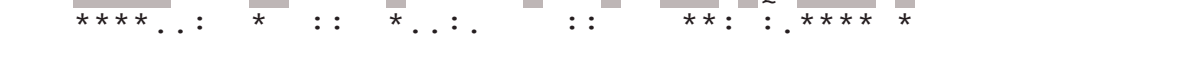 \\
\hline & YIKEVNEVNYP HYCDTTQSYGCPAGQAAYYGRGP IQLSWNFNYKAAGDALGINLLANPYI \\
\hline iIS & YVVEQNTSNYP HYCDSSQPYGCPAGQAAYYGRGP IQLSWNFNYKAAGDALGIDLLGNPYL \\
\hline eis & CFKEENNGNAPTYCEPKPEWP CAA-AKKYYGRGP IQITYNYNYG-RGAGIGSDLLNNPDL \\
\hline \multirow[t]{2}{*}{ Tabak } & CYLREQ-GNPP SYCVQSSQWP CAP - GQKYYGRGP IQ I SYNYNYGP CGRAIGQNLLNNPDL \\
\hline & 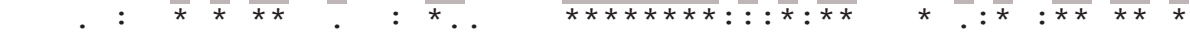 \\
\hline iC & VEQDPAVAWKTGLWYWNSQNGP---------GTMTP HNG IVNN---AGFGET IRS INGAL \\
\hline & VEQDASVAWKTGLWYWNTQNGP---------GTMTAHAAMVNG---AGFGETIRS INGSL \\
\hline & VAS-DLVSFKTAFWFWMTPQSPKP SCHAVITGQWTP SADDQP T--VPGYGEITNI INGGV \\
\hline \multirow[t]{2}{*}{ Tabak } & VATNAVVSFKSA IWFWMTAQSPKP SCHDVITGRWTP SAADRAANRLP GYGVITNI INGGL \\
\hline & 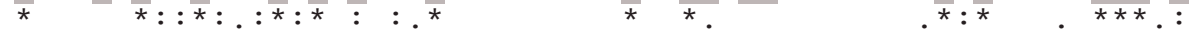 \\
\hline & ECNGGNPAQVQIRINKFTQFTQILESTTGPNLSCZ \\
\hline IS & ECNGGNPAQVQSRIDRYKSLTQILGTTPGPNLSCZ \\
\hline Reis & ECGH-ADDKVADRIGFYKRYCTMLGVQYGDNLDCY \\
\hline \multirow[t]{2}{*}{ Tabak } & ECGHGSDARVQDRIGFYRRYCSILGVSPGDNIDCG \\
\hline & 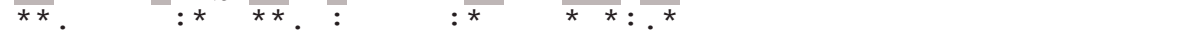 \\
\hline
\end{tabular}

\section{Abb. 28: Vergleich der Aminosäuresequenzen der Chitinase IS aus WG3 und der} Chitinase C aus einer Anreicherungskultur zu Pflanzenchitinasen der Familie 19

Die Chitin-Bindedomäne ist durch einen Rahmen markiert. Dargestellte Sterne deuten identische Aminosäuren an, die Doppelpunkte und Punkte ähnliche Aminosäuren. $\mathrm{ChiC}=$ Chitinase aus Anreicherungskultur; ChiIS= Chitinase aus Isolat WG3; Reis (Q40668); Tabak (P29059)

Bei dem Vergleich der katalytischen Domänen ist festzustellen, dass diese bei der Chitinase IS aus WG3 und der Chitinase C kodiert vom Insert aus pSG deutliche Ähnlichkeiten zu den 
Chitinasen der Vertreter der Familie 19, Reis und Tabak, aufwiesen und sich somit in die Familie 19 der Glykosyl-Hydrolasen eingliedern ließen. Bei dem Vergleich der Sequenzen der N-terminalen Chitin-Bindedomänen ist jedoch festzustellen, das in diesem Bereich keine signifikante Ähnlichkeit der Chitinasen aus pWG3 und pSG zu den dargestellten Pflanzenchitinasen feststellbar war. Um Ähnlichkeiten der Chitin-Bindedomänen zu bekannten Chitinasen zu finden, wurde die entsprechende Aminosäuresequenz (37-88) am Beispiel der Chitinase IS aus WG3 mit Chitinasen der Familie 18 verglichen (s. Abb. 29). Dabei konnten Ähnlichkeiten zu Chitin-Bindedomänen von Vertretern der Familie 18, wie z.B. aus B. circulans (WATANABE et al., 1990), Aeromonas sp. (UEDA et al., 1994) und Serratia marcescens (HARPSTER und DUNSMUIR, 1989) festgestellt werden. Ebenso lagen Ähnlichkeiten zur Cellulase-Bindedomäne aus B. sp. (FUKUMORI et al., 1988) vor.

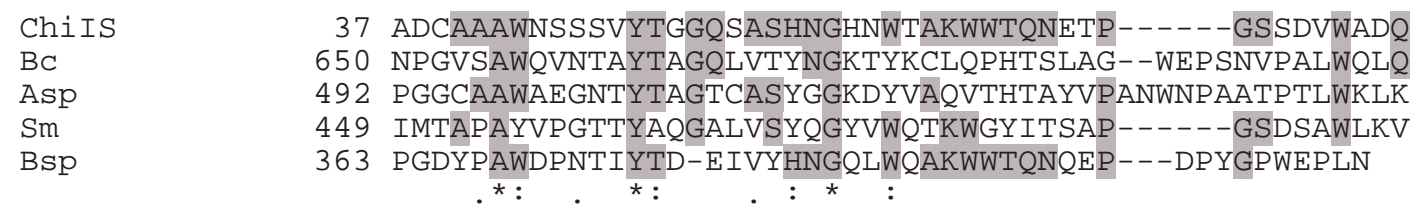

Abb. 29: Sequenzvergleich der Chitin-Bindedomäne der Chitinase IS aus WG3 zu Chitinasen der Familie 18

Bc ChiA1 aus B. circulans (WATANABE et al., 1990); Asp Chill aus Aeromonas sp. (Q59145); Sm, ChiB aus Serratia marcescens (P11797); Bsp, Cellulase B aus B. sp.(P06565); ChiIS, Chitinase IS aus dem Isolat WG3.

Dargestellte Sterne deuten identische Aminosäuren an, die Doppelpunkte und Punkte ähnliche Aminosäuren.

Aus diesen Sequenzanalysen ergibt sich, das die katalytischen Domänen der Chitinasen aus WG3 und der vom Insert aus pSG kodierten Chitinase C ebenso wie die bereits bekannte Chitinase C aus S. griseus HUT 6037 signifikante Ähnlichkeiten zu Pflanzenchitinasen der Familie 19 aufwiesen. Die Chitin-Bindedomäne jedoch wies Ähnlichkeiten zur Familie 18 der Glykosyl-Hydrolasen auf. Dies zeigte, das die Chitinasen aus pWG3 und pSG zusammengesetzt sind aus Domänen beider Chitinase-Familien. Zum Überblick ist eine schematische Darstellung der Chitinasen aus Bacillus WG3 und der vom Insert aus pSG kodierten Chitinase C im Vergleich zur Chitinase C aus S. griseus und der Chitinase aus Tabak in Abb. 30 dargestellt. 


\section{Chitin-Bindedomäne Katalytische Domäne \\ (Familie 19) \\ (Familie 19) \\ (24-65) \\ (66-327)}

Tabak

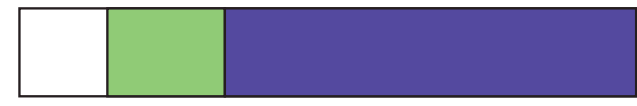

Chitin-Bindedomäne Katalytische Domäne

(Familie 18)

(Familie 19)

(29-80)

(80-295)

S. griseus

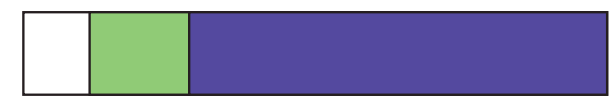

(37-88)

(89-307)

Chitinase IS

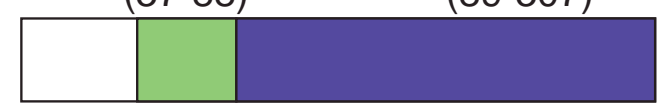

Chitinase C

$(29-80)$

(80-295)

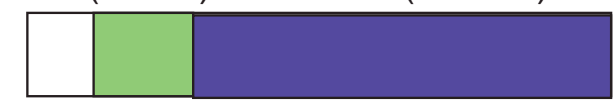

Abb. 30: Schematische Darstellung der Chitinasen IS aus WG3 und der Chitinase C kodiert vom Insert aus pSG im Vergleich zur Chitinase C aus S. griseus HUT6037 und der Chitinase aus Nicotiana tabacum (Tabak)

Die katalytische- bzw. Chitin-Bindedomäne ist durch die Position innerhalb der Aminosäuresequenz dargestellt

3.9.2

Identifizierung und Charakterisierung von Chitinasen aus den Isolaten WG1 und SE1 sowie einer Anreicherungskultur aus Meeres-Proben

Beim Vergleich der aus den Inserts von pWG1, pSE1 und pVH abgeleiteten Aminosäuresequenzen mit bekannten Chitinasen der Familie 18 zeigte sich anhand der Sequenz-Ähnlichkeiten, das die katalytische Domäne aus allen drei identifizierten Chitinasen der Familie 18 angehörte. In Abb. 31 wurde als Beispiel dafür die katalytische Domäne der aus dem Insert von pVH abgeleiteten Aminosäuresequenz mit bekannten Chitinasen aus 
B. circulans (WATANABE et al., 1990), S. marcescens (HARPSTER und DUNSMUIR, 1989) und S. lividans (FUJI und MIYASHITA, 1993) verglichen. Die Aminosäuresequenzen der Chitinasen A aus WG1 und SE1 sind aufgrund ihrer hohen Ähnlichkeit zur Chitinase A kodiert vom Insert aus pVH dazu analog.

ChiA 264 PDLKIIPSIGGWTLSDP-------FYDFVD-KKNRDTFVASVKKFLKTWKFYDGVDIDWEFPGGGG B.C. 52 PNLKTIISVGGWTWSN-------RF SDVAATAATREVF ANSAVDFLRKYNF-DGVDLDWEFPVSGG S.m. 85 PSLRIMF IGGWYYSNDLGVSHANYVNAVKTPAARTKFAQSCVRIMKDYGE-DGVDIDWEFPQAAS.1. 329 PNIKILYSFGGWTWSGGFP------DAVKNPAAFAKSCHDLVEDPRWADVFDGVDLDWEFPNAC-

Abb. 31: Vergleich der katalytischen Domäne der aus dem Insert von pVH abgeleiteten Aminosäuresequenz mit bekannten Chitinasen der Familie 18

ChiA, Chitinase A kodiert von pVH; B.c Chitinase A1 aus B. circulans (WATANABE et al., 1990); S.m Chitinase B aus Serratia marcescens (P11797); S.1. Chitinase C aus S. lividans (P36909);

Es zeigen sich deutlich Ähnlichkeiten der Chitinasen zueinander

Da es bei der Chitinase A, kodiert vom Insert aus pVH, gelang auch die Chitin-Bindedomäne zu klonieren, ist in Abb. 32 ein Vergleich der Sequenz mit anderen Chitin-Bindedomänen der Familie 18, einer Cellulase-Bindedomäne und einer Protease durchgeführt worden.

$\begin{array}{lll}\text { ChiA } & 795 & \text { TNAWDATAVYTGGDQVTYAGKTWEAKWWDSRVKILASLANGVFGKKLVHLTVT } \\ \text { BC } & 653 & \text { VSAWQVNTAYTAGQLVTYNGKTYKCLQPHT------SLAGWEP SNVPALWQLQ } \\ \text { Sm } & 453 & \text { APAYVPGTTYAQGALVSYQGYVWQTKWGYITS------APGSDSAWLKVGRLA } \\ \text { Bsp } & 363 & \text { YPAWDPNTIYTD-EIVYHNGQLWAKWWTQNQEP---DPYGPWEPLN } \\ \text { Prot. } & 210 & \text {-GTWAVGTAYAAGATVTYGGATYRCLQAHTAQPG------WTPADVPALWQRV }\end{array}$

Abb. 32: Vergleich der Chitin-Bindedomäne der aus dem Insert von pVH abgeleiteten Aminosäuresequenz mit bekannten Chitinasen der Familie 18

ChiA, Chitinase A kodiert von pVH; Bc Chitinase A1 aus B. circulans (WATANABE et al., 1990) ; Sm Chitinase B aus S. marcescens (P11797); Bsp, Cellulase B aus B. sp. (P06565); Prot, Proteinase C aus S. griseus(AF515832)

Aus den in Abb. 31 und 32 aufgeführten Sequenzvergleichen ist zu ersehen, das bei der aus dem Insert von pVH abgeleiteten Chitinase entgegen der Chitinase IS aus dem Isolat WG3 und der Chitinase $\mathrm{C}$ abgeleitet aus dem Insert von pSG, sowohl die Chitin-Bindedomäne als auch die katalytische Domäne einer Familie, in diesem Falle der Familie 18 der GlykosylHydrolasen, angehören. Im folgenden ist schematisch die Struktur der Chitinasen aus den Isolaten WG1 und SE1 als auch der aus dem Vektor pVH abgeleiteten Chitinase A mit dem der Chitinase A aus V. harveyi (Abb. 33). 
Katalytische Domäne

(Familie 18)

260-321
Chitin-Bindedomäne

(Familie 18)

$795-835$

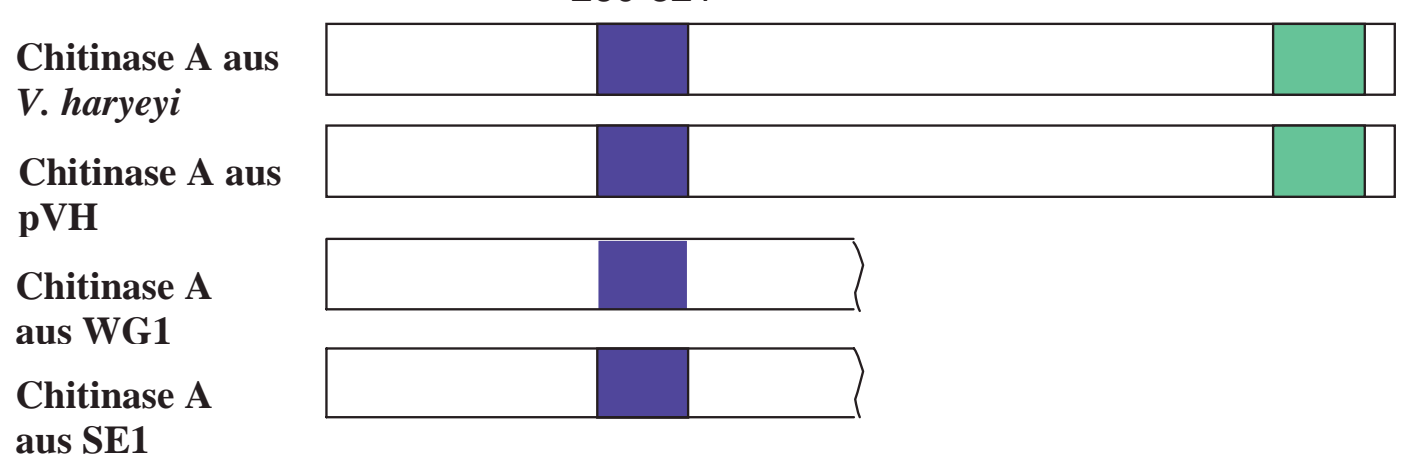

Abb. 33: Schematische Darstellung der Chitinasen aus WG1, SE1 und der Chitinase A kodiert vom Insert aus pVH im Vergleich zur Chitinase A aus V. harveyi

Die katalytische- bzw. Chitin-Bindedomäne ist durch die Position innerhalb der Aminosäuresequenz dargestellt

\subsection{Expression der identifizierten Chitinasegene}

Um die klonierten Chitinase-Gene bzw. deren Produkte auf ihre fungizide Wirkung hin zu überprüfen und die korrespondierenden Enzyme zu charakterisieren, sollten diese in die Expressionsvektoren pET 100 oder pET 101 umkloniert werden (s. 2.9.5.1). Mit Hilfe dieser Vektoren lässt sich das jeweilige Enzym heterolog in E. coli produzieren und durch den an das Protein fusionierten His $_{6}$-Tag reinigen. Ziel war es, die vollständig klonierten Chitinasegene aus pVH, pWG3 und pSG zu expremieren. Auf eine Umklonierung der Gene aus pWG1 und pSE1 in das pET-System wurde verzichtet, da diese Gene nur ohne die ChitinBindedomäne kloniert werden konnten. Untersuchungen zeigten, das eine Chitinase ohne Chitin-Bindedomäne in der Regel über nur sehr schwache Aktivitäten verfügt (SVITIL und Kirchman, 1998). 


\subsubsection{Expression des chiA-Gens aus pVH}

Nach Amplifikation des chiA-Gens aus pVH mit für das pET-System notwendigen modifizierten Oligonukleotiden VhpETfor/Vh-Stop (s. 2.1), wurde versucht das erhaltene PCR-Produkt in den Vektor pET101 umzuklonieren. Alle Untersuchungen des rekombinanten Vektors pET101 nach der Ligation wiesen jedoch ausschließlich Inserts in nicht korrekter Orientierung innerhalb der Klonierungsstelle des Vektors auf. Daraufhin wurde mit dem Oligonukleotid VhpET-Signal. (s. 2.1) ein PCR-Produkt ohne Signalsequenz amplifiziert. Dieses Produkt sollte ebenfalls in den Vektor pET101 kloniert werden. Zudem wurde versucht, das Insert mit dem Oligonukleotid-Paar Vhpet100for/Vh2542 (s. 2.1) in den Vektor pET100 umzuklonieren. Auch diese Versuche führten $\mathrm{zu}$ keinem positiven Resultat. Aufgrund dieses Befundes war anzunehmen, dass das chiA-Gen-Produkt für E. coli toxisch ist, da sich trotz aller Versuche das Chitinase-Gen aus pVH nicht in korrekter Orientierung in einen Expressionsvektor klonieren ließ.

\subsubsection{Expression der Chitinase-Gene aus den Inserts aus pWG3 und pSG}

Bei den beiden auf den Inserts aus pWG3 und pSG lokalisierten Chitinase-Genen gelang es, unter Verwendung der Oligonukleotide SGpET und ChiCrev-Stop (s. 2.1) das jeweilige Gen in den Vektor pET101 zu klonieren. Die so erstellten rekombinanten Expressionsvektoren erhielten die Bezeichnung pWG3-1 bzw. pSG-1. Induktionsversuche mit dem pETExpressionssystem (s. 2.9.5.1) und dem E. coli-Stamm BL21 als Wirt, in den der jeweilige Vektor transformiert worden war, wiesen jedoch nach Auftragung der Rohextrakte auf SDSGele eine sehr geringe Produktion der Chitinasen auf. Daraufhin wurde bei den Chitinasen aus pWG3-1 und pSG-1 die Signalsequenz durch PCR mit den entsprechenden Oligonukleotiden entfernt. Dabei wurde die Oligonukleotide SGpET-Signal./ChiCrev-Stop (s. 2.1) verwendet. Das PCR-Produkt wurde erneut in den Vektor pET101 kloniert und die Produktion der Chitinasen untersucht. Die Produktion an rekombinanter Chitinase ließ sich auf diese Weise steigern. Die Chitinasen wurden anschließend mit Hilfe des His 6 -Tag über Affinitätschromatographie an Ni-NTA-Agarose gereinigt (s. 2.17.1). Das Enzym aus E. coli/pWG3-1 und E. coli/pSG-1 besaß eine Molekularmasse von jeweils ca. $30 \mathrm{kDa}$ (s. Abb. 34). Diese Größe stimmte mit der aus der Sequenz abgeleiteten Molekularmasse überein. 


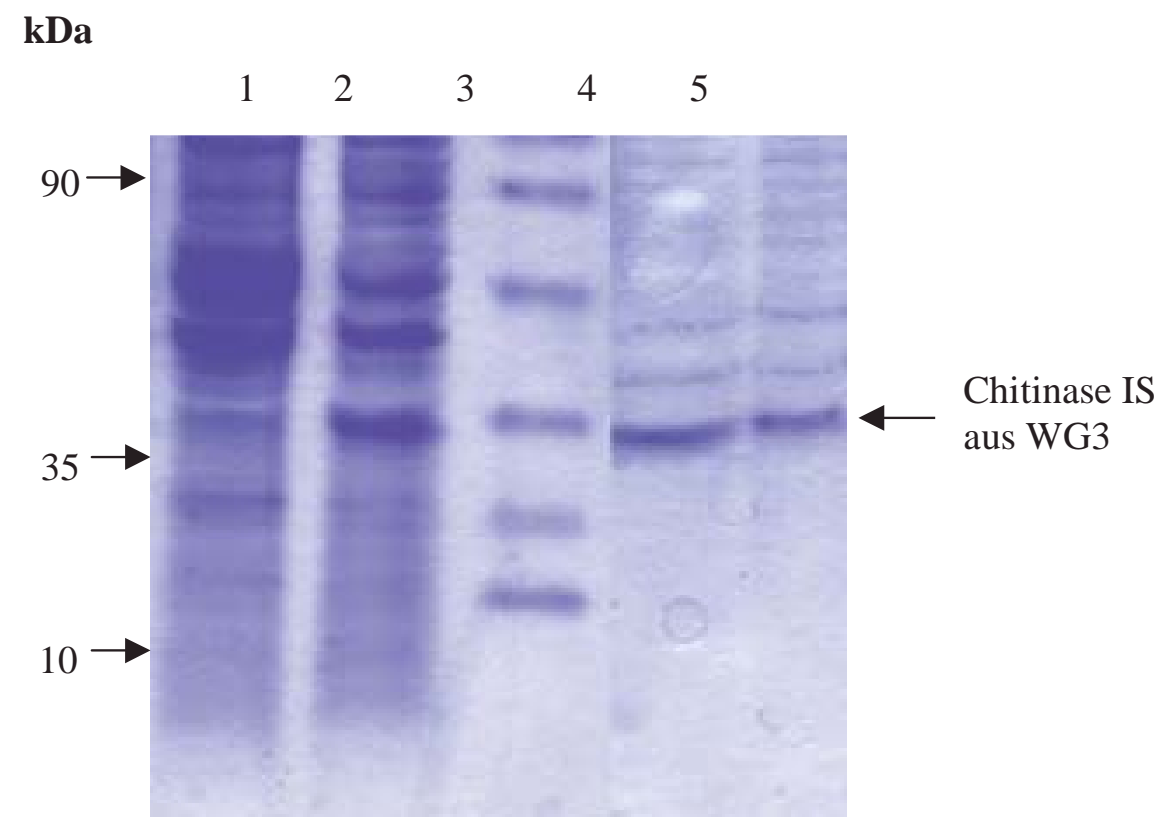

Abb. 34: Produktion der Chitinasen aus $E$. coli/pWG3-1 und $E$. coli/pSG-1 und Reinigung durch Affinitätschromatographie

Bande 1: E. coli/pWG3-1 nicht induziert

Bande 2: E. coli/pWG3-1 induziert (1 mM IPTG)

Bande 3: Größenstandart

Bande 4: Chitinase aus E. coli/pSG-1 nach Ni-NTA-Reinigung

Bande 5: Chitinase aus E. coli/pWG3-1 nach Ni-NTA-Reinigung

Der Pfeil markiert die produzierte Chitinase

Die Chitinasen aus E. coli/pWG3-1 und E. coli/pSG-1 konnten mit Ni-NTAAffinitätschromatographie nicht vollständig gereinigt werden. Im Rahmen der SDS-PAGEAnalyse der Eluate waren noch Verunreinigungen erkennbar (s. Abb. 34). Möglicherweise erschwerte die Konformation der Enzyme die Zugänglichkeit des His6-Tag an die Ni-NTASäulen.

\subsection{Charakterisierung der Chitinasen aus $E$. coli/pWG3-1 und $E$. coli/pSG-1}

Nachdem die beiden Enzyme rekombinant über E. coli produziert worden waren, wurden die gereinigten Enzyme charakterisiert. Dazu gehörten die Ermittlung der spezifischen 
Chitinaseaktivität bei der Spaltung von kolloidalem Chitin und Chitin-Pulver. Ebenso wurde das $\mathrm{pH}$ - und Temperaturoptimum ermittelt sowie die Untersuchung auf fungizide Eigenschaften der produzierten Chitinasen durchgeführt. Durch diese Tests ließ sich feststellen, ob diese Chitinasen für die mögliche Erstellung eines Chitinasepräparates zum Schutz vor Pilzbefall von z.B. Nutz- oder Zierpflanzen geeignet wären. Zudem ließ sich dadurch überprüfen, inwieweit die bereits in Punkt 3.2 dargestellte fungizide Wirkung des Enyzmüberstandes des Isolates WG3 auf die von diesem Bakterium produzierte Chitinase zurückführbar war, da das entsprechende Genprodukt kloniert und gereinigt vorlag.

\subsubsection{Bestimmung der spezifischen Chitinaseaktivität der Chitinasen aus E. coli/pWG3-1 und E. coli/pSG-1}

Zur Bestimmung der spezifischen Chitinaseaktivitäten der fast vollständig gereinigt vorliegenden Chitinasen aus E. coli/pWG3-1 und E. coli/pSG-1 wurden Enzymtest wie unter 2.16.1 beschrieben durchgeführt. Als Testsubstrat wurde kolloidales Chitin und Chitin-Pulver eingesetzt. Die Reaktionen wurden bei pH 6 und $50{ }^{\circ} \mathrm{C}$, dem jeweiligem Optima der EnzymAktivität, durchgeführt. Die Ergebnisse sind in Tab. 16 wiedergegeben.

Tabelle 16: Spezifische Aktivität der Chitinasen aus $E$. coli/pWG3-1 und $E$. coli/pSG-1

\begin{tabular}{|l|l|l|}
\hline Chitinase & $\begin{array}{l}\text { Kolloidales Chitin (U/mg } \\
\text { Protein) }\end{array}$ & Chitin-Pulver (U/mg Protein) \\
\hline E. coli/pWG3-1 & 1,5 & 0,8 \\
\hline E. coli/pSG-1 & 1,8 & 0,9 \\
\hline
\end{tabular}

Dabei zeigte die Chitinase aus E. coli/pWG3-1 eine spezifische Aktivität beim Umsatz von kolloidalem Chitin von 1,5 U/mg Protein. Bei der Verwendung von Chitin-Pulver waren 0,8 U/mg gemessen worden. Beim Test der Chitinase aus E. coli/pSG-1 konnten demgegenüber die spezifische Aktivität beim Umsatz von kolloidalem Chitin mit 1,8 U/mg und bei ChitinPulver mit 0,9 U/mg Protein ermittelt werden. 


\subsubsection{Bestimmung des Temperatur-Optimums der Chitinasen aus E. coli/pWG3-1 und $E$. coli/pSG-1}

Zur Ermittlung des Temperaturoptimums wurde die Aktivität der gereinigten Enzyme in einem 20 mM Kalium-Phosphat-Puffersystem ( $\mathrm{pH}$ 6,0) im Bereich von 20-65 ${ }^{\circ} \mathrm{C}$ gemessen (s. 2.17.1). Bei der Chitinase aus E. coli/pWG3-1 zeigte sich dabei ein Temperaturoptimum von $50{ }^{\circ} \mathrm{C}$. Bei $20^{\circ} \mathrm{C}$ lag die relative Aktivität bei $20 \%$. Bei $65^{\circ} \mathrm{C}$ war keine Aktivität mehr nachweisbar (s. Abb. 35).

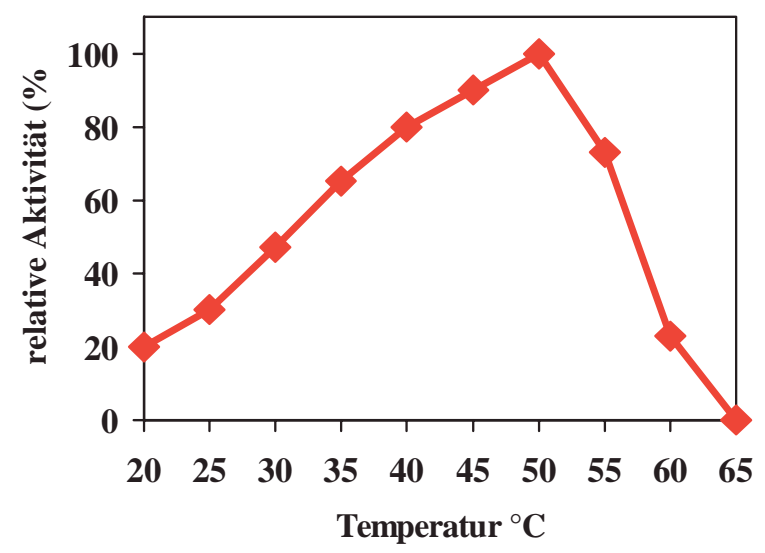

Abb. 35: Bestimmung des Temperaturoptimums der Chitinase aus E. coli/pWG3-1

Zur Messung der Chitinase-Aktivität bei pH6,0 wurde das gereinigte Enzym aus E. coli /pWG3-1 verwendet. $100 \%$ entsprechen 1,5 U/mg Protein

Bei der Bestimmung des Temperaturoptimums der rekombinant produzierten Chitinase aus E. coli/pSG-1 zeigte sich ein Optimum zwischen 50 und $55^{\circ} \mathrm{C}$. Bei $20{ }^{\circ} \mathrm{C}$ war die Aktivität wie bei $65{ }^{\circ} \mathrm{C}$ auch auf ca. $30 \%$ gesunken (s. Abb. 36). 


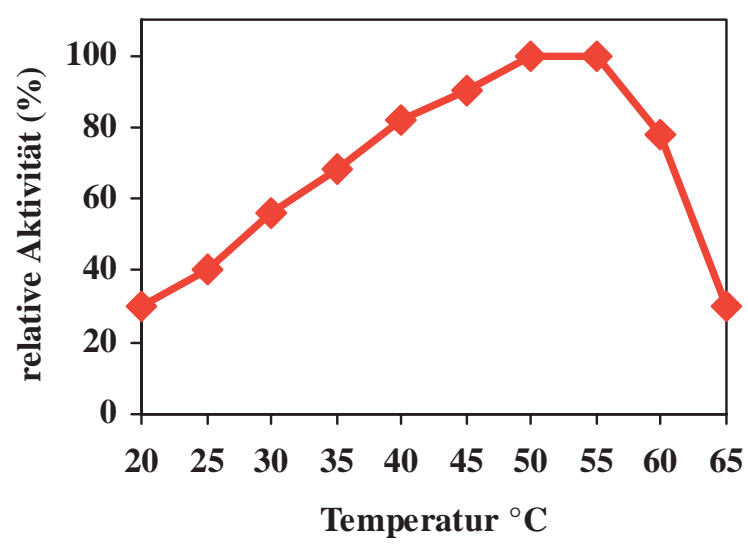

Abb. 36: Bestimmung des Temperaturoptimums der Chitinase aus $E$. coli/pSG-1

Zur Messung der Chitinase-Aktivität bei pH 6,0 wurde das gereinigte Enzym aus E. coli/pSG1 verwendet. $100 \%$ entsprechen $1,8 \mathrm{U} / \mathrm{mg}$ Protein

\subsubsection{Bestimmung des pH-Optimums der Chitinasen aus $E$. coli/pWG3-1 und E. coli/pSG-1}

Die Ermittlung des pH-Optimums fand im Ansatz bei $50{ }^{\circ} \mathrm{C}$ statt. Bei dieser Temperatur wiesen beide Chitinasen ihr Aktivitätsmaximum auf. Dabei zeigte sich, dass die Chitinase aus pWG3-1 ein pH-Optimum zwischen pH 5 und 7 aufwies (s. Abb. 37). Auch bei pH 8 lag die relative Aktivität des Enzyms noch bei 90 \%. Selbst im basischen Bereich von pH 10 konnte noch eine Aktivität von etwa $45 \%$ gemessen werden. Diese Daten zeigten, dass die Chitinase aus dem Isolat WG3 über Aktivität in einem weiten $\mathrm{pH}$-Bereich verfügte.

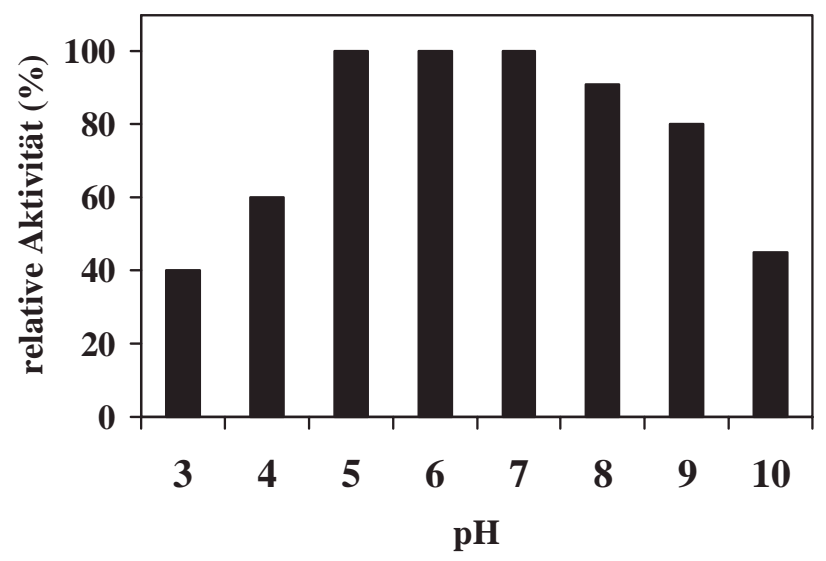

Abb. 37: pH-Optimum der Chitinase aus $E$. coli/pWG3-1

Die Messung der Chitinase-Aktivität bei unterschiedlichen $\mathrm{pH}$-Werten erfolgte bei $50{ }^{\circ} \mathrm{C}$ mit dem gereinigtem Enzym aus E. coli/pWG3-1. $100 \%$ Chitinase-Aktivität entsprechen 1,5 U/mg Protein 
Bei der Chitinase aus pSG-1 lag das pH-Optimum im Bereich zwischen 5 und 6. Auch bei pH 7 lag die Aktivität noch bei über 95 \% (s. Abb. 38). Bei pH 10 wies die Chitinase eine relative Aktivität von $50 \%$ auf. Somit ist festzustellen, das ebenso wie bei der Chitinase aus dem Isolat WG3 die Chitinase aus E. coli/pSG-1 über Aktivität in einem weitem pH-Bereich verfügte.

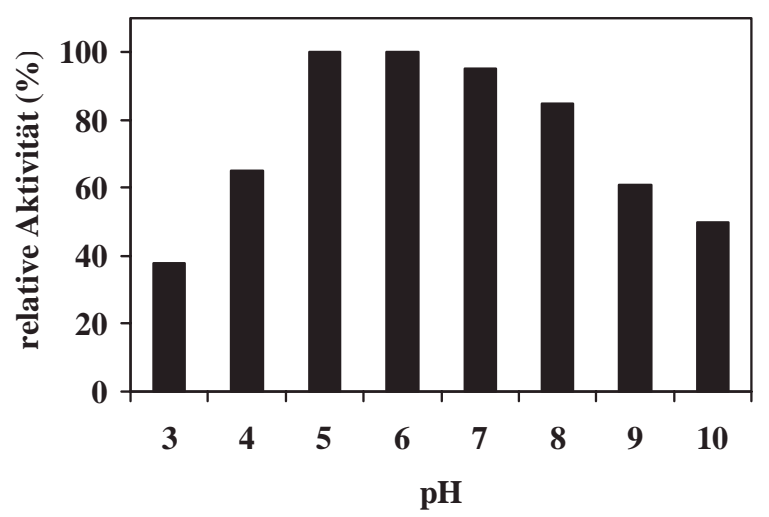

\section{Abb. 38: pH-Optimum der Chitinase aus E. coli/ pSG-1}

Die Messung der Chitinase-Aktivität bei unterschiedlichen $\mathrm{pH}$-Werten erfolgte bei $50{ }^{\circ} \mathrm{C}$ mit dem gereinigtem Enzym aus E. col/pSG-1. 100 \% Chitinase-Aktivität entsprechen 1,8 U/mg Protein

\subsubsection{Untersuchung der Chitinasen aus $E$. coli/pSG-1 und $E$. coli/pWG3-1 auf fungizide Eigenschaften}

Um zu Überprüfen, ob die rekombinant produzierten Chitinasen aus dem Isolat WG3 und der aus einer Anreicherungskultur amplifizierten Chitinase C, kodiert vom Insert aus pSG-1, über fungizide Eigenschaften verfügten, wurden Agarplatten mit den unter Punkt 3.3 beschriebenen Pilzen beimpft und Papier-Filterscheiben an den Randbereich der Agarplatten gelegt. Diese wurden mit der jeweiligen rekombinanten Chitinase getränkt und auf ein hemmende Wirkung gegenüber dem Pilzwachstum untersucht. Bei diesem Test waren jeweils $40 \mu \mathrm{g}$ Protein in $20 \mathrm{mM}$ Kalium-Phosphatpuffer $(\mathrm{pH} \mathrm{6,0)}$ auf die Filterscheibe aufgetragen worden. Die Platten wurden anschließend bei $30{ }^{\circ} \mathrm{C}$ inkubiert, um für die Pilze optimale Wachstumsbedingungen zu gewährleisten. Bei allen 5 getesteten Pilzstämmen, A. nidulans, $B$. 
cinerea, F. culmarum, G. bidwellii und S. sclerotiorum konnte die Hyphenbildung der Pilze gehemmt werden. Beim Einsatz von $20 \mu \mathrm{g}$ Protein konnte weder beim Enzym aus E. coli /pWG3-1 als auch aus E. coli/pSG-1 eine Hemmhofbildung beobachtet werden. Dieser Test zeigte, dass die beiden getesteten Chitinasen über fungizide Eigenschaften gegenüber allen vier getesteten pflanzenpathogenen Pilzen und einem Vertreter der Schimmelpilze aufwiesen (s. Abb. 39 A und 39 B). Diese antifungale Wirkung war beim Isolat WG3 bereits bei den Vorversuchen mit der Bakteriensuspension bzw. dem Kulturüberstand von WG3 festgestellt worden (s. 3.3).

1

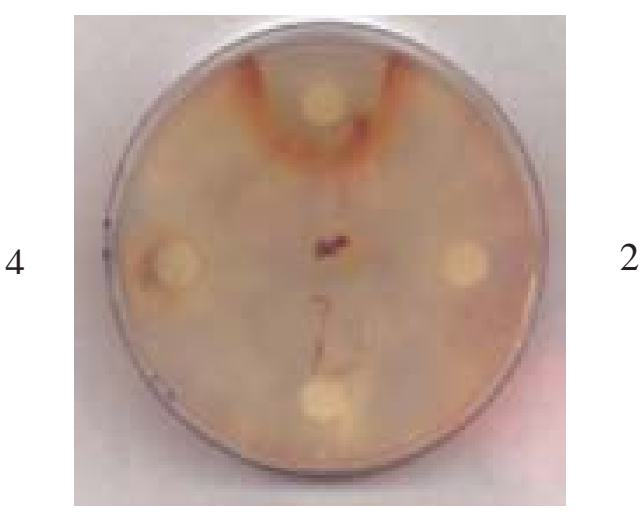

3

\section{Abb. 39 A: Hemmung des fungalen}

Wachstums von Fusarium culmarum durch die Chitinase aus $E$. coli/pWG3-1

1: $40 \mu \mathrm{g}$ Enzym

2: $20 \mu \mathrm{g}$ Enzym

3: $10 \mu \mathrm{g}$ Enzym

4: Negativkontrolle

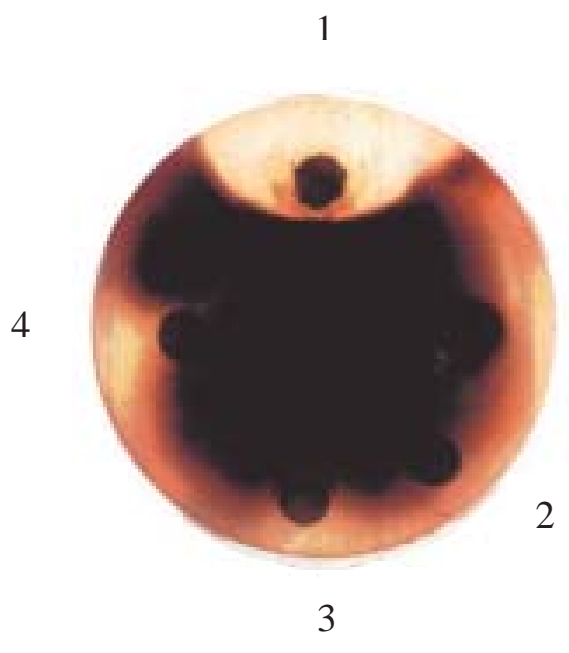

Abb. 39 B: Hemmung des fungalen Wachstums von Guignardia bidwellii durch die Chitinase aus $E$. coli/pSG-1

1: $40 \mu \mathrm{g}$ Enzym

2: Negativkontrolle

3: $10 \mu \mathrm{g}$ Enzym

4: $20 \mu \mathrm{g}$ Enzym

Diese Ergebnisse zeigten, dass beide Chitinasen für die Erstellung eines Chitinasepräparates in Frage kämen, da nicht nur eine fungizide Wirkung sondern auch ein relativ breites $\mathrm{pH}$ Spektrum (s. 3.11.3) gegeben ist. Zudem war die Hemmung des fungalen Wachstums bei beiden Chitinasen über den gesamten Testzeitraum von 4 Wochen stabil. Dieses sind für ein Chitinasepräparat wichtige Kriterien, da es je nach Beschaffenheit der mit den Chitinasen zu behandelnden Fläche zu unterschiedlichen $\mathrm{pH}$ Bedingungen kommen kann. Zudem sollte das Präparat eine möglichst lange stabile Aktivität aufweisen. 


\subsection{Charakterisierung der Chitinasen aus WG1, SE1, E2 und SL3 im Kulturüberstand}

Um die Chitinasen der Isolate mit fungiziden Eigenschaften näher zu charakterisieren, deren Chitinasegen nicht bzw. nur partiell kloniert werden konnten, wurden diese einer Reihe von Tests unterzogen. Diese wurden nach Fällung der Chitinasen aus dem Kulturüberstand durchgeführt (s. 2.16). Diese Untersuchungen bezogen sich auf die Chitinasen der Isolate SE1, SL3, WG1 und E2. Dabei wurden außer der Chitinaseaktivität auch das pH- und Temperaturoptimum bestimmt.

\subsubsection{Bestimmung des Temperaturoptimums der Chitinasen aus E2, SE1, SL3 und WG1}

Zur Bestimmung des Temperaturoptimums wurde die Chitinase-Aktivität der Isolate in einem Temperaturbereich von 20 bis $70{ }^{\circ} \mathrm{C}$ gemessen. Die Temperaturverläufe für die ChitinaseAktivitäten aus den Isolaten SE1 und SL3 sind in Abb. 40 dargestellt. Sowohl die von SE1 als auch die von SL3 produzierte Chitinase hatte ein Temperaturoptimum von $50{ }^{\circ} \mathrm{C}$. Bei $70{ }^{\circ} \mathrm{C}$ zeigten beide Enzyme keine signifikante Aktivität mehr.

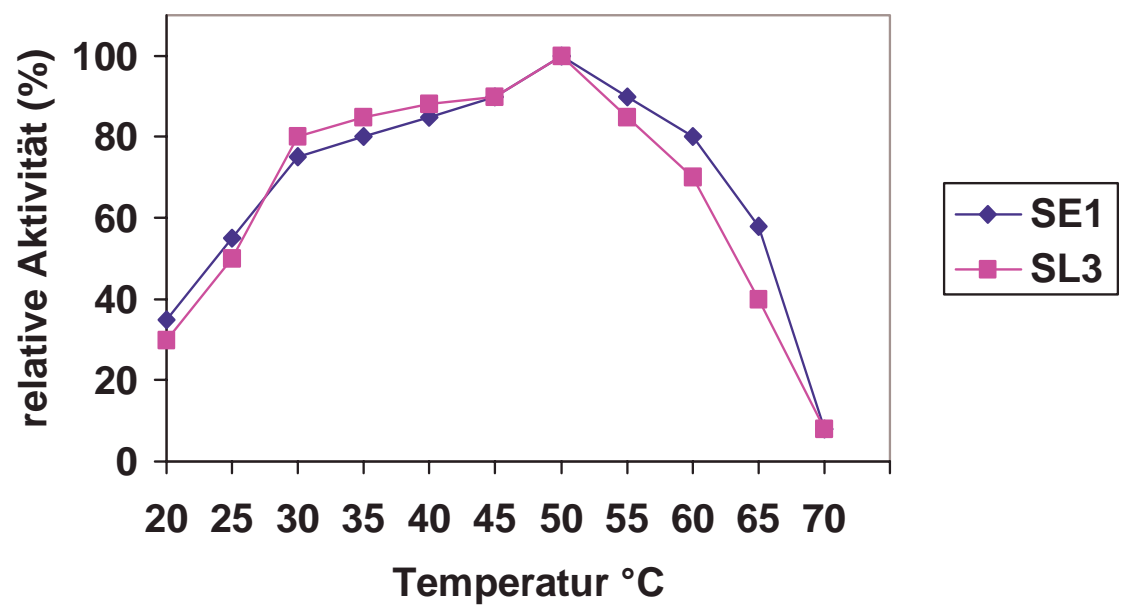

\footnotetext{
Abb. 40: Bestimmung des Temperaturoptimums der Chitinasen von SE1 und SL3 im Kulturüberstand

Zur Messung der Chitinase-Aktivität bei pH 6,0 bei SE1 und $\mathrm{pH} 4$ bei SL3 wurden die Kulturüberstände von SE1 und SL3 gefällt und konzentriert. $100 \%$ entsprechen 0,3 U/mg Protein bei SE1 und 0,37 U/mg Protein bei SL3
} 
Das Temperaturoptimum von WG1 und SL3 ist in Abb. 41 ersichtlich. Das Temperaturoptimum der Chitinase von WG1 lag ebenfalls wie bei SE1 und SL3 bei $50{ }^{\circ} \mathrm{C}$, dasjenige von E2 bei $45{ }^{\circ} \mathrm{C}$. Bei $70{ }^{\circ} \mathrm{C}$ fiel die Aktivität der Chitinase von WG1 und E2 auf unter $10 \%$.

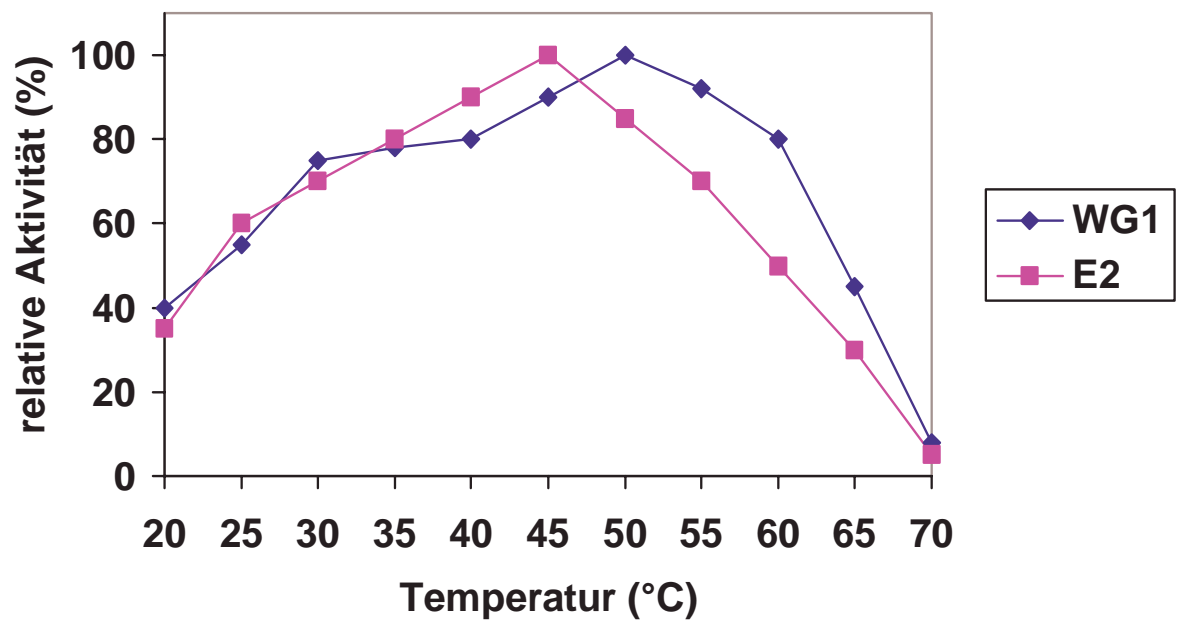

Abb. 41: Bestimmung des Temperaturoptimums der Chitinasen von WG1 und E2 im Kulturüberstand

Zur Messung der Chitinase-Aktivität bei pH 6,0 bei WG1 und $\mathrm{pH} 5$ bei E2 wurden die Kulturüberstände von WG1 und E2 gefällt und konzentriert. $100 \%$ entsprechen 0,22 U/mg Protein bei WG1 und 0,3 U/mg Protein bei E2

\subsubsection{Bestimmung des pH-Optimums der Chitinasen aus E2, SE1, SL3 und WG1}

Die Bestimmung der pH-Abhängigkeit der Chitinase-Aktivität aus den Isolaten WG3, SE1 und SL3 fand bei $50{ }^{\circ} \mathrm{C}$ statt, da bei dieser Temperatur die Enzyme ihre maximale Aktivität aufwiesen. Bei E2 wurde dieses entsprechend bei $45^{\circ} \mathrm{C}$ ermittelt. Die Aktivität der Chitinasen wurde im pH-Bereich von 3 bis 10 gemessen. Es ergab sich bei WG1 ein pH-Optimum von 6 (s. Abb. 42). Im sauren Bereich war bei $\mathrm{pH} 3$ nur noch eine sehr schwache Aktivität messbar. Bei pH 10 lag die Aktivität unter $20 \%$. 


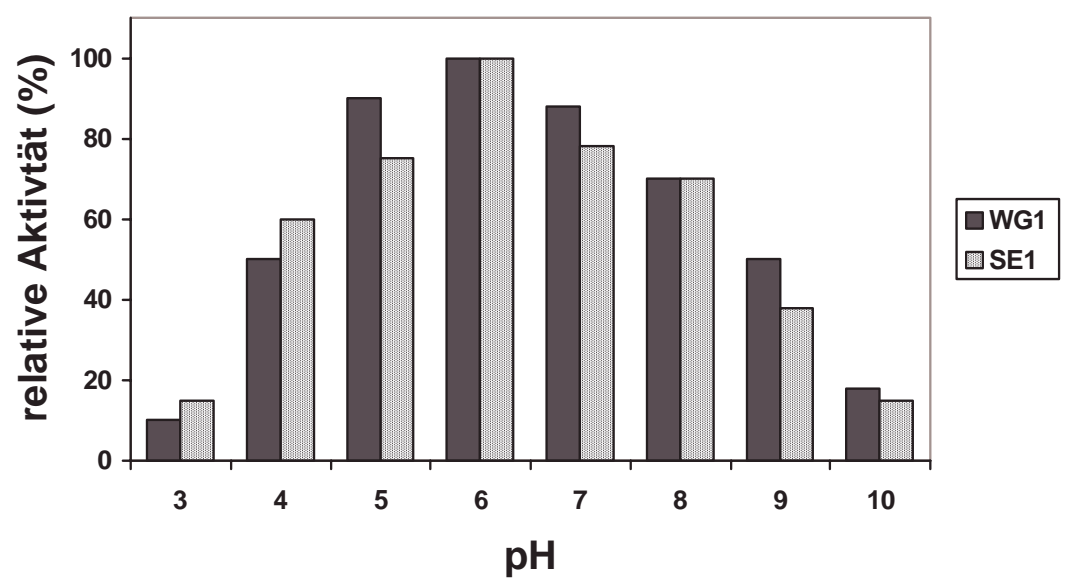

Abb. 42: pH-Optimum der Chitinasen WG1 und SE1 im Kulturüberstand

Die Messungen der Chitinase-Aktivitäten bei unterschiedlichen $\mathrm{pH}$-Werten erfolgten bei $50{ }^{\circ} \mathrm{C}$, dem Temperaruroptimum der aus dem Kulturüberstand gefällten Chitinasen von WG1 und SE1. $100 \%$ Chitinaseaktivität entsprechen 0,22 U/mg Protein bei WG1 und 0,3 U/mg Protein bei SE1

Bei der Messung des pH-Optimums der Chitinase aus SE1 zeigte sich ebenfalls bei pH 6 die maximale Aktivität (s. Abb. 42). Bei pH 3 und pH 10 lag die Aktivität bei unter $20 \%$.

Bei der Ermittlung des pH-Optimums des Isolates SL3 zeigte sich, dass die maximale Aktivität des Enzyms bei pH 4 im lag (s. Abb. 43). Bei pH 5 wies die Aktivität des Enzyms $98 \%$ auf. Im basischem Bereich waren bei $\mathrm{pH} 9$ und 10 nur noch eine sehr geringe Aktivitäten von $<20 \%$ messbar.

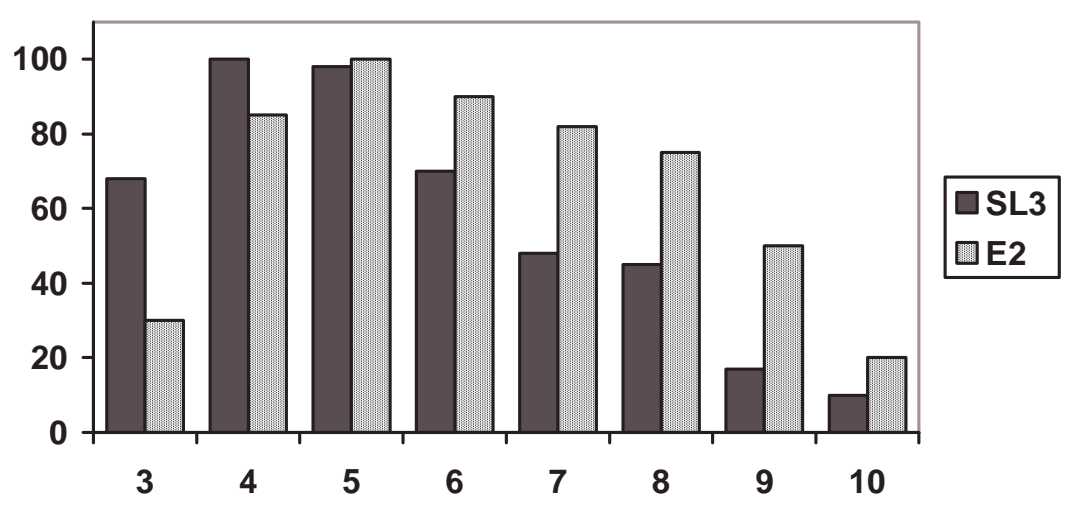

\section{Abb. 43: pH-Optimum der Chitinase SL3 und E2 im Kulturüberstand}

Die Messungen der Chitinase-Aktivitäten bei unterschiedlichen $\mathrm{pH}-$ Werten erfolgten bei 50 ${ }^{\circ} \mathrm{C}$ bei SL3 und $45{ }^{\circ} \mathrm{C}$ bei E2, dem jeweiligem Temperaruroptimum der aus dem Kulturüberstand gefällten Chitinasen von SL3 und E2. $100 \%$ Chitinaseaktivität entsprechen 0,37 U/mg Protein bei SL3 und 0,3 U/mg Protein bei E2 
Beim Isolat E2 lag das pH-Optimum bei pH 5 (s. Abb. 42). Bei pH 4 und 6 wies das Enzym noch Aktivitäten von über $80 \%$ auf. Bei pH 10 sank die Aktivität der Chitinase auf $20 \%$ ab.

Die ermittelten biochemischen Daten zeigten, das die Chitinasen von WB1 und SE1 sehr ähnlich sind. Die Kurvenverläufe im Bereich des Temperatur- als auch des pH-Optimums sind fast identisch. Das pH-Optimum von SL3 liegt mit pH 4 im sauren Bereich.

Die Messungen bezüglich der spezifischen Aktivitäten liegen bei allen Chitinasen deutlich unter $0,4 \mathrm{U} / \mathrm{mg}$ Protein. Da die Messungen nach Fällung aus dem Kulturüberstand stattfanden, stellte dieses Ergebnis nicht die endgültige spezifische Aktivität der Chitinasen dar, weil das Vorhandensein einer Vielzahl von Proteinen im Messansatz das Ergebnis verfälschten. Die Werte sind in U/mg Protein in Tab. 17 angegeben. Zudem sind die Chitinaseaktivität und das Optima des Isolates WG3 nach Fällung aus dem Kulturüberstand angegeben. Das Chitinasegen aus diesem Isolat war wie beschrieben kloniert worden. Der Wert der spezifischen Aktivität lag im Kulturüberstand bei 0,25 U/mg Protein und damit wie zu erwarten deutlich unterhalb des Wertes, der nach heterologer Produktion und Reinigung gemessen worden war. Dieser Wert lag bei 1,5 U/mg Protein (s. 3.11.1). Die höchste Aktivität wies die Chitinase aus dem Isolat SL3 mit 0,37 U/mg Protein auf.

Tab. 17: Charakteristika der Chitinasen aus dem Kulturüberstand von WG1, SE1, E2 WG3 und SL3

\begin{tabular}{|c|c|c|c|}
\hline Isolat & $\begin{array}{c}\text { Spezifische Aktivität } \\
\text { (U/mg Protein) }\end{array}$ & Temperaturoptimum & pH-Optimum \\
\hline E2 & 0,3 & $45^{\circ} \mathrm{C}$ & 5 \\
\hline SE1 & 0,3 & $50{ }^{\circ} \mathrm{C}$ & 6 \\
\hline SL3 & 0,37 & $50{ }^{\circ} \mathrm{C}$ & 6 \\
\hline WG1 & 0,22 & $50^{\circ} \mathrm{C}$ & 6 \\
\hline WG3 & 0,25 & $50^{\circ} \mathrm{C}$ & 4 \\
\hline
\end{tabular}




\subsection{Bestimmung der molekularen Masse der Chitinasen aus den Isolaten mit fungizider Wirkung}

Zur Bestimmung der molekularen Masse der Enzyme, wurde ein Aktivitätstest im nativen Gel durchgeführt (s. 2.18.3). Nach Inkubation des Gels über 12 Stunden konnten Aufklarungszonen im Gel detektiert werden (s. Abb. 44).

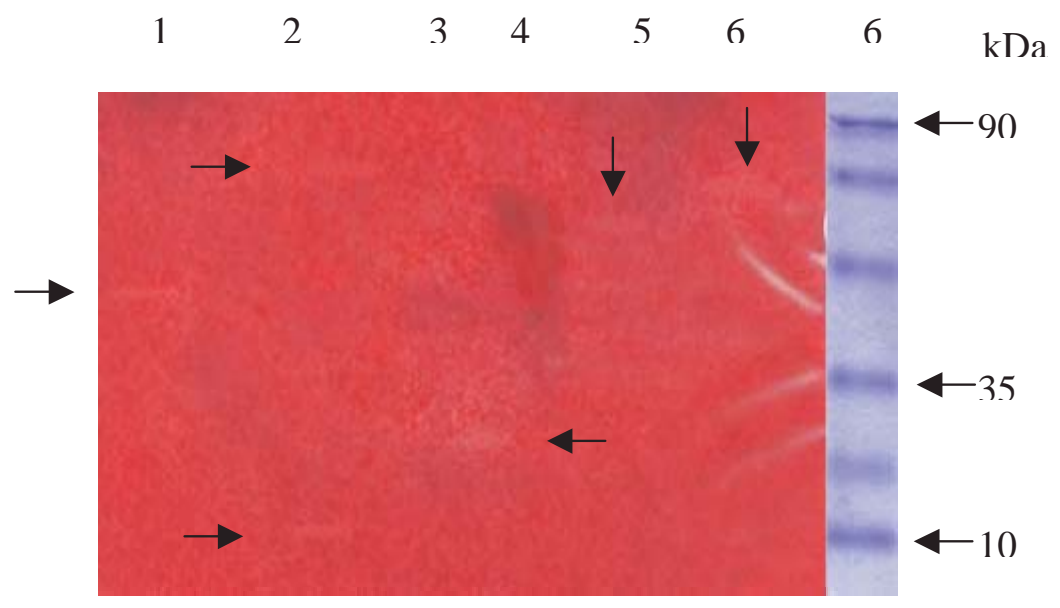

\section{Abb. 44: Aktivitätsfärbung nach Auftrennung der Enzyme über native-Gradienten- PAGE}

Spur 1: Enzymüberstand von E2

Spur 2: Enzymüberstand von SE1

Spur 3: Enzymüberstand von WG3

Spur 4: Enzymüberstand von SL3

Spur 5: Enzymüberstand von WG1

Spur 6: Größenmarker

Die schwach sichtbaren Banden sind jeweils mit einem Pfeil markiert

Bei WG1, SE1 und SL3 konnte ein Bande bei ca. $90 \mathrm{kDa}$ ermittelt werden. In 3.8.2 wurde beschrieben, dass das komplette Genprodukt aus WG1 und SE1 aufgrund der hohen Ähnlichkeit zur Chitinase A aus $V$. harveyi ca. $90 \mathrm{kDa}$ aufweisen würde. Die Aktivitätsfärbung nach Auftrennnung des Kulturüberstandes aus diesen Isolaten wies diese erwartete Molekularmasse auf. Zudem zeigte sich bei SE1 eine zweite Bande von ca. 10 kDa. Offenbar produzierte der Organismus noch eine weitere Chitinase. Verschiedene Untersuchungen zeigte, das viele Chitin-verwertende Bakterien mehr als nur eine Chitinase produzieren (SVITIL und KIRCHMAN, 1996).

Die Chitinase aus E2 wies ca. 70 kDa auf. Bei dem Isolat WG3 konnte eine Bande mit einer Molekularmasse von ca. $30 \mathrm{kDa}$ detektiert werden. Diese Bande korrespondierte mit der aus dem Isolat klonierten und rekombinant produzierten Chitinase aus E. coli/pWG3-1, deren 
Aminosäuresequenz ein Enzym von 31 kDa umfasste (s. 3.8.2). Die Daten sind in Tab. 18 zusammengefasst.

Tabelle 18: Durch Aktivitätsfärbung ermittelte Proteingrößen der Chitinasen in kDa

\begin{tabular}{|c|c|}
\hline Chitinase des Isolates & Größe der Chitinase in kDa \\
\hline WG1 & 90 \\
\hline WG3 & 30 \\
\hline SE1 & $90 / 10$ \\
\hline E2 & 70 \\
\hline SL3 & 90 \\
\hline
\end{tabular}

Es gelang somit die Chitinasen aus 5 Isolaten mit fungizider Wirkung näher zu charakterisieren. Aus den Isolaten WG1 und SE1 konnte das Chitinasegen partiell und beim Isolat WG3 komplett kloniert werden. Des weiteren konnten zwei Chitinasen aus Anreicherungen vollständig identifiziert und kloniert werden. Die rekombinanten Vektoren erhielten dabei die Bezeichnungen pSG und pVH. Von diesen insgesamt drei komplett klonierten Chitinase-Genen konnten im Laufe der Arbeit zwei expremiert und auf ihre fungiziden Eigenschaften hin untersucht werden. Die dabei erzielten Resultate zeigten, das beide für die Erstellung eines Chitinasepräparates in der Verwendung als Biopestizid geeignet sein könnten. 
4. Diskussion

\subsection{Isolierung von Chitinase-Produzenten}

Chitin ist das am zweithäufigsten auf der Erde vorkommende Biopolymer. Pro Jahr wird etwa 1 Milliarde Tonnen produziert. Dabei ist Chitin die Haupt Kohlenstoff- und Energiequelle der Ozeane. Ein erheblicher Teil stellt das Chitin dar, das von Arthropoden gebildet wird. So fallen allein in der Fischindustrie 2 Millionen Tonnen des Biopolymers an.

Chitinasen sind in der Lage, das in Wasser unlösliche Chitin in lösliche N-AcetylGlukosamin-Einheiten zu spalten. Dieser Prozess ist von elementarer Bedeutung, da ohne diese Spaltung das Chitin nicht in den Nahrungskreislauf der Erde zurückgeführt werden könnte. Aufgrund der großen Mengen des anfallenden Chitins sind Chitinasen für die industrielle Anwendung interessant, da diese Enzyme das Polymer in N-Acetyl-GlukosaminEinheiten spalten und so als Zucker verfügbar machen. Zur Zeit wird der größte Teil an anfallendem Chitin auf Deponien entsorgt. Chitinasen sind in der Natur weit verbreitet und erfüllen eine Reihe von unterschiedlichen Aufgaben. Bei Arthropoden sind sie notwendig für die Häutung, bei Pilzen erfüllen sie wichtige Funktionen beim Hyphenwachstum. Pflanzen produzieren Chitinasen zur Abwehr von phytopathogenen Pilzen. Die Produktion von Chitinasen als Fungizid konnte auch bei vielen Bakterien nachgewiesen werden. Zudem setzen Bakterien Chitinasen zur Nutzung des Chitins als C- und N-Quelle frei (HERRERAESTRELLA und CHET, 1999).

Durch Verwendung von Boden- bzw. Meeresproben verschiedener Habitate sollten im Rahmen dieser Arbeit Chitinase-produzierende Bakterien isoliert werden. Chitin-verwertende Bakterien sind bislang aus einer Vielzahl von Gattungen identifiziert worden. So finden sich chitinolytische Bakterien z.B. in Alcaligenes, Alteromonas, Bacillus, Chitinophaga, Cytophaga, Enterobacter, Ewingella, Flexibacter, Lysobacter, Micromonospora, Paenibacillus, Photobakterium, Planomonospora, Serratia, Streptomyces und Vibrio (KUROSHIMA et al., 1996)

Der größte Teil des in der Natur gebildeten Chitins wird in den Meeren durch Zooplankton und Phytoplankton produziert (SVITIL und KIRCHMAN et al., 1998). Daher ist davon auszugehen, dass marine Standorte ein hohes Potential an chitinolytischen Bakterien aufweisen. Untersuchungen zeigten, dass etwa $10 \%$ aller aus Meerwasser kultivierten Bakterien in der Lage sind, Chitin abzubauen (OKUTANI 1975). Durch weitere Untersuchungen, bei denen ein fluorogenes Analogon (4-Methylumbelliferyl-D-N,N- 
diacetylchitobiosid) von Chitin als Substrat eingesetzt wurde, konnte ein Anteil an chitinverwertenden Bakterien aus marinen Standorten von $90 \%$ ermittelt werden (COTTRELL et al., 1999). RAMAIAH et al., 2000, untersuchten Isolate aus der Chesapeake Bay (USA) auf das Vorhandensein von chitinolytischen Bakterien, deren Chitinase-Gene Ähnlichkeiten zum chiA-Gen der Familie 18 aus $V$. harveyi besaßen. Von 650 Standortisolaten konnten bei $29 \%$ ein positives Ergebnis erzielt werden. In diesem Ergebnis sind also nur die Bakterien mit einem chiA-Gen erfasst, so das die Gesamtzahl an chitinolytischen Bakterien noch weit größer sein dürfte.

Im Rahmen dieser Arbeit gelang es 13 Chitinaseproduzenten zu isolieren. Anhand der 16S rRNA-Gen-Analyse konnten diese Stämme näher charakterisiert und in Gattungen eingeordnet werden (s. 3.2). Diese Stämme ließen sich als bislang unbekannte Vertreter der Gattungen Bacillus, Paenibacillus, Sphingobakterium, Streptomyces, Flexibacter und Alcaligenes einordnen. Nur ein Isolat zeigte bei der 16S rRNA-Analyse eine $100 \%$ Übereinstimmung mit einem bekannten Organismus, Stenotrophomonas maltophilia. Diese oben erwähnten Bakteriengattungen sind bekannt dafür, dass einige ihrer Vertreter chitinolytische Aktivitäten besitzen. Unter den Isolaten aus Boden-Proben befand sich ein Vertreter der Streptomyceten. In Anbetracht dessen, das fast jede Streptomyceten-Spezies chitinolytische Fähigkeiten besitzt und in Boden-Proben stark vertreten ist (ca. $10^{5}$ bis $10^{7}$ Kolonie bildende Einheiten/g Erde, SMITHER-KOPPERL et al., 2002), war zu erwarten gewesen, das sich unter den Isolaten Streptomyceten identifizieren lassen. Ebenfalls weit verbreitet in Boden- und Meeres-Habitaten ist die Gattung Bacillus. Von 10 Isolaten aus Bodenproben waren 4 als Vertreter der Gattung Bacillus identifiziert worden (s. 3.2). Ebenso bei einem von drei Isolaten aus Meeresproben. KUROSHIMA et al. (1996), untersuchte Boden-Proben auf chitinolytische Bakterien und erhielt 5 Isolate die alle als Vertreter der Gattung Bacillus identifiziert wurden. Bei der Isolierung Chitinase-produzierender Bakterien aus Bodenproben erhielt auch WEN et al. (2002) einen Vertreter der Gattung Bacillus. Dabei verwendeten die Arbeitsgruppen ebenfalls Mineralmedium mit kolloidalem Chitin als einzige Kohlenstoff- und Energiequelle. IVANOVA et al. (1999) isolierte 20 Bakterien der Gattung Bacillus für taxonomische Untersuchungen aus Meerwasser. Ein Isolat aus Bodenproben konnte aufgrund der 16S rRNA-Gen-Analyse als Stenotrophomonas maltophilia eingeordnet werden. Dieses Bakterium ist ein in der Rhizosphaere weit verbreitetes Bakterium mit chitinolytischer Aktivität (KOBAYASHI et al., 2001). Drei Isolate aus Bodenproben wiesen Ähnlichkeiten zur Gattung Paenibacillus auf (s. 3.2). Einige Vertreter dieser Gattung sind als Chitinase-Produzenten bekannt, darunter Paenibacillus macerans (SINGH et al., 1998), zum 
dem die 3 Isolate die größte Ähnlichkeit aufwiesen. Ein Isolat zeigte Ähnlichkeiten zu Flexibacter sancti, ebenfalls ein Chitinase-produzierender Organismus der aus Bodenproben isoliert worden war (SLY et al., 1999).

In marinen Stadorten dominiert unter den chitinolytischen Bakterien die Gattung Vibrio (BASSLER et al., 1990). Bei der Isolierung von Bakterien aus marinen Standorten konnten 3 Stämme erhalten werden, von denen keiner in die Gattung Vibrio eingeordnet werden konnte. Stattdessen gehörten diese bislang unbekannten Vertretern der Gattungen Alcaligenes, Bacillus und Sphingobakterium an. Das Isolat, das sich als bislang unbekannter Vertreter der Gattung Alcaligens einorden ließ, zeigte die größte Ähnlichkeit zu A. xylosoxidans. Dieses chitinolytische Bakterium war aus Bodenproben isoliert worden (VAIDJAH et al., 2001). Ein weiteres Isolat zeigte die größte Ähnlichkeit zu Sphingobakterium multivorum, ein ebenfalls aus Bodenproben isoliertes chitinolytisches Bakterium (MATSUDA et al., 2001). Bei der Isolierung von chitinolytischen Bakterien aus Boden- und Meeresproben wurden somit 12 Stämme isoliert, von denen bis auf ein Isolat alle als bislang unbekannte Vertreter verschiedener Bakterien-Gattungen identifiziert werden konnten.

\subsection{Untersuchung der Isolate auf fungizide Eigenschaften}

$\mathrm{Zu}$ den Pestiziden gehören neben den Insektiziden auch die Herbizide und Fungizide. Diese werden unter anderem in der Landwirtschaft eingesetzt. Durch den Einsatz von Pestiziden in der Landwirtschaft wird der Ernteertrag durch den Schutz der Nutzpflanzen vor z.B. phytopathogenen Pilzen und Insekten erhöht. Obwohl die Menge der jährlich eingesetzten Pestizide in den Jahren von 1930 bis 1980 um 1900 \% zugenommen hat, werden auch heute noch ca. 33 \% der Ernteerträge durch Schädlinge vernichtet (HALL, 1991). Ein Nachteil der synthetisch hergestellten Pestizide liegt in der Bedrohung der Umwelt und des Menschen durch Kontamination der zu schützenden Feldfrüchte selbst und der Gewässer. Eine Möglichkeit, den Einsatz der synthetischen Pestizide zu mildern, läge in der Entwicklung von biologisch vollständig abbaubaren Biopestiziden. Chitinolytische Bakterien könnten dabei für die Entwicklung von Chitinasen als Biopestizid von Nutzen sein. So konnte für die Chitinase aus Bacillus thuringiensis eine insektizide Wirkung nachgewiesen werden. Insekten besitzen Chitin nicht nur im Exoskelett, sondern auch in der peritrophen Membran des Darms. Für die Chitinase aus B. thuringiensis konnte eine pathogene Wirkung auf Insekten nachgewiesen werden. Diese war auf den Abbau des Chitins der peritrophen Membran zurückzuführen. 
Hieraus resultierte eine Destabilisierung der Membranintegrität, die eine verstärkte Osmosensitivität des Insekts bedingte (FLYG et al., 1988.; SAMPSON et al., 1998). Verschiedene Stämme von $B$. thuringiensis werden weltweit als Schädlingsbekämpfungsmittel gegen Insekten eingesetzt (SAMPSON et al., 1998). Neben der Chitinase besitzt $B$. thuringiensis das sogenannte $\delta$-Endotoxin, das während der Sporulation als Protoxin gebildet und in den Darm von Insektenlarven proteolytisch zu toxischen Polypeptiden gespalten wird (DOWNING et al., 2000). Die Sensitivität der Insekten gegenüber diesem Toxin wird durch die Chitinase erhöht, da diese die Chitin-haltige Darmmembran porös macht und das Eindringen des Toxins fördert (DOWNING et al. 2000). Das $\delta$-Endotoxin als auch die Chitinase A aus S. marcescens wurden in P. fluorescens, einem als Endophyt lebendem Bakterium eingeführt. Tests zeigten, dass das transformierte Bakterium in der Lage war, die Abwehr der Zuckerrohr-Wirtspflanze gegenüber dem phytopathogenen Pilz Eldana saccharina zu steigern (DOWNING et al., 2000).

Neben S. griseus HUT6037 (OHNO et al., 1996) sind noch weitere Bakterien identifiziert worden, deren Chitinasen fungizide Eigenschaften besitzen. Diese können die Chitinpolymere in der Zellwand von Pilzen angreifen. Dadurch werden die Pilze osmotisch sensitiv und lysieren (SELITRENNIKOFF, 2001). Nicht alle Chitinasen weisen fungizide Wirkungen auf. So konnten bakterielle Chitinasen identifiziert werden, für die keinerlei fungizide Eigenschaften nachgewiesen wurden. Ein Beispiel dafür ist die Chitinase A1 aus B. circulans, (WATANABE et al. 1999). Andere dagegen zeigten starke fungizide Eigenschaften und konnten als Fungizid eingesetzt werden. Die fungizide Wirkung der Chitinase A aus $S$. marcescens wurde durch eine Hemmung des Wachstums von $R$. solani nachgewiesen. Zudem wurde von Pilzen infizierten Pflanzen E. coli-Zellen zugegeben, die ein Plasmid mit dem chiA-Gen trugen. Auch die rekombinanten E. coli-Stämme konnten das Wachstum der Pilze hemmen (SHAPIRA et al., 1995). Das Chitinase C-Gen aus S. griseus HUT6037 wurde in Reis-Pflanzen expremiert. Die erhaltenen transgenen Pflanzen zeigten danach einen verstärkten Schutz gegen pflanzenpathogene Pilze (ITOH et al., 2002). Chitinasen wurden anhand ihrer Aminosäuresequenzen der katalytischen Domäne klassifiziert und in die Klassen 18 und 19 der Glykosyl-Hydrolasen eingeordnet (DAVIES und HENRISSAT, 1995). Die Familie 18 enthält die Chitinasen von Bakterien, Pilzen, Viren und die Klassen III und V der Pflanzen. Die Familie 19 umfasst Chitinasen der Klassen I, II und IV der Pflanzen und einiger Bakterien die bislang nur in Streptomyceten entdeckt wurden (ITOH et al., 2003). Untersuchungen zeigten, das Chitinasen der Familie 19 der Glykosyl-Hydrolasen, die zunächst nur von Pflanzen her bekannt waren, in der Regel über stärkere antifungale 
Eigenschaften verfügten als diejenigen der Familie 18 (BROEKAERT et al., 1998; LEAH et al., 1991; SCHLUMBAUM et al., 1986; ISELI et al., 1993). Diese fungizide Wirkung wurde auch bei der Chitinase C aus S. griseus HUT6037 beobachtet, welche die erste aus einem Prokaryoten isolierte Chitinase der Familie 19 war (WATANABE et al., 1999). Die Chitinase $\mathrm{C}$ besitzt keine Chitin-Binde-Domäne wie sie bei Pflanzen-Chitinasen der Klasse I und IV innerhalb der Familie 19, vorkommt. Die Pflanzen-Chitinasen der Klasse II verfügen über keine Chitin-Binde-Domäne. Bei der Untersuchung der Chitinase der Klasse I aus Tabak wurde festgestellt, das die Chitin-Binde-Domäne wichtig für die Chitin-Bindung nicht aber für die antifungale Wirkung ist (ISELI et al., 1993). Die Chitin-Binde-Domäne der Chitinase A1 aus B. circulans, eine Chitinase der Familie 18, weist Ähnlichkeiten zu der Domäne der Chitinase C aus S. griseus HUT6037 auf. Ebenso zeigt diese Ähnlichkeiten zu der vom Insert aus pSG-1 kodierten Chitinase C bzw. zu der in dieser Arbeit aus dem Isolat WG3 erhaltenen Chitinase IS auf (s. Abb. 16 und 23). Die Chitinase A1 besitzt aber selbst keine antifungale Wirkung (WATANABE et al., 1999). Daher ist anzunehmen, das die Chitin-Binde-Domäne der Chitinase C aus S. griseus bzw. der in dieser Arbeit klonierten Chitinasen C und IS, die von den Inserts aus pWG3-1 und pSG-1 kodiert wurden, nicht für die antifungalen Eigenschaften der Enzyme notwendig ist, sondern allein die katalytischen Domänen dieser Enzyme.

Zur Identifizierung von fungiziden Eigenschaften der Isolate wurde ein Agartestverfahren durchgeführt. Bei diesem wurde entweder der Kulturüberstand der Isolate verwendet oder der Organismus selbst eingesetzt. Im Kulturüberstand sollten sich Chitinasen finden, da diese Enzymgruppe zu den Exoenzymen zählt. Die zu testende Lösung wurde Filterscheiben, die an den Rand von Agarplatten gelegt wurden, aufgeträufelt. Bildete sich beim Wachstum des in die Mitte der Platte beimpften Pilzes ein Hemmhof um die Filterscheiben, so war dies ein Beweis für fungizide Eigenschaften des jeweiligen Isolates. Dieser Hemmhof könnte auch von anderen Enzymen oder Verbindungen, die der Organismus produziert, stammen. Jedoch war dieser Test ein Hinweis darauf, dass das Isolat für das Ziel der Arbeit von Interesse war. Erst durch Identifizierung und Klonierung des Chitinasegens aus einem Isolat und der Produktion und Reinigung des Enzyms konnte die fungizide Wirkung gegebenfalls auf die Chitinase zurückgeführt werden.

Die für den Agartest verwendeten Pilze stellten vier typische Pflanzenpathogene sowie einen Vertreter der Schimmelpilze dar. Die Wahl von bekannten pflanzenpathogenen Pilzen war motiviert von dem Versuch, Chitinasen zu identifizieren, die für den Einsatz als Fungizid in der Landwirtschaft geeignet wären. Botrytis cinerea ist dabei der Erreger der 
Grauschimmelfäule, einer Krankheit, die eine Vielzahl von Pflanzen befallen kann (BÜTTNER, 1999). Fusarium culmarum ist ein Pilz, der die Ähren von Getreide befällt und absterben lässt. Guignardia bidwellii verursacht die Schwarzfäule an Wurzeln z.B. der Kartoffel. Sclerotia sclerotiorum schließlich ist der Verursacher der Weißstengeligkeit. Dabei wird der Stengel vieler Pflanzen befallen und geschädigt (VON HÖRSTEN, 1996). Aspergillus nidulans ist ein Vertreter der Schimmelpilze, zu denen auch der bekannte pathogene Pilz A. fumigatus gehört. Diese Tests dienten also der Selektion von isolierten Bakterien, die fungizide Chitinasen aufweisen könnten.

Bei fünf der dreizehn Isolaten und deren Kulturüberstand konnte eine fungizide Wirkung nachgewiesen werden. Zwei dieser Isolate, WG1 und WG3, die beide Bodenproben aus dem Raum Göttingen entstammten, zeigten dabei die stärkste Wirkung. Diese besaßen eine deutlich ausgeprägtere fungizide Wirkung gegenüber den eingesetzten Pilz-Stämmen als die anderen drei Isolate E2, SE1 und SL3. Somit lag der Fokus dieser Arbeit auf der Klonierung und Produktion der Chitinasen aus den Isolaten WG1 und WG3.

Aus den Isolaten aus marinen Standorten zeigte ein Isolat, SE1, eine schwache fungizide Wirkung. Die anderen 4 Stämme mit antifungalen Eigenschaften entstammten Bodenproben. Dies lässt sich wahrscheinlich darauf zurückführen, dass die Bakterien in terrestrischen Habitaten durch die starke Präsenz von unterschiedlichsten Pilzstämmen verstärkt über fungizide Mechanismen verfügen. In marinen Habitaten sind Pilze dagegen seltener vertreten. Daher könnte der Selektionsdruck in Richtung auf die Entwicklung einer Chitinase mit fungiziden Eigenschaften bei Bodenbakterien erhöht sein.

Bei den Isolaten SE1, SL3 und E2 konnte die fungizide Wirkung, die vom jeweiligem Kulturüberstand ausging, auf Enzyme zurückgeführt werde (s. 3.3). Bei den Isolaten WG1 und WG3 lässt sich die fungizide Eigenschaft des Kulturüberstandes offenbar auch auf Verbindungen (z. B. Antibiotika) zurückführen, die die Organismen produzieren (s. 3.3). Um die fungiziden Eigenschaften der Organismen auf die Aktivitäten von Chitinasen zurückführen zu können, war es daher notwendig, die für die Chitinasen kodierenden Gene zu klonieren und heterolog zu expremieren.

Die von den fünf Isolaten ausgehende fungizide Wirkung wies eine hohe Langzeitstabilität auf, da der Hemmhof während der Plattentests über den gesamten Testzeitraum von 2 Monaten erhalten blieb. Daher scheinen die isolierten Organismen für die Entwicklung eines antifungalen Präparates gerade auch für den Einsatz im Pflanzenschutz geeignet zu sein. 


\subsection{Klonierung von Chitinase-Genen aus den Isolaten WG1, SE1 und SL3}

Von den 13 isolierten chitinolytischen Bakterienstämmen wiesen 5 eine fungizide Eigenschaft auf. Dabei handelte es sich um 4 bislang unbekannte Vertreter der Gattung Bacillus und einen Streptomyceten. Um die fungizide Eigenschaft der jeweiligen Organismen auf die Aktivität von Chitinasen zurückführen zu können, war es wie erwähnt notwendig, die für die Chitinase kodierenden Gene zu klonieren und das Genprodukt zu produzieren. Mit diesem können dann Versuche zur fungiziden Wirkung durchgeführt werden. Um die Chitinasegene aus diesen Organismen zu identifizieren, wurden wie in Punkt 3.5 beschrieben die jeweilige genomische DNA einer „Southern“-Blot-Analyse unterzogen. Bis auf das Gen des Isolates E2 konnten so Chitinase-Gen tragende Fragmente der Isolate lokalisiert werden.

Zur Identifizierung der Chitinase-Gene aus den Isolaten wurde die Methode der Koloniehybridisierung angewandt. Mit diesem Verfahren konnte nur beim Isolat SE1 partiell das Chitinase-Gen kloniert werden.

Eine Möglichkeit dafür, das nicht alle Chitinase-Gene der so untersuchten chromosomalen DNA der Isolate kloniert werden konnte lag möglicherweise daran, das die Genbanken aus den Isolaten nicht vollständig vorlagen (s. 3.6). Eine andere Möglichkeit für die Schwierigkeit bei der Auffindung von Klonen könnte an toxischen Genprodukten liegen. So konnten z.B. die Gene der mal-Region aus Streptococcus pneumoniae, welche an der Umsetzung von Maltosacchariden durch diesen Organismus beteiligt waren, nicht über „Multi-Copy“Vektoren in E. coli kloniert werden (STASSI und LACKS, 1982). Solche Phänomene sind nicht nur für Streptococcus-Spezies beschrieben worden. Bei der Suche nach amylolytischen Enzymen aus Bacillus subtilis wurde eine aus 25000 Klonen bestehende Genbank auf Gene für den Stärkeabbau durchmustert. Dabei wurden beim initialen Screening nur 15 positive Klone identifiziert. Nachfolgende Sequenzanalysen ergaben jedoch, dass weder die gefundenen Nucleotidsequenzen, noch die abgeleiteten Aminosäuresequenzen Ähnlichkeiten zu bekannten Amylasen aufwiesen. Kontrollexperimente mit typischen B. subtilis-Vektoren zeigten in diesem Stamm keinerlei amylolytische Aktivität mehr, obwohl sie in E. coli einen stärkeabbauenden Phänotyp erzeugten (GOMEZ et al., 1994). Hieraus wurde gefolgert, dass die Genexpression der klonierten Fragmente eine Zellyse des Wirtes auslösten, welche zur Freisetzung periplasmatischer oder cytosolischer $E$. coli eigener $\alpha$-Amylasen oder Amylomaltasen führte (SCHWARTZ, 1987; RAHA et al., 1992).

Für den Transport von heterolog in E. coli produzierten Proteinen in das Periplasma ist das N- 
terminale Signalpeptid des Proteins notwendig. Dieses wird in E. coli von einem Sekretionsweg erkannt und reguliert, der von den sec-Genen kodiert wird (LOUIS et al., 2000). Es erfolgen Spaltung und Acylierung. Die in E. coli für den Export nötige „Maschinerie“ beginnt mit dem Export der in hohen Konzentrationen vorhandenen „FremdProteine“. Damit einhergehend wird der Export wirtseigener Proteine beeinträchtigt und aufgrund dessen die Kopplung von Transportprozessen an den elektrochemischen Gradienten der Membran beeinflusst. Dies führt zur Verringerung und anschließend zum vollständigen Verlust des Membranpotentials mit nachfolgendem Zelltod (MARTIN et al., 1989; SUTCLIFFE und RUSSELL, 1995). Ebenso kann die Akkumulation des Proteins im Periplasma für E. coli zu einer toxischen Wirkung führen, in dem der SEC-Weg blockiert wird. Zudem kann es zur Induktion von zelleigenen Proteasen kommen, was zu einer verstärkten Permeabilität der Äußeren Membran führt (BANEYX, 1999; PLÜCKTHUN et al., 1996). Solche Ereignisse führen entweder zu einer sehr geringen Produktion des Proteins oder zu einer Lyse der Zelle (ERBEZNIK et al., 1998). Ein Indiz für eine mögliche toxische Wirkung der von den Chitinase-Genen der Isolate SE1, SL3 und WG1 kodierten Chitinasen könnte sich durch die Klonierung eines weiteren chiA-Gens aus einer Anreicherungskultur bestätigt haben. Das chiA-Gen, das über die Methode der PCR aus Anreicherungskulturen amplifiziert werden konnte, ließ sich zwar in den Vektor pCR2.1-TOPO klonieren, jedoch gelang es nicht, das Gen in einen Expressionsvektor umzuklonieren. Das Gen inserierte in die Klonierungsstelle des Vektors nicht in der korrekten Orientierung, so dass die Expression des Chitinase-Gens nicht erfolgen konnte.

Um festzustellen, ob eine mögliche toxische Wirkung von den Signalsequenzen der Chitinasen aus den Isolaten WG1 und SE1, die beide der Gattung Bacillus angehörten oder derjenigen kodiert vom Insert aus pVH ausging, wurden diese näher untersucht. Die Signalsequenzen der Chitinasen aus den Isolaten SE1 und WG1 waren untereinander und von der Position 12 der Aminosäuresequenz abgesehen identisch zur Chitinase A aus V. harveyi. Die Signalsequenz der Chitinase A kodiert vom Insert aus pVH war im Vergleich zur Chitinase aus $V$. harveyi vollständig identisch (s. 3.8.2). Im folgenden wurde die Signalsequenz der Chitinase aus WG1 mit denen aus Chitinasen, Chitosanasen und Cellulasen, die von Bakterien der Gattung Bacillus produziert wurden, verglichen und der Anteil an hydrophoben Aminosäuren bestimmt (s. Abb. 45). Dabei konnten keine signifikanten Ähnlichkeiten der Sequenz aus WG1 als auch der Sequenzen untereinander gefunden werden. Beim Vergleich des Anteils an hydrophoben Aminosäuren innerhalb der Signalsequenzen konnten teilweise Übereinstimmungen gefunden werden. 
Die Signalsequenz aus WG1 zeigte einen hydrophoben Anteil an Aminosäuren von $65 \%$. Die der Chitosanase wies ebenfalls $65 \%$ und diejenige der Chitinase A aus B. circulans $57 \%$ auf. Die Signalsequenz der Chitinase aus B. licheniformis wies einen hydrophoben Anteil von 68 $\%$ auf. Den höchsten Anteil zeigten die Chitinasen aus B. sp mit 76,9\% und die Chitinase D aus B. circulans mit $77 \%$. Alle bekannten Signalsequenzen gehörten Exoenzymen an, die rekombinant durch E. coli expremierbar waren. Insgesamt lässt sich die Schwierigkeit bei der Klonierung der Chitinase-Gene aus WG1 und SE1 durch Koloniehybridisierung nicht auf die Signalsequenz beziehen. Das gleiche gilt für die erfolglose Klonierung des Chitinase-Gens aus dem Insert aus pVH in einen Expressionsvektor.

$\begin{array}{llll}\text { WG1 } & 1 & \text { MIRFNLCAAGVALALSGAANAAPTAP } & 26 \\ \text { Blich } & 1 & \text { MNIVLVNKSKKFFVFSFIFVMLLSL- } & 25 \\ \text { Chitosanase } & 1 & \text { MREADWWGKAAISLLVFTMFFTLMMS } & 26 \\ \text { Cellulase } & 1 & \text { MKKLTTIFIVFTLALLFVGNSTSANN } & 26 \\ \text { BcircuChiA } & 1 & \text { MINLNKHTAFKKTAKFFLGLSLLLSV } & 25 \\ \text { B.circuChiD } & 1 & \text { LNQAVRFRPVITFALAFILIITWFAP } & 26 \\ \text { B.sp. } & 1 \text { MLNKFKFFCCILVMFLLLPLSPFQAQ } & 26\end{array}$

Abb. 45: Vergleich der Signalsequenz der Chitinase aus WG1 mit entsprechenden Sequenzen von Chitinasen, Chitosanasen und Cellulasen aus Bakterien der Gattung Bacillus

WG1, Chitinase aus WG1; Blich, Chitinase aus B. licheniformis (U71214); Chitosanase aus B. $s p$; Cellulase B aus B. sp.; BcircChiA, Chitinase A1 aus B. circulans WL-12 (WATANABE et al., 1990); B.sp. Chitinase aus B.sp. NCTU2 (WEN at al., 2002)

Aufgrund dessen ist zu vermuten, dass das heterolog produzierte Gesamtprotein eine für $E$. coli toxische Wirkung aufwies. Diese Vermutung bestätigt sich zudem darin, das auch nach Entfernung der Signalseqenz vom chiA-Gen aus pVH die Umklonierung in einen Expressionsvektor nicht gelang (s. 3.10.1).

\subsection{Identifizierung und Charakterisierung von Chitinasen aus Isolaten und Anreicherungen}

Die Enzyme, die für den Polysaccharid-Abbau zuständig sind, gliedern sich in 50 Familien der Glykosyl-Hydrolasen. Die Chitinasen gehören dabei wie bereits erwähnt den Familien 18 und 19 an. Die Vertreter beider Familien zeigen keine signifikanten Sequenzähnlichkeiten, so dass von einer konvergenten Entstehung der Familien ausgegangen werden kann 
(HENRISSAT, 1991). Zudem unterscheiden sie sich in ihren strukturellen und katalytischen Eigenschaften. Chitinasen der Familie 19 weisen zahlreiche $\alpha$-helicale Segmente auf. Hydrophobe Aminosäuren bilden den Kern des Enzyms, während polare Aminosäuren eine Spalte bilden, in der sich die Chitin-Bindestelle und das aktive Zentrum finden (HART et al., 1995; SASAKI et al., 2002). Zwei essentielle Glutamat-Reste sind dabei für die Katalyse wichtig. Untersuchungen der Chitinase aus der Riesenbohne zeigten, dass das Glu90 als Base ein angreifendes Wassermolekül polarisiert, während das Glu68 als katalytische Säure für die Protonierung des abgehenden Zuckers dient (s. Abb. 46; HAHN et al., 2000).

Diese Glutamat-Reste ließen sich auch bei der Chitinase IS, kodiert vom Insert aus pWG3-1 und der Chitinase $\mathrm{C}$ die vom Insert aus pSG-1 kodiert wurde, zeigen (s. Abb. 47). Bei der Chitinase IS aus pWG3-1 waren die korrespondierenden Glutamat-Reste an der Position 156 bzw. 165 und bei der Chitinase C aus pSG-1 an der Position 147 bzw. 156 identifiziert worden.

Durch NMR-Spektroskopie konnte gezeigt werden, das die Chitinase-Reaktion über einen positiv geladenen Oxocarbonium-Übergangszustand läuft, wobei die Säure-Base-Katalyse über Inversion der Konfiguration erfolgt (HOLLIS et al., 1997).

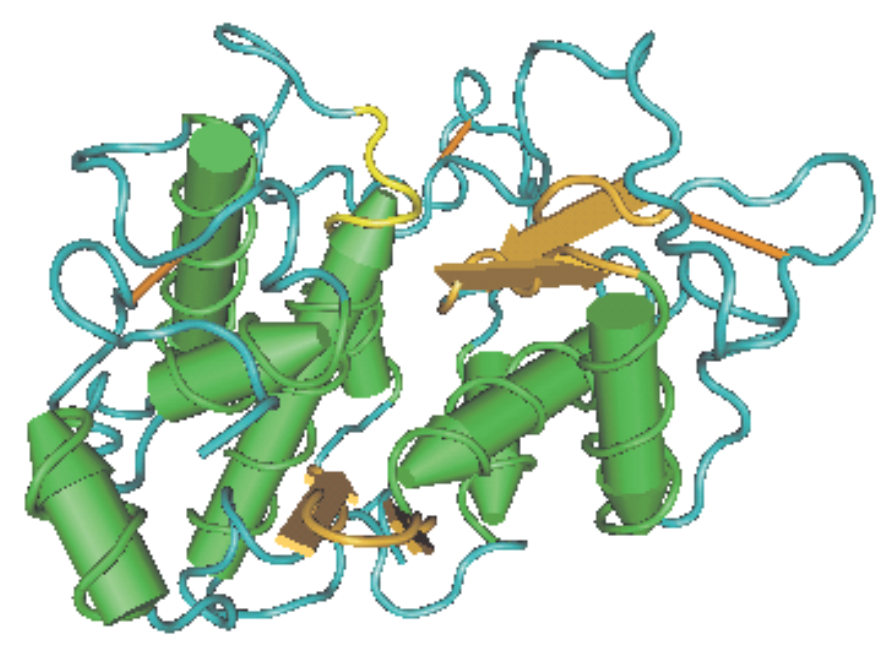

\section{Abb. 46: 3D-Struktur der Chitinase aus der Riesenbohne (Canavalia ensiformis)}

Ein Teil des aktiven Zentrums mit der Position des für die Katalyse essentiellen Glu68 ist gelb markiert (Struktur wurde aufgeklärt von HAHN et al., 2000). 
Chitinasen der Klasse IV zeigen im Vergleich zu Chitinasen der Klasse I zwei Deletionen im Bereich der katalytischen Domäne. Diese Deletionen konnten auch bei der Chitinase C aus $S$. griseus HUT6037 (WATANABE et al., 1999) und den aus den Inserts aus pWG3-1 und pSG-1 abgeleiteten Aminosäuresequenzen gefunden werden (s. Abb. 47). Aufgrund dieser Übereinstimmungen ließen sich diese ebenfalls in die Klasse IV der Familie 19 einordnen.

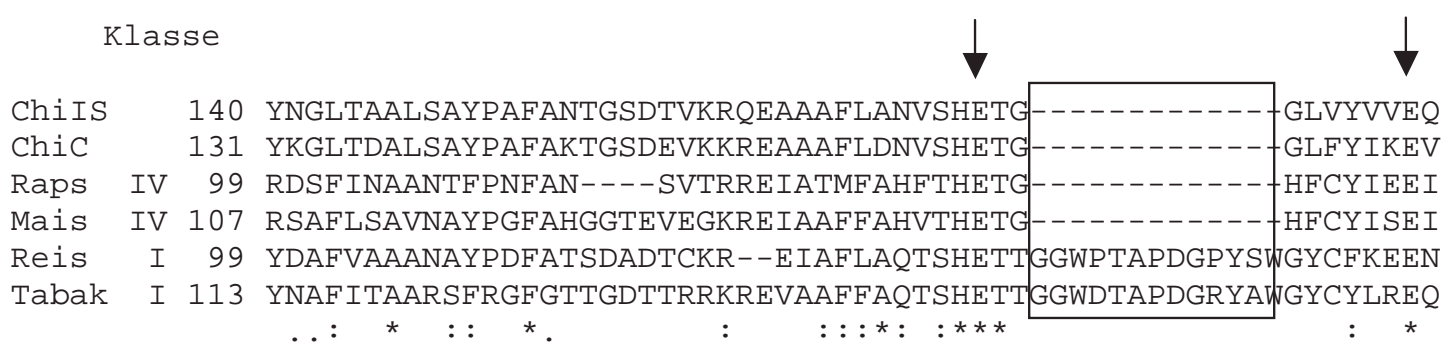

ChIIS 187 NTSNYPHYCDSSOPYGCPAGQAAYYGRGP IOLSWNFNYKAAGDALGIDLLGNPYLVEODA

ChIC 159 NEVNYPHYCDTTQSYGCPAGQAAYYGRGP IQLSWNFNYKAAGDALGINLLANPYLVEQDP

Raps IV 142 NGASRDYCDENNRQYPCAPGKG-YFGRGP IQLSWNYNYGACGQSLNLNLLGQPELVSSNP

Mais IV 154 N-KSNAYCDASNRQWPCAAGQK-YYGRGPLQISWNYNYGPAGRDIGFNGLADPNRVAQDA

Reis I 158 NGNAPTYCEPKP-EWPCAAAKK-YYGRGPIQITYNYNYG-RGAGIGSDLLNNPDLVAS-D

Tabak I 173 -GNPPSYCVQSS-QWPCAPGQK-YYGRGPIQISYNYNYGPCGRAIGQNLLNNPDLVATNA

ChIIS 227 SVAWKTGLWYWNTQNGP-------GGTMTAHAAMVNG---AGFGETIRSIN

ChiC 218 AVAWKTGLWYWNSQNGP---------GTMTP HNGIVNN---AGFGETIRS IN

Raps IV 201 TVAFRTGLWFWMNSVRP---------------------VLNQGFGATIRAIN

Mais IV 212 VIAFKTALWFWMNNVHA--------------------VMPQGFGATIRAIN

Reis I 213 LVSFKTAFWFWMTPQSP KPSCHAVITGQWTPSADDQPT--VPGYGEITNIIN

Tabak I 230 VVSFKSAIWFWMTAQSP KPSCHDVITGRWTP SAADRAANRLPGYGVITNI IN

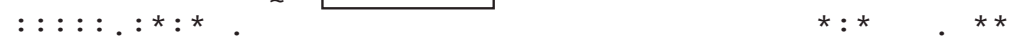

Abb. 47: Vergleich von partiellen Sequenzen der aus den Inserts von pSG-1 und pWG3-1 abgeleiteten Aminosäuresequenzen zu bekannten Chitinasen der Klassen I und

\section{IV der Familie 19}

Eingerahmt sind die für die Klasse IV typischen Deletionen in der Aminosäuresequenz im Vergleich zu Chitinasen der Klasse I; Pfeile markieren die beiden für die Katalyse essentiellen Glutamat-Reste (147 bzw. 156 bei der Chitinase C und 156 und 165 bei der Chitinase IS). Dargestellte Sterne deuten identische Aminosäuren an, die Doppelpunkte und Punkte ähnliche Aminosäuren. ChiIS, Chitinase IS aus E. coli/WG3-1; ChiC, Chitinase C aus E.coli/pSG-1; Raps, (Q06209); Mais, (P29022); Reis, (Q40668); Tabak, (P29059)

Während einige Vertreter der Familie 19 nur eine katalytische Domäne aufweisen, zeigen andere eine cysteinreiche Chitin-Binde-Domäne am N-Terminus (HENRISSAT, 1999; HAHN et al., 2000). Chitinasen der Klasse II fehlt dagegen diese Chitin-Binde-Domäne. Ebenso wie bei der Chitinase C aus S. griseus HUT6037 ließ sich innerhalb der ChitinBindedomäne der beiden aus den Inserts von pSG-1 und pWG3-1 abgeleiteten Chitinasen 
keine cysteinreiche Chitin-Binde-Domäne am N-Terminus finden (s. 3.9.1). Anstelle dessen ließ sich die Chitin-Binde-Domäne dieser Chitinasen in die Familie 18 einordnen. Die Verknüpfung der Chitin-Binde-Domäne aus der Familie 18 mit einer katalytischen Domäne der Familie 19 innerhalb einer Chitinase war von OHNO et al., (1996) erstmals beschrieben worden. Wie es zur Entstehung dieser Verbindung kam, ist bislang ungeklärt. Ebenso ist der Umstand bemerkenswert, das Chitinasen der Familie 19, die eigentlich den Pflanzen zugeordnet waren, in prokaryotischen Organismen aufzufinden waren. Möglichweise entstammten diese einem horizontalem Gentransfer (WATANABE et al., 1999). Bakterielle Chitinasen der Familie 19 sind bislang ausschließlich in Streptomyces-Stämmen identifiziert worden (SASAKI et al., 2002).

Das Chitinase-Gen aus pSG-1 entstammte einer Anreicherung, die mit Boden-Proben beimpft und inkubiert worden war. Im Boden sind Bakterien der Gattung Streptomyces stark vertreten (BROCK et al., 1994). Da das klonierte Chitinase-Gen eine Ähnlichkeit von 98 \% zum bekannten chiC-Gen aus S. griseus HUT6037 aufwies, ist davon auszugehen, dass diese Chitinase ebenfalls aus einem Streptomyceten stammte. Die Chitinase IS aus E. coli/pWG3-1 entstammte dem Isolat WG3, welches durch 16S rRNA-Gen-Analyse als bislang unbekannter Vertreter der Gattung Streptomyces eingeordnet werden konnte. Somit gelang es, zwei weitere prokaryotische Chitinasen der Familie 19 aus Streptomyceten zu identifizieren.

Die Chitinase IS aus dem Isolat WG3 war um etwa $1 \mathrm{kDa}$ größer als diejenige aus der Chitinase IS von $S$. $s p$. AJ9463 (SAKUDA und NAGASAWA, 2003) zu der die größte Ähnlichkeit bestand. Ebenso wies die vom Insert aus pSG-1 kodierte Chitinase C eine um 1 kDa geringere Molekularmasse auf. Grund dafür ist eine Wiederholung in der Signalsequenz aus sich je 3 mal wiederholenden Serin-Resten (S) und Alanin-Resten (A) gefolgt von einem Phenylalanin-Rest. Alle dargestellten Signalsequenzen außer der der Chitinase C aus $S$. lividans weisen eine Deletion in diesem Bereich auf. (s. Abb. 48). Von dieser Deletion abgesehen wiesen die genannten Signalsequenzen jedoch eine höhere Ähnlichkeit (75\%) zur Signalseqenz der Chitinase aus WG3 auf als die der Chitinase aus S. lividans (30\%). Dieser zusätzliche Aminosäureabschnitt ist wahrscheinlich ein für den Organismus WG3 notwendiger Bestandteil der Signalsequenz, um das Protein aus der Zelle hinaus zu transportieren 


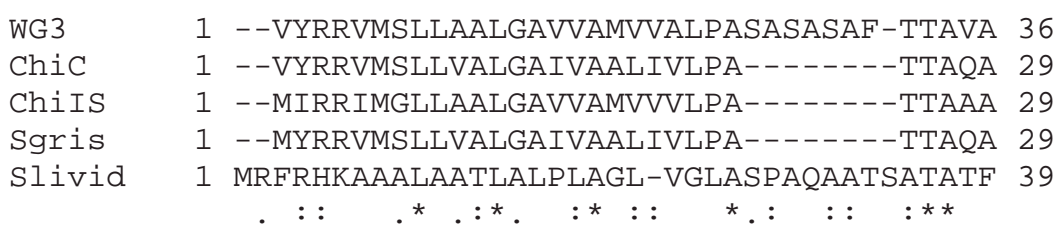

Abb. 48: Vergleich der Signalsequenz der Chitinase IS aus dem Isolat WG3 und der Chitinase C aus E. coli/pSG-1 mit Signalsequenzen bekannter Chitinasen aus Streptomyceten

WG3, Chitinase IS aus WG3; ChiC, Chitinase C aus E. coli/pSG-1; ChiIS, Chitinase IS aus S.sp. AJ9463 (SAKUDA und NAGASAWA, 2003); Sgris, Chitinase C aus S. griseus HUT6037 (OHNO et al., 1996); Slivid, Chitinase C aus S. lividans (P36909); Dargestellte Sterne deuten identische Aminosäuren an, die Doppelpunkte und Punkte ähnliche Aminosäuren.

Neben der Familie 19 lassen sich Chitinasen zudem in die Familie 18 einordnen. Die Familie 18 der Glykosyl-Hydrolasen umfasst die Klassen III und V der Chitinasen aus Pflanzen sowie die Mehrheit der bakteriellen Chitinasen. Zudem lassen sich die Di-N-Acetyl-Chitobiasen und Endo-N-Acetyl-Glukosamidasen in diese Familie einordnen (WATANABE et al., 1999). Innerhalb der Chitinasen der Familie 18 können große Sequenzunterschiede vorliegen. Außer der katalytischen besitzt diese Chitinase-Familie auch immer eine Chitin-Binde-Domäne (HENRISSAT, 1999; SVITIL und KIRCHMAN, 1998). Anhand von Sequenzvergleichen der katalytischen Domäne lässt sich die Familie 18 grob in fünf Gruppen unterteilen. In der Gruppe I finden sich Chitinasen aus $\gamma$-Proteobakterien wie z.B. die Chitinase A aus $S$. marcescens oder die Chitinase aus Aeromonas caviae. Die katalytischen Domänen dieser Gruppe sind untereinander zu ca. 90 \% identisch (SVITIL und KIRCHMAN, 1998). In die Gruppe II gehören z.B. die Chitinase B aus S. marcescens und die Chitinase C aus S. lividans. Innerhalb dieser Gruppe lassen sich $\gamma$-Proteobakterien und Chitinasen von Gram-positiven mit hohem G+C-Gehalt einordnen. Die Sequenzen der katalytischen Domäne sind in dieser Gruppe zu etwa $85 \%$ identisch. In die Gruppe III lassen sich die Chitinasen von Grampositiven Bakterien mit einem geringen $\mathrm{G}+\mathrm{C}-\mathrm{Gehalt}$ eingliedern, zu denen die Chitinasen aus B. thuringiensis und B. licheniformis gehören (SVITIL und KIRCHMAN, 1998). Die Ähnlichkeiten untereinander betragen hier ca. $83 \%$. Innerhalb der Gruppe IV finden sich Chitinasen aus der Gattung Vibrio und aus Gram-positiven Bakterien. Zur Gruppe IV gehören z.B. die Chitinase A aus $V$. harveyi und die Chitinase D aus B. circulans WL-12. Die Ähnlichkeiten der katalytischen Domänen beträgt hier untereinander ca. 71 \% (SVITIL und KIRCHMAN, 1998). Katalytische Domänen von Chitinasen, die in keine der aufgeführten Gruppen eingeordnet werden können, wurden der Gruppe V zugewiesen. Die Ähnlichkeiten 
der Aminosäuresequenzen liegt bei dieser Gruppe bei ca. $50 \%$. Beispiele für diese Gruppe sind die Chitinase C aus B. circulans WL-12 und die Chitinase aus Ewingella americana (SVITIL und KIRCHMAN, 1998). Aufgrund der bereits dargestellten hohen Ähnlichkeiten der Aminosäuresequenzen der Chitinasen aus den Isolaten WG1, SE1 und der Chitinase A, kodiert vom Insert aus pVH zur Chitinase A aus $V$. harveyi, lassen sich auch diese in die Gruppe IV der Familie 18 eingliedern.

Den Chitinasen der Familie 18 ist gemeinsam, dass sie eine $(\beta / \alpha)_{8}$-Barrel-Struktur aufweisen (ROBERTUS und MONZINGO 1999). Diese Struktur besteht aus 8 Einheiten rechtsgängiger $\beta$-Sekundärstrukturelemente, die parallel angeordnet den hydrophoben Kern, der von acht Helices umgeben ist, formen (LEVITT und CHIOTA, 1976). Diese Struktur wird als TIMBarrel bezeichnet, da diese Struktur zuerst bei der Triosephosphat-Isomerase (TIM) in Gallus gallus entdeckt wurde (BANNER et al., 1975). Die Struktur der bislang aufgeklärten Chitinasen der Familie 18 zeigten das aktive Zentrum als lange Spalte, in der viele hydrophobe Aminosäuren lokalisiert sind.

Die katalytische Aminosäure ist das bei allen Chitinasen dieser Familie konservierte Glu144, dem die Positionsbezeichnung der Aminosäuresequenz der Chitinase B aus S. marcescens zugrunde liegt (VAN AALTEN et al., 2000). Diese befindet sich am Ende des 4. $\beta$-Stranges. Drei Aspartat-Reste (Asp142, Asp140 und Asp137) gehören ebenfalls zu dem in fast allen Chitinasen ausgebildeten Motiv DxxDxDxE und bilden durch eine Wendung in das Innere des TIM-Barrels einen hydrophilen Kern (s. Abb. 49). Die genaue Funktion dieses Kerns ist unbekannt (VAN AALTEN et al., 2000). Mutagenese-Experimente belegten, dass die Funktion dieses hydrophilen Kerns jedoch für die katalytische Aktivität der Enzyme notwendig ist (WATANABE et al., 1994). Der hydrophile Kern im $(\beta / \alpha)_{8}$-Barrel ist von Interesse, da in den meisten Enzymen außerhalb der Chitinasen, die einen $(\beta / \alpha)_{8}-$ Barrel aufweisen, ein hydrophober Kern vorliegt. Eine Ausnahme von dieser Regel ist die Enolase und die Methyl-Malonyl-CoA-Mutase (VAN AALTEN et al., 2000). 


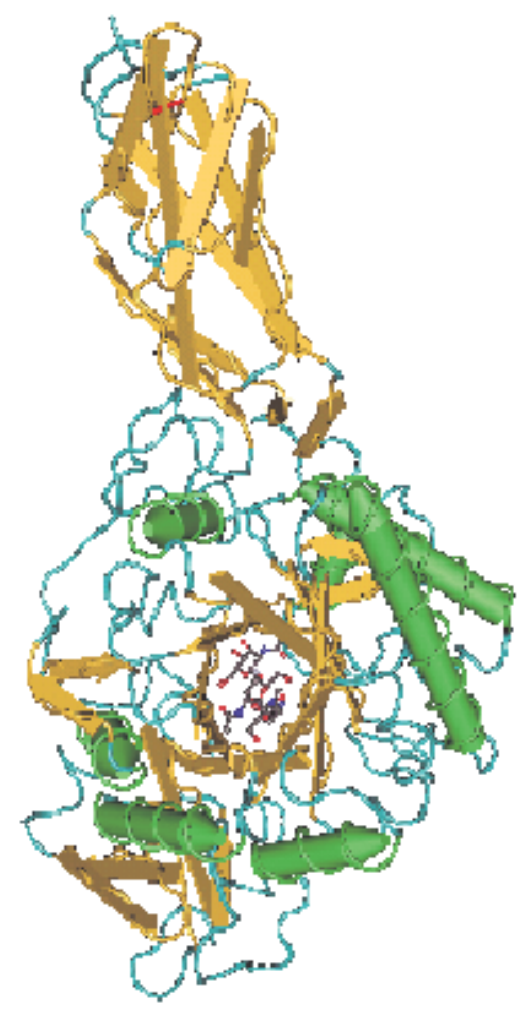

Abb. 49: 3D-Struktur der Chitinase A aus $S$. marcescens

Im kreisförmigen TIM-Barrel im Zentrum des Enzyms ist der Inhibitor Allosamidin dargestellt (PAPANIKOLOU et al., 2001).

Eine weitere Besonderheit ist das gehäufte Vorkommen von $3_{10}$ - anstelle von $\alpha$-Helices. Diese 310 -Helices weisen eine stärkere Drehung als $\alpha$-Helices auf. Grund hierfür sind Wasserstoff-Brücken-Bindungen, die von der Carbonylgruppe einer Peptidbindung statt zur Amidgruppe der viertnächsten zur Amidgruppe der drittnächsten Peptidbindung geknüpft sind. Daher sind an der Windung der $3{ }_{10}$-Helices nur 3 Aminosäuren anstelle der durchschnittlich 3,6 Aminosäuren beteiligt (KARLE et al., 1989). Im Durchschnitt sind in Proteinen nur 12,6\% der Aminosäurereste, die an helikalen Strukturen beteiligt sind, $3_{10^{-}}$ Helices. Bei Chitinasen ist dieser Anteil höher. So beträgt der Anteil bei der Chitinase A und B von S. marcescens $29 \%$.

Bei den aus den partiell vorliegenden Chitinase-Genen der Inserts von pSE1 und pWG1 abgeleiteten Aminosäuresequenzen konnten diese bei der Chitinase B aus S. marcescens aufgeklärten Strukturen im Bereich der TIM-Barrel $\beta$-Stränge 1-6 identifiziert werden. Bei der Chitinase A, kodiert vom Insert aus pVH, konnten diese Strukturen bis zum $\beta$-Strang 8 analysiert werden. Beim Vergleich der abgeleiteten Aminosäuresequenzen zum TIM-Barrel der Chitinase B aus $S$. marcescens ließ sich das DxxDxDxE-Motiv als konservierte Sequenz 
identifizieren. Die Position des katalytischen Glutamat-Restes in der Aminosäuresequenz ist bei allen dreien in dieser Arbeit identifizierten Chitinasen der Familie 18 die Position 315. Ebenso gelang es, die $\alpha$-Helices, die $3_{10}$-Helices und die Aminosäuren der Seitenketten, die an der Bildung des Netzwerkes von Wasserstoff-Brücken-Bindungen innerhalb des TIMBarrels beteiligt sind, zu identifizieren (s. Abb. 50).

$\beta 1$

SSSSSSS

333

ChIA WEG1 155 TDPSVVMGTYFVEWGIYGRDYTVDNMPVDNLTHILYGFIPICGPNESVKSVGGNSFNAL

ChIA SE1 155 TDPSVVMGTYFVEWGIYGRDYTVDNMPVDNLTHILYGF IP ICGPNESVKSVGGNSFNAL

ChiA pVH 155 TDPSVVMGTYFVEWGIYGRDYTVDNMPVDNLTHILYGFIPICGPNESVKSDGGNSFNAL

ChIB Sm 1 MSTRKAVIGYYFIPT----------NQINNYTETDTSVVPFPVSN-----ITPAKAKQL

$\beta 2$

$\beta 3$

SSSSSSS SS HHнHнHнHнHнH3333 SSSSS

ChIA WG1 214 QTACRGVNDYEVVIHDPWAAYQKSFAQAGHEYSTPIKGNYAMLMALKQRNPDLKIIPSI

ChIA SE1 214 QTACRGVNDYEVVIHDPWAAYQKSFAQAGHEYSTPIKGNYAMLMALKQRNPDLKIIPS I

ChIA pVH 214 QTACRGVNDYEVVIHDPWAAYQKSFPQAGHEYSTPIKGNYAMLMALKQRNPDLKIIPSI

ChiB Sm 45 THINFSFLDINSNLECAWDPATN---------DAKARDVVNRLTALKAHNPSLRIMFS I

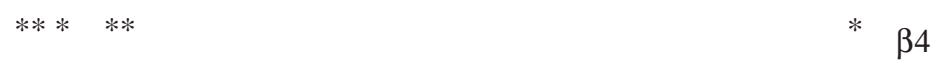

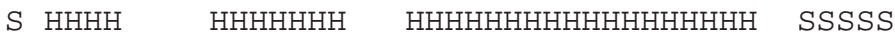

ChIA WG1 273 GGWTLS-------DPFFDFVDKANRDTFVASVKKFLKTWKFYDGVDIDWEFPGGGGAAA

ChIA SE1 273 GGWTLS-------DPFFDFVDKANRDTFVASVKKFLKTWKFYDGVDIDWEFPGGGGAAA

ChiA pVH 272 GGWTLS-------DPFYDFVDKKNRDTFVASVKKFLKTWKFYDGVDIDWEFPGGGGAAA

ChiB Sm 273 GGWYYSNDLGVSHANYVNAVKTPAARTKFAQSCVRIMKDYGFDGVDIDWEYP-----QA

$\beta 5$

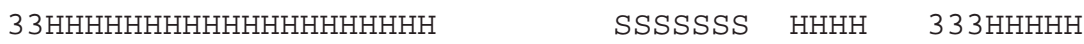

ChIA WG1 325 DKGDPVNNGPAYIALMRELRAMLDELEAETGRTYELTSAIGVGYDKIEPVDYANAVQYM ChIA SE1 325 DKGDPVNDGPAYIALMRELRAMLDELEAETGRTYELTSAIGVGYDKIEHVDYANAVQYM ChIA pVH 325 DKGDAVNDGPAYIALMRELRVMLDELEAETGRTYELTSAIGVGYDKIEDVDYADAVQYM ChiB Sm 151 AEVDGFIAALQEIRTLLNQQTITDGRQALP-YQLTIAGAGGAFFLSRYYSKLAQIVAPL

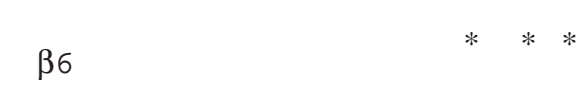

SSSSS $3333 \quad$ ннннннннннннн

ChiA WG1 384

ChIA SE1 384

ChiA pVH 384

ChiB Sm 207

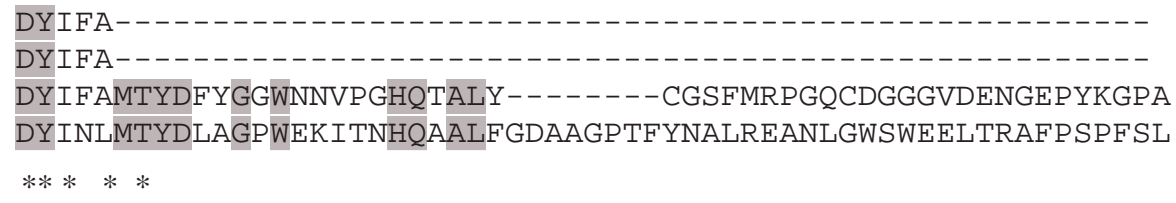


HНHнHнHнH 333 SSSSS SSSSS

ChiA WG1

ChIA SE1

ChiA pVH

ChiB Sm
434

266
Y

TADNGIQLLLAQGVPAIKLVLGTAVYGRGWEGVTPDTLTDPNDPMTGTATGKLKGSTAQ TVDAAVQQHLMMEGVP SAKIVMGVPFYGRAFKGVSGGNGGQYSSHSTP GEDPYPNADYWL

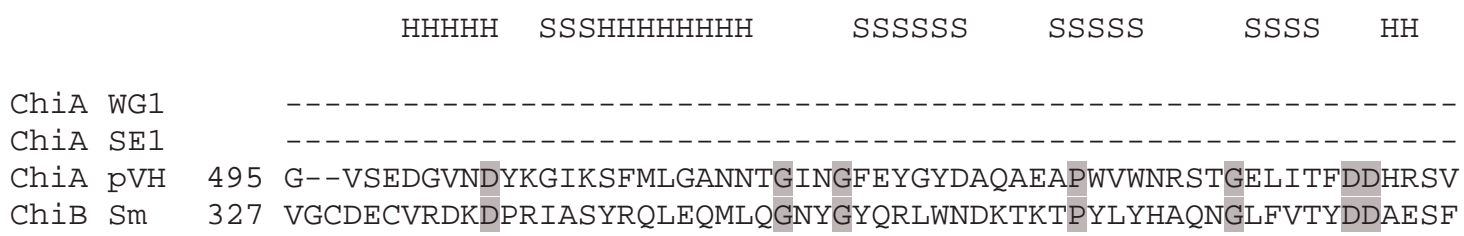

$\beta 8$

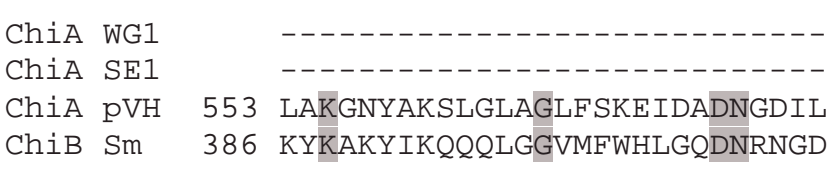

\section{Abb. 50: Vergleich der Aminosäuresequenzen der Chitinasen A aus SE1, WG1 und der Chitinase A kodiert vom Insert aus pVH mit der Chitinase B aus S. marcescens}

Der Analyse der Sequenzen liegen die Sekundärstruktur der Chitinase B aus S. marcescens (P11797) zugrunde (ChiB Sm). ChiA WG1, Chitinase A aus WG1; ChiA SE1, Chitinase A aus SE1; ChiA pVH, Chitinase A kodiert vom Insert aus pVH; Hervorgehoben sind konservierte Aminosäuren. * bezeichnet die Beteiligung von Wasserstoff-Brücken-Bindungen im Netzwerk der Seitenketten innerhalb des TIM-Barrel-Kerns; S, $\beta$-Strang; H, $\alpha$-Helix; 3 , $3_{10}$-Helix; die rot gefärbten Bereiche bezeichnen das DxxDxDxE-Motiv und den katalytischen Glutamat-Rest 144

Im Gegensatz zum Katalyse-Mechanismus der Familie 19 Chitinasen, ist derjenige der Familie 18 bislang wenig ergründet. Verschiedene Modelle sind entwickelt worden, die den Mechanismus der Retention der Konfiguration des anomeren C-Atoms an der Spaltungsstelle aufdecken sollten (ROBERTUS und MONZINGO, 1999). Das bevorzugte Modell ist derzeit die Substrat-gesteuerte Katalyse, die von der Kristallstruktur von Hevamin (Chitinase aus Hevea brasiliensis) im Komplex mit dem Inhibitor Allosamidin gestützt wird (TERWISSCHA und VAN SCHELTINGA 1999). Der Inhibitor Allosamidin verfügt über eine Oxazolin-Einheit, die im Katalysemechanismus als Übergangszustand fungiert. Im anfänglichen Katalyseschritt wird das Sauerstoff-Atom der glykosidischen Bindung durch die Carboxyl-Gruppe des Glutamats protoniert. Dieses ist in allen Chitinasen konserviert. Die Besonderheit dieses Vorganges liegt darin, dass das benötigte Nukleophil nicht vom Enzym, 
sondern von der Acetamido-Gruppe der Position 2 des zu spaltenden Zuckers gestellt wird. Das Zwischenprodukt ist ein Oxazolinium-Ion (DROUILLARD et al., 1997). Für die Aufklärung des Katalysemechanismus wurde der Chitinase-Inhibitor Allosamidin als ChitinAnalogon verwendet (s. Abb. 51).

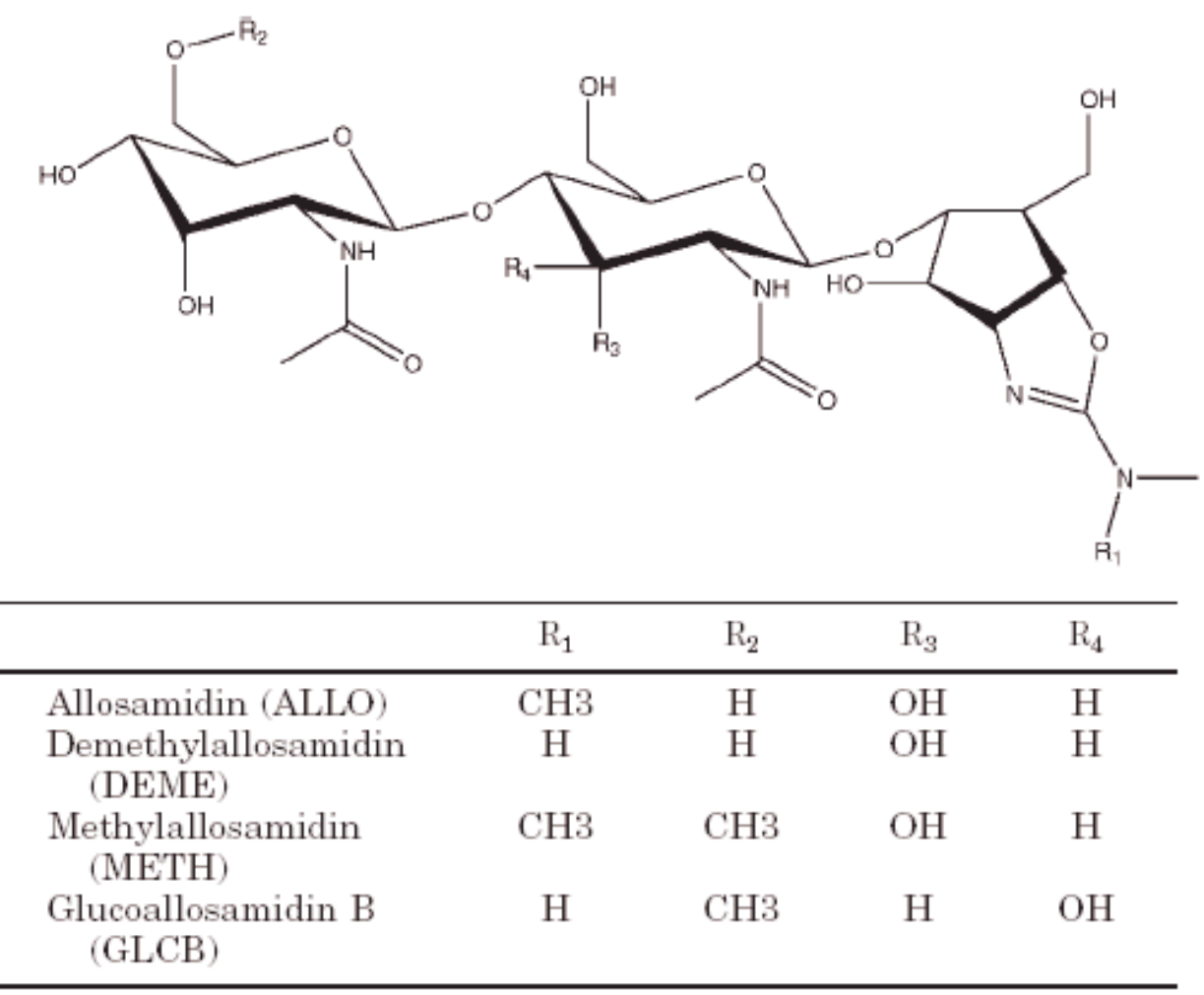

\section{Abb. 51: Struktur des Chitin-Analogon Allosamidin und seiner Derivate}

Die zweidimensionale Struktur ist abgebildet. Je nach den Substituenten $R_{1}-R_{4}$ können verschiedene Derivate auftreten (RAHO et al., 2003).

Eine Hemmung kann bei fast allen Chitinasen der Familie 18 und bei nur sehr wenigen der Familie 19 beobachtet werden (SPINDLER und SPINDLER-BARTH, 1999). Dieser Inhibitor wurde aus dem Kulturüberstand von Streptomyces sp. isoliert (SAKUDA et al., 1986). Als ein weiterer Hemmstoff ist das Dipeptid Cyclo(L-Arg-D-Pro) bekannt, das bei dem marinen Bakterium Pseudomonas sp. entdeckt wurde und die Aktivität der Chitinasen aus Bacillus sp, Saccharomyces und Candida hemmt (IZUMIDA et al., 1996). Des Weiteren ist das aus dem Meerschwamm gewonnene Styloguanidin ein Inhibitor der Chitinase aus Shewanella sp. (KATO et al., 1995). Metallionen wie $\mathrm{Cu}^{2+}, \mathrm{Zn}^{2+}$ und $\mathrm{Hg}^{2+}$ haben ebenfalls eine hemmende Wirkung auf bakteriell Chitinasen, während Ionen wie $\mathrm{Na}^{+}, \mathrm{K}^{+}, \mathrm{Mg}^{+}$und $\mathrm{Ca}^{+}$aktivierend auf 
die Chitinase aus Alteromonas wirken (SPINDLER und SPINDLER-BARTH, 1999).

Eine weitere wichtige Untereinheit von Chitinasen ist neben der katalytischen Domäne die Chitin-Bindedomäne. Chitin-Bindedomänen aus Pflanzen wurden bereits hinreichend untersucht. Dabei wurden cysteinreiche Regionen innerhalb dieser Domäne entdeckt. Die Chitinase aus z.B. B. circulans WL-12 enthält demgegenüber lediglich ein Cystein in dieser Domäne und weist keine Ähnlichkeiten zu denen aus Pflanzen auf (WATANABE et al., 1994). Ein Unterschied zwischen Chitinasen der Familie 18 und 19 zueinander liegt auch darin, das die Chitin-Bindedomäne bei der Familie 18 C-terminal und die der Familie 19 Nterminal auf dem Protein lokalisiert ist. Insgesamt weisen auch Chitin-Binde-Domänen der Familie 18 untereinander nur geringe Sequenz-Ähnlichkeiten auf. So zeigte die Chitinase A kodiert vom Insert aus pVH nur $25 \%$ Identität zur Chitin-Bindedomäne der Chitinase A1 aus B. circulans (s. Abb. 31). Die Chitin-Bindedomänen sind in der Regel für die Umsetzung des Chitins notwendig. Die Aktivität der Chitinase A aus Pseudomonas sp. PE2 wurde nach Entfernung der N-terminalen Chitin-Bindedomäne deutlich eingeschränkt (KITAMURA und KAMEI, 2002). MORIMOTO et al (1997) hingegen belegten, dass nach Entfernung der Chitin-Bindedomäne aus der Chitinase B von C. paraputrificum zwar die Hydrolyse von Chitin nicht aber die von kolloidalem Chitin beeinträchtigt wurde. Offenbar wirkte sich die Funktion der Chitin-Bindedomäne nur auf das kompakte Chitin aus. Untersuchungen legen nahe, dass die Domänen, die für die Chitin-Bindung verantwortlich sind, die Zugänglichkeit von Bindungen innerhalb des Chitinstranges beeinflussen und damit die Hydrolyse bestimmter Chitin-Formen erhöhen (SVITIL und KIRCHMAN 1998).

Die Chitin-Bindedomänen lassen sich aufgrund der geringen Ähnlichkeiten zueinander nicht in die gleichen Klassen wie die katalytischen Domänen einordnen. Anstelle dessen sind sie aufgrund ihrer Aminosäuresequenzen in 3 Familien kategorisiert worden.

Zur Familie 1 und 2 gehören Domänen, die bei Chitinasen und nicht-hydrolytischen Proteinen gefunden wurden. Die Familie 3 enthält Domänen die sich außer in Chitinasen noch in SerinProteasen und Cellulasen finden lassen (KITAMURA und KAMEI, 2002). Bezüglich der Struktur der Chitin-Binde-Domäne wurde diejenige der Chitinase B aus S. marcescens näher charakterisiert. Diese wird von 3 anti-parallelen $\beta$-Strängen die durch lange Loops verbunden sind gebildet und gehört der Familie 3 an. Sie verfügt über eine große Anzahl von aromatischen Aminosäuren, die eine Art Weg zum aktiven Zentrum bilden. Dabei weist die Chitin-Bindedomäne Ähnlichkeiten zu Cellulose-Bindedomänen der Klasse V auf (VAN AALTEN et al., 1999).

Bei der Chitinase A, kodiert vom Insert aus pVH, konnte im Gegensatz zu den Chitinasen aus 
den Isolaten WG1 und SE1 die Chitin-Bindedomäne kloniert werden. Diese umfasste 53 Aminosäuren am N-Terminus (s. Abb. 26). Aufgrund von Ähnlichkeiten zu bekannten ChitinBindedomänen wie der Chitinase A1 aus B. circulans, der Chitinase B aus S. marcescens, der Cellulase B aus B. sp und einer Protease C aus S. griseus (s. Abb. 32), die alle der Familie 3 angehörten, konnte auch diese in die gleiche Familie 3 eingeordnet werden.

Außer den erwähnten drei für Chitinasen typischen Chitin-Bindedomänen, sind noch Fibronectin Typ III-ähnliche Module (FN3) und Cellulose-Bindedomänen der Klasse II bei Chitinasen bekannt (HENRISSAT 1999). Die Chitin-Bindedomäne und die katalytische Domäne sind durch ein unflexibles Verbindungsstück, die FN3-Domäne, verbunden, die zuerst in der Chitinase A1 von B. circulans WL-12 entdeckt wurde (WATANABE et al., 1990). Diese wurde danach in weiteren bakteriellen Chitinasen, Cellulasen, Amylasen und Poly(3-Hydroxybutyrat)-Depolymerasen nachgewiesen. Die Funktion der FN3-Domäne ist bislang nicht geklärt, jedoch scheint sie für die Struktur der Chitinasen wichtig zu sein, indem sie für die optimale Distanz und Orientierung der katalytischen- zur Chitin-Bindedomäne sorgt (SUZUKI et al., 1999). Bei der von pVH kodierten Chitinase A konnte eine Ähnlichkeit zu FN3-Domänen bekannter Chitinasen hergestellt werden (s. Abb. 52). Diese Sequenz lag wie erwartet zwischen der katalytischen- und der Chitin-Bindedomäne (im Bereich 592-693 der Aminosäuresequenz) und scheint damit die für die FN3-Domäne beschriebene Funktion innerhalb dieser Chitinase zu erfüllen.

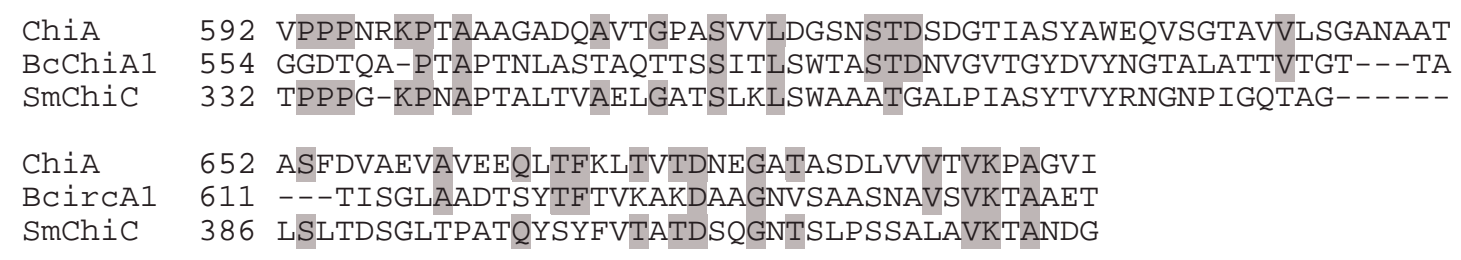

\section{Abb. 52: Sequenzvergleiche der FN3-Domäne bekannter bakterieller Enzyme zur} Chitinase A (ChiA) kodiert vom Insert aus pVH

Hervorgehoben sind konservierte Aminosäuren, die sich bei der Chitinase A fanden. BcChiA1, Chitinase A1 aus B. circulans WL-12 (M57601); SmChiC, Chitinase C aus S. marcesens (SUZUKI et al., 1999)

Sowohl das Isolat SE1 als auch WG1 konnten als bislang unbekannte Vertreter der Gattung Bacillus identifiziert werden. Daher ist auffällig, das die partiell klonierten Chitinasen aus 
diesen Organismen eine Ähnlickeit von $95 \%$ auf Aminosäureebene zur Chitinase A aus V. harveyi aufwiesen. Zu erwarten wäre eine Ähnlichkeit zu Chitinasen von Bakterien der gleichen Gattung gewesen, z.B. zur Chitinase aus B. thuringiensis oder B. licheniformis. Die Chitinasen aus SE1 und WG1 lassen sich somit nicht aufgrund der phylogenetischen Verwandtschaft zu bekannten Chitinasen aus der gleichen Gattung einordnen. Auch lassen sich durch Vergleich der Signalsequenzen der Chitinasen aus den beiden Isolaten (s. 4.2) keine Verwandtschaft zu bekannten Chitinasen aus Bacillus-Stämmen ableiten, da auch diese nahezu identisch zur Signalsequenz der Chitinase aus $V$. harveyi waren.

Die Chitinase A, kodiert vom Insert aus pVH, stammte aus einer Anreicherungskultur. Diese war fast identisch zur Chitinase A aus V. harveyi. Die Anreicherungskultur, der das ChitinaseGen entstammte, war mit Meeresproben beimpft und inkubiert worden. Das chiA-Gen besitzt konservierte Bereiche, die unter den verschiedensten Bakterien-Gattungen verbreitet sind. So findet sich das chiA-Gen z.B. in den Gattungen Serratia, Alteromonas, Bacillus, Clostridium, Enterobacter und Vibrio. Von 650 Isolaten aus Meeresproben konnten $29 \%$ mit einer Sonde aus dem chiA-Gen als positiv getestet werden (RAMAIAH et al., 2000). Aufgrund des Vorkommens der Chitinase A in vielen verschiedenen Bakterien-Gattungen lässt sich nicht mit Sicherheit vorhersagen, welcher Spezies das so klonierte Chitinase A-Gen entstammte.

\subsection{Produktion und Charakterisierung der Chitinasen aus E. coli/pWG3-1 und $E$. coli/pSG-1}

Die Chitinase-Gene chiIS aus dem Isolat WG3 (Vektor pWG3) und chiC aus einer Anreicherungskultur (Vektor pSG) konnten in Expressionsvektoren umzukloniert werden (s. 3.10.2). Das an die Chitinase-Gene fusionierte His $_{6}-$ Tag ermöglichte eine Reinigung der rekombinant in E. coli BL21 produzierten Chitinasen durch Affinitätschromatographie. Dabei gelang es nicht, die Enzyme vollständig zu reinigen. Offenbar erschwerte die Konformation der Proteine die Zugänglichkeit des $\mathrm{His}_{6}-\mathrm{Tag}$ an die Ni-NTA-Agarose. Beim enzymatischen Test zur Bestimmung der spezifischen Aktivität mit Chitin-Pulver aus Krabben wiesen die Chitinasen Aktivitäten von 0,8 bzw. 0,9 U/mg Protein auf. Bei der Chitinase C aus $S$. griseus HUT6037 waren demgegenüber 1,84 U/mg Protein gemessen worden (WATANABE et al., 1999). Diese Messdaten lassen sich aufgrund der ähnlichen Ergebnisse einander angleichen. Die spezifischen Aktivitäten der Chitinasen IS aus E.coli/pWG3-1 und der Chitinase C aus E. 
coli/pSG-1 beim Abbau von kolloidalem Chitin wurde mit 1,5 bzw. 1,8 U/mg Protein gemessen. Bei Untersuchungen der Chitinase C aus S. griseus HUT6037 waren im Vergleich dazu jedoch 24,5 U/mg Protein gemessen worden. Die große Differenz der Messdaten beim Vergleich der spezifischen Aktivitäten der Chitinase IS aus E.coli/pWG3-1 und der Chitinase C aus E. coli/pSG-1, die zu 99 \% identisch war mit der Chitinase C aus S. griseus HUT6037, ist bei der Messung der Aktivität mit kolloidalem Chitin möglicherweise auf das verwendete Substrat zurückführbar. Das für diese Arbeit benötigte kolloidale Chitin wurde durch HClHydrolyse selbst hergestellt. Die große Abweichung der gemessenen Enzymaktivitäten zur Referenz-Chitinase C könnte daher in dem noch zu grobkörnigen kolloidalem Chitin liegen. Dies ist vor allem daraus $\mathrm{zu}$ folgern, dass bei der Verwendung von Chitin-Pulver sehr ähnliche Werte erhalten wurden.

Die weiteren ermittelten Charakteristika der Chitinase IS aus E. coli/pWG3-1 und der Chitinase C aus E. coli/pSG-1, wurden mit der Chitinase C aus S. griseus HUT 6037 verglichen. Dabei konnten signifikante Ähnlichkeiten zur Referenz-Chitinase ermittelt werden. Das pH-Optimum der Chitinasen aus E. coli/pWG3-1 und E.coli/pSG-1 lag im Bereich von pH 5-7. Das Temperaturoptimum wies bei beiden Chitinasen den Bereich von 50-55 ${ }^{\circ} \mathrm{C}$ auf (s. 3.10.2). Die entsprechenden Werte bei der Chitinase C aus S. griseus HUT 6037 lagen im gleichen Bereich (WATANABE et al., 1999). Nur beim pH-Optimum konnte bei beiden Chitinasen bei $\mathrm{pH}$ 4,0 ein abweichender Wert im Vergleich zu den Referenzdaten durch das Absinken der Aktivität auf ca. 60 \% festgestellt werden. Bei der Referenz-Chitinase C lag die Aktivität in diesem Bereich noch bei ca. $100 \%$.

Beim Test der Chitinasen aus E. coli/pSG-1 und E.coli/pWG3-1 auf fungizide Eigenschaften konnten bei diesen Enzymen im Agartestverfahren fungizide Eigenschaften gegen die pflanzenpathogenen Pilze Fusarium culmorum, Botrytis cinerea, Guignardia bidwellii und Sclerotia sclerotiorum sowie einen Vertreter der Schimmelpilze, Aspergillus nidulans, festgestellt werden. Eine Hemmhofbildung gegenüber den im Plattentest eingesetzten Pilzstämmen konnte bei einem Einsatz von ca. $40 \mu \mathrm{g}$ Protein erzielt werden. Dies lag im vergleichbarem Bereich wie die Proteinkonzentration, die bei der Chitinase C aus S. griseus HUT6037 in einem gleichen Plattentestverfahren ermittelt wurde (WATANABE et al. 1999), um gegenüber Pilzen einen Hemmhof durch die Chitinase $\mathrm{C}$ zu erzielen. 


\subsection{Charakterisierung der Chitinasen aus den Isolaten WG1, SE1, SL3 und E2}

Für die enzymatischen Tests der Chitinasen aus den Isolaten von E2, SE1, SL3 und WG1 wurde der konzentrierte Enzymüberstand verwendet, da es nicht bzw. nur partiell gelang die Chitinase-Gene dieser Stämme zu identifizieren und heterolog zu expremieren. Die spezifische Aktivität der Chitinasen bei der Hydrolyse von kolloidalem Chitin lagen dabei zwischen 0,22 U/mg Protein bei WG1 und 0,37 U/mg Protein bei SL3. Beim Vergleich dieser Ergebnisse mit der spezifischen Chitinaseaktivität von ebenfalls nicht gereinigten Enzymen von z.B. Enterobacter agglomerans-Stämmen, lag diese bei 2 bis 5 U/mg Protein (CHERNIN et al., 1995). Möglicherweise liegt die geringere spezifische Aktivität der aus dem Kulturüberstand der Isolate gemessenen spezifischen Aktivität an der Struktur des für den Test verwendeten kolloidalen Chitins (s. 4.4). Das Temperaturoptimum der Chitinasen lag zwischen 45 und $50{ }^{\circ} \mathrm{C}$ und das $\mathrm{pH}$-Optimum im Bereich zwischen $\mathrm{pH} 4$ und 6. Die Temperaturoptima von Chitinasen aus mesophilen Organismen liegen zumeist im Bereich von 40 bis $55^{\circ} \mathrm{C}$ (GAL et al., 1998; VIONIS et al., 1996; WIWAT et al., 1999). Die pH-Optima bekannter bakterieller Chitinasen liegen zwischen 3,5 und 8 (KOGA et al., 1999). Damit ordnen sich die gemessenen $\mathrm{pH}$ - und Temperatur-Optima in diesen von anderen Chitinasen gemessenen Bereich ein. Bezüglich der Erfassung der Molekularmassen der Chitinasen aus WG1, SE1, SL3 und E2 gelang es, diese durch Aktivitätsfärbung nach Auftrennung der Enzyme aus dem Kulturüberstand über native-Gradienten-PAGE zu ermitteln. Dabei zeigten die Chitinasen aus WG1 und SE1 Molekularmassen von 90 kDa. Diese Werte waren erwartet worden, da die partiell aus diesen Isolaten klonierten Chitinase-Gene hohe Übereinstimmungen zum Chitinase A-Gen aus V. harveyi aufwiesen (s. 3.8.2). Das aus dem Chitinase A-Gen abgeleitete Genprodukt wies dabei eine Molekularmasse von $91 \mathrm{kDa}$ auf (SUGINTA et al., 2000). Beim Isolat SE1 konnte mit Hilfe der Aktivitätsfärbung ein Protein mit einer Molekularmasse von ca. 10 kDa detektiert werden. Möglicherweise handelt es sich dabei um eine weitere vom Isolat SE1 produzierte Chitinase. Die Produktion mehrerer Chitinasen aus einem Bakterium ist bei verschiedenen Bakterien-Stämmen dokumentiert. So konnten z.B. bei $V$. harveyi 10 verschiedene Chitinasen nachgewiesen werden (RAMAIAH et al., 2000).

Beim Isolat SL3 konnte nur ein 220 Bp umfassendes Teilstück des Chitinase-Gens amplifiziert werden. Dieses zeigte eine große Ähnlichkeit zum chiA-Gen, jedoch reichte das erhaltene Fragment nicht aus, weitere Analysen vorzunehmen. Durch Aktivitätsfärbung 
konnte jedoch auch hier eine Molekularmasse der Chitinase von SL3 von ca. 90 kDa festgestellt werden. Dies wies darauf hin, dass die Chitinasen aus diesem Isolat wie auch diejenige aus SE1 und WG1 eine hohe Ähnlichkeit zur Chitinase A aus V. harveyi aufweist. Bei der Auftrennung des Kulturüberstandes und anschließender Aktivitätsfärbung der Chitinase aus E2 konnte eine Molekularmasse von ca. $70 \mathrm{kDa}$ festgestellt werden. Diese Größe weist daraufhin, dass die Chitinase aus E2, einem bislang unbekannten Vertreter der Gattung Bacillus, ebenfalls in die Familie 18 der Glykosyl-Hydrolasen einzuordnen war, da die Chitinasen der Familie 19 in der Regel ca. $30 \mathrm{kDa}$ nicht überschreiten (HENRISSATT 1999).

Das Ziel dieser Arbeit war die Identifizierung von Chitinasen mit fungiziden Eigenschaften, die sich für die Erstellung eines Chitinase-Präparates als Biopestizid eignen könnten. Im Zuge der Arbeit konnten zwei Chitinase-Gene kloniert werden, deren heterolog expremierte Genprodukte fungizide Eigenschaften gegen fünf verschiedene Pilz-Stämme aufwiesen. Da die fungiziden Eigenschaften dieser Chitinasen über einen Test-Zeitraum von über 4 Wochen stabil blieben und die Enzyme ein breites pH-Spektrum aufwiesen, scheinen sie für die Verwendung in einem Chitinasepräparat geeignet zu sein.

\subsection{Ausblick}

Es gelang, zwei Chitinase-Gene der Familie 19 zu klonieren, zu expremieren und zu charakterisieren. Beide Chitinasen zeigten antifungale Eigenschaften gegen bekannte pflanzenpathogene Pilze. Damit könnten sie als Chitinasepräparat einsetzbar sein.

Einsatzmöglichkeiten der Chitinasen als Fungizid lägen in der Bekämpfung von Verunreinigungen in Innenräumen durch Pilze (Wandfeuchtigkeit). Die schädigende Wirkung eingeatmeter Pilzsporen auf das Immunsystem und die Gefahr ernsthafter Erkrankungen wie z.B. Aspergillosen und Mykosen ist gut dokumentiert (REISS, 1986). Eine weitere Möglichkeit läge im Schutz von z.B. Nutz-und Zierpflanzen. Die Bekämpfung von Pilzen wird derzeit fast auschließlich von synthetischen Fungiziden durchgeführt. Nachteilig ist, das viele synthetische Fungizide verantwortlich sind u.a. für eine große Anzahl von Reizungen/Verletzungen der Haut, der Schleimhäute, Augen und der Atmungsorgane. Zudem können Allergien verursacht werden (REIGERT et al., 1998; DALVI, 1988). Diese Befunde lassen unter dem Aspekt des Verbraucher- und Umweltschutzes den Einsatz von biologischen Fungiziden als sehr interessant erscheinen, da hier die Möglichkeit besteht, die Verwendung 
von synthetischen Fungizide einzuschränken. Die in dieser Arbeit identifizierten Chitinasen könnten für dieses Ziel verwendbar sein, da sie außer der antifungalen Wirkung ein breites pH-Spektrum aufwiesen. Dies ist für ein Präparat, das auf verschiedenen Oberflächen anwendbar sein muss, wichtig. Um festzustellen, ob diese Enyzme auch als Biopestizid in vivo verwendet werden könnten, müssten verschiedene Tests durchgeführt werden. Wichtig wären Versuche zur Langzeitstabilität der Enzyme unter Berücksichtigung verschiedener Temperaturen, insbesondere im Bereich von 10-30 ${ }^{\circ} \mathrm{C}$. In diesem Temperaturbereich müssten die Chitinasepräparate in Innenräumen und auf landwirtschaftlichen Nutzflächen ein starke antifungale Wirkung über möglichst große Zeiträume hinweg entfalten. Dazu könnten die Chitinasen einem Puffer mit optimalen pH-Bedingungen zugesetzt werden. Mit diesem Präparat ließe sich die Einsatzfähigkeit der Chitinasen feststellen, indem z.B. Pflanzenblätter, die mit Pilzen befallen sind, mit dem Präparat besprüht werden.

Zudem müssten weiterführende Untersuchungen zur Umweltverträglichkeit der rekombinant produzierten Chitinasen im Vergleich zu kommerziell erhältlichen Fungiziden durchgeführt werden. Der Einsatz der Chitinasen als Fungizid erscheint zunächst unbedenklich, da es sich um biologisch vollständig abbaubare Enyzme handelt. Dennoch müssten die im Rahmen der Arbeit identifizierten Chitinasen im Hinblick auf ihre Umweltfreundlichkeit bzw. ökotoxikologische Wirkung mit herkömmlichen synthetischen Fungiziden verglichen werden, um eine Gefährdung für den Menschen und die Umwelt auszuschliessen.

Möglich wäre auch der Einsatz der Isolate WG3 und WG1 bzw. deren Kulturüberstand selbst. Beide Isolate verfügten über eine starke fungizide Wirkung. So könnte anstelle des rekombinant produzierten Enzyms der natürliche Produzent selbst eingesetzt werden. Dabei wäre zu untersuchen, wie der jeweilige Stamm auf z.B. Nutzpflanzen auszubringen ist und wie er sich auf verschiedenen Oberflächen (Wandflächen, Pflanzenblätter etc.) verhält. Beim Einsatz der Isolate könnte auch untersucht werden, in wie weit die Zugabe von Chitin zum Boden von Nutz- und Zierpflanzen das Wachstum dieser Bakterien-Stämme fördern und damit einen Schutz vor pflanzenpathogenen Pilzen ergeben würde. Ähnliche Versuche waren bereits erfolgreich in anderen Arbeitsgruppen durchgeführt worden (CHERNIN et al., 1995; PLEBAN et al., 1997). Zudem wäre es auch hier notwendig, wie beim rekombinant erstellten Chitinasepräparat, toxikologische Tests durchzuführen, um eine Gefährdung von Mensch und Umwelt auszuschließen.

Um die Chitinase-Gene der Isolate aus E2, SE1, WG1 und SL3 vollständig zu klonieren, könnte versucht werden, durch weitere PCR-Reaktionen mit aus dem vom chiA-Gen von $V$. harveyi abgeleiteten Oligonukleotiden den restlichen Abschnitt der Gene zu erhalten. 
Eine andere Möglichkeit, die Chitinase-Gene zu identifizieren, läge in einem Aktivitätsscreening. Aus den Isolaten erstellte Genbanken könnten in E. coli transformiert und dann auf Agarplatten mit sehr feinkörnigem kolloidalem Chitin oder RBV-Chitin plattiert werden (WOLF et al., 1990). Ein Klon, der eine Chitinase produziert, könnte anhand einer Hofbildung um die Kolonie herum detektiert werden. Nach Erhalt der Chitinase-Gene müssten diese in Expressionsvektoren, z.B. pET101 umkloniert und expremiert werden, um so in gereinigter Form biochemisch charakterisiert zu werden. Da Hinweise daraufhin bestehen, das die Genprodukte der Chitinase-Gene aus SL3, SE1 und WG1 toxisch für E. coli sind, könnte versucht werden die Gene über einen anderen Wirt als E. coli zu klonieren. Eine Möglichkeit wäre dabei die Verwendung von Bacillus subtilis W600. Dabei könnte das betreffende Chitinase-Gen in den Vektor pWB705 kloniert werden, der für die Expression extrazellulärer Enzyme mit B. subtilisW600 als Wirt geeignet ist (LEE et al., 1996). Nach Expression der Gene würde insbesondere die Untersuchung auf fungizide Eigenschaften von Interesse sein, um festzustellen, ob die Chitinasen dieser Isolate für die Verwendung als Biopestizid geeignet wären. 


\section{Zusammenfassung}

1.) Zur Isolierung von chitinolytischen Bakterien wurden als Ausgangsmaterialien Bodenund Meeresproben aus Deutschland, Israel und Ägypten verwendet und in Mineralmedium mit Chitin als einziger Kohlenstoff- und Energiequelle inkubiert. Durch mehrmaliges Überimpfen und Vereinzelungsausstriche auf Chitin-Agarplatten konnten 13 chitinolytische Bakterien-Stämme isoliert werden. Durch 16S rRNA-Gen-Analyse konnten 12 Stämme als bislang unbekannte Vertreter verschiedener Gattungen identifiziert werden. Ein Isolat wurde als Stenotrophomonas maltophilia identifiziert. Vier Stämme (E2, SE1, SL3 und WG1) ließen sich in die Gattung Bacillus, drei (SL1, SL2 und SL4) in die Gattung Paenibacillus und zwei (E2 und WG2) als unbekannte Vertreter der Gattung Sphingobakterium einordnen. Zudem konnte jeweils ein Vertreter der Gattungen Alcaligenes (E1), Streptomyces (WG3) und Flexibacter (LK) isoliert werden.

2.) Fünf der 13 isolierten Bakterienstämme, SE1, SL3, E2, WG1 und WG3 wiesen eine fungizide Wirkung gegen vier getestete phytopathogenen Pilze (Botrytis cinerea, Fusarium culmorum, Guignardia bidwellii und Sclerotia sclerotiorum) und ebenso gegenüber einem Vertreter der Schimmelpilze (Aspergillus nidulans) auf. Im Vergleich zu den Isolaten WG1 und WG3 zeigten die drei Isolate E2, SE1 und SL3 dabei eine schwächer ausgeprägte Wirkung, die sich nicht gegen alle getesteten Pilzstämme richtete. Die Isolate WG1 und WG3 wiesen eine starke antifungale Wirkung gegen alle getesteten Pilze auf. Durch ProteaseBehandlung und Hitzeinaktivierung des Kulturüberstandes der fünf Isolate konnte festgestellt werden, das die fungizide Wirkung von WG1 und WG3 nicht nur auf Chitinasen, sondern auch auf weitere vom jeweiligem Isolat produzierte Verbindungen beruht. Die fungiziden Eigenschaften von E2, SE1 und SL3 konnten dagegen ausschließlich auf die von diesen Stämmen produzierten Chitinasen zurückgeführt werden.

3.) Das Substratspektrum der fünf isolierten Stämme mit fungiziden Eigenschaften wurde ermittelt. Die Isolate wiesen dabei signifikante Ähnlichkeiten zum Substratspektrum des jeweiligen am nächsten verwandten Referenzorganismus auf. Zudem wurden die Wachstumskurven dieser Isolate mit kolloidalem Chitin als einziger Kohlenstoffquelle aufgenommen. Die Verdopplungszeit lag bei den Isolaten E2, SL3 und WG3 zwischen 2,4 
und 3,9 h. Die Isolate WG1 und SE1 zeigten eine längere Verdopplungszeit von 6,3 und $11,55 \mathrm{~h}$.

4.) Die Chitinase A-Gene aus den Isolaten SE1 und WG1 konnten partiell kloniert werden. Die aus dem jeweiligen Gen abgeleitete Aminosäuresequenz wies eine Ähnlichkeit von $95 \%$ zur Chitinase A aus $V$. harveyi auf. Aufgrund dieser Übereinstimmungen konnten beide Chitinasen in die Klasse IV innerhalb der Familie 18 der Glykosyl-Hydrolasen eingeordnet werden. Das Chitinase IS-Gen aus WG3 konnte vollständig kloniert werden. Das abgeleitete Genprodukt besaß eine Molekularmasse von 31 kDa und zeigte eine Übereinstimmung von 90 $\%$ zur Chitinase IS aus Streptomyces sp. AJ9463. Durch Sequenzanalysen konnte die Chitinase IS aus WG3 in die Klasse IV innerhalb der Familie 19 der Glykosyl-Hydrolasen eingeordnet werden.

5.) Aus Anreicherungskulturen konnten zwei vollständige Chitinase-Gene amplifiziert und kloniert werden. Die daraus abgeleiteten Aminosäuresequenzen zeigten zum einen eine Übereinstimmung von 99 \% zur Chitinase C aus S. griseus HUT6037. Das vom Gen kodierte Protein wies eine Molekularmasse von $30 \mathrm{kDa}$ auf. Sequenzvergleiche ergaben, dass es sich um eine Chitinase der Klasse IV innerhalb der Familie 19 handelte. Zum anderen wurde ein Chitinase A-Gen kloniert, das für ein $91 \mathrm{kDa}$ großes Enzym kodierte. Dieses zeigte eine Ähnlichkeit von 98 \% zur Chitinase A aus V. harveyi. Damit gehörte die Chitinase zur Klasse IV innerhalb der Familie 18 der Gykosyl-Hydrolasen.

6.) Die Chitinase-Aktivitäten aus den Isolaten SE1, WG1, SL3 und E2 konnten im konzentrierten Zellüberstand nachgewiesen werden. Die spezifischen Aktivitäten der Chitinasen lagen im Bereich von 0,22 und 0,34 U/mg Protein. Durch Aktivitätsfärbung nach gelelektrophoretischer Auftrennung der im Zellüberstand vorhandenen Proteine wurden für die Chitinasen von WG1, SL3 und SE1 Molekularmassen von ca. 90 kDa und für das Enzym aus E2 eine Molekularmasse von ca. $70 \mathrm{kDa}$ ermittelt. Die spezifischen Aktivitäten der Chitinasen von WG1 und SE1 wiesen bei $50{ }^{\circ} \mathrm{C}$ und einem pH-Wert von 6 das Optimum auf. Dem gegenüber besaß die Chitinase-Aktivität von E2 ein Temperaturoptimum von $45^{\circ} \mathrm{C}$ und ein pH-Optimum von 5. Die entsprechenden Werte für die Chitinase aus SL3 lagen bei $50{ }^{\circ} \mathrm{C}$ und $\mathrm{pH} 4$. 
7.) Das identifizierte Chitinase IS-Gen aus dem Isolat WG3 und das aus einer Anreicherung amplifizierte Chitinase C-Gen wurden rekombinant expremiert und die Genprodukte partiell gereinigt. Beide Enzyme zeigten antifungale Eigenschaften gegen alle fünf getesteten Pilzstämme. Somit ließ sich die fungizide Wirkung des Isolates WG3 auch auf die Aktivität der von diesem Organismus produzierten Chitinase IS zurückführen. Die spezifische Aktivität der rekombinant produzierten Chitinasen wies ein Temperaturoptimum von $50-55{ }^{\circ} \mathrm{C}$ und ein pH-Optimum von pH 5-8 auf. Die spezifische Aktivität der Chitinase IS konnte bei kolloidalem Chitin mit 1,5 U/mg und bei Chitin mit 0,8 U/mg Protein ermittelt werden. Bei der Chitinase $\mathrm{C}$ waren dies entsprechen 1,8 und 0,9 U/mg Protein. 


\section{LITERATURVERZEICHNIS}

AMANN, B. W., LORENZ, M. G., KRUMBEIN, W. E. (1983). Protection of sedimentadsorbed transforming DNA against enzymatic inactivation. Appl. Environ. Microbiol. 46: 417-420

ANDERSON, D.G., McKAY, L.C. (1983). Simple and rapid method for isolating large plasmid DNA from lactic streptococci. Appl. Environ. Microbiol. 46 (3): 549-552

ANDERSSON, L. O., BORG, H., MIKAELSSON, M. (1972). Molecular weight estimation of proteins by electrophoresis in polyacrylamide gel of graded porosity. FEBS Lett. 20:199202.

ANDERSEN, M. D., JENSEN, A., ROBERTUS, J. D., LEAH, R., SCRIVERS, K. (1997). Heterologous expression and characterization of wild-type and mutant forms of a $26 \mathrm{kDa}$ endochitinase feom barley (Hordeum vulgare L.). Biochem. J. 322: 815-822.

BANEYX, F. 1999. Recombinant protein expression in Escherichia coli. Curr. Opin. Biotechnol. 10:411-421

BANNER, D. W., BlOOMER, A. C., PETSKO, D. C., PAGSON, C. I., WILSON, I. A., CORRAN, P. H., FURTH, A. J., MILMANN, J. D., OFFORD, R. E., phosphate isomerase determined crystallographically at $2.5 \AA$ resultion using amino acid sequence data. Nature 255: 609-614.

BASSLER, B. L., YU, C., LEE, Y. C., ROSEMAN, S. (1991). Chitin utilization by marine bacteria. J. Biol. Chem. 266: 24260-24267.

BENNETT, J.W., LASURE, L.L. (1991). Growth media. In: BENNETT, J.W., LASURE, L:L: (eds.), More genmanipulation in fungi. Academic Press Inc.

BERGEY`S Manual of Determinative Bacteriology (1996). William und Wilkins, Baltimore, Maryland ISBN 0-68400603-7 
BIBERSTEIN, H. (1995) Schimmelpilze in Wohnräumen - Was tun? alpha \& omega Verlag, Stuttgart. ISBN 3-927656-06-2

BLATTNER, F. R., PUNKETT, G., BLOCH, C. A., PERNA, N. T., BURLAND, V., RILEY, M., COLlADO-VIDES, J., GLASNER, J. D., RODE, C. K., MAYHEW, G. F., GREGOR, J., DAVIS, N. W., KIRKPATRICK, H.A., GOEDEN, M. A., ROSE, D. J., MAU, B., SHAO, Y. (1997). The complete genome sequenze of Escherichia coli K-12. Science 277 (5331): 1453-1574.

BÖHM, R. (Hrsg.) (1994) 5. Hohenheimer Seminar: Nachweis und Bewertung von Keimemissionen bei der Entsorgung von Kommunalen Abfällen sowie Spezielle Hygieneprobleme bei der Bioabfallkompostierung. Dt. Veterinärmed. Ges. Giessen ISBN 3924851-98-0

BORNEMANN, J., TRIPLETT, E.W. (1997). Molecular microbial diversity in soils from Eastern Amazonia: Evidence for unusual microorganisms and microbial population shifts associated with deforestation. Appl. Environ. Microbiol. 63:2647-2653

BRADFORD, M. M. (1976). A rapid and sensitive method for the quantitation of microgram quantities of protein utilizing the principle of protein-dye binding. Anal. Biochem. 72: 248254.

BREZNAK, J. A., COSTILOW, R. N. (1994). Physocochemical factors in growth. In:

Gerhardt, P., Murray, R. G. E., Wood, W. A., Krieg, N. R. (Hrsg.) Methods for general and molecular bacteriology, 137-154. American Society for Microbiology, Washington D. C., USA.

BROCK, T. D., MADIGAN M. T., MARTINKO, J. M., PARKER, J. (1994). Biology of Microorganisms. Simon and Schuster. New York ISBN 0-13-176660-0

BROEKART, W. F., PARIJS, J. V., ALLEN, A:, PNEUMANS, W. J. (1988). Comparison of some molecular enzymatic and antifungal properties of chitinases from thorn-apple, tobacco and wgear. Physiol. Mol. Plant Pathol. 33: 319.331 
BULUWELA, L., FORSTER, A., BOEHM, T., RABBITTS, T. H. (1989). A rapid procedure for colony screening using nylon filters. Nucl. Acids. Res. 17: 23-24.

BÜTTNER, P. (1999). Variabilität und Pathogenität bei Botrytic cinerea. Bibliotheca Mycologica 177. ISBN 3-3443-59079-9

CHEN, H. C., HUANG, M. Y., MOODY, M. W., JIANG, S. T. (1991). Distribution and hydrolytic enzyme activities of aerobic, heterotrophic bacteria isolated from grass pawn, Penaeus monodon. J fish. Soc. Taiwan 18: 301-310.

CHERNIN, L., ISMAILlOV, Z., HARAN, S., and CHET, I. (1995). Chitinolytic Enterobacter agglomerans antagonistic to fungal plant pathogenes. Appl. Environ. Microbiol. 61: $1720-1726$.

CLARKE, D. und CARBON, J. (1976). A colony bank containing synthetic colEl hybrid plasmids representative of the entire Escherichia coli genome: Cell 9: 91-99.

COTTRELL, M. T., WOOD, D. N., YU, L., KIRCHMAN, D. L.. (2000). Selected chitinase genes in cultured and uncultured marine bacteria. Appl. Environ. Microbiol. 66 (3): 11951201.

COTTRELL, M. T., MOORE, J. A., KIRCHMAN, D. L. (1999). Chitinases from uncultured marine mircoorganisms. Appl. Environ. Microbiol.: 65: 2553-2557.

DAVIS, B., EVELEIGH, D.E. (1984) Chitosanases: occurence, production and immobilization in Chitin, Chitosan and Related Enzymes. Zikakis, J.P. (Hrsg.), S. 161-180, Academic Press, London.

DORSCH, M., LANE, D., STACKEBRANDT, E. (1992). Towards a phylogeny of the genus Vibrio based on 16S rRNA sequenzes. Int. J. Syst. Bacteriol. 42 (1): 52-63.

DOWER, W. J., MILLER, J. F., RAGSDALE, C.W. (1988). High efficency transformation of E. coli by high voltage electroporation. Nucl. Acids Res. 16: 145-148 
DOWNING, K. J., LESLIE, G., THOMSON, J. A. (2000). Biocontrol of the sugar cane borer Eldana saccharina by expression of the Bacillus thuringiensis cry1Ac7 and Serratia marcescens chiA genes in sugar cane associated bacteria. Appl. Environ. Microbiol. 66: 28042810.

DOWNING, K. J. und THOMSON, J. A. (2000). Introduction of the Serratia marcescens chiA gene into an enophytic Pseudomonas fluorescens for the biocontrol of phytopathogene fungi. Can. J. Microbiol. 46: 363-369.

DROUILLARD, S., AMAND, S., DAVIES, G. J., FOLGIAS, C. E., HENRISSAT, B. (1997). Serratia marcescens chitobiase is a retaining glycosidase utilizing substrate acetamido group participation. Biochem. 328: 945-949.

EBERZNIK, M., STROBEL, H. J., DAWSON, K. A., JONES, C. R. (1998). The D-xylosebinding protein, XylF, from Thermoanaerobacter ethanolicus 39E: cloning, molecular analysis and expression of the structural gene. J. Bacteriol. 180 (14): 3570-3577

FABER, G. K. (1993). An $\alpha / \beta$-barrel full of evolutionary trouble. Curr. Opin. Struc. Biol. 3: 409-412.

FERNANDEZ, L.A., SOLA, I., ENJUANES, L., DE LORENZO, V. (2000).

Specific Secretion of Active Single-Chain Fv Antibodies into the Supernatants of Escherichia coli Cultures by Use of the Hemolysin System. Applied and Environmental Microbiology 66(11): 5024-5029

FERRIS, M.J. MUYZER, G., WARD, D.M. (1997). Denaturatio gradient gel electrophoresis profiles of $16 \mathrm{~S}$ rRNA-defined populations inhabiting a hot spring microbial mat community. Appl. Environ. Microbiol. 62:340-346

FLYG, C., BOMAN,H. G. (1988). Drosophila genes cut and minature are associates with the susceptibility to infection in Serratia marcescens. Genet. Res. 52: 51-56. 
FOLDERS, J., ALGRA, J., ROELOFS, M., VAN LOON, L., TOMMASSEN, J., BITTER, W. (2001). Characterization of Pseudomonas aeruginosa Chitinase, a Gradually Secreted Protein. Journal of bacteriology 183 (24) 7044-7052

FUCHS, R.L., McPHERSON, S.A., DRAHOS, D.J. (1986) Cloning of a Serratia marcescens gene encoding chitinase. Appl. Environ. Microbiol. 51: 504-509.

FUKAMIZO, T. KOGA, D, GOTO, S (1995). Comparative biochemistry of chitinaseanomeric form of reaction products. Biosci. Biotechnol., Biochem. 59: 311-313

FUKOMORI, F., SASHIHARA, N., KUDO, T., HORIKOSHI, K (1988). Nucleotide sequences of the two cellulase genes from alkalophilic Bacillus sp. Strain N-4 and their strong homology. J. Bacteriol. 168 (2). 479 485

GAL, S.W., CHOI, J.Y., KIM, C.Y., CHEONG, Y.H., CHOI, Y.J., LEE, S.Y., BAHK, J.D., CHO, M.J. (1997). Isolation and characterization of the 54-kDa and $22 \mathrm{kDa}$ chitinase genes of Serratia marcescens KCTC2172. FEMS 151, 197-204

GAL, S.W., CHOI, J.Y., KIM, C.Y., CHEONG, Y.H., CHOI, Y.J., LEE, S.Y., BAHK, J.D., CHO, M.J. (1998). Cloning of the 52-kDa chitinase gene from Serratia marcescens KCTC2172 and ist proteolytic cleavage into an active 35-kDa enzyme. FEMS 160: 151-158

GERSTEIN, M. (1997). A structural census of genomes: comparing bacterial, eucariotic, and archaeal genomes in terms of protein structure. J. Mol. Biol. 274: 562-576.

GOMEZ, A., EAMON, D., SANZ, P. (1994). The Bacillus subtilis lipoprotein Lp1A causes cell lysis when expressed in E. coli. Microbiol. 140: 1839-1845

GOODAY, G. W. (1999). Aggressive and defensive roles for chitinases. EXS 87: 157-170.

GOTO, K., OMURA, T., HARA, Y., SADAIRE, Y. (2000). Application of the partial 16S rDNA sequence as an index for rapid identification of species in the genus Bacillus. J. Gen. Appl. Microbiol. 46: 1-8. 
HAHN, M., HENNIG, M., SCHLESIER, B., HÖHNE, W. (2000). Structure of jack bean chitinase. Acta Cryst. D56: 1096-1099 ISBN 0907-4449

HART, P. J., PFLUGER, H: D:, MONZINGO, A. f., HOLliS, T., ROBERTUS, J. D. (1995), The refined crystal structure of an endochitinase from Hordeum vulgare L. Seeds at 1,8 A resolution. J. Mol. Biol. 248: 402-413.

HALL, F. R. (1991). Pesticide application technology and integrated pest management in agriculture. CRC Press, Boca Raton: 135-163.

HANAHAN, D. (1983). Studies on transformation of Escherichia coli with plasmids. J. Mol. Biol. 166: 557-580.

HANAHAN, H.D., 1985, Frozen storage of kompetent cells, protocoll 3 in: DNA-Klon : Practical Approach, Vol. (Glover, D. M., Hrsg.), S. 121, IRL-Press, Oxford.

HARPSTER M., DUNSMUIR, T. (1989). Nucleotide sequence of the Chitinase B gene of Serratia marcescens. Nucleic Acid. Res. 17: 5395-5395.

HENNE, A., DANIEL, R., SCHMITZ, R.A., GOTTSCHALK, G. (1999). Construction of Environmental DNA Libraries in Escherichia coli and Screening for the Presence of Genes Conferring Utilization of 4-Hydroxybutyrate. Appl. Environ. Microbiol. 65 (9): 3901-3907.

HENRISSAT, B. (1999). Classification of chitinases modules: EXS 87: 137-156.

HENRISSAT, B. (1991). A classification of glycosylhydrolases based on amino acid sequence similarity. Biochem. J. 280: 309-316.

HERRERA-ESTRELLA, A. und CHET, I. (1999). Chitinases in biological control. 87: 171184.

HOLlis, T., HONDA, FUKAMIZO, T., MARCOTTE, E. M., ROBERTUS, J. D. (1997). Kinetic analysis of barley chitinase. Arch. Biochem. Biophys. 344: 335-342. 
HOLMES, D. S., QUICKLEY, M. (1981). A rapid boiling method for preparation of bacterial plasmids. Anal. Biochem. 114: 193-197.

IMOTO, T., YAGASHITA, K (1971). A simple activity measurment of lysozyme. Agric. Biol. Chem. 35: 1154-1156

INBAR, J., and CHET, I. (1991). Evidanse that chitinase produced by Aeromonas caviae is involved in the biological control of soil-borne plant pathogens by this bacterium. Soil Biol. Biochem. 23: 973-978.

INOUE, H., NOJIMA, H., OKAYAMA, H. (1990). High efficiency transformation of Escherichia coli with plasmids. Gene 96: 23-28.

ISELI, B., BOLLER, T, NEUHAUS, J. M. 81993). The N-terminal cystein-rich domain of tobacco class I chitinase is essential for chitin binding but not for catalytic or antifungal activity. Plant Physiol. 103: 221-226

ITOH, Y., TAKAHASHI, K., TAKIZAWA, H., NIKAIDOU, N., TANAKA, H., NISHIHASHI, H., WTANABE, T., NISHIZAWA, Y. (2002). Familiy 19 Chitinase of Streptomyces griseus HUT6037 Increases plant resistance to the fungal Disease. Biosci. Biotechnol., 67(4), 847-855

IVANOVA, I.P., VYSOTSKI, M. V., SVETASHEV, V., GORSHKOVA, M., TAGUCHI, T., YOSHIKAWA, S. (1999). Characterization of bacillus strains of marine origin. Internat. Microbiol. 2: 267-271

IZUMIDA, H., NISHIJIMA, M., TAKADERA, T., NOMOTO, A. M., SANO, H. (1996). The effect of chitinase inhibitors, cyclo(Arg-Pro) against cell separation of Saccharomyces cerevisiae and the morphological change of Candida albicans. J. Antibiotics 49: 829-831.

JACH, G., GORNHARDT, B., MUNDY, J., LOGEMANN, J., PINSDORF, E., LEAH, R., SCHELL, J., MAAS, C. (1995). Plant J. 8 (1): 97-109. 
JACOBSEN, C. S., RASMUSSEN, O. F.(1992). Development and application of a new method to extract bacterial DNA from soil based on separation of bacteria from soil with cation-exchange resin. Appl. Environ. Microbiol. 58: 2258-2462

JONES, J. D. G., GRADY, K. L., SURLOW, T. V., BREDBROOK, J. R. (1986). Isolation and characterization of genes encoding two chitinase enzymes from Serratia marcescens. EMBO J. 5: 467-473.

KATO, T., SHIZURA, Y, IZUMIDA, H., YOKOYAMA., A., ENDO, M. (1995). Styloguanodine, new chitinase inhibitors from the marine sponge Stylotella aurantium. Tetrahedron. Lett. 36: 2133-2136.

KARLE, I. L., et al., (1989). $\alpha$-Helix and mixed 310 -/ $\alpha$-helix in cocrystallized conformers of Boc-Aib-Val-Aib-Val-Val-Val-Aib-Val-Aib-OMe. Proc. Natl. Sci. USA 86: 765-769.

KIM, Y., BAEK, J., PARK, H., CHOI, Y., KIM, S. (1996). Isolation and characterization of the cDNA clones encoding class I chitinase in suspension cultures of rice cell. Biosci., Biotechnol., Biochem.

KITAMURA, E., KAMEI, Y. (2002). Molecular cloning, sequencing and expression of the gene encoding a novel chitinase A from a marine bacterium, Pseudomonas sp PE2, and its domain structure. Appl. Microbiol. Biotechnol. 61(2):140-149

KOBAYASHI, D., REEDY, R. M., BICK, J., OUDEMANS, P. V. (2002), Characterization of a Chitinase Gene from Stenotrohomonas maltophilia Strain 34S1 and Its Involment in Biological Control. Applied and Environmental Microbiology 68 (3) 1047-1045

KOBY, S., SCHICKLER, H., CHET, I., OPPENHEIM, A. (1994). The Chitinase encoding Tn7-based chiA gene endows Pseudomonas fluorescens with the capacity to control plant pathogenes in soil. Gene, 147: 81-83.

KOGA, D., MITSUTOMI, M., KONO, M., MATSUMiYA, M. (1999). Biochemistry of chitinases. EXS 87: 111-123. 
KOUKER, G., JÄGER, K.-E. (1987). Specific and sensitive Plate Assey for Bacterial Lipases. Appl. Environ. Microbiol. 53: 211-213

KUROSHIMA, K-I, SAKANE, T., TAKATA, R., YOKOTA, A. (1996). Bacillus ehimensis $s p$. nov. and Bacillus chitinolyticus sp. nov. new chitinolytic members of the genus Bacillus. Int. J. Syst. Bacteriol. 46: 76-80.

LECHNER, S., MAYR, R., FRANCIS, K. B., PRUSS, B. M., KAPLAN, T., WIESSNERGUNKEL, E., STEWART, G. S., SCHERER, S. (1998). Bacillus weihenstephanensis sp. nov. is a new psychrotolerant species of the Bacillus cereus group. Int. J. Syst. Bacteriol. 48 (4): 1373-1382.

LEE, J. W., CHOI, W. J., RHIM, S., (1996). Expression of Streptomyces albus KSM 35 Amylase with a Bacillus subtilis Secretions Vector. Foods and Biotechnology 5(4) 358-362

LEVITT, M. und CHOTHIA, C. (1976). Structural pattern in globular proteins. Nature 261: $552-558$.

LONHIENNE, T., MAVROMATIS, K., VORGIAS, C. E., BUCHON, L., GERDAY, c. BOURIOTIS, V. (2000). CLONING, Sequences, and characterization of two chitinase genes from the antarctic Arthrobacter sp strain TAD20: Isolation and Partial characterization of the enzymes. J Bacteriol. 183 (5): 1773-1779.

MARTIN, B., ALlOING, G., BOUCRAUT, C., CLAVERYS, J-P. (1989). The difficulty of cloning Streptococcus pneumoniae mal and ami loci in Escherichia coli-txicity of malX and amiA gene products. Gene 80:227-238

MATSUDA, Y., IIDA, Y., SHINOGI, T., KAKUTANI, K., NONOMURA, T., TOYODA, H. (2001). In vitro suppression of mycelial growth of Fusarium oxysporum by extracellular chitosanase of Sphingobacterium multivorum and cloning of the chitosanase gene csnSM1. J. Gen. Plant Pathol. 67:318-324 
MASSON, J.Y., DENIS, F., BRZEZINSKI, R. (1994) Primary sequence of the chitosanase from Streptomyces sp. strain N174 and comparison with other endoglycosidases. Gene 140, 103-107

MEYER, M. P. (1995). A new set of useful cloning and expression vectors derived from pBlueScript. Gene 163: 41-46.

MITSUTOMI, M., UCHIYAMA, A., YAMAGAMI, T., WATANABE, T. (1997). Mode of action of family 19 chitinasses. In: Domard, A., ROBERTS, G. A. F, VÅRUM, K. M. (eds): Advances in chitin science, Vol 2. Jaques Andre, Lion, 250-255.

MORIMOTO, K., KARITA, S., TETSUYA, K., SAKKA, K., OHMIYAM K. (1997). Cloning, Sequenzing and Expression of the Gene Encoding Clostridium paraputrificum Chitinase ChiB and Analysis of the Functions of Novel Cadhering-Like Domains and a Chitin-Binding Domain. J. Bacteriol. 179 (23) 7306-7314

MUYZER, G., TESKE, A., WISSEN, C. O., JANNASCH, H. W., (1995). Phylogenetic relationships of Thiomicrospira species and their identification in deep-sea hydrothermal vent samples by denaturing gradient gel electrophoresis of $16 \mathrm{~S}$ rDNA fragments. Archives of Microbiology, 164, 165-172.

NIEHAUS, A. STEGMÜLLER, J., DIERS-FENGER, M., TROTTER, J (1999). Cell-surface glycoprotein of oligodendrocyte progenitors involved in migration. J Neurosci. 1999 19(12): 4948-4961.

NISHIZAWA, H., KITA, N., OKIMURA, S., TAKAO, E., ABE, Y. (1988). Determination of molecualar weight of native proteins by polyacrylamide gradient gel electrophoresis. Electrophoresis 9: 803-806.

OGRAM, A., SAYLER, G. S., BARKEY, T. (1987). The extraction and purification of microbial DNA from sediments. J. Microbiol. Meth. 7: 57-66 
OHNO, T., ARMAND, S., HATA, T., NIKAIDOU, N., HENRISSAT, B., MITSUTOMI, M., WATANABE, T. (1996). A Modular Family 19 Chitinase Found in the Prokaryotic Organism Streptomyces griseus HUT 6037. J. Bacteriol.: 5065-5070.

OKUTAMI, K. (ed.). 1975. Microorganisms related to mineralization of chitin in aquatic environments. University of Tokyo Press, Tokyo, Japan.

PAPANIKOLOU, Y., PRAY, G., TAVLAS, G., VORGIAS, C., OPPENHEIM, A. B., PETRATOS, K. (2001). High Resolution structural analyses of mutant chitinase A complexes with substrates provide new insights into the mechanisms of catalysis. Biochemistry 40(38): 11338-11343

PEARSON, W. R., LIPMANN, D. J. (1988). Improved tools for biological sequence comparison. Proc. Natl. Acad. Sci. 85: 2444-2448.

PELlETIER, A., SYGUSCH, J. (1990) Purification and characterization of three chitosanase activities from Bacillus megaterium P1. Appl. Environ. Microbiol.

PERAKIS, A., TEWS, I., DAUTER, Z., OPPENHEIM, A. B., CHET, I., WILSON, K. S., VORGIAS, C. E. (1994). Cristall structure of a bacterial chitinase at 2,3 $\AA$ resolution. Strucure 2: 1169-1180.

PFENNIG, N., LIPPERT, K. D. (1966). Über das Vitamin B12-Bedürfnis phototropher Schwefelbakterien. Arch. Microbiol. 55: 245-256.

PLEBAN, S., INGEL, F., CHET, I. (1997). Control of Rhizoctonia solani and Sclerotium rolfsii in greenhouse using endophytic Bacillus spp. Eur. J. Plant. Pathol.. 101: 665-672.

PLÜCKTHUN, A., C. KREBBER, U. KREBBER, U. HORN, U. KNÜPFER, R. WENDEROTH, L. NIEBA, K. PROBA, D. RIESENBERG. 1996. Producing antibodies in Escherichia coli: from PCR to fermentation, p. 203-252. J. McCafferty, and H. R. Hoogenboom (ed.), Antibody engineering: a practical approach. IRL Press, Oxford, England. 
PÖHLE, H., (1997) Pilzemissionen aus Biofiltern. S 47-49. Entsorgungspraxis 7/8

RAMAIAH, N., HILL, R.T., CHUN, J., RAVEL, J., MATTE, M. H., STAUBE, L.S., COLWELL, R.R. (2000). Use of a chiA probe for detection of chitinase genes in bacteria from the Chesapeake Bay. FEMS 34: 63-71.

RAHA, M., KAWAGISHI, I., MÜLLER, V., KIHARA, M., MACNAB, R., (1992). Escherichia coli produces a cytoplasmic -amylase. J. Bacteriol. 174: 6644-6652

REIGERT, R., ROBERTS, J. (1998). Recognition and management of pesticides poisonings. Unites States Environmental Protection Agency (EPA).

REISS, J., (1986) Schimmelpilze: Lebensweise, Nutzen, Schaden Bekämpfung. Springer Verlag Berlin, Heidelberg, New York, Tokyo.

RINDERKNECHT, H., WILDING, P., HAVERBACH, B. J. (1967). A new method for the determination of $\alpha$-amylase. Experimentia 23: 805 .

ROBERTUS, J. D. und MONZINGO, A. F. (1999). The structure and action of chitinases. EXS 87: 125-135.

SAKUDA, S, NAGASAWA, H. (2003). Nucleotide sequences of genes encoding allosamidin-sensitive and -insensitive chitinases produced by allosamidine-producing Streptomyces. Unpublished.

SAKUDA, S., ISOGAI, A., MATSUMOTO; A., SUZUKI, A., KOSEKI, K., (1986). The structure of allosamidin, a novel insect chitinase inhibitor, produced by Streptomyces $s p$. Tetrahedron. Lett. 27: 2475- 2478.

SAMBROOK, J., FRITSCH, E. F., MANIATIS, T. (1989). Molecular cloning: A laboratory manual (2. Aufl.). Cold Spring Harbor Laboratory, Cold Spring Habor, New York, USA. samples of diverse composition. Appl. Environ. Microbiol. 62:316-322. 
SAMPSON, M. N. und GOODAY, G.W. (1998). Involvement of chitinases of Bacillus thuringiensis during pathogenesis in insects. Microbiol. 144: 2189-2194.

SCHLUMBAUM, A., MAUCH, F., VÖGELI, U., BOLLER, T. (1986) Plant chitinases are potent inhibitors of fungal growth. Nature 324, 365-367.

SCWARTZ, M. (1987). The maltose regulon. In: NEIDHART, F. C., SCHAECHLER, M., UMBARGER, H.E. (Hrsg.). Escherichia coli and Salmonella typhimurium: Cellular and Molecular Biology: 1408-1502. American Society for Microbiology, Washington D. C.

SELITRENNIKOFF, C. P. (2001). Antifungal proteins. Appl. Environ. Micribiol. 67: 28832894.

SHAPIRA, R. ORDENTLICH, A., CHET, I, OPPENHEIM, A. B. (1995). Control of plant deseases by chitinase expressed from cloned DANN in Escherichia coli. Phytophathology 79: 1246-1249.

SINGH, P., SHIN, Y. C., PARK, C. S., CHUNG, Y. R. (1998). Biological control of Fusarium Wilt of Cucumber by Chitinolytic Bacteria. Phytopathology 89 (1): $92-99$

SLY, L. I., TAGHAVI, M., FEGAN, M. (1999). Phylogenetic position of Chitinophaga pinensis in the Flexibacter-Bacteroides-Cytophaga phylum. International Journal of Systematic Bacteriology 49: 479-481

SMITHER-KOPPLER, M. L., HEWLETT, T. E., NORRIS, L. P.

STAIB, F., TOMPAK, B., THIEL, T. (1978) Aspergillus fumigatus in der Topferde von Zimmerpflanzen. ein Beitrag zur Epidermologie der Aspergillose des Menschen. Bundesgesundheitsblatt 21, 209-213

SPINDLER, K. D. und SPINDLER-BARTH, M. (1999). Inhibitors of chitinases. EXS 87: 201-209. 
SUGINTA, W., RIGDEN, D.J., ESTIBAIRO,P., DUNCAN, R.R., KETUDAT-CAIMS,J., FOTHERGILL-GILMORE,L.A. (2000). Isolation and Characterization of the gene encoding the precursor of chitinase chiA from Vibrio carchariae, unveröffentlicht.

STASSI, D. L., LACK, S. A. (1982). Effect of strong promoters on the cloning in Escherichia coli of DNA fragments from Streptococcus pneumoniae. Gene 18: 319-328

SUTCLIFFE, I. C., RUSSEL, R. R. B. (1995). Lipoproteins of Gram-positive bacteria. J. Bacteriol. 177: 1123-1128

SUZUKI, K., TAIYOJI, M., SUGARAWA, N., NIKAIDOU, N., HENRISSAT, B., WATANABE, T. (1999).The third chitinase gene (chic) of Serratia marcescens 2170 and the relationship of its product to other bacterial chitinases. Biochem J. 343, 587-596

SVITIL, A. L. und KIRCHMAN, D. L. (1998). Chitin-binding domain in a marine bacterial chitinase and other microbial chitinases: implications for the ecology end evolution 1,4-(glycanases. Microbiol. 144: 1299-1308.

TAKAYANAGI, T., AJISAKA, K., TAKIGUCHI, Y., SHIMAHARA, K. (1991). Isolation and characterization of thermostable chitinases from Bacillus licheniformis X-7u. Biochim. Biophys. Acta 1078: 404-410.

TANTIMANAVICH., S., PANBANGRED, W. (1996). Direct submission. Microbiol. Mahidol University, Bangkok

TERWISSCHA VAN SCHELTINGA , A. C., ARMAND, S., KALK, K. H., ISOGAI, A., HENRISSAT, B., DIJKSTRA, B. W. (1995). Steriochemisty of chitin hydrolysis by a plant chitinase/lysozyme and x-ray structure of a complex with allosamidin: Evidence for substrate assisted catalysis. Biochemistry 34: 15619-23.

TSUJIBO, H., ORIKOSHI, H., TANNO, H., FUJIMOTO, K., Miyamoto, K., IMADA, C., OKAMI, Y., INAMORI, Y. (1992). Cloning, Sequence and Expression of a Chitinase Gene from a Marine Bacterium, Alteromonas sp. Strain O-7. J. Bacteriol. 175: 176-181 
UEDA M., KOJIMA M., YOSHIKAWA T., MITSUDA N., MIYATAKE K, ARAI M., FUKAMIZO T. (1999). A novel type of family 19 chitinase from Aeromonas sp. No.10S-24 Eur. J. Biochem. 270: 2513-2520

VAN AALTEN, D. M. F., SYNSTAD, B., BRURBERG, M. B., HOUGH, E., RIISE, B. W., EIJSINK, V. G. H., WIERENGA, R. K. (2000). Structure of a two domain chitotriosidase from Serratia marcescens at 1,9 ̊-resolution. PNAS 97: 5842-5247.

VAIDYA R.J., SHAH, I.M., VYAS, P.R, CHHATPAR, H.S. (2001). Production of chitinase and its optimization from a novel isolate Alcaligenes xylosoxydans: potential in antifungal biocontrol. World Journal of Microbiology and Biotechnology. 17 (7):691-696

VAN BUUREN; M., NEUHAUS, J. M., SHINSHI, H., RYALS, J., MEINS, F. (1992). The structure and regulation of homeologous tobacco endochitinase genes of Nicotia sylvestris and N. tomentosiformis origin. Mol. Gen. Genet. 232: 460-469

VIEIRA, J., MESSING, J. (1982). The pUC plasmid, an M13mp7-derived system for insertion mutagenesis and sequencing with universal primers. Gene 19: 259-268.

VIONIS, A. P., NIEMAYER, F., KARAGOUNI, A. D. SCHREMPF, H. (1996). Production and processing of a $59 \mathrm{kDa}$ exochitinase during growth of Streptomyces lividans carrying pCHIO12 in soil microcosm amended with crab or fungal chitin. Appl. Environ. Microbiol. 62: $1774-1780$.

VON HÖRSTEN, P. (1996). Thermische Saatgutbehandlung- Vergleich unterschiedlicher Verfahren zur Abtötung von Krankheitserregern. Landtechnik 51: 142-143

WANG, S-L und CHANG, W-T (1997). Purifikation and characterization of two bifunctional chitinases/lysozymes extracellulary produced by Pseudomonas aeroginosa K-187 in a shrimp and crab shell powder medium. Appl. Environ. Microbiol. 63: 380-386.

WATANABE, T., KANAI, R., KAWASE, T., TANABE, T. , MITSUTOMI, M., SAKUDA, S., MIYASHITA, K. (1999). Family 19 chitinases of Streptomyces species: Characterization and distribution. Microbiol. 145: 3353-3363. 
WATANABE, T., ITO, Y., YAMADA, T., HASHIMOTO, M., SEKINE, S., TANAKA, H. (1994). The roles of the C-terminal domain and typ III domains of chitinase A1 from Bacillus circulans WL-12 in chitindegradation. J. Bacteriol. : 4575-4472.

WATANABE, T., KOBORI, K., MIYASHITA, K., FUJI, T., SAKAI, H., UCHIDA, M., TANAKA, H. (1993). Identification of glutamic acid 204 and aspartic acid 200 in chitinase A1 of Bacillus circulans WL-12 as essential residues for chitinase activity. J. Biol. Chem. 268: $18567-18572$

WATANABE, T., OYANAGI, W., SUZUKI, K., OHNISHI, K., TANAKA, H. (1991). Structure of the Gen Encoding Chitinase D of Bacillus circulans WL-12 and Possible Homology of the Enzyme to other Prokaryotic Chitinases and Class III Plant Chitinases. J. Bacteriol. 174 (2): 408-414

WEN, C. M., TSENG, C.S., LI, Y-K. (2002). Purification, characterization and cloning of a chitinase from Bacillus sp. NCTU. Biotechnol. Appl. Biochem. 35: 213-219

WILliaMS; S. T., GOODFELlOW, G., WELlingTON, E. M., VICKER, J. C., ALDERSON, P. H., SACKIN, J. S. (1983). Numerical classification of Streptomyces and related genera. J. Gen . Microbiol. 129: 1743-1813

WIWAT, C., SIWAYAPRAHM, P., BHUMIRATANA, A. (1999). Purification and characterization of chitinase from Bacillus circulans No 4.1. Curr. Microbiol. 39: 134-140.

WINTZINGERODE v., F., GÖBEL, U.B., STACKERBRANDT, E. (1997). Determination of microbial diversity in environmental samples: pitfalls of PCR-based rRNA analysis. FEMS Microbiol. Let. 21:213-229.

WIRTH, S.F., WOLF, G.A. (1990). Dye-labelled substrates for the assay and detection of chitinases and lysozyme activity. J. Microbiol. Meth. 12:197-205

WOLIN, E. A., WOLFE, R: S., WOLIN, M. J.(1964). Viologen dye inhibition of methane formation by Methanobacterium omelianskii. J. Bacteriol. 87: 993-998 
WU, M., CHUANG, Y. C., CHEN, J. P., CHEN, C. S., CHANG, M. C. Identification and Characterization of three Chitin-Binding Domains within the Multidomain Chitinase Chi92 from Aeromonas hydrophila JP101. Applied and Environmental Microbiology 67 (11): 51005106

YU C., BASSLER B.L, ROSEMAN S. (1991). Chitin utilization by marine bacteria. A physiological function for bacterial adhesion to immobilized carbohydrates. J. Biol. Chem., Vol. 266 (36): 24260-24267

ZHOU, J., BURNS, M.A., TIEDJE, J. M. (1996). DNA recovery from soil samples of diverse composition Appl. Environ. Microbiol. 62:316-322 


\section{ANHANG}

Im Anhang sind die Nukleotidsequenzen der 16S rRNA-Gene aus den Isolaten E1-E3, SE1, SL1-SL4, WG2-WG4 und LK vom 5`zum 3`-Ende wiedergegeben. Das 16S rRNA-Gen aus dem Isolat WG1 wurde von der DSMZ (Braunschweig) sequenziert und analysiert.

\section{Nukleotidsequenz des 16S rRNA-Gens aus E1}

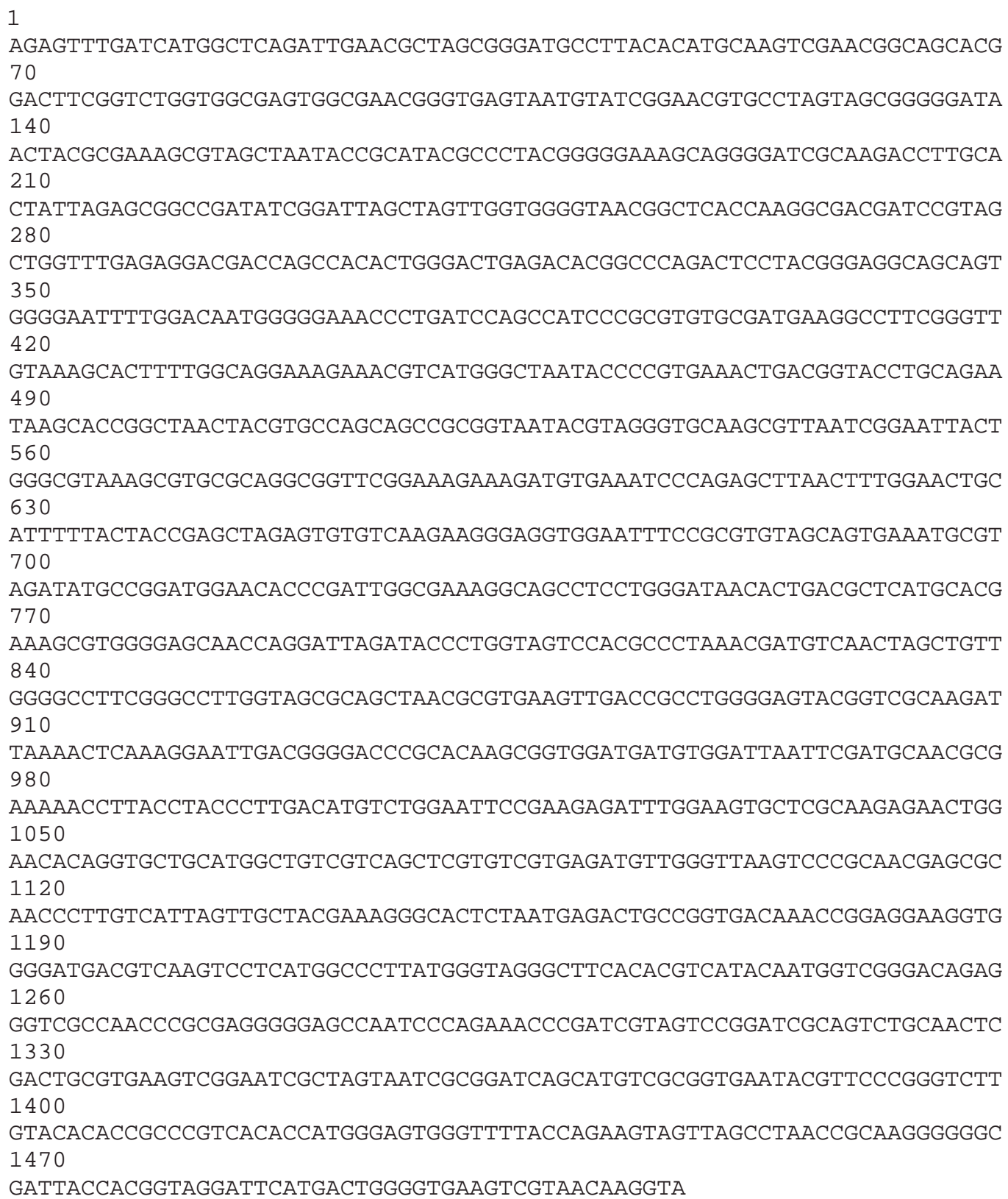




\section{Nukleotidsequenz des 16S rRNA-Gens aus E2}

1

AGAGTTTGATCATGGCTCAGGACGAACGCTGGCGGCGTGCCTAATACATGCAAGTCGAGCGGACTTGAA 70

GAGAAGCTTGCTTCTCGGATAGTTAGCGGCGGACGGGTGAGTAACACGTAGGCAACCTGCCTGTAAGAT 140 CGGGATAACTACCGGAAACGGTAGCTAAGACCGGATAATCGGTTTCTCCGCATGGGGAGATCGTGAAAC 210 ACGGAGCAATCTGTGGCTTACGGATGGGCCTGCGGCGCATTAGCTAGTTGGTGAGGTAACGGCTCACCA 280 AGGCGACGATGCGTAGCCGACCTGAGAGGGTGAACGGCCACACTGGGACTGAGACACGGCCCAGACTCC 350 TACGGGAGGCAGCAGTAGGGAATCTTCCGCAATGGACGCAAGTCTGACGGAGCAACGCCGCGTGAGTGA 420 TGAAGGTTTTCGGATCGTAAAGCTCTGTTGCCAGGGAAGAACGCCAAGGAGAGTAACTGCTCTTTGGGT 490 GACGGTACCTGAGAAGAAAGCCCCGGCTAACTACGTGCCAGCAGCCGCGGTAATACGTAGGGGGCAAGC 560 GTTGTCCGGAATTATTGGGCGTAAAGCGCGCGCAGGCGGTTTTTTAAGTCTGGTGTTTAATCCCGAGGC 630 TCAACCTCGGTTCGCACCGGAAACTGGGAGACTGGAGTGCAGGAGAGGAAAGTGGAATTCCACGTGTAG 700 CGGTGAAATGCGTAGAGATGTGGAGGAACACCAGTGGCGAAGGCGACTTTCTGGCCTGTAACTGACGCT 770 GAGGCGCGAAAGCGTGGGGAGCAAACAGGATTAGATACCCTGGTAGTCCACGCCGTAAACGATGCATGC 840 TAGGTGTTAGGGGTTTCGATACCCTTGGTGCCGAAGTTAACACAGTAAGCATGCCGCCTGGGGAGTACG 910 CTCGCAAGAGTGAAACTCAAAGGAATTGACGGGGACCCGCACAAGCAGTGGAGTATGTGGTTTAATTCG 980 AAGCAACGCGAAGAACCTTACCAGGTCTTGACATCCCTCTGACCGGCTTAGAGATAAGCCTTTCCTTCG 1050 GGACAGAGGAGACAGGTGGTGCATGGTTGTCGTCAGCTCGTGTCGTGAGATGTTGGGTTAAGTCCCGCA 1120 ACGAGCGCAACCCTTGAACTTAGTTGCCAGCAGGTAAGGCTGGGCACTCTAAGTTGACTGCCGGTGACA 1190 AACCGGAGGAAGGCGGGGATGACGTCAAATCATCATGCCCCTTATGACCTGGGCTACACACGTACTACA 1260 ATGGCCGGTACAACGGGAAGCGAAGGAGCGATCCGGAGCCAATCCTAGAAAAGCCGGTCTCAGTTCGGA 1330 TTGCAGGCTGCAACTCGCCTGCATGAAGTCGGAATTGCTAGTAATCGCGGATCAGCATGCCGCGGTGAA 1400 TACGTTCCCGGGTCTTGTACACACCGCCCGTCACACCACGAGAGTTTACAACACCCGAAGTCGGTGAGG 1470 TAACCGTAAGGGGCCAGCCGCCGAAGGTGGGGTAGATGATTGGGGTGAAGTCGTAACAAGGT

\section{Nukleotidsequenz des $16 \mathrm{~S}$ rRNA-Gens aus E3}

1 CAGCGGCCTAATACATGCAAGTCGGACGGGATCCGTCGGAGAGCTTGCTCGAAGACGGTTAGAGCGGCG 70 CACGGGTGCGTAACGCGTGAGCAACCTACCTCTATCAGGGGGATAGCCTCTCGAAAGAGAGATTAACAC 140 CGCATAACATATCTGCCGGCATGGTGGCTATTAAATATTTATAGGATAGAGATGGGCTCGCGTGACATT 210 AgCTAGTTGGTAGGgTAACGGCTTACCAAGGCGACGATGTCTAGGGGCTCTGAGAGGAGAATCCCCCAC 
280

ACTGGTACTGAGACACGGACCAGACTCCTACGGGAGGCATCAGTAAGGAATATTGGTCAATGGGCGGAA 350

GCCTGAACCAGCCGTGCCGCGTGCAGGATGACTGCCCTATGGGTTGTAAACTGCTTTTGTCCAGGAATA 420

AACCTTTCTACGTGTAGGAAGCTGAATGTACTGGAAGAATAAGGATCGGCTAACTCCGTGCCAGCAGCC 490

GCGGTAATACGGAGGATCCGAGCGTTATCCGGATTTATTGGGTTTAAAGGGTGCGTAGGCTGCCTATTA

560

AGTCAGGGGTGAAATACGGTGGCTCAACCATCGCAGTGCCTTTGATACTGATGGGCTTGAATCCATTTG

630

AAGTGGGCGGAATAAGACAAGTAACGGTGAAATGCATAGATTTGTCTTAGAACTCCGATTGCGAACGCA 700

GCTCACTAAGCTGGTATTGACGCTGATGCACGAAAGCGTGGGGATCGAACAGGATTAGATACCCTGGTA 770

GACCACGCCCTAAACGATGATAACTCGATGTTGGCGATAGACAGCCAGCGTCCAAGCGAAAGCGTTAAG 840

TTATCCACCTGGGGAGTACGCCCGCAAGGGTGAAACTCAAAGGAATTGACGGGGGCCCGCACAAGCGGA 910

GGAGCATGTGGTTTAATTCGATGATACGCGAGGAACCTTACCCGGGCTTGAAAGTTAGTGAAGAATGCA 980

GAGGCGCATTCGTCCTTCGGGACACGAAACTAGGTGCTGCATGGCTGTCGTCAGCTCGTCCCGTGAGGT 1050

GTTGGGTTAAGTCCCGCAACGAGCGCAACCCCTATGTTTAGTTGCCAGCATTTAAGATGGGGACTCTTA 1120 ACAGACTGCCTGTGCAAACAGAGAGGAAGGTGGGGACGACGTCAAGTCCTCATGGCCCTTACGTCCGGG 1190 GCTACACACGTGCTACAATGGATGGTACATCGGGCAGCTACATAGCAATATGATGCTAATCTCTAAAAG 1260 CCATTCACAGTTCGGATTGGGGTCTGCAACTCGACCCCATGAAGTTGGATTCGCTAGTAATCGCGTATC 1330 AGCAATGAGGCGGTGAATACGTTCCCGGGCCTTGTACACACCGCCCGTCAAGCCATGAAAGTTGGGGGT 1400 ACCTAAAGCATGTTACCGCAAGGAGCTTTTAGGGTTGA

\section{Nukleotidsequenz des 16S rRNA-Gens aus LK}

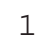


770

GGGGATCAAACAGGATTAGATACCCTGGTAGTCCACGCCCTAAACGATGGATACTCGACATTTGCGATA 840

CAAAGTAAGTGTCTGAGCGAAAGCATTAAGTATCCCACCTGGGAAGTACGACCGCAAGGTTGAAACTCA 910

AAGGAATTGACGGGGGTCCGCACAAGCGGTGGAGCATGTGGTTTAATTCGATGATACGCGAGGAACCTT 980

ACCTGGGCTAGAATGCAGTCTGACCGTGGATGAAAGTTCACTTTGTAGCAATACACAGATTGTAAGGTG 1050

CTGCATGGCTGTCGTCAGCTCGTGCCGTGAGGTGTTGGGTTAAGTCCCGCAACGAGCGCAACCCCTATC

1120

ACTAGTTGCCAGCACTTCGGGTGGGAACTCTAGTGAAACTGCCGTCGTAARACGCGAGGAAGGAGGGGA 1190

TGATGTCAAGTCATCATGGCCTTTATGCCCAGGGCTACACACGTGCTACAATGGTAGAGACAAAGGGCT 1260

GCTCCCTGGTAACAGGCTGCTAATCTCAAAAACTCTATCTCAGTTCGGATTGAGGTYCTGCAACTCGAC 1330 CTCATGAAGCTGGAATCGCTAGTAATCGTATATCAGCAATGATACGGTGAATACGTTCCCGGACCTTG 1400 TACACACCGCCCGTCAAGCCATGAAAGCCGGGGGGACCTGAAGTCGGCAACCGCAAGGAACCGC 1470 CTAGGGTAAAATCGGTAATTGGGGCTAAGTCGTAACAAGGTAGCCGTATCGGAA

\section{Nukleotidsequenz des 16S rRNA-Gens aus SE1}

1 GCCCTTAGAGTTTGATCATGGCTCAGGACGAACGCTGGCGGCCGGCCTAATACATGCAAGTCGAGCGGA 70

CTTGAAGAGAAGCTTGCTTCTCGGATGGTTAGCGGCGGACGGGTGAGTAACACGTAGGCAACCTGCCTG 140

TAAGATCGGGATAACTACCGGAAACGGTAGCTAAGACCGGATAATCGGTATCTCCGCATGGAGAGATCG 210 TGAAACACGGAGCAATCTGTGGCTTACGGATGGGCCTGCGGCGCATTAGCTAGTTGGTGAGGTAAGGGC 280 TCACCAAGGCGACGATGCGTAGCCGACCTGAGAGGGTGAACGGCCACACTGGGACTGAGACACGGCCCA 350 GACTCCTACGGGAGGCAGCAGTAGGGAATCTTCCGCAATGGACGCAAGTCTGACGGAGCAACGCCGCGT 420 GAGTGATGAAGGTTTTCGGATCGTAAAGCTCTGTTGCCAGGGAAGAACGCCAAGGAGAGTAACTGCTCT 490 TTGGGTGACGGTACCTGAGAAGAAAGCCCCGGCTAACTACGTGCCAGCAGCCGCGGTAATACGTAGGGG 560 GCAAGCGTTGTCCGGAATTATTGGGCGTAAAGCGCGCGCAGGCGGTTTTTTAAGTCTGGTGTTTAATCC 630 CGAGGCTCAACCTCGGTTCGCACCGGAAACTGGGAGACTGGAGTGCAGGAGAGGAAAGTGGAATTCCAC 700 GTGTACCGGTGAAATGCGTAGAGATGTGGAGTAACACCAGTGGCGAAGGCGACTTTCTGCGCCTGTAAC 770 TAGCGCTGAGGCGCGAAAGCGTGGGGAGCAAACAGGATTAGATACCCTGGTAGTCCACGCCGTAAACGA 840 TGCATGCTAGGTGTTAGGGGTTTCGATACCCTTGGTGCCGAAGTTAACACAGTAAGCATGCCGCCTGGG 910 GAGTACGCTCGCAAGAGTGAAACTCAAAGGAATTGACGGGGACCCGCACAAGCAGTGGAGTATGTGGTT 980 TAATTCGAAGCAACGCGAAGAACCTTACCAGGTCTTGACATCCCTCTGACCGGCTTAGAGATAAGCCTT 1050 TCCTTCGGGACAGAGGAGACAGGYGGTGCATGGTTGTCGTCAGCTCGTGTCGTGAGATGTTGGGTTAAG 1120 TCCCGCAACGAGCGCAACCCTTGAACTTAGTTGCCAGCAGGTAAGGCTGGGCACTCTAAGTTGACTGCC 
1190

GGTGACAAACCGGAGGAAGGCGGGGATGACGTCAAATCATCATGCCCCTTATGACCTGGGCTACACACG 1260

TACTACAATGGCCGGTACAACGGGAAGCGAAGGAGCGATCCGGAGCCAATCCTAGAAAAGCCGGTCTCA 1330

GTTCGGATTGCAGGCTGCAACTCGCCTGCATGAAGTCGGAATTGCTAGTAATCGCGGATCAGCATGCCG 1400 CGGTGAATACGTTCCCGGGTCTTGTACACACCGCCCGTCACACCACGAGAGTTTACAACACCCGAAGTC 1470 GGTGAGGTAACCGCAAGGGGCCAGCCGCCGAAGGTGGGGTAGATGATTGGG

\section{Nukleotidsequenz des 16S rRNA-Gens aus SL1}

1 CGGCGTGCCTAAtACATGCAAGTCGAGCGGAGTTAATCGGGAGCTTGCTCCTGATTAACTTAGCGGCGG 70 ACGGGTGAGTAACACGTAGGCAACCTGCCCGTAAGACTGGGATAACTACCGGAAACGGTAGCTAATACC 140 GGATACGCAAGTTCCTCGCATGGGGAGCTTGGGAAAGGCGGAGCAAgTCTGTCACTTACGGATGGGCCT 210 GCGGCGCATTAGCTAGTTGGTGGGGTAACGGCTCACCAAGGCGACGATGCGTAGCCGACCTGAGAGGGT 280 GAACGGCCACACTGGGACTGAGACACGGCCCAGACTCCTACGGGAGGCAGCAGTAGGGAATCTTCCGCA 350 ATGGACGAAAGTCTGACGGAGCAACGCCGCGTGAGTGATGAAGGTTTTCGGATCGTAAAGCTCTGTTGC 420 CAGGGAAGAACGTCTTCTAGAGTAACTGCTAGGAGAGTGACGGTACCTGAGAAGAAAGCCCCGGCTAAC 490

TACGTGCCAGCAGCCGCGGTAATACGTAGGGGGCAAGCGTTGTCCGGAATTATTGGGCGTAAAGCGCGC 560 GCAGGCGGCTGTTTAAGTCTGGTGTTTAATCCTGGGGCTCAACTCCGGGTCGCACTGGAAACTGGGCAG 630 CTTGAGTGCAGAAGAGGAGAGTGGAATTCCACGTGTAGCGGTGAAATGCGTAGAGATGTGGAGGAACAC 700 CAGTGGCGAAGGCGACTCTCTGGGCTGTAACTGACGCTGAGGCGCGAAAGCGTGGGGAGCAAACAGGAT 770 TAGATACCCTGGTAGTCCACGCCGTAAACGATGAATGCTAGGTGTTAAGGGTTTCGATACCCTTGGTGC 840 CGAAGTTAACACATTAAGCATTCCGCCTGGGGAGTACtGCCGCaAGGCTGAAACTCAAAGGAATTGACG 910 GGGACCCGCACAAGCAGTGGAGTATGTGGTTTAATTCGAAGCAACGCGAAGAACCTTACCAGGTCTTGA 980

CATCCCTCTGACCGGTACAGAGATGTgCCTTTCCTTCGGGACAGAGGAGACAGGTGGTGCATGGTTGTC 1050 GTCAGCTCGTGTCGTGAGATGTTGGGTTAAGTCCCGCAACGAGCGCAACCCTTGACTTTAGTTGCCAGC 1120 AATTCGGTTGGGCACTCTAGAGTGACTGCCGGTGACAAACCGGAGGAAGGTGGGGATGACGTCAAATCA 1190 TCATGCCCCTTATGACCTGGGCTACACACGTACTACAATGGCCGGTACAACGGGAAGCGAAGTCGCGAG 1260 ATGGAGCGAATCCTAGAAAAGCCGGTCTCAGTTCGGATTGCAGGCTGCAACTCGCCTGCATGAAGTCGG 1330 AATTGCTAGTAATCGCGGATCAGCATGCCGCGGTGAATACGTTCCCGGGTCTTGTACACACCGCCCGTC 1400 ACACCACGAGAGTTTACAACACCCGAAGTCGGTGAGGTAACCGCAAGGAGCCAGCCGCCGAAGGTGGGT 1470 ACAA 


\section{Nukleotidsequenz des 16S rRNA-Gens aus SL2}

1

CGGCGTGCCTAAtACATGCAAGTCGAGCGGACCTGATGGAGTGCTTGCACTCCTGATGGTGAGCGGCGG 70

ACGGGTGAGTAACACGTAGGCAACCTGCCCGTAAGACCGGGATAACTACCGGAAACGGTAGCTAATACC

140

GGATAATCAAGTCTTCCGCATGGGAGGCTTGGGAAAGGCGGAGCAATCTGTCACTTACGGATGGGCCTG

210

CGGCGCATTAGCTAGTTGGTGGGGTAACGGCTCACCAAGGCGACGATGCGTAGCCGACCTGAGAGGGTG

280

AACGGCCACACTGGGACTGAGACACGGCCCAGACTCCTACGGGAGGCAGCAGTAGGGAATCTTCCGCAA 350

TGGACGAAAGTCTGACGGAGCAACGCCGCGTGAGTGATGAAGGTTTTCGGATCGTAAAGCTCTGTTGCC 420

AGGGAAGAACGTCTTCTGGAGTAACTGCCAGGAGAGTGACGGTACCTGAGAAGAAAGCCCCGGCTAACT 490

ACGTGCCAGCAGCCGCGGTAATACGTAGGGGGCAAGCGTTGTCCGGAATTATTGGGCGTAAAGCGCGCG

560

CAGGCGGCTGTTTAAGTCTGGTGTATAATCCTGGGGCTCAACTCCGGGTCGCACTGGAAACTGGACAGC

630

TTGAGTGCAGAAGAGGAGAGTGGAATTCCACGTGTAGCGGTGAAATGCGTAGAGATGTGGAGGAACACC 700

AGTGGCGAAGGCGACTCTCTGGGCTGTAACTGACGCTGAGGCGCGAAAGCGTGGGGAGCAAACAGGATT 770

AGATACCCTGGTAGTCCACGCCGTAAACGATGAATGCTAGGTGTTAAGGGTTTCGATACCCTTGGTGCC 840

GAAGTTAACACATTAAGCATTCCGCCTGGGGAGTACGGCCGCAAGGCTGAAACTCAAAGGAATTGACGG 910

GGACCCGCACAAGCAGTGGAGTATGTGGTTTAATTCGAAGCAACGCGAAGAACCTTACCAGGTCTTGAC 980

ATCCCTCTGACCGCTGTAGAGATATGGCTTTCCTTCGGGACAGAGGAGACAGGTGGTGCATGGTTGTCG 1050

TCAGCTCGTGTCGTGAGATGTTGGGTTAAGTCCCGCAACGAGCGCAACCCTTGACTTTAGTTGCCAGCA 1120

ATAAAGTTGGGCACTCTAGAGTGACTGCCGGTGACAAACCGGAGGAAGGTGGGGATGACGTCAAATCAT 1190

CATGCCCCTTATGACCTGGGCTACACACGTACTACAATGGCCGGTACAACGGGAAGCGAAGTCGCGAGA 1260

TGGAGCGAATCCTAGAAAAGCCGGTCTCAGTTCGGATTGCAGGCTGCAACTCGCCTGCATGAAGTCGGA 1330

ATTGCTAGTAATCGCGGATCAGCATGCCGCGGTGAATACGTTCCCGGGTCTTGTACACACCGCCCGTCA 1400 CACCACGAGAGTTTACAACACCCGAAGTCGGTGAGGTAACCGCAAGGAGCCAGCCGCCGAAGGTGGGTA 1470 CAA

\section{Nukleotidsequenz des 16S rRNA-Gens aus SL3}

1 GCCCTTAGAGTTTGATCATGGCTCAGGACGAACGCTGGCGGCGTGCCTAATACATGCAAGTCGAGCGGA 70 CTTGAAGAGAAGCTTGCTTCTCCGATAGTTAGCGGCGGACGGGTGAGTAACACGTAGGCAACCTGCCTG 140 TAAGATCGGGATAACTACCGGAAACGGTAGCTAAGACCGGATAATCGGTTTCTCCGCATGGAGAGACCG 210 TGAAACACGGAGCAATCTGTGGCTTACGGATGGGCCTGCGGCGCATTAGCTAGTTGGTGAGGTAACGGC 


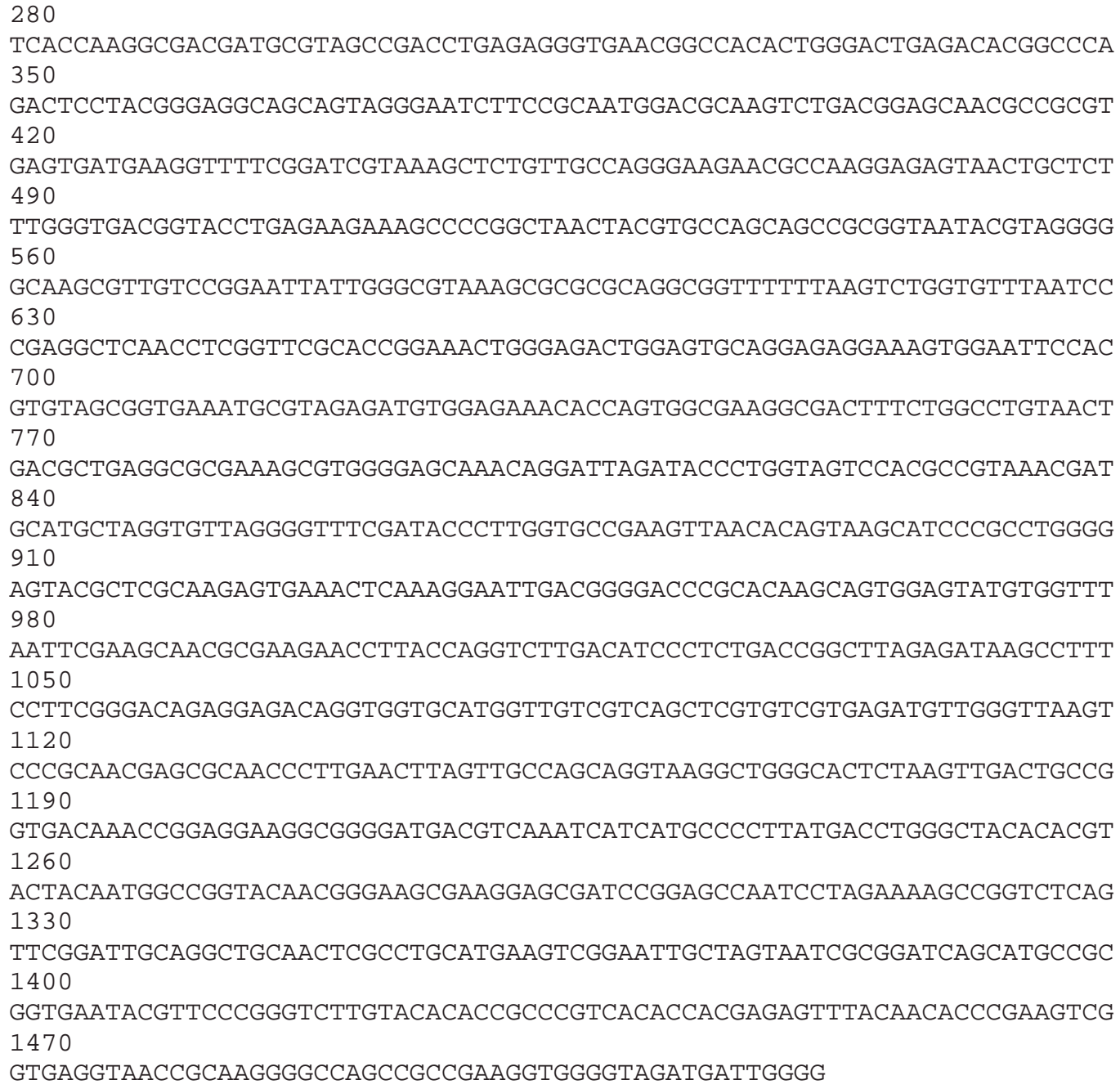

\section{Nukleotidsequenz des 16S rRNA-Gens aus SL4}

1 CGGCGTGCCTAAtACATGCAAGTCGAGCGGAGTTAATCGGGAGCTTGCTCCTGATTAACTTAGCGGCGG 70 ACGGGTGAGTAACACGTAGGCAACCTGCCCGTAAGACTGGGATAACTACCGGAAACGGTAGCTAATACC 140 GGATACGCAAGTTCCTCGCATGGGGAGCTTGGGAAAGGCGGAGCAAgTCTGTCACTTACGGATGGGCCT 210 GCGGCGCATTAGCTAGTTGGTGGGGTAACGGCTCACCAAGGCGACGATGCGTAGCCGACCTGAGAGGGT 280 GAACGGCCACACTGGGACTGAGACACGGCCCAGACTCCTACGGGAGGCAGCAGTAGGGAATCTTCCGCA 350 ATGGACGAAAGTCTGACGGAGCAACGCCGCGTGAGTGATGAAGGTTTTCGGATCGTAAAGCTCTGTTGC 420 CAGGGAAGAACGTCTTCTAGAGTAACTGCTAGGAGAGTGACGGTACCTGAGAAGAAAGCCCCGGCTAAC 490 TACGTGCCAGCAGCCGCGGTAATACGTAGGGGGCAAGCGTTGTCCGGAATTATTGGGCGTAAAGCGCGC 560 GCAGGCGGCTGTTTAAGTCTGGTGTTTAATCCTGGGGCTCAACTCCGGGTCGCACTGGAAACTGGGCAG 630 CTTGAGTGCAGAAGAGGAGAGTGGAATTCCACGTGTAGCGGTGAAATGCGTAGAGATGTGGAGGAACAC 


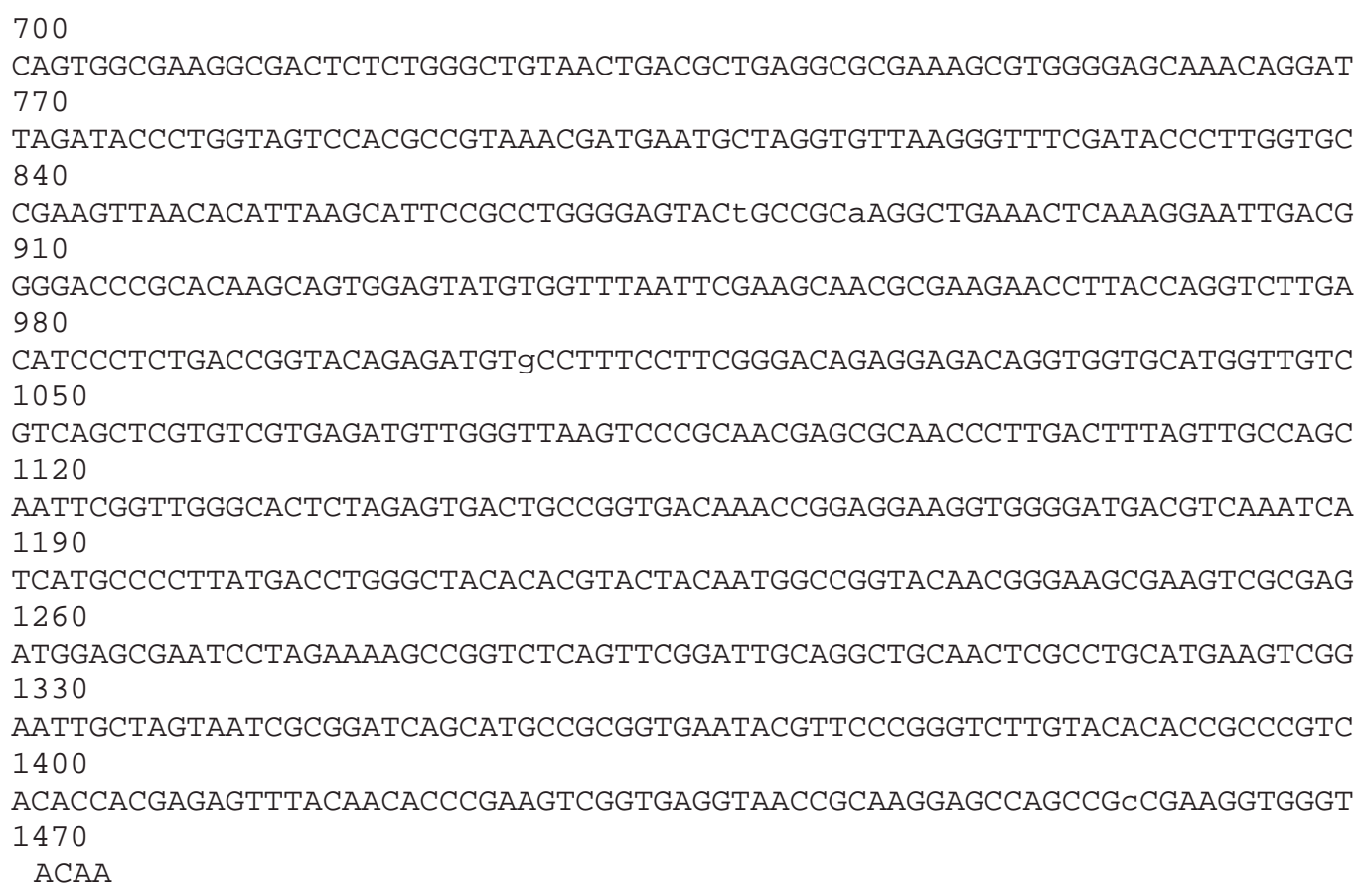

\section{Nukleotidsequenz des 16S rRNA-Gens aus WG2}

1 TACCTTGTTACGACTTAGCCCCAATTATCGGTTTTACCCTAACACGCTCCTCGCGGTAACATGCTTTAG 70 GTACCCCCAACTTTCATGGCTTGACGGGCGGTGTGTACAAGGCCCGGGAACGTATTCACCGCGTCATTG 140 CTGATACGCGATTACTAGCGAATCCAACTTCATGGGGTCGAGTTGCAGACCCCAATCCGAACTGTGAAT 210 GGCTTTTAGAGATTAGCATCATATTGCTATGTAGCTGCCCGCTGTACCATCCATTGTAGCACGTGTGTA 280 GCCCCGGACGTAAGGGCCATGATGACTTGACGTCGTCCCCACCTTCCTCACTGTTTGCACAGGCAGTCT 350 GTTTAGAGTCCCCACCATTACATGCTGGCAACTAAACATAGGGGTTGCGCTCGTTGCGGGACTTAACCC 420 AACACCTCACGGCACGAGCTGACGACAGCCATGCAGCACCTAGTTTCGTGTCCCGAAGGACGAATGCGT 490 CTCTGCATTCTTCACTAACTTTCAAGCCCGGGTAAGATTCCTCGCGTATCATCGAATTAAACCACATGC 560 TCCTCCGCTTGTGCGGGCCCCCGTCAATTCCTTTGAGTTTCACCCTTGCGGGCGTACTCCCCAGGTGGA 630 TAACTTAACGCTTTCGCTTGGACGCTGGCTGTCTATCGCCAACATCGAGTTATCATCGTTTAGGGCGTG 700 GACTACCAGGGTATCTAATCCTGTTCGATCCCCACGCTTTCGTGCATCAGCGTCAATACCAGCTTAGTG 770 AGCTGCCTTCGCAATCGGAGTTCTAAGACATATCTATGCATTTCACCGCTACTTGTCTTATTCCGCCCA 840 CTTCAAATGGATTCAAGCCCATCAGTATCAAAGGCACTGCGATGGTTGAGCCACCGTATTTCACCCCTG 910 ACTTAATAGGCCGCCTACGCACCCTTTAAACCCAATAAATCCGGATAACGCTCGGATCCTCCGTATTAC 980 CGCGGCTGCTGGCACGGAGTTAGCCGATCCTTATTCTTCCAGTACATTCAGCTCCCTACACGTAGAAAG 1050 GTTTATTCCTGGACAAAAGCAGTTTACAACCCATAGGGCAGTCATCCTGCACGCGGCATGGCTGGTTCA 1120 
GGCTTCCGCCCATTGACCAATATTCCTTACTGCTGCCTCCCGTAGGAGTCTGGTCCGTGTCTCAGTACC 1190 AGTGTGGGGGATTCTCCTCTCAGAGCCCCTAGACATCGTCGCCTTGGTAAGCCGTTACCCTACCAACTA 1260 GCTAATGTCACGCGAGCCCATCTCTATCCTATAAATATTTAATATCCAACCGATGCCGGTCAGATATAT 1330 TATGCGGTGTTAATCTCTCTTTCGAGAGGCTATCCCCCTGATAGAGGTAGGTTGCTCACGCGTTACGCA 1400 CCCGTGCGCCACTCTCACCGTCTTCGAGCAAGCTCTCCAACGGATCCCGTCCGACTTGCATGTATTAGG 1470 CCTGCCGCTAGCGTTCATCCTGAGCCATGATCAAACTCT

\section{Nukleotidsequenz des 16S rRNA-Gens aus WG3}

1 CATGCTCGAGCGGCCGCCAGTGTGATGGATATCTGCAGATTCGCCCTTAGAGTTTGATCATGGCTCAGG 70 ACGAACGCTGGCGGCGTGCTTAACACATGCAAGTCGAACGATGAAGCCTTTCGGGGTGGATTAGTGGCG 210 AACGGGTGAGTAACACGTGGGCAATCTGCCCTTCACTCTGGGACAAGCCCTGGAAACGGGGTCTAATAC 280 CGGATAACACTCTGTCCCGCATGGGGCGGGGTTGAAAGCTCCAGCGGTGAAGGATGAGCCCGCGGCCTA 350 TCAGCTTGTTGGTGGGGTGATGGCCTACCAAGGCGACGACGGGTAGCCGGCCTGAGAGGGCGACCGGCC 420 ACACTGGGACTGAGACACGGCCCAGACTCCTACGGGAGGCAGCAGTGGGGAATATTGCACAATGGGCGC 490 AAGCCTGATGCAGCGACGCCGCGTGAGGGATGACGGCCTTCGGGTTGTAAACCTCTTTCAGCAGGGAAG 560 AAGCGTGAGTGACGGTACCTGCAGAAGAAGCGCCGGCTAACTACGTGCCAGCAGCCGCGGTAATACGTA 630 GGGCGCAAGCGTTGTCCGGAATTATTGGGCGTAAAGAGCTCGTAGGCGGCTTGTCGCGTCGGTTGTGAA 700

AgCCCGGGGCTTAACCCCCGGGTCTGCAGTCGATACGGGCAGGCTAGAGTGTGGTAGGGGAGAATTCGA 770 TTTCCTGGTGTAGCGGTGAAATGCGCAGATATCAGGAGGAACACCGGTGGCGAAGGCGGATCTCTGGGC 840 CATTACTGACGCTGAGGAGCGAAAGCGTGGGGAGCGAACAGGATTAGATACCCTGGTAGTCCACGCCGT 910 AAACGTTGGGAACTAGGTGTTGGCGACATTCCACGTCGTCGGTGCCGCAGCTAACGCATTAAGTTCCCC 980 GCCTGGGGAGTACGGCCGCAAGGCTAAAACTCAAAGGAATTGACGGGGGCCCGCACAAGCAGCGGAGCA 1050 TGTGGCTTAATTCGACGCAACGCGAAGAACCTTACCAAGGCTTGACATACATCGGAAAGCATCAGAGAT 1120 GGTGCCCCCCTTGTGGTCGGTGTACAGGTGGTGCATGGCTGTCGTCAGCTCGTGTCGTGAGATGTTGGG 1190 TTAAGTCCCGCAACGAGCGCAACCCTTGTTCTGTGTTGCCAGCATGCCTTTCGGGGTGATGGGGACTCA 1260 CAGGAGACTGCCGGGGTCAACTCGGAGGAAGGTGGGGACGACGTCAAGTCATCATGCCCCTTATGTCTT 1330 GGGCTGCACACGTGCTACAATGGCCGGTACAATGAGCTGCGATGTCGTGAGGCGGAGCGAATCTCAAAA 1400 AGCCGGTCTCAGTTCGGATTGGGGTCTGCAACTCGACCCCATGAAGTCGGAGTTGCTAGTAATCGCAGA 1470 TCAGCATTGCTGCGGTGAATACGTTCCCGGGCCTTGTACACACCGCCCGTCACGTCACGAAAGTCGGTA 1540 ACACCCGAAGCCGGTGGCCCA 


\section{Nukleotidsequenz des 16S rRNA-Gens aus WG4}

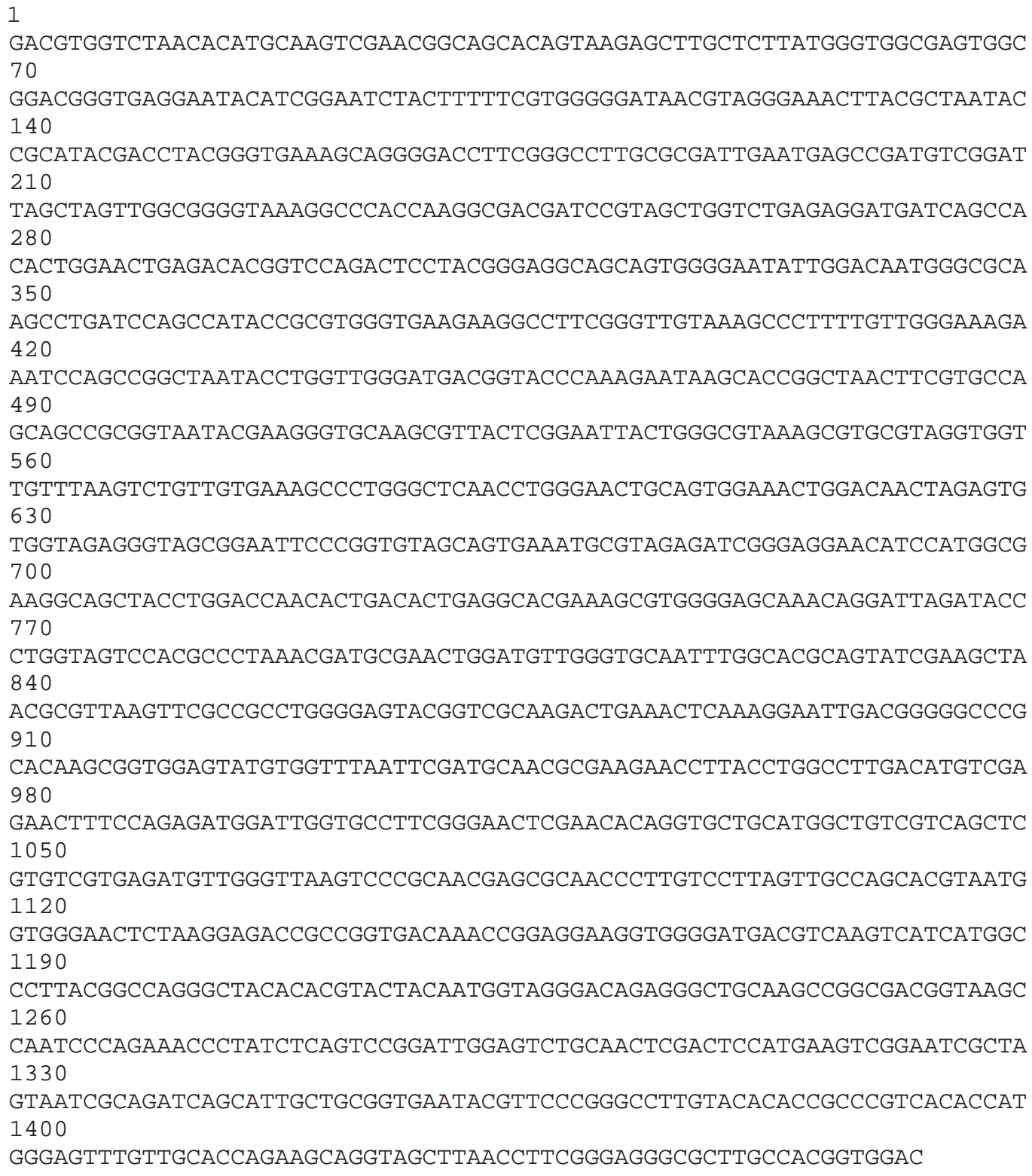




\section{Lebenslauf}

01.04.1972 Geburt in Hamburg

1978-1982 Besuch der Grundschule Tostedt

1982-1984 Besuch der Orientierungsschule Tostedt

1984-1985 Besuch des Gymnasiums Tostedt

1986-1989 Besuch der Realschule Tostedt

1989-1992 Besuch des Lessing-Gymnasiums Hamburg

Juni 1992 Abitur

1992-1993 Zivildienst in Großalmerode

Oktober 1993 Immatrikulation an der Georg-August Universität zu Göttingen im Fach Biologie

Oktober 1995 Vordiplom in den Fächern Mikrobiologie, Botanik, anorganische Chemie und physikalische Chemie

Mai 1998 Diplomprüfung in den Fächern Mikrobiologie, organische Chemie und Biochemie

1998-1999 Diplomarbeit mit dem Titel ,Suche und Identifizierung von thermostabilen Dextranasen“ am Institut für Mikrobiologie der Georg-August -Universität Göttingen bei Prof. Dr. G. Gottschalk

September 1999 Beginn der Arbeiten zur vorliegenden Dissertation 